Assessment of Effectiveness of

Geologic Isolation Systems

\title{
PABLM - A Computer Program to Calculate Accumulated Radiation Doses From Radionuclides in the Environment
}

\author{
B. A. Napier \\ W. E. Kennedy, Jr. \\ J. K. Soldat
}

March 1980

Prepared for the

Office of Nuclear Waste Isolation

Under its Contract with the

U.S. Department of Energy

Pacific Northwest Laboratory

Operated for the U.S. Department of Energy

by Battelle Memorial Institute 


\title{
NOTICE
}

This report was prepared as an account of work sponsored by the United States Government. Neither the United States nor the Department of Energy, nor any of their employees, nor any of their contractors, subcontractors, or their employees, makes any warranty, express or implied, or assumes any legal liability or responsibility for the accuracy, completeness or usefulness of any information, apparatus, product or process disclosed, or represents that its use would not infringe privately owned rights.

The views, opinions and conclusions contained in this report are those of the contractor and do not necessarily represent those of the United States Government or the United States Department of Energy.

\author{
PACIFIC NORTHWEST LABORATORY \\ operated by \\ BATTELLE \\ for the \\ UNITED STATES DEPARTMENT OF ENERGY \\ Under Contract EY-76-C-06-1830
}

\begin{tabular}{|c|c|c|}
\hline \multicolumn{3}{|c|}{$\begin{array}{c}\text { Printed in the United States of America } \\
\text { Available from } \\
\text { National Technical Information Service } \\
\text { United States Department of Commerce } \\
5285 \text { Port Royal Road } \\
\text { Springfield, Virginia } 22151\end{array}$} \\
\hline Price: & Printed Copy & $\because$ Microfiche $\$ 3.00$ \\
\hline & - Pages & $\begin{array}{c}\text { NTIS } \\
\text { Selling Price }\end{array}$ \\
\hline & $001-025$ & $\$ 4.00$ \\
\hline & $026-050$ & $\$ 4.50$ \\
\hline & $051-075$ & $\$ 5.25$ \\
\hline & $076-100$ & $\$ 6.00$ \\
\hline & $101-125$ & $\$ 6.50$ \\
\hline & $126-150$ & 57.25 \\
\hline & $151-175$ & $\$ 8.00$ \\
\hline & $176-200$ & $\$ 9.00$ \\
\hline & $201-225$ & $\$ 9.25$ \\
\hline & $226-250$ & $\$ 9.50$ \\
\hline & $251-275$ & $\$ 10.75$ \\
\hline & $276-300$ & $\$ 11.00$ \\
\hline
\end{tabular}


PNL -3209

UC -70

\section{7}

Assessment of Effectiveness of Geologic Isolation Systems

PABLM - A COMPUTER PROGRAM TO CALCULATE ACCUMULATED RADIATION DOSES FROM

RADIONUCLIDES IN THE ENVIRONMENT

B. A. Napier

W. E. Kennedy, Jr.

J. K. Soldat

March 1980

Prepared for the

Office of Nuclear Waste Isolation under its contract with the

U.S. Department of Energy

Pacific Northwest Laboratory

Richland, Washington 99352 
a

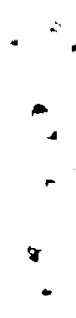




\section{ACKNOWLEDGMENT}

This research was supported by the Waste Isolation Safety Assessment Program (WISAP) conducted by Pacific Northwest Laboratory. The program was sponsored by the Office of Nuclear Waste Isolation, managed by Battelle Memorial Institute for the Department of Energy under Contract EY-76-C-06-1830. On 1 October 1979, WISAP became the Assessment of Effectiveness of Geologic - Isolation Systems (AEGIS) Program and the Waste/Rock Interactions Technology (WRIT) Program. This report was issued by AEGIS. 


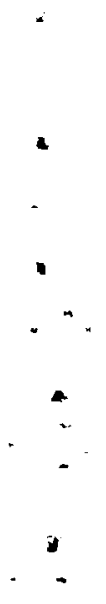

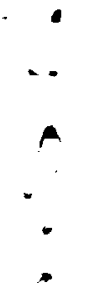


A computer program, PABLM, was written to facilitate the calculation of internal radiation doses to man from radionuclides in food products and external radiation doses from radionuclides in the environment. This report contains details of mathematical models used and calculational procedures required to run the computer program. Characteristics of the PABLM models are:

- Radiation doses from radionuclides in the environment may be calculated from deposition on the soil or plants during an atmospheric or liquid release, or from exposure to residual radionuclides in the environment after the releases have ended.

- Radioactive decay is considered during the release of radionuclides, after they are deposited on the plants or ground, and during holdup of food after harvest. A chain decay scheme is used; it includes branching to account for transitions to and from isomeric states.

- The radiation dose models consider several exposure pathways. They include exposure to radionuclides deposited on the ground or crops from contaminated air, radionuclides on the ground or crops from contaminated irrigation water, radionuclides in contaminated drinking water, radionuclides in aquatic foods raised in contaminated water, and radionuclides in bodies of water and sediments where people might fish, boat, or swim. For vegetation, the radiation dose model considers both direct deposition on leaves and uptake through roots.

- Doses may be calculated for either a maximum-exposed individual or for a population group. The doses calculated are accumulated doses from continuous chronic exposure. A first-year committed dose is calculated as well as an integrated dose for a selected number of years.

- The equations for calculating internal radiation doses are derived from those given by the International Commission on Radiological Protection (ICRP) for body burdens and MPC's of each radionuclide. 
- The radiation doses from external exposure to contaminated water and soil are calculated using the basic assumption that the contaminated medium is large enough to be considered an "infinite" volume or plane relative to the range of the emitted radiations.

- The equations for calculations of the radiation dose from external exposure to shoreline sediments include a correction for the finite width of the contaminated beach.

Return of the form on the last page of this report is required in order to remain on the Distribution List for future revisions of the model. 


\section{CONTENTS}

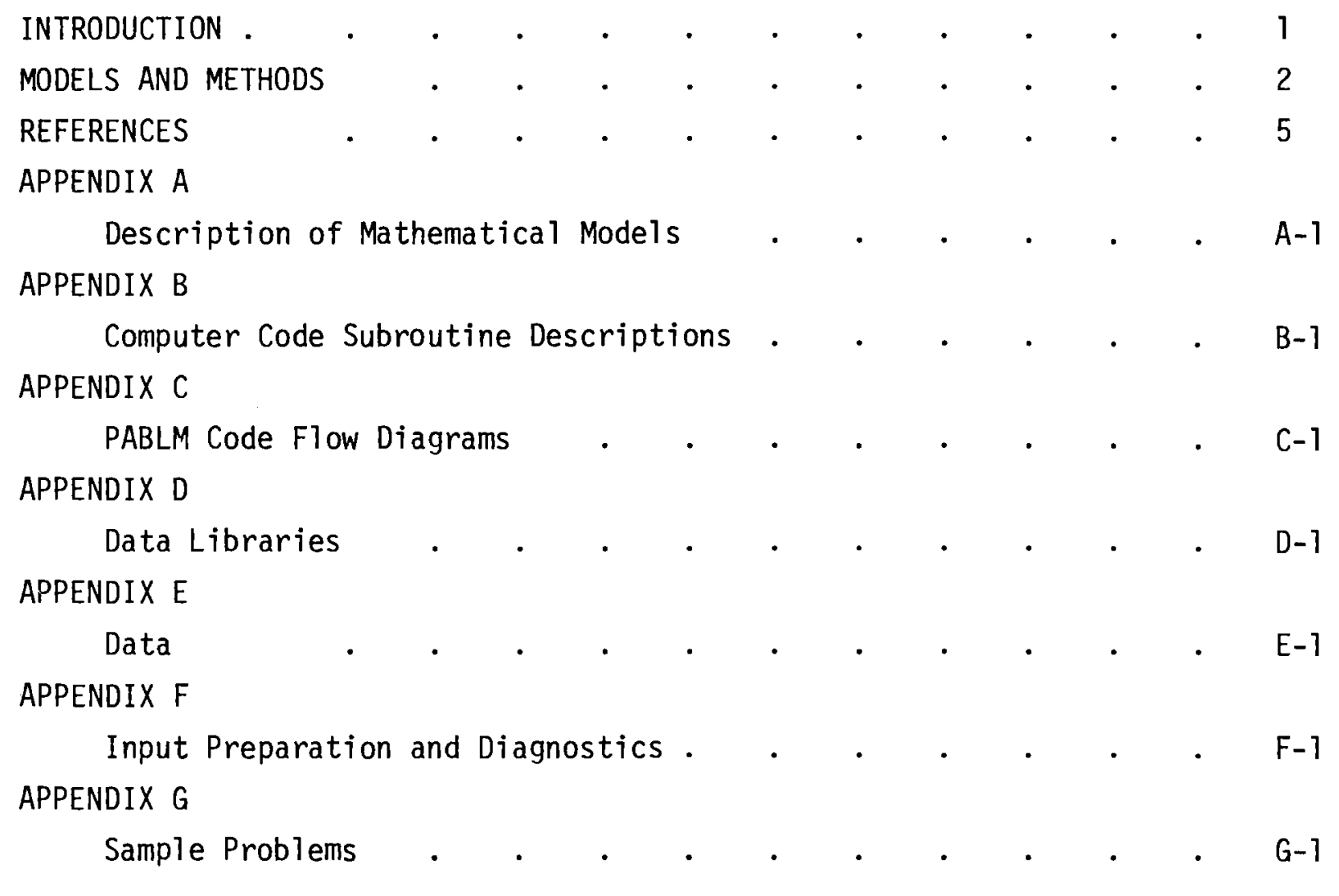




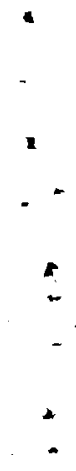

-

$\div$

.

-

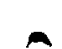

$+$

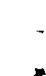




\section{INTRODUCTION}

The computer program PABLM was written as an enhancement of the dose calculation capabilities of the Environmental Analysis Section of the Ecological Sciences Department at Pacific Northwest Laboratory. The report contains details of the program for use in calculating accumulated radiation doses from radionuclides found in food products and from radionuclides in the environment. PABLM permits rapid and consistent estimates of the accumulated radiation dose to man resulting from radioactive materials released to the environment. The program is designed to calculate accumulated radiation doses from the chronic ingestion of food products that contain radionuclides, and doses from the external exposure to radionuclides in the environment.

A total of 19 ingestion pathways (or food products) may be selected with corresponding consumption rates, growing periods, and air or water concentrations and deposition rates. A total of 4 external exposure pathways may also be selected with corresponding exposure times and soil or water concentrations. For a 11 exposure pathways chosen, radionuclides in the soil may continue to be deposited for the life of the releasing facility. After the facility is shut down, the nuclides remain in the soil and are assumed to be removed orily by radioactive decay. The type and amount of crops grown around the site of a nuclear facility determines which terrestrial pathways are considered. The presence of liquid effluents determines which, if any, of the aquatic pathways or irrigation pathways are activated.

Dose factors for persons swimming in contaminated water are calculated using the water concentration of radionuclides, and the assumption that the water is an infinite medium with respect to the range of the emitted radiations. The radiation dose rate to people boating on this water is assumed to be half that for swimmers.

The computer program can be used to caiculate accumulated doses to 23 possible body organs or tissues for any one or combination of radionuclides. A maximum of 5 organs and 100 radionuclides may be selected in a mixture in any one case. 
The computer output consists of radiation dose sumaries to all chosen organs listed by exposure pathway and by radionuclide. Dose summaries may be chosen for all terrestrial food pathways and all aquatic food pathways. In addition, an option exists for a complete listing of dose contributions by radionuclide in each pathway. The complete listing includes radionuclide concentrations in all ingested plant and animal material.

\section{MODELS AND METHODS}

The model for estimating the transfer of radionuclides (except for ${ }^{3} \mathrm{H}$ and ${ }^{14} \mathrm{C}$ ) from air or irrigation water to plants through both leaves and soil to food products was derived by Soldat and Harr for a study of the potential doses to people from a nuclear power complex in the year 2001.

The source of contamination on farm land or garden plots may be from acute or chronic airborne or waterborne radionuclide releases or from residual environmental contamination after a release. In the absence of specific data for sites where irrigation is used, sprinkler irrigation is normally assumed, rather than surface irrigation, because the aerial spray produced leads to foliar deposition resulting in an additional source of radionuclide contamination in the plants. Trickle or flood irrigation systems can be simulated, if desired, by setting the foliar retention factor in the program to zero. For atmospheric contamination, a deposition velocity is assumed for the airborne radionuclides onto the plant foliage and ground. If the initial deposition model is selected, the foliar contamination terms are automatically zeroed, and all plant concentrations are derived from the soil concentration only.

Concentration of radionuclides in plants depends on the concentrations in the soil, air, and water. A plant accumulation factor is used to relate these concentrations. Concentration of radionuclides in farm animal products, such as milk, meat, or eggs, depends on the animals' consumption of feed, forage, and water containing radionuclides.

Two radionuclides, ${ }^{3} \mathrm{H}$ and ${ }^{14} \mathrm{C}$, are treated differently than the others. These two are assumed to be in equilibrium with their surroundings. Thus the concentration of tritium or carbon-14 in the hydrogen or carbon in environmental media (soil, plants, and animal products) is assumed to have the same specific 
activity ( $\mathrm{pCi}$ of nuclide per $\mathrm{kg}$ of stable element) as in the contaminating medium (air or water). The fractional content of hydrogen or carbon in a plant or animal product is then used to compute the concentration of tritium or carbon-14 in the food product under consideration.

Radionuclide concentrations in aquatic food products are based on the radionuclide concentrations in the contaminated water. ${ }^{2}$ ) The water concentration is based on the release rate of radioactive contamination from the operating nuclear facility and the characteristics of the receiving water body. Formulae for the three most common reconcentration situations for receiving water bodies are included in the computer program.

If there is no water reconcentration, for example, if the cooling water for a nuclear facility is drawn from a river in which the outfall is downstream of the inlet, the reconcentration factor is set to unity. A second option is available for the case where the inlet is downstream of the outfall or so arranged on a lake or ocean site that recirculation occurs. The third option models cooling water drawn from a pond, lake, or reservoir which is connected to a larger body of water or is fed by a stream.

A simple model is used to predict the radionuclide concentration in the sediments of a river or lake downstream from a nuclear facility. The model is based on the assumption that there is a constant water concentration for each year of the release. The deposition rate to the sediment is assumed to be dependent only on the water concentration. Daughter radionuclides occur in the sediment from buildup in the decay of the parents in the sediment, and direct deposition from daughter radionuclides in the water.

The concentrations of radionuclides in aquatic foods are directly related to the concentration in water. They are calculated using equilibrium ratios between the two concentrations, called bioaccumulation factors. Radionuclide concentrations in drinking water downstream from a water treatment plant are calculated assuming element-specific removal in the treatment plant.

External doses from radionuclides deposited in farm fields are calculated assuming an infinite flat plane source model. A factor of two is included for self-shielding by surface roughness. For a person standing next to a body of 
contaminated water, the dose from nuclides deposited in the shoreline sediments is calculated using the same model as that used for farm fields, modified to include a shore-width factor. For persons swimming in contaminated water, the dose is calculated using the basic assumption that the body of contaminated water is large enough to be considered an "infinite medium" relative to the range of emitted radiations. Persons boating on the water are assumed to be exposed to a dose rate half that to which swimmers are exposed.

Internal doses are calculated as a function of radionuclide concentration in food products (as described above), ingestion rates, and a radionuclidespecific dose-commitment factor. The concentration in foods varies with time, release rate, and buildup and decay in the soil. The ingestion rate of food products are assumed to be constant. The dose commitment is calculated for each year of intake, to the end of the dose period. It is based on the model of ICRP Publication 2 for internally deposited radionuclides. (3) The accumulated dose is then the sum of the series of annual dose commitments from each year of ingestion to the end of the dose period.

The details of the mathematical models, computer code, data libraries, and input preparation are given in Appendices $A$ through $F$. A sample problem and example input and output is given in Appendix G. 


\section{REFERENCES}

1) Soldat, J. K., and R......Harr, "Radiation Dose Mode1," pp. 81-175. In: HERMES--A Digital Computer Code for Estimating Regional Radiological Effects from the Nuclear Power Industry, USAEC Report HEDL-TME-71-168, Hanford Engineering Development Laboratory, Richland, WA, 1971.

2) Soldat, J. K., N. M. Robinson and D. A. Baker, Models and Computer Codes for Evaluating Environmental Radiation Doses, USAEC Report BNWL-1754, Pacific Nor thwest Laboratory, Richland, WA, 1974.

3) International Commission on Radiological Protection, Report of ICRP Committee II on Permissible Dose for Internal Radiation, ICRP Publication 2, Pergamon Press, New York, 1959. 


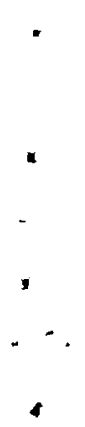

4

4 
APPENDIX A

DESCRIPTION OF MATHEMATICAL MODELS 


\section{DESCRIPTION OF MATHEMATICAL MODELS}

This appendix describes the mathematical models used in the computer program PABLM to calculate the external exposures and accumulated internal doses from releases of radionuclides to the environment. The models presented for estimating the transfer of radionuclides from irrigation water or air to plants through both leaves and soil to food products were derived by Soldat and Harr for a study of the potential doses to people from a nuclear power complex. (1) Aquatic food parameters are adapted from the computer program ARRRG. ${ }^{(2)}$ other parameters are adapted from the computer program FOOD. (3) PABLM is designed to be compatable with the present FORTRAN versions of both FOOD and ARRRG.

\section{A. 1 BASIC DOSE COMMITMENT EQUATION}

The fundamental equation for calculation of accumulated radiation dose to man from radionuclides in the environment is:

where:

$$
D_{i p r}=\sum_{T=1}^{\text {No. of yrs }}{ }^{y p}(T) U_{p} F_{i p r}(T)
$$

$D_{i p r}$ - the dose commitment to organ $r$ from radionuclide $i$ via pathway $p$, rem,

$C_{i p}(T)$ - the concentration of nuclide $i$ in the medium of pathway $p$ at time $T, p C i / k g, p C i / l$, or $p C i / m^{2}$

$U_{p}$ - the usage, i.e. exposure or intake rate associated with pathway $\mathrm{p}, \mathrm{kg} / \mathrm{yr}, \mathrm{l} / \mathrm{yr}$, or hrs/year

$F_{i p r}(T) \bullet a$ dose factor, a value specific to a given nuclide $i$, pathway $p$ and organ $r$ which is used to calculate radiation dose commitments, from exposure to a given radionuclide concentration or intake in a particular year to the end of the dose period. 
The three terms on the right of Equation A.I are discussed in the following sections. Equations tailored to each specific exposure pathway are derived from Equation A.1. The principle difference between pathways is the manner in which the radionuclide concentrations are calculated.

\section{A.2 CONCENTRATIONS OF NUCLIDES IN ENVIRONMENTAL MEDIA}

Concentrations of radionuclides in air, water, soil, and foods are calculated as intermediate steps in the computer program PABLM for each year of exposure. The concentrations in air and water are based on the annual releases from the nuclear facility. Radionuclide concentrations in soil and sediment are accumulated from the annual air and water deposition and are removed by radioactive decay after the facility shuts down.

\section{A.2.1 Concentration in Terrestrial Food Products}

The source of the radionuclide contamination of terrestrial foods is, either directly or indirectly, uptake through roots from contaminated ground and either deposition from the atmosphere or from water used for sprinkier irrigation. Local air concentrations are based on a factor which has units of concentration per unit release rate $\left(\bar{x} / Q^{\prime}\right)$ and which must be calculated separately and input to the computer program. Water concentrations are calculated internally as described below. In the absence of site-specific data for cases where irrigation is used, sprinkler irrigation is assumed, rather than surface irrigation, because the aerial spray leads to the foliar deposition of radionuclides. This results in a higher radionuclide concentration in the plants (and in the animals consuming them) than from trickle or surface irrigation. Surface-irrigation systems can be simulated by setting the foliar retention factor in the program to zero.

\section{A.2.1.1 Soil}

Radionuclides accumulate in the soil from continuous deposition from air or irrigation water. The deposition rate from air is given by

$$
d_{i}=3.15 \times 10^{7} \bar{x}_{i} v_{d i}
$$


where:

$d_{j}$ - the deposition rate of radionuclide $i, \mathrm{pCi} \cdot \mathrm{m}^{-2} \cdot \mathrm{yr}^{-1}$,

$3.15 \times 10^{7}$ - a conversion factor of sec $\cdot \mathrm{yr}^{-1}$,

$\bar{x}_{j}$ - the annual average air concentration, $\mathrm{pCi} \cdot \mathrm{m}^{-3}$, and

$v_{d i}$ - the deposition velocity of nuclide $i, \mathrm{~m} \cdot \mathrm{sec}^{-1}$.

For irrigation water the deposition rate is

$$
d_{i}=C_{i w} I
$$

where:

$C_{i w}$ - the water concentration of nuclide $i$ in $\mathrm{pCi} / \ell$, and

I the average annual irrigation rate, $\ell \cdot \mathrm{m}^{-2} \mathrm{yr}^{-1}$.

The concentration of radionuclides in soil, $c_{i s}$, at the end of one year of deposition from either air or water is:

$$
c_{i s}=d_{i}\left(1-e^{-\lambda_{i} \cdot 1}\right) / \lambda_{i}
$$

where:

$c_{i s}$ the soil concentration of nuclide $i, \mathrm{pCi} \cdot \mathrm{m}^{-2}$,

$\lambda_{i}$ - the decay constant of nuclide $i, \mathrm{yr}^{-1},(1$ is for one year).

This soil concentration value is added to the residual soil concentration from previous years' deposition. Chain decay with daughter buildin is handled using a modified Bateman equation. (4)

\section{A.2.1.2 Vegetation}

The concentration of radionuclides at the time of harvest in terrestrial vegetation from direct deposition during a chronic release is:

$$
c_{i d}=d_{i} r T_{v}\left(1-e^{-\lambda} E i^{t} e\right) / \lambda_{E i} Y_{v}
$$

and the concentration at harvest from root uptake is: 


$$
c_{i r}=C_{i s} B_{i v} / p
$$

where:

$\mathrm{C}_{\mathrm{id}}$ - the vegetation concentration from direct deposition, $\mathrm{pCi} / \mathrm{kg}$,

$C_{\text {ir }}$ - the vegetation concentration from root uptake, $\mathrm{pCi} / \mathrm{kg}$,

$r$ - the fraction of direct deposition retained on the plant leaves (dimensionless), taken to be 0.25 ,

$T_{v}$ - the factor for translocation of externally deposited radionuclides to edible parts of plants (dimensionless). For simplicity it is taken to be independent of radionuclide and set to 1.0 for leafy vegetables and fresh forage, and to 0.1 for all other produce including grain.

$t_{e}$ - the growing period during which the plant is above ground, days,

$\lambda_{E i}$ - the effective environmental removal constant for radionuclides from plants in day ${ }^{-1} . \lambda_{E j}=\lambda_{j}+\lambda_{w}$, where $\lambda_{w}$ is the weathering removal constant, taken to be $0.693 / 14$ days.

$\mathrm{Y}_{\mathrm{V}}$ - the plant yield, $\mathrm{kg}$ (wet weight) $/ \mathrm{m}^{2}$.

$B_{i v}$ - the concentration ratio for plant uptake of radionuclide $i$, $\mathrm{pCi} / \mathrm{kg}$ (wet weight) per $\mathrm{pCi} / \mathrm{kg}$ (dry weight soil).

$\mathrm{p}$ - the soil "surface density," $\mathrm{kg}(\mathrm{dry}$ soi1)/m². Taken to be $224 \mathrm{~kg} / \mathrm{m}^{2}$ (1)

The PABLM program is designed to handle continuous chronic releases. However PABLM can also be used for an acute release followed by continuous environmental exposure. Because the continued exposure is only to radionuclides left in the soil by the release, the deposition must be modified to provide proper soil concentration. Instead of a release in curies per year, the release is taken to be in curies. The facility life is still taken to be one year. This allows the foliar concentration to be modeled correctly. Equation A.5 is modified so that decay and weathering after deposition is eliminated. This 
modification does not affect the continuous annual release methodology in the remainder of the code (e.g. uptake from soil via roots). The resultant foliar contamination is equivalent to an instantaneous deposition on the crops just prior to harvest. This is felt to be the most conservative approximation of foliar contamination after an accident involving an acute release.

The concentration in farm- or garden-grown crops, $C_{i v}$, is:

$$
c_{i v}=\left[c_{i d}+c_{i r}\right] e^{-\lambda_{i} t_{n}}
$$

where $t_{h}$ is the holdup time between harvest and consumption. The first term in the bracketed expression represents the concentration in the plant derived from direct deposition during the growing season (zero after facility shutdown). The second term in the bracketed expression represents uptake from the soil by plant roots and reflects the total accumulated soil concentration corrected for radioactive decay between the time of deposition and harvest.

\section{A.2.1.3 Animal Products}

The radionuclide concentration in an animal product such as meat, milk or eggs is dependent on the amount of contaminated water, feed or forage consumed by the animal. The following equation describes this calculation.

$$
c_{i a}=S_{i a}\left[\begin{array}{lll}
C_{i F} & Q_{F}+C_{i a w} & Q_{a w}
\end{array}\right]
$$

where:

$\mathrm{C}_{\mathrm{ia}}$ - the concentration in animal product, $\mathrm{pCi} / \mathrm{l}$ or $\mathrm{pCi} / \mathrm{kg}$,

$S_{i a}$ - the transfer coefficient of radionuclide $i$ from daily intake of animal to edible portion of animal product, $\mathrm{pCi} / \mathrm{l}$ (milk) per $\mathrm{pCi} / \mathrm{d}$ or $\mathrm{pCi} / \mathrm{kg}$ (animal product) per $\mathrm{pCi} / \mathrm{d}$,

$C_{i F}$ - the concentration of nuclide $i$ in feed or forage, $p C i / k g$, calculated from Equation A.7, above,

$Q_{F}$ - the consumption rate of nuclide $i$ in feed or forage by animal, $\mathrm{kg} / \mathrm{d}$, 
$\mathrm{C}_{\text {iaw }}$ - the concentration of nuclide $i$ in water consumed by animals, $\mathrm{pCi} / \mathrm{l}$, . assumed to be equal to $C_{i w}$, and

$Q_{a w} \cdot$ the consumption rate of contaminated water by the animal, $\ell / d$,

The second term in the brackets of Equation A. 8 is omitted if the animal does not drink contaminated water. Default values of the animal consumption rates in the program PABLM are listed in Table A- 1 .

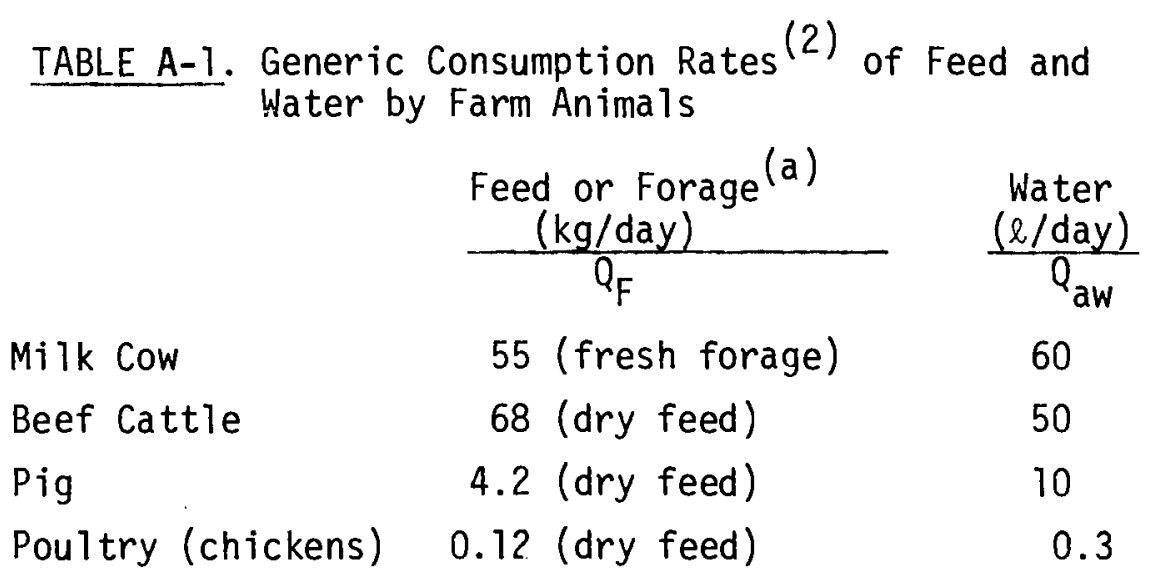

(a) Equivalent fresh weight required to ensure proper calculation of radionuclide intake by animal.

\section{A.2.1.4 Transfer Parameters}

Values for plant concentration ratios and animal product transfer coefficients are given by element in the PABLM input file FTRANSLIB, described in Appendix $D$ and listed in Appendix E.

Plant concentration factors are taken from UCRL-50163, part IV ${ }^{(5)}$ and supplemented with radionuclide data as explained in Reference 1. The literature yielded coefficients of transfer from feed to animal products for only a limited number of radionuclides. For those radionuclides lacking data, comparisons were made with the behavior of chemically similar elements in man ${ }^{(6)}$ and animals. In some instances where other data is lacking, transfer coefficients are set to a "default" value of $9.9 \times 10^{-4}$. The most complete 1 isting of transfer coefficients to be found is that for milk in Reference 5 . The milk transfer coefficients given in that reference were intended to be maximun or "worst case" 
values. The authors imply, by reference to ${ }^{131} \mathrm{I}$, that average values would be about one-half of their 1isted values. As a result, the milk transfer values in FTRANSLIB for elements lacking specific radionuclide data are one-half of those found in Reference 5 .

Some experimental data are available on the transfer of several radionuclides for chicken, meat and eggs. (7) Some of these literature sources were referenced in HERMES. (1) Unfortunately very 1ittle data are currently available on the transfer of radionuclides to beef and pork. Uncontrolled studies have been performed on the principal constituents of fallout ${ }^{90} \mathrm{Sr},{ }^{131} \mathrm{I}$ and ${ }^{137}$ Cs. (1)

\section{A.2.1.5 Tritium and $\mathrm{C}-14$}

The radionuclides tritium and carbon-14 are handled in a special manner. The concentrations of tritium or carbon-14 in environmental media (soil, plants and animal products) are assumed to have the same specific activity ( $\mathrm{pC} \mathbf{i}$ of radionuclide per $\mathrm{kg}$ of soluble element) as the contaminating medium (air or water). The fractional content of hydrogen or carbon in a plant or animal product is then used to compute the concentration of tritium or carbon14 in the food product under consideration. Hydrogen contents in both the water and the nonwater (dry) portion of the food product are used when calculating the tritium concentration. It is assumed that plants obtain all their carbon from airborne carbon dioxide and that animals obtain al1 their carbon through ingestion of plants.

When carbon-14 is present only in the water used for irrigation it is difficult to model its transfer to vegetation, because plants acquire most of their carbon from the air. At this time we have not yet determined the transfer of carbon from the water to the air or soil. We have therefore conservatively assumed that plants obtain all their carbon from the irrigation water. Such an assumption could lead to plant concentrations which are high by about an order of magnitude or more. To date no operating nuclear facilities have been identified which specify releases of carbon-14 in their liquid effluents. However, this pathway can be postulated to exist from migration of carbon-14 into the ground water from long-term storage of nuclear wastes. 
The concentration of tritium in vegetation, $\mathrm{C}_{\mathrm{HV}}$, is calculated as:

$$
C_{H v}=9 C_{H w} F_{h v}
$$

where:

$\mathrm{C}_{\mathrm{HW}}$ - the concentration of tritium in the environmental water $(\mathrm{pC} \mathrm{i} / \mathrm{l})$; for a water release $\mathrm{C}_{\mathrm{HW}}$ represents concentration in irrigation water. For an airborne release $\mathrm{C}_{\mathrm{HW}}$ represents concentration in airborne moisture, hence $\mathrm{C}_{\mathrm{HW}}=$ air concentration in $\mathrm{pCi}\left({ }^{3} \mathrm{H}\right) / \mathrm{m}^{3} \div$ absolute humidity in $\ell \cdot \mathrm{m}^{-3}$,

$F_{h v}$ - the fraction of hydrogen in total vegetation (see Table A-2). The coefficient 9 converts tritium concentration in environmental water to concentration in hydrogen.

The concentration of tritium in the animal product, $\mathrm{C}_{\mathrm{Ha}}$, is:

$$
C_{H a}=\left[\frac{C_{H F} Q_{F}+C_{H a w} Q_{a w}}{F_{h f} Q_{F}+Q_{a w} / 9}\right] F_{h a}
$$

where

$\mathrm{C}_{\mathrm{HF}}$ - the concentration of tritium in feed or forage $(\mathrm{pCi} / \mathrm{kg})$ calculated by Ec. A.9 above, where now $\mathrm{C}_{\mathrm{HF}}=\mathrm{C}_{\mathrm{Hv}}$

$F_{h F}$ - the fraction of hydrogen in animal feed, where now $F_{h f}=F_{h v}$ (grain),

$F_{\text {ha }}$ - the fraction of hydrogen in animal product (see Table A-2), and

$\mathrm{C}_{\text {Haw }}$ - the concentration of tritium in animal drinking water (set to 0 unless there is a release of water).

Similarly, the concentration of ${ }^{14} \mathrm{C}$ in vegetation, $\mathrm{C}_{14 \mathrm{CV}}$, is:

$$
C_{14 C V}=C_{14 C w} F_{C V}
$$

where 
$\mathrm{C}_{14 \mathrm{CW}}$-the concentration of ${ }^{14} \mathrm{C}$ in the environmental medium $\div$ carbon concentration in that medium $\left(\mathrm{pCi}{ }^{14} \mathrm{C} / \mathrm{kg} \mathrm{C}\right) . \mathrm{C}_{14 \mathrm{CW}}$ represents $\mathrm{pCi}{ }^{14} \mathrm{C} / \mathrm{l} \div$ carbon concentration in irrigated water $(\mathrm{kg} / \mathrm{l})$ for water release and $\mathrm{pCi}{ }^{14} \mathrm{C} / \mathrm{m}^{3} \div$ carbon concentration in air $\left(\mathrm{kg} / \mathrm{m}^{3}\right)$ for air release, and

$\mathrm{F}_{\mathrm{CV}} \bullet$ is the fraction of carbon in total vegetation.

The concentration of ${ }^{14} \mathrm{C}$ in the animal product is:

$$
c_{14 C a}=\left[\begin{array}{lll}
C_{14 C F} Q_{F}+c_{14 C a w} & Q_{a w} \\
\hline F_{C F} & Q_{F}+F_{C w} & Q_{\partial w}
\end{array}\right] F_{c a}
$$

For an air release $C_{14 C a w}=0$, and since $F_{C W}$ is very small compared to $F_{c f}$, Equation $A .12$ reduces to:

$$
C_{14 C a}=C_{14 C F}\left(\frac{F_{C a}}{F_{C F}}\right)
$$

Table A-2 contains the various parameters and fractions needed for Equations A. 9 through A.13 that are used in PABLM.

\section{A.2.2 Concentration in Water, Sediment, and Aquatic Food}

Concentration of radionuclides in water, in aquatic foods, and on shoreline sediments are calculated from the annual radionuclide release rate from the nuclear facility, the effluent flow rate, the mixing and dilution in the receiving waters, and bioaccumulation factors for aquatic foods.

\section{A.2.2.1 Water Concentrations}

Mixing and dilution are characterized by a mixing ratio and a reconcentration factor. The mixing ratio, $M_{p}$, accounts for the dilution of the liquid effluent between the point of discharge and the point of exposure, and is best determined from site-specific hydrological studies. If the temperature increase 
TABLE A-2. Generic Fractions and Concentrations of Hydrogen and Carbon in Environmental Media, Vegetation, and Animal Products

A. Fractions in Food

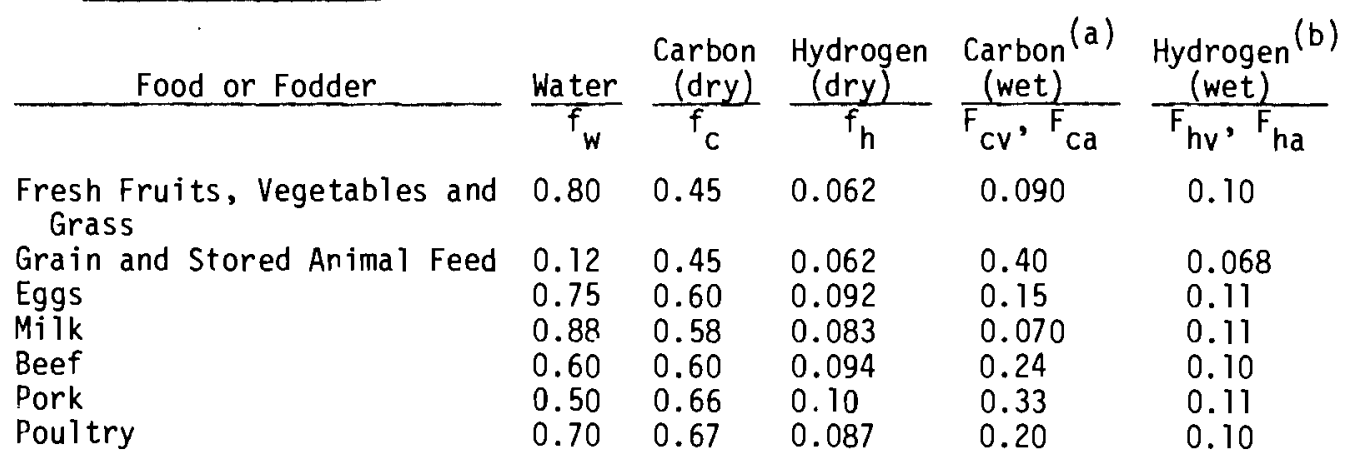

B. Concentrations in media

Absolute Humidity . . . . . . . . . $0.008 \mathrm{l} / \mathrm{m}^{3}$

Concentrations of carbon in water . $2.0 \times 10^{-5} \mathrm{~kg} / \ell(\mathrm{c})$

Concentrations of carbon in air. . $1.6 \times 10^{-4} \mathrm{~kg} / \mathrm{m}^{3(\mathrm{~d})}$

Fraction of soil which is carbon . . . . . . . 0.03

Soil moisture. . . . . . . . . . . . $0.1 \mathrm{\ell} / \mathrm{kg}$

(a) $F_{C v}$ or $F_{c a}=f_{c}\left(1-f_{w}\right)$

(b) $F_{h v}$ or $F_{h a}=f_{w} / 9+f_{h}\left(1-f_{w}\right)$

(c) Assumes a typical bicarbonate concentration of $100 \mathrm{mg} / \mathrm{l}$

(d) Assumes a typical atmospheric $\mathrm{CO}_{2}$ concentration of $320 \mathrm{ppm}_{\mathrm{v}}$.

which results solely from mixing is known at point of exposure, then the mixing ratio is estimated from:

where:

$$
M_{p}=\frac{T_{p}-T_{A}}{T_{0}-T_{A}}
$$

$T_{A}-$ ambient temperature of the receiving sink,

$T_{p}$ - temperature which would exist at the point of exposure for pathway $p$ if no evaporation or best radiation effects were present.

$T_{0}$ - temperature of the effluent at the outlet. 
The value for $T_{p}$ can be estimated from a plot of isotherms due to mixing only in the receiving waters if they are available.

The reconcentration factor, $N_{i}$, accounts for the extent to which the effluent is recycled through the nuclear facility. The computer program PABLM is designed to allow the user a choice of the following reconcentration models:

(1) If the cooling water is drawn from a cooling pond, small lake or reservoir which is connected to a larger body of water or is fed by a stream, then:

$$
N_{i}=\left[1-\frac{(F-L) e^{-\lambda_{i} t_{c}}}{F+V \lambda_{T}}\right]^{-1}
$$

(2) If the cooling water intake is downriver from the outfall or on a lake or ocean site and arranged such the recirculation occurs, then:

$$
N_{i}=\frac{1-\left[g e^{-\lambda_{i} t} c\right]^{n+1}}{1-g e^{-\lambda_{i} t_{c}}}
$$

(3) If there is no reconcentration, for example, if the cooling water is drawn from a river in which the outfall is below the intake, then:

$$
N_{i}=1.0
$$

where:

$g$ - recycle fraction (the mixing ratio at the point of intake), unitless

- coolant flow, $f t^{3} / \mathrm{sec}$,

$L$ - makeup flow (water drawn into the intake to replace losses), $\mathrm{ft}^{3} / \mathrm{sec}$,

$V$ - pond volume, $f t^{3}$,

$\lambda_{T} \cdot$ pond turnover rate, $\sec ^{-1}$,

$t_{c} \cdot$ cycle time, $h r$,

$\lambda_{i} \cdot$ decay constant, $\mathrm{hr}^{-1}$,

$n$ - number of cycles during facility lifetime $=\frac{\text { plant life }(\mathrm{hr})}{t_{c}}$. 
These three models were chosen for the program because they apply to the most common reconcentration situations. Unusual cases could require that special reconcentration formulas be added to the program.

Equation A. 16 is the closed form of the series

$$
N_{i}=1+G_{i}+G_{i}^{2}+G_{i}^{3}+\ldots .+G_{i}^{n}
$$

where $G_{i}=g \exp \left(-\lambda_{i} t_{c}\right)$ for nuclide $i$.

Equation A.15, the most complex of the reconcentration models, is used for sites on a cooling pond, lake or reservoir where the water is exchanged by stream flow or connection with a larger body of water such as the ocean. It can also be used for a system of cooling canals where a fresh dilution stream (makeup) is injected into the inlet pipe along with the recycled water from the cooling pond. From elementary considerations of mass balance, assuming steadystate conditions and instantaneous mixing in the cooling pond, Equation A.15 is of the form of Equation A. 16 with $n \rightarrow \infty$ and with the recycle fraction a function of hydrological parameters and the radionuclide decay constant (see Figure $A-1$ ). Thus:

$$
N_{i}=\left[1-\frac{(F-L) e^{-\lambda_{i} t_{c}}}{(F-L)+V\left(\lambda_{T}+\frac{L}{V}\right)}\right]^{-1}
$$

The volume, $V$, for Equation A.15 may be taken to be a series of canals, a pond, small bay, small lake, etc. However, the model loses.credibility if $V$ is very large since instantaneous mixing in $V$ was assumed; therefore, Equation A.16 should be used for large $V$.

Once the mixing ratio, $M_{p}$, and the reconcentration factor, $N_{i}$, are determined, the water concentration, $C_{i w}$, of nuclide $i$ is found as:

$$
C_{i w}=1119 Q_{i} N_{i} M_{p} / F_{r}
$$




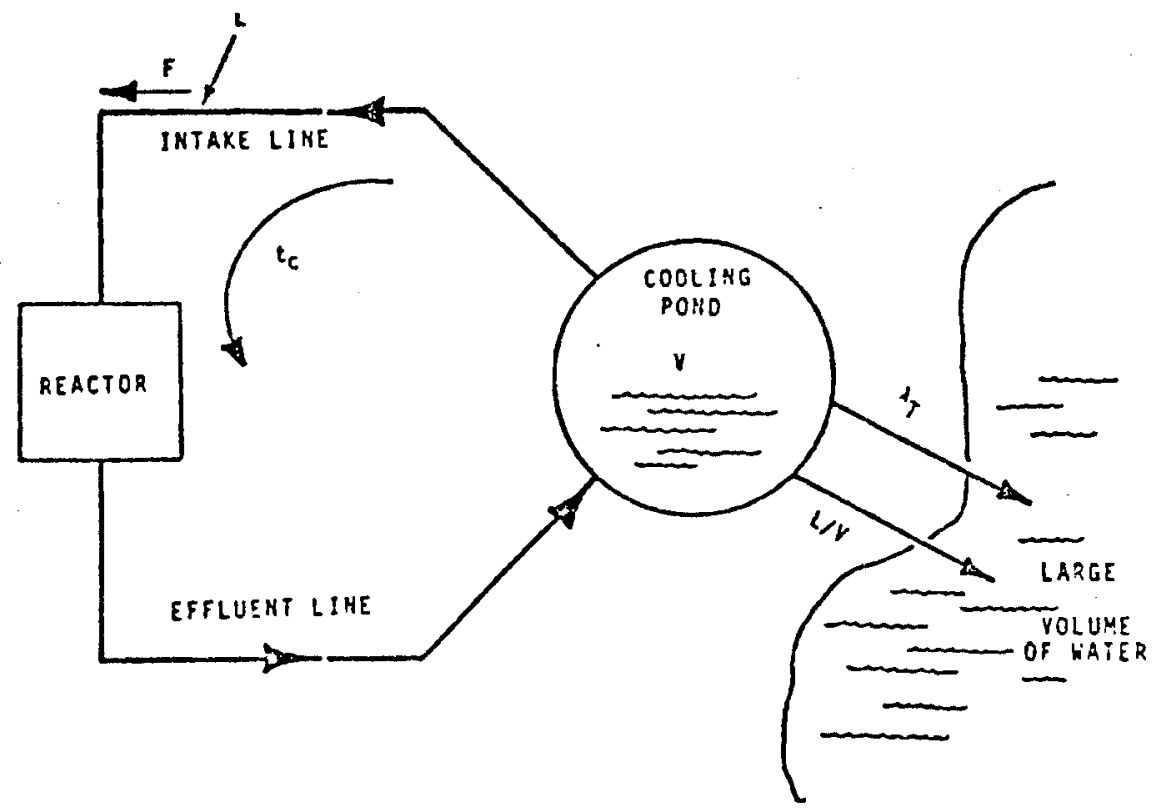

FIGURE A.1. Reconcentration in Reactor Effluent Due to Recycling Through a Cooling Pond

where:

1119 - a unit conversion factor from $(\mathrm{Ci} / \mathrm{hr}) /\left(\mathrm{ft}^{3} / \mathrm{sec}\right)$ to $\mathrm{pCi} / 1 \mathrm{iter}$

$\mathrm{Q}_{\mathrm{i}}$ - the release rate of radionuclide $\mathrm{i}, \mathrm{C} i / \mathrm{yr}$, and

$F_{r}$ - the annual average river flow rate, $\mathrm{ft}^{3} / \mathrm{sec}$.

Dose factors for persons swimming in contaminated water are calculated using the water concentration of radionuclides and the assumption that the water is an infinite medium with respect to the range of the emitted radiations. The radiation dose rate to people boating on this water is assumed to be haif that for swimmers.

\section{A.2.2.2 Aquatic Foods}

Concentrations of radionuclides in aquatic foods are directly related to the concentrations in the water. Equilibrium ratios between the two concentrations, called bioaccumulation factors in this report, are taken from References 8 and 9 and are listed in file BIOAC, presented in Appendix D. The concentration in aquatic foods, $C_{i p}$, is related to the water concentration as 


$$
C_{i p}=C_{i w} B_{i p}
$$

where $B_{i p}$ is the bioaccumulation factor for nuclide $i$ and pathway $p$, dimensionless.

\section{A.2.2.3 Drinking Water}

The concentrations of radionuclides in drinking water are also related to concentrations in the river water. Water consumed by humans is subject to a wide variety of types of treatment processing prior to consumption. Radionuclides are removed with varying degrees of efficiency depending on the specific treatment used. Radionuclide removal efficiencies for water treatment plants assumed for use in the computer code PABLM are based on extensive experience with the alum-floc process used in the water treatment plants, Richland and Pasco, Washington. These two cities are on the Columbia River downstream of the Hanford Site. Water samples were collected before and after processing at these treatment plants for several years $(1,10)$. From these data, the fractions of contained radionuclides that pass through a water treatment plant were estimated. These fractions were presented in the data file $B I O A C$, in Appendix $D$. They are used as is $B_{i p}$.

\section{A.2.2.4 Sediments}

The calculation of sediment load, transport and concentrations of radionuclides associated with suspended and deposited materials is a complex problem. Some studies have shown that radionuclides in water adhere to particles in suspension ${ }^{(11)}$, and that they deposit with the particles. Therefore, for the program PABLM, a simplified scheme for obtaining an order of magnitude estimate of the concentration of radionuclides in shoreline sediments is used $(2,12)$. The mode 1 assumes a constant water concentration per year, as long as the release lasts, and a deposition rate dependent only on water concentration. This is described mathematically as:

$$
\frac{d C_{i s}}{d t}=K C_{i w}-C_{i s} \lambda_{i}
$$


where:

$\mathrm{C}_{\text {is }}$ - the sediment surface concentration, $\mathrm{pCi} / \mathrm{m}^{2}$, and

$k$ - a rate constant, 1 iter $/ \mathrm{m}^{2}-y r$.

The buildup of an individual radionuclide is:

$$
c_{i s}=k C_{i W}\left(1-e^{-\lambda_{i} t}\right) / \lambda_{i}
$$

In the original evaluation of Equation $A .22, \lambda_{i}$ was chosen to be the radiological decay constant, although the true value should include an unknown "environmental" removal constant. The value of $k$ was derived from radionuclide concentrations measured in water and sediment samples collected over a period of years in the Columbia River between Richland, Washington and the river mouth and in Tillamook. Bay, Oregon, $75 \mathrm{~km}$ (47 miles) south of the river mouth $(13,14)$. The value used is $25300 \mathrm{\ell} \cdot \mathrm{m}^{-2} \mathrm{yr}^{-1}$. (a) Radioactive daughter products are allowed to build up in both the water and sediment. Once the release of radionuclides to the river ceases, removal from the sediments is assumed to be by radioactive decay only.

External radiation doses to people standing near the sediments are calculated based on an infinite flat plane source model. To correct for the actual geometry of a river bank or other beach, shore width factors $(2,15)$ are used. Shore width factors, W, suggested for use with PABLM are given in Table A-3. These are multiplicative factors used to describe the effective surface contamination, $C_{\text {is }}$, as:

(a) A value for a constant $k^{1}, \ell \cdot m^{-2} \cdot d^{-1}$, was originally derived as $210^{2}$ for an equation of the form

$$
c_{i s}=k c_{i w R i}{ }^{\top}\left(1-e^{-\lambda} i t\right)
$$

where $T_{R i}=\ln n_{2} / \lambda_{i}$, days.

Conversion of $T_{R i}$ days to $\mathrm{in}_{2} / \lambda_{i}$ in years ${ }^{-1}$ leads to the value of $2.53 \times 10^{4} \mathrm{e} \cdot \mathrm{m}^{-2} \cdot \mathrm{yr}^{-1}$ used for Equation A.22 in the PABLM code. Three "significant" digits are carried to ensure that the PABLM code yields answers comparable to those obtained with the older expression. The answer is, however, still an order of magnitude estimate of the sediment surface concentration. 


$$
c_{i s}=S_{i} W
$$

TABLE A-3. Shore Width Factors

\begin{tabular}{lc} 
Exposure Situation & Shore Width Factor $(W)$ \\
\hline Discharge canal bank & 0.1 \\
River shoreline & 0.2 \\
Lake shore & 0.3 \\
Nominal ocean site & 0.5 \\
Tidal basin & 1.0
\end{tabular}

\section{A. 3 USAGE PARAMETERS}

Usage refers to duration of human exposure to external sources of radiation and to intake rates of food and water. The usage depends on the specific exposure pathway and situation. The hypothetical "maximum-exposed individual" has usage rates higher than an average individual, to realistically maximize potential dose. For population dose calculations, the usages of the average adult are assumed for the entire exposed population. Usage values are input to the PABLM computer models.

\section{A. 4 DOSE COMMITMENT FACTORS}

The form of the dose commitment factor used depends on the exposure pathway considered. For external exposure, the dose is accrued only during the year of exposure. However, for ingestion pathways, the radionuclides may accumulate in the body and one year of exposure may result in a dose received over a several-year period. Thus, there are different equations for the two types of exposure. For some radionuclides, there are also special models for some specific organs.

\section{A.4.1. External Dose Commitment Factors}

For calculating external dose factors from water immersion, the penetrating power of the radiation emitted determines whether it contributes to skin dose onty, or to both skin and total-body dose. Beta and gamma radiation which can penetrate $7 \times 10^{-3} \mathrm{~cm}$ of tissue is considered to contribute to skin dose; radiation which can penetrate $5 \mathrm{~cm}$ of tissue is considered to contribute to 
tota 1-body dose (and dose to internal organs). The dose factors for immersion are derived assuming that the contaminated water is an infinite medium compared with the range of the emitted radiations. Under this assumption, the energy emitted per gram of water equals the energy absorbed per gram of water. Corrections are applied for differences in energy absorption between tissue and water, physical geometry of the specific exposure situation, and the conversion from $\mathrm{MeV}$ per disintegration per gram to rem. The resulting dose factors, input to PABLM from the file GRDFLIB, are presented in Appendix E. The units are mrem/hr per $\mathrm{pCi} / \mathrm{Titer}$.

Material deposited from the air or from irrigation water onto the ground represents a large, uniform thin sheet of contamination. The factors for converting surface contamination in $\mathrm{pCi} / \mathrm{m}^{2}$ to gamma dose at one meter above a uniformly contaminated plane are also presented in file GRDFLIB in Appendix E. The units are $\mathrm{mrem} / \mathrm{hr}$ per $\mathrm{pCi} / \mathrm{m}^{2}$ of surface.

The total accumulated dose from external irradiation is thus calculated as

$$
D_{p r}=\sum_{T=1}^{\substack{\text { no. of } \\ \text { years }}} \sum_{i=1}^{\text {radionuclides }} C_{i p}(T) \cdot U_{p} \cdot F_{i p r}
$$

The dose factor $F_{i p r}$ is independent of the year in which the dose is received. The organ, $r$, is either skin or total body. The doses to internal organs are set eoual to the total-body dose.

\section{A.4.2. Internal Dose Commitment Factors}

Unlike the external dose factors, the factors for dose from internaliy deposited radionuclides are dependent on the length of time the nuclides have been in the body. Therefore the internal factors are calculated in PABLM

. from more basic nuclear and metabolic data.

The dose model used is derived from that originally given by the International Commission on Radiological Protection $(6)$ for body burden and maximum permissible concentration. For the PABLM computer program, effective decay energies for radionuclides are calculated using the ICRP model. This model is 
based on the assumption that the entire quantity of a given radionuclide is located at the center of a spherical organ with an appropriate effective radius. (2) Metabolic parameters for the standard man are used. (16) The equation for committed radiation dose equivalent per picocurie per year ingested, $F_{i p r}$ for organ $r$, for an arbitrary period following ingestion for a period $T_{i}$ is:

$$
F_{i p r}=0.0187 \frac{f_{\text {wir }}^{\varepsilon} i r}{m_{r}\left(\lambda_{e}{ }^{2}\right)}\left[T_{1} \lambda+e^{-\lambda e^{T} 2}-e^{-\lambda e^{\left(T_{2}-T_{1}\right)}}\right]
$$

where:

$$
\begin{aligned}
& F_{i p r}\left(T_{2}\right) \text { - the dose commitment for } T_{2} \text { years following ingestion of } \\
& \text { of a radionuclide at the rate of one picocurie/yr over } \\
& T_{1} \text { years, rem/pCi over } T_{2} \text { Years. (Note this is independent } \\
& \text { of pathway } p \text { ). } \\
& 0.0187 \text { a unit conversion factor }= \\
& \left(1.602 \times 10^{-8} \frac{\mathrm{g}-\mathrm{rad}}{\mathrm{MeV}}\right)\left(\frac{0.037 \mathrm{dis}}{\mathrm{sec}-\mathrm{pCi}}\right)\left(\frac{3.15 \times 10^{7} \mathrm{sec}}{\mathrm{yr}}\right) \text {, } \\
& f_{\text {wir }} \\
& \varepsilon_{\text {ir }} \\
& m_{r} \\
& \text { - the effective mass of organ } r \text {, grams. Organ masses used in } \\
& \text { PABLM are those taken from ICRP-23, (16) listed in } \mathrm{g} \text {, } \\
& \text { Table A-4, } \\
& T_{1} \text { - the intake time, taken to be } 1 \text { year in PABLM } \\
& T_{2} \text { - the time over which the dose is accumulated, years. } \\
& \lambda_{e} \quad \text { - the effective removal half-time, related to the biological } \\
& \text { half-time, } T_{B i} \text {, and the radiological half-time, } T_{R i} \text {, as }
\end{aligned}
$$


TABLE A-4. Organs and Organ Masses Used in PABLM (a)

\begin{tabular}{|c|c|c|}
\hline Organ & $\begin{array}{l}\operatorname{mass} \\
(\mathrm{g})\end{array}$ & $\begin{array}{c}\text { Organ } \\
\text { Reference } \\
\text { No. } \\
\end{array}$ \\
\hline Total-body & 70,000 & 1 \\
\hline Body water & 63,000 & 2 \\
\hline Kidney & 310 & 3 \\
\hline Liver & 1,800 & 4 \\
\hline Spleen & 180 & 5 \\
\hline Bone & 7,000 & 6 \\
\hline Fat & 13,500 & 7 \\
\hline Lung & 1,000 & 8 \\
\hline Adrenals & 14 & 9 \\
\hline Testes & 35 & 10 \\
\hline Ovaries & 11 & 11 \\
\hline Skin & 2,600 & 12 \\
\hline Brain & 1,400 & 13 \\
\hline Muscle & 28,000 & 14 \\
\hline Prostate & 16 & 15 \\
\hline Thyroid & 20 & 16 \\
\hline Pancreas & 100 & 17 \\
\hline Heart & 330 & 18 \\
\hline GI-general (b) & 0 & 19 \\
\hline GI-stomach $^{(b)}$ & 250 & 20 \\
\hline GI-smal1 intestine ${ }^{(b)}$ & 400 & 21 \\
\hline GI-large intestine ${ }^{(b)}$ & 250 & 22 \\
\hline GI-lower large intestine ${ }^{(b)}$ & 135 & 23 \\
\hline
\end{tabular}

(a) from Reference 16.

(b) masses for GI are contents of compartment 


$$
\lambda_{e}=\frac{0.693\left(T_{R i}+T_{B i}\right)}{T_{R i} T_{B i}} \text { years }{ }^{-1} \text {. }
$$

Therefore, using this formulation, the total accumulated dose over $T_{2}$ years to an organ of reference, $r$, from ingestion of food products contaminated with radionuclides is written as:

$$
\begin{aligned}
& \text { No. of } \\
& D_{r}=\sum_{T=1}^{T_{2}} \sum_{p=1}^{\substack{\text { Food } \\
\text { Pathways }}} \sum_{i=1}^{\substack{\text { No. of } \\
\text { Nuclides }}} c_{i p}(T) U_{p} F_{i p r}\left(T_{2}-T\right)
\end{aligned}
$$

Notice that the concentration of radionuclide $i$ in pathway $p, C_{i p}(T)$, is allowed to change with time. The $\left(T_{2}-T\right)$ formulation implies that the dose period ends at year $T_{2}$. In PABLM, $T_{2}$ is generally taken to be either 50 or 70 years.

The computer program PABLM accounts for special cases which deviate from Equation A.26. For the radionuclides ${ }^{3} \mathrm{H}$ and ${ }^{14} \mathrm{C}$, the accumulated dose for the organs total-body and bone are calculated as above. Since these radionuclides distribute evenly in the rest of the body, the doses for all the other organs are set equal to that for total-body. For isotopes of sodium, all organs including bone are set equal to total-body. The GI tract model also differs from that of Equation A.26.

The four compartments of the GI tract, stomach, SI, ULI, and LLI, are modeled as a four-compartment system with a plug flow, and no long term storage or retention. The portions of the GI tract are assumed to be irradiated from radionuclides uniformly distributed in the material passing through each compartment; therefore, the dose in any one year is equal to the dose commitment for that year. The dose factor per picocurie per year ingested is calculated as

$$
F_{i p r}=2.56 \times 10^{-5} \frac{{ }^{\tau}{ }_{r}^{f_{i r}^{*} \varepsilon_{i r}}}{m_{r}} e^{-\lambda i^{\tau} r}
$$

where: 
$2.56 \times 10^{-5}$ - a unit conversion factor, equal to

$$
\left(1.602 \times 10^{-8} \frac{\mathrm{g}-\mathrm{rad}}{\mathrm{MeV}}\right)\left(\frac{0.037 \mathrm{dis}}{\mathrm{sec} \cdot \mathrm{pCi}}\right)\left(\frac{86400 \mathrm{sec}}{\mathrm{day}}\right) / 2
$$

The factor of $1 / 2$ accounts for the fact that the dose is calculated for the inner wall of the organs and not to the contents,

$\tau_{r}$

$\tau^{\prime \prime} r$

f

- the travel time of the contents of the GI tract through compartment $r$, days,

- the travel time to the entrance of the compartment, days, and

- the fraction of the total quantity of the ingested radionuclide $i$ that remains at the entrance of the compartment, $r$.

Values of the travel times for the four compartments of the GI tract are given in Table A-5.

The total accumulated dose for the GI tract is:

$$
D_{r}=\sum_{T=1}^{T_{2}} \sum_{p=1}^{\substack{\text { no. of } \\ \text { pathways }}} \sum_{i=1}^{\substack{\text { no. of } \\ \text { nuclides }}} c_{i p}(T) U_{p} F_{i p r}
$$

\begin{tabular}{|c|c|c|}
\hline Organ & $\begin{array}{c}\text { Travel Time } \\
\text { through } \\
\text { Organ, } \tau, \\
\text { (days) } \\
\end{array}$ & $\begin{array}{l}\text { Travel Time } \\
\text { to Organ, }{ }^{\prime} \\
\text { (days) } \\
\end{array}$ \\
\hline Stomach & $0.0417^{(a)}$ & 0.0 \\
\hline GI-small intestine & 0.1667 & 0.0417 \\
\hline GI-upper large intestine & 0.3333 & 0.2083 \\
\hline GI-lower large intestine & 0.7500 & 0.5417 \\
\hline
\end{tabular}

TABLE A-5. Travel Times for the GI Tract Model

(a) Ingested material does not flow through the stomach. It remains in there for 1 hour after which time it is passed to the SI in a relatively short time. 
$B_{i v}$

$$
B_{\text {ip }}
$$

$\mathrm{C}_{\text {ia }}$ $c_{\text {iaw }}$

$c_{\text {id }}$

$\mathrm{C}_{\text {iF }}$

$c_{\text {ir }}$

$C_{\text {ip }}$

$c_{\text {is }}$

$c_{\text {iv }}$

$c_{i w}$

$d_{i}$

Dipr

$\varepsilon_{\text {ir }}$

$f_{i}^{\star}$

$f_{\text {wir }}$

$\mathrm{F}$

$F_{i p r}(T)$
- concentration ratio for plant uptake, dimensionless

- bioaccumulation factor for aquatic food products, dimensionless

- time-dependent concentration of nuclide $i$ in pathway $p, p C i / g$, $\mathrm{pCi} / \mathrm{l}$, or $\mathrm{pCi} / \mathrm{m}^{3}$

- concentration of nuclide $i$ in animal products, $\mathrm{pCi} / \mathrm{kg}$ or $\mathrm{pCi} / \mathrm{l}$

- concentration of nuclide $i$ in animal drinking water, $\mathrm{pC} i / \ell$

- concentration of nuclide $i$ on terrestrial vegetation from direct deposition, $\mathrm{pCi} / \mathrm{kg}$,

- concentration of nuclide $i$ in feed or forage, $\mathrm{pCi} / \mathrm{kg}$

- concentration of nuclide $i$ in plants from root uptake, $\mathrm{pCi} / \mathrm{kg}$

- concentration of nuclide $i$ in aquatic foods, $\mathrm{pCi} / \mathrm{kg}$

- concentration of nuclide $\mathrm{i}$ in soil or sediment, $\mathrm{pCi} / \mathrm{kg}$ or $\mathrm{pCi} / \mathrm{m}^{2}$

- concentration of nuclide $i$ in farm or garden crops, $\mathrm{pCi} / \mathrm{kg}$

- concentration of nuclide $i$ in water, $p C i / k g$

- deposition rate of nuclide $i, p C i / m^{2}-y r$

- the dose to organ $r$ from nuclide $i$ through exposure pathway $p$, rem

- effective decay energy of nuclide $i$ in organ $r, M e V$

- fraction of nuclide $i$ remaining at the entrance to GI organ $r$, dimensionless

- fraction of nuclide $i$ ingested reaching organ 4, dimensionless

- flow rate, $\mathrm{ft}^{3} / \mathrm{sec}$

- dose commitment factor for organ $r$ from nuclide $i$ through pathway $p$, time-dependent, $r e m / p C i$. 


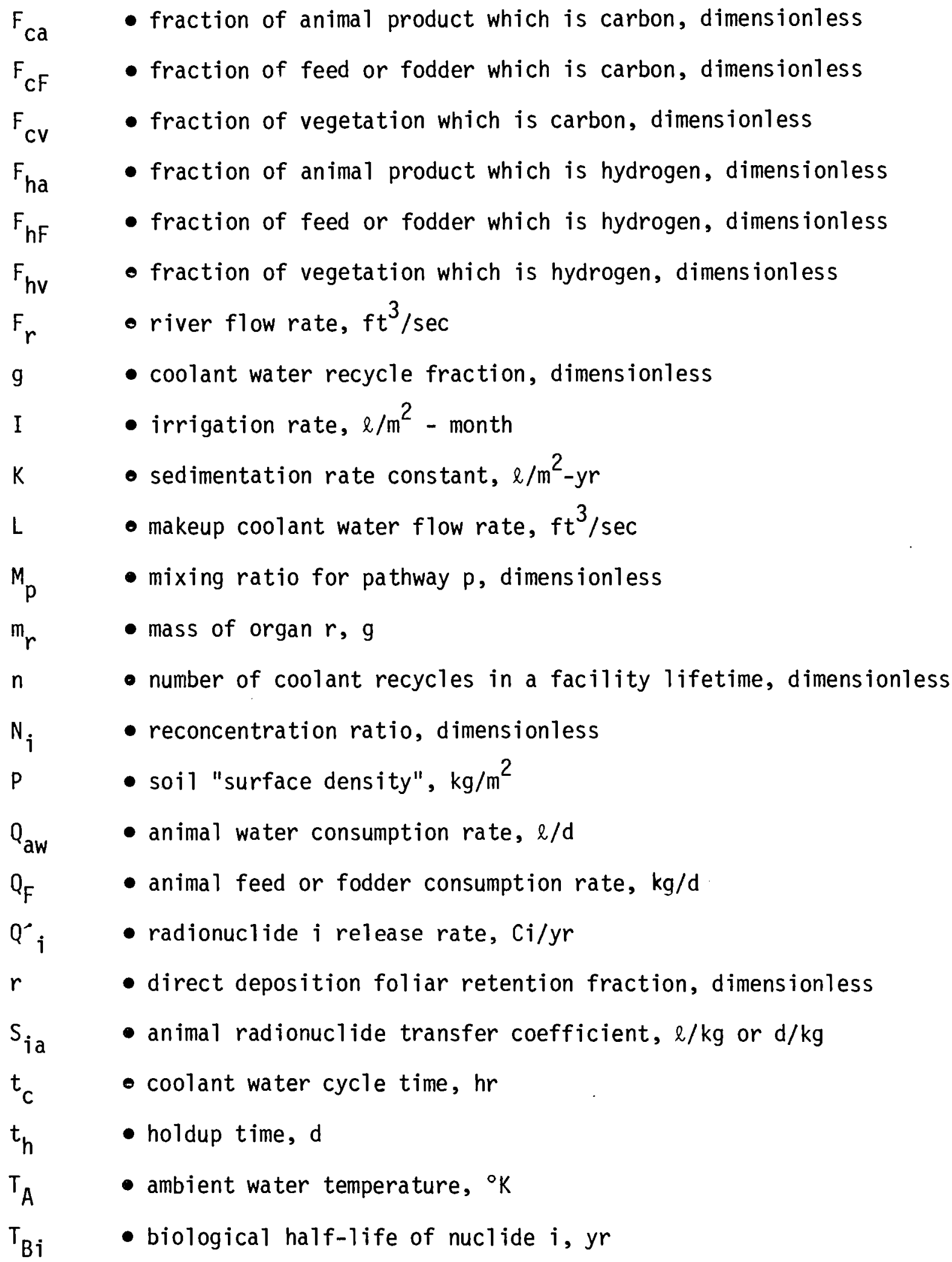




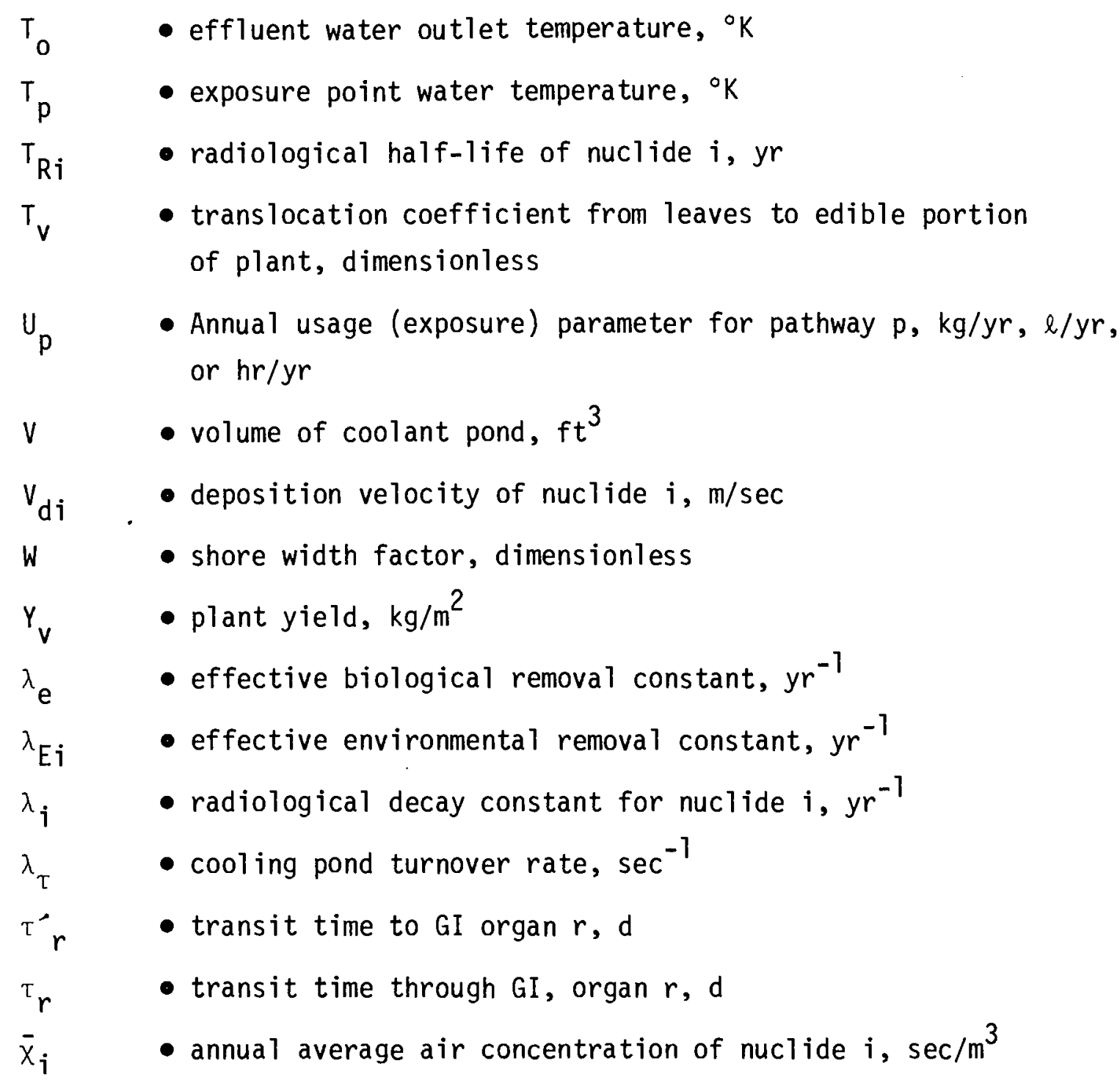




\section{REFERENCES FOR APPENDIX A}

1. Soldat, J. K., and R. D. Harr, "Radiation Dose Mode1" pp. 81-175, in, (J. F. Fletcher and W. L. Dotson, compilers) HERMES--A Digital Computer Code for Estimating Regional Radiological Effects from the Nuclear Power Industry, USAEC Report HEDL-TME-71-68. Hanford Engineering Development Laboratory, Richland, WA, 1971.

2. Soldat, J. K., et a1., Models and Computer Codes for Evaluating Environmental Radiation Doses, USAEC Report BNWL-1754, Batte11e, Pacific Northwest Laboratories, Richland, WA, February 1974.

3. Baker, D. A., G. R. Hoenes and J. K. Soldat, F00D--An Interactive Code to Calculate Internal Radiation Doses from Contaminated Food Products, BNWL-SA-5532, Batte11e, Pacific Northwest Laboratories, February 1976.

4. Bateman, H., Proc. Cambridge Phil. Soc., 16: 423, (1910).

5. Ng, Y. C., et. al., Prediction of the Maximum Dosage to Man from the Fallout of Nuclear Devices--IV, Handbook for Estimating the Maximum Internal Dose from Radionuclides Released to the Biosphere, USAEC Report, UCRL-50163, Lawrence Radiation Laboratory, University of California, Livermore, CA, 1968.

6. International Commission on Radiological Protection, Report of ICRP Committee II on Permissible Dose for Internal Radiation, ICRP Publication 2, Pergamon Press, New York, 1959.

7. Annenkov, I. K., et al., The Radiobiology and Radioecology of Farm Animals, AEC-TR-7523, 1974.

8. Thompson, S. E., C. A. Burton, D. J. Quinn and Y. C. Ng, Concentration Factors of Chemical Elements in Edible Aquatic Organisms, USAEC Report UCRL50564 Rev. 1, University of California, Lawrence Livermore Laboratory, 1972.

9. Freke, A. M. "A Model for the Approximate Calculation of Safe Rates of Discharge of Radioactive Wastes into Marine Environments," Health Physics, 13:743, (1965).

10. Denham, D. H., and J. K. Soldat, A Study of Selected Parameters Affecting the Radiation Dose from Drinking Water Downstream of Nuclear Facilities, BNWL-SA-4545 Rev., Battelle, Pacific Northwest Laboratory, Richland, WA.

- 11. Gardener, K., and 0. Skulburg, "Sorption Phenomena of Radionuclides to Clay Particles in River Water," Int. J. Wat. Pol1., 8:229-241, (1964).

12. Sche11, W. Sedimentation Rates and Mean Residence Times of Stable Pb and $210 \mathrm{~Pb}$ in Lake Washington, Puget Sound Estuaries, and a Coastal Region, U. W. College of Fisheries, Seattle, 1974. 
13. Nelson, J. L. "Distribution of Sediments and Associated Radionuclides in the Columbia River below Hanford," p. 3.80 in (D. W. Pearch and J. K. Green, Eds.), Hanford Radiological Sciences Research and Development Annual Report for 1964, USAEC Report BNWL-36, Battelle, Pacific Northwest Laboratories, Richland, WA, 1965.

14. Toombs, G. L., and P. B. Culter (compilers), Comprehensive Final Report for the Lower Columbia River Environmental Survey in Oregon, June 5, 1961-July 31, 1967, Oregon State Board of Health, Div. Of Sanitation and Engineering, Portland, OR, 1968.

15. Handbook of Radiological Protection, Part I: Data, prepared by a Panel of the Radioactivity Advisory Committee (H. J. Dunster, Chairman), Dept. of Employment, Dept. of Health and Social Security, Ministry of Health and Social Services, Northern Ireland, number SBN 11360079 8, Her Majesty's Stationery Office, London, England, 1971.

16. International Commission on Radiological Protection, Report of the Task Group on Reference Man, ICRP Publication 23, Pergamon Press, New York, 1975. 
APPENDIX B

COMPUTER CODE SUBROUTINE DESCRIPTIONS 
APPENDIX B

\section{COMPUTER CODE SUBROUTIIVE DESCRIPTIONS}

The models decribed in Appendix $A$ are incorporated into the computer code PABLI, which is programed for the UNIVAC 1100/44 in ASCII FORTRAiv. A short description of the functions of each subroutine in PABLM is given in this Appendix.

MAIN

MAIN is the main program and calls the other subroutines to perform the calculations requested by the user. The data library reading subroutines are called by the main program. All other input data is read by the main program. Input data that is required is explained in detail in Appendix $F$. The main program is designed for flexibility and ease of running related calculations. Many cases can be run using one input of control or inventory data. The main program controls the calling of the environmental concentration and dose calculating subroutines. The time loop on years for the accumulated dose commitment is contained in MAIN.

There are no common or equivalence statements. All input to subroutines is through the calling sequence.

$\underline{\text { RLIBIN }}$

Subroutine RLIBIN reads the radiological deca:" data from the radionuclide master library, including half-life, decay chain position, and branching ratios. It also tests for consistency in the library decay chains.

\section{FLIBIN}

Subroutine FLIBIN reads the food transfer coefficient library. 
OLIBS

Subroutine OLIBS reads biological data from the organ data library. It also checks for consistency with the master radionuclide library read by RLIBIN.

\section{$\underline{\text { SLIBIN }}$}

Subroutine SLIBIN reads dose factors from the library for external exposure from radionuclides in the soil or in water. It also checks for consistency with the master radionuclide library read by RLIBIN.

\section{BLIBIN}

Subroutine BLIBIN reads bioaccumulation factors from the library for aquatic organisms in salt and fresh water. It also reads a factor for cleanup of drinking water by water treatment plants.

ZEROR

Subroutine ZEROR is used to set the values of real number arrays to real zero.

ZEROI

Subroutine ZEROI is used to set the values of integer arrays to integer zero.

IDNUC

Subroutine IDIIUC checks the nuclides from the input source term against the radionuclide master library. If a nuclide is not found, the program aborts. The subroutine also initializes flags indicating which decay chains are active in the calculation.

OFPCHK

Subroutine OFPCHK counts the number of organs, terrestrial exposure pathways, and aquatic exposure pathways chosen for the calculation. If no organs or no exposure patinways are initialized, the program aborts. 
SETDAT

Subroutine SETDAT selects required data from that read by the library reading subroutines and creates condensed data arrays for the calculations based on the decay chains for the radionuclides in the input inventory. This subroutine also adjusts units on the input data to make it compatible with the later calculations. If no data is available for a nuclide in any decay chain, a message is printed and the radionuclide is dropped, but the program is not aborted.

QAPAGE

Subroutine QPAPAGE performs no calculations. It prints back the options chosen and parameters used in the calculation. It allows the user to check his input and verify the problem run.

\section{DFCALC}

Subroutine DFCALC uses the biological data from the organ data library to prepare the time-independent portion of the dose commitment factor for each radionuclide in each active decay chain. The dose factors are organ-specific. These are special cases for ${ }^{3} \mathrm{H},{ }^{14} \mathrm{C},{ }^{13} \mathrm{~N},{ }^{22} \mathrm{Na}$, and ${ }^{24} \mathrm{Na}$. For these radionuclides, all organ dose factors are set equal to that for total body, except for those for bone for ${ }^{3} \mathrm{H}$ and ${ }^{14} \mathrm{C}$. There is also a separate model for organs of the GI tract.

DOSE

In subroutine DOSE, a 11 environmental concentrations of radionuclides are calculated from the initial input inventory. The initial inventory are specified for either an initial deposition on the soil in $\mathrm{Ci} / \mathrm{m}^{2}$, as a chronic atmospheric release in $\mathrm{Ci} / \mathrm{yr}$, as a chronic liquid release in $\mathrm{Ci} / \mathrm{yr}$, as an acute atmospheric release in $\mathrm{C} i$, or as an acute liquid release in $\mathrm{Ci}$. For a source such as a tank with a constant mass leak rate, the source term may be decayed with time. For atmospheric releases, air and soil concentrations are calculated. For liquid releases, a reconcentration factor may be calculated in one of three ways. Then water, shoreline sediment, and irrigated field soil concentrations 
are calculated. From the water and soil concentrations, the concentrations of radionuclides in food products is determined. There are special specific activity models included for tritium and carbon-14.

SOIL

This subroutine is used to initialize the soil concentration for the terrestrial food pathways for the initial deposition mechanism. It is not used in scenarios involving chronic releases.

\section{ACHAIN}

Subroutine ACHAIN is called by DOSE to perform the radiological chain decay calculations on the source term and on nuclides built up in the environment. It solves both the integral and differential forms of the Bateman equations.

EXMO

Function EXMO for ACHAIN calculates the function $\left(1-e^{-\lambda t}\right) / \lambda$, used in the integral formulation of the Bateman equations.

ASUM

Function ASUM for ACHAIN sums terms in the coefficients of the Bateman equations.

SUMPRD

Function SUMPRD for ACHAIN sums the products of the coefficients and exponential terms of the Bateman equations.

DOSC1

Subroutine DOSCl calculates dose commitments from ingestion of contaminated farm crops and from exposure to contaminated soil, and calculates the accumulated dose. It also sets up arrays for the output routines. 
$\underline{D O S C 2}$

Subroutine DOSC2 calculates dose commitments from ingestion of contaminated aquatic food products and exposure to contaminated shoreline and water, and calculates the accumulated dose. It also sets up arrays for the output routines.

$\underline{\text { DOSOUT }}$

Subroutine DOSOUT controls the calling of the summary and complete accumulated dose output table.

SUMMRY

Subroutine SUMMRY prints three summary dose commitment tables from all exposure pathways combined.

OUTI

Subroutine OUTl prints summary and complete output accumulated dose tables for all terrestrial exposure pathways.

$\underline{\text { OUT2 }}$

Subroutine OUT2 prints summary and complete output accumulated dose tables for all aquatic exposure pathways. 
APPENDIX $C$

\section{PABLM CODE FLOW DIAGRAMS}

1. Subroutine Hierarchy

2. Main Routine

3. Subroutine SETDAT

4. Subroutine DFCALC

5. Subroutine DOSE

6. Subroutine DOSCl

7. Subroutine DOSC? 


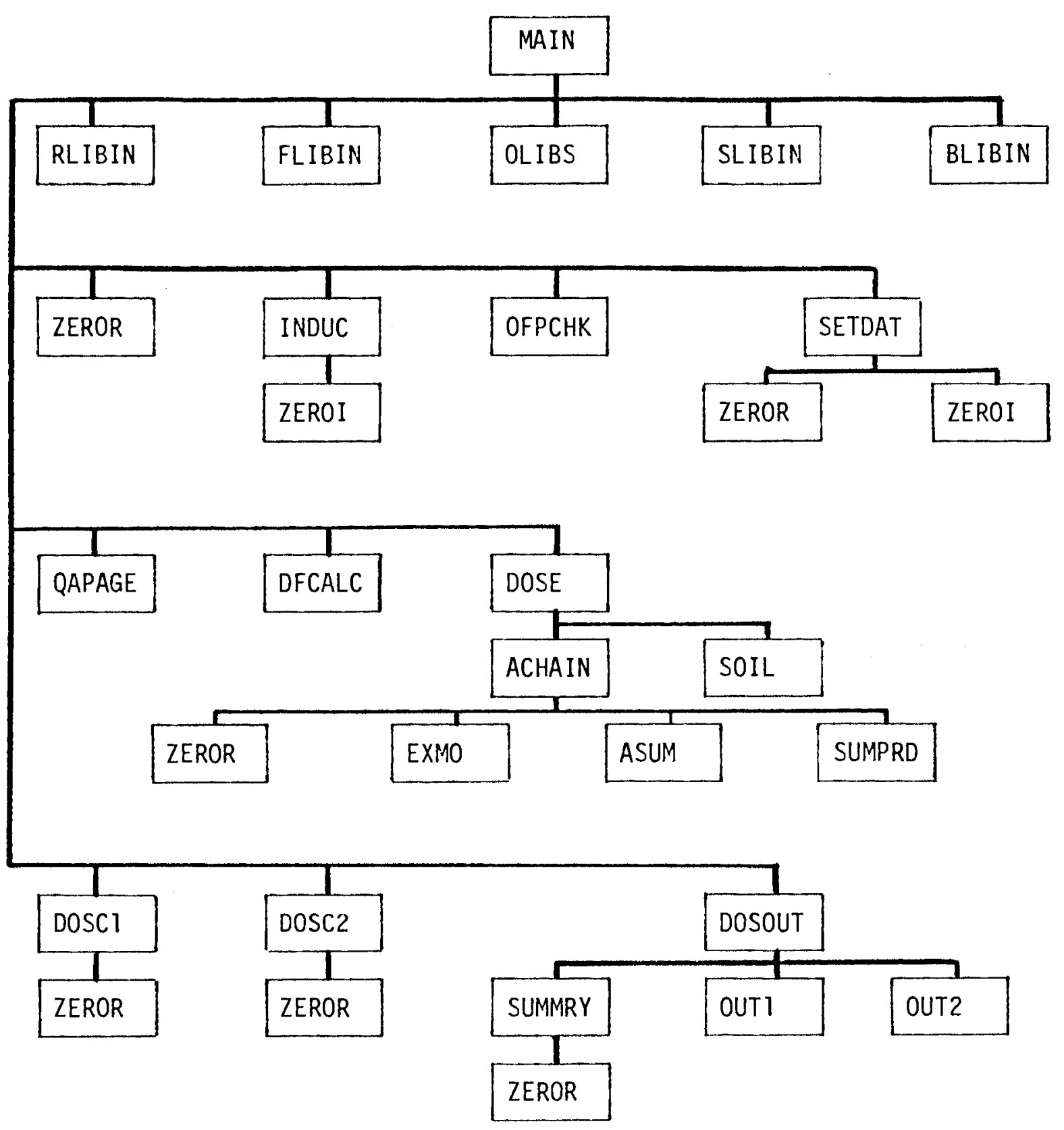

C-1 


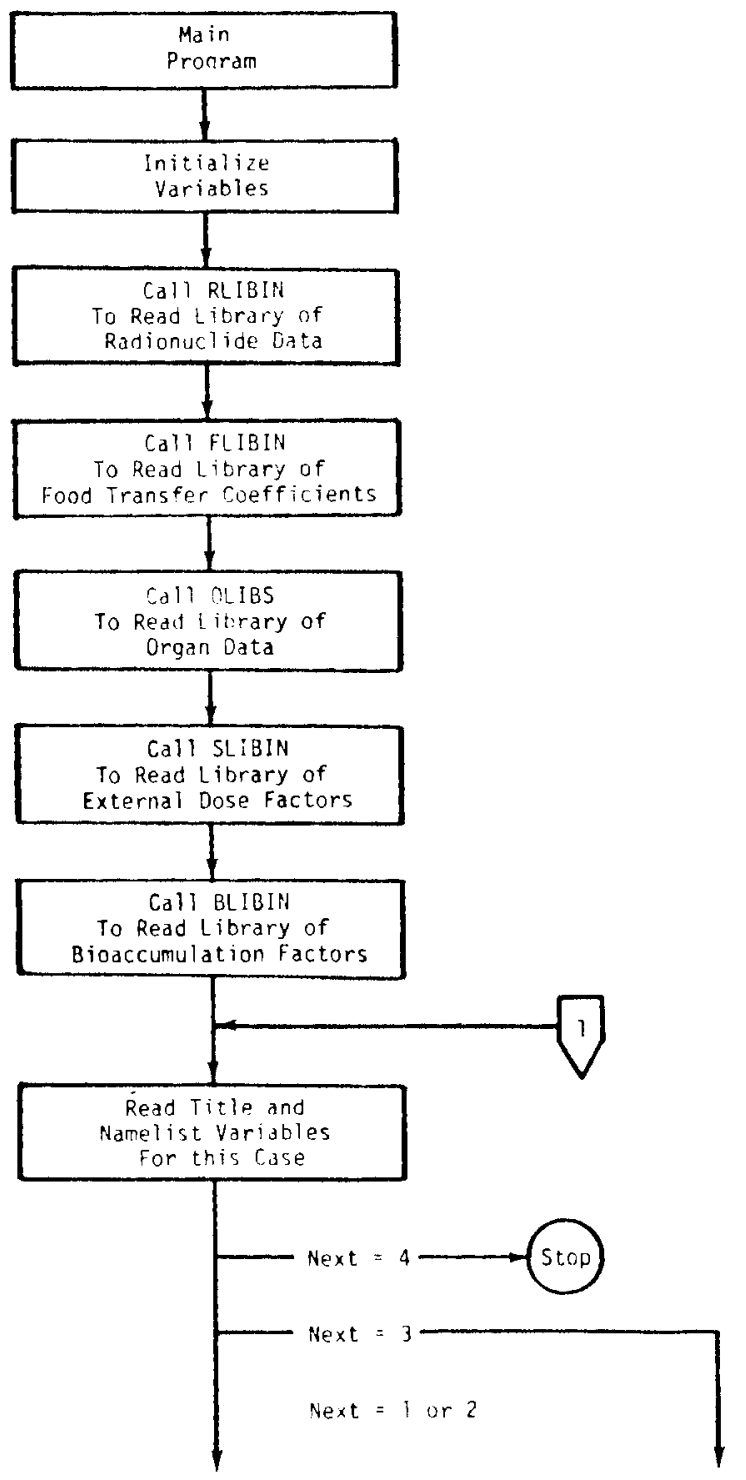




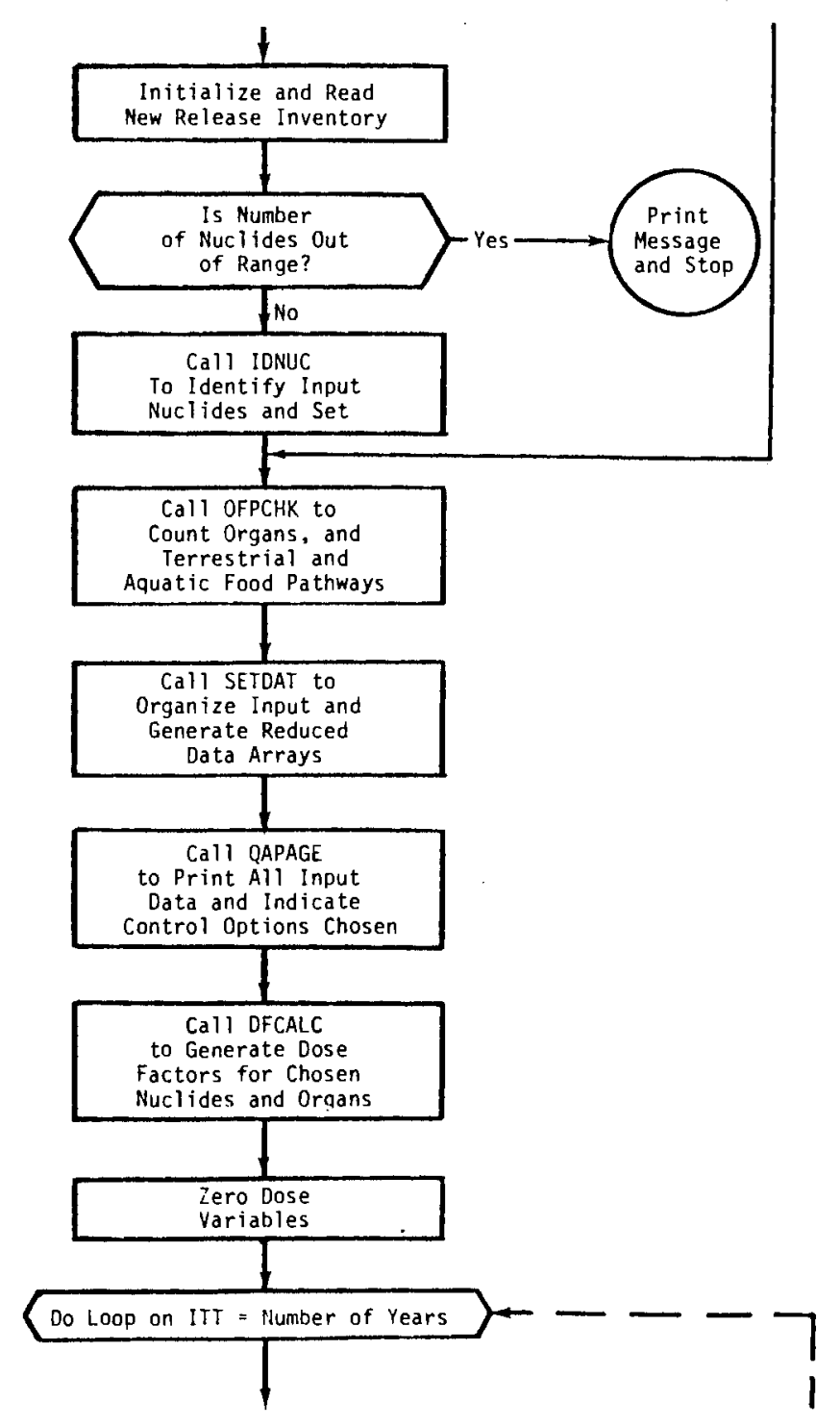

.

-

,

$*$ 


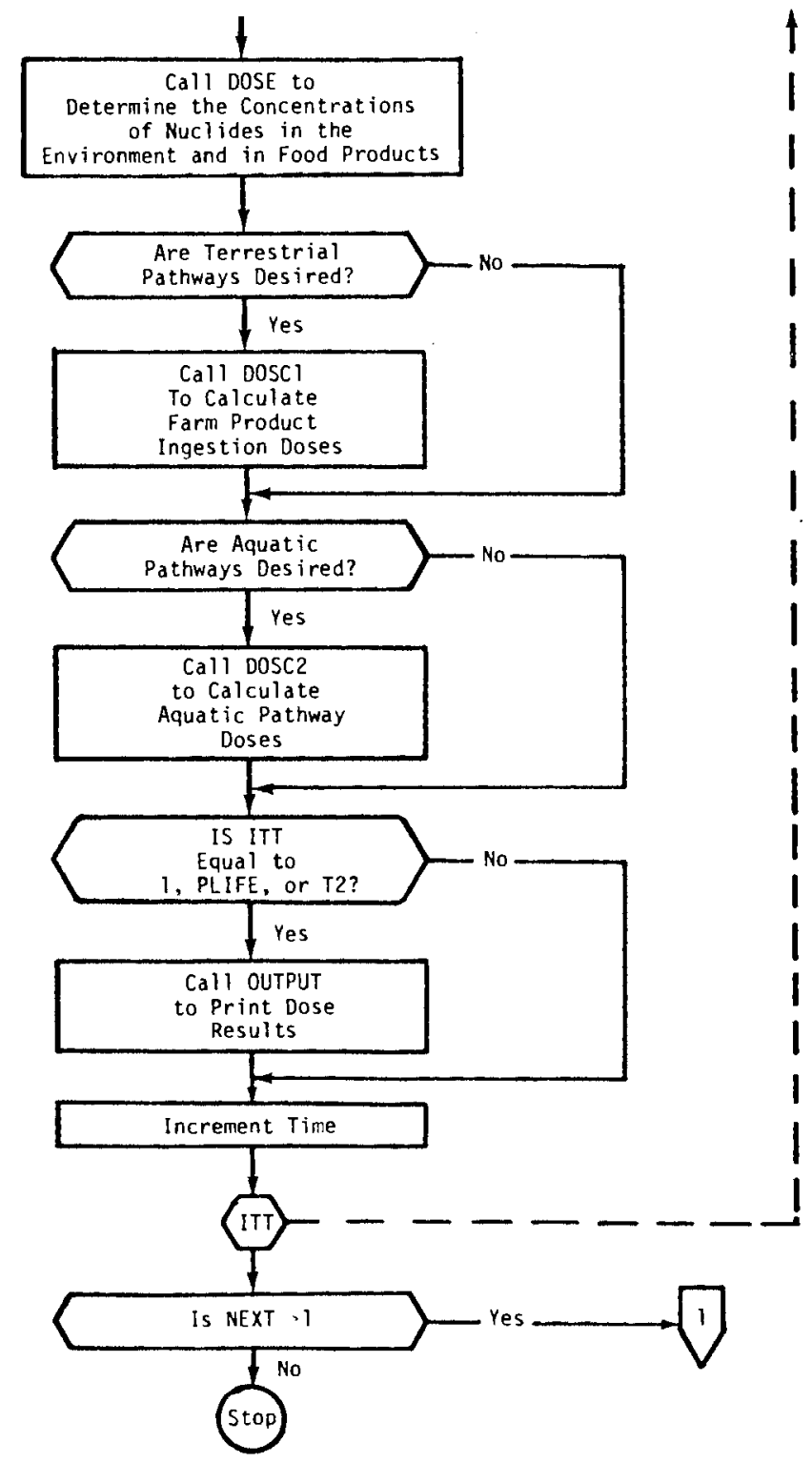




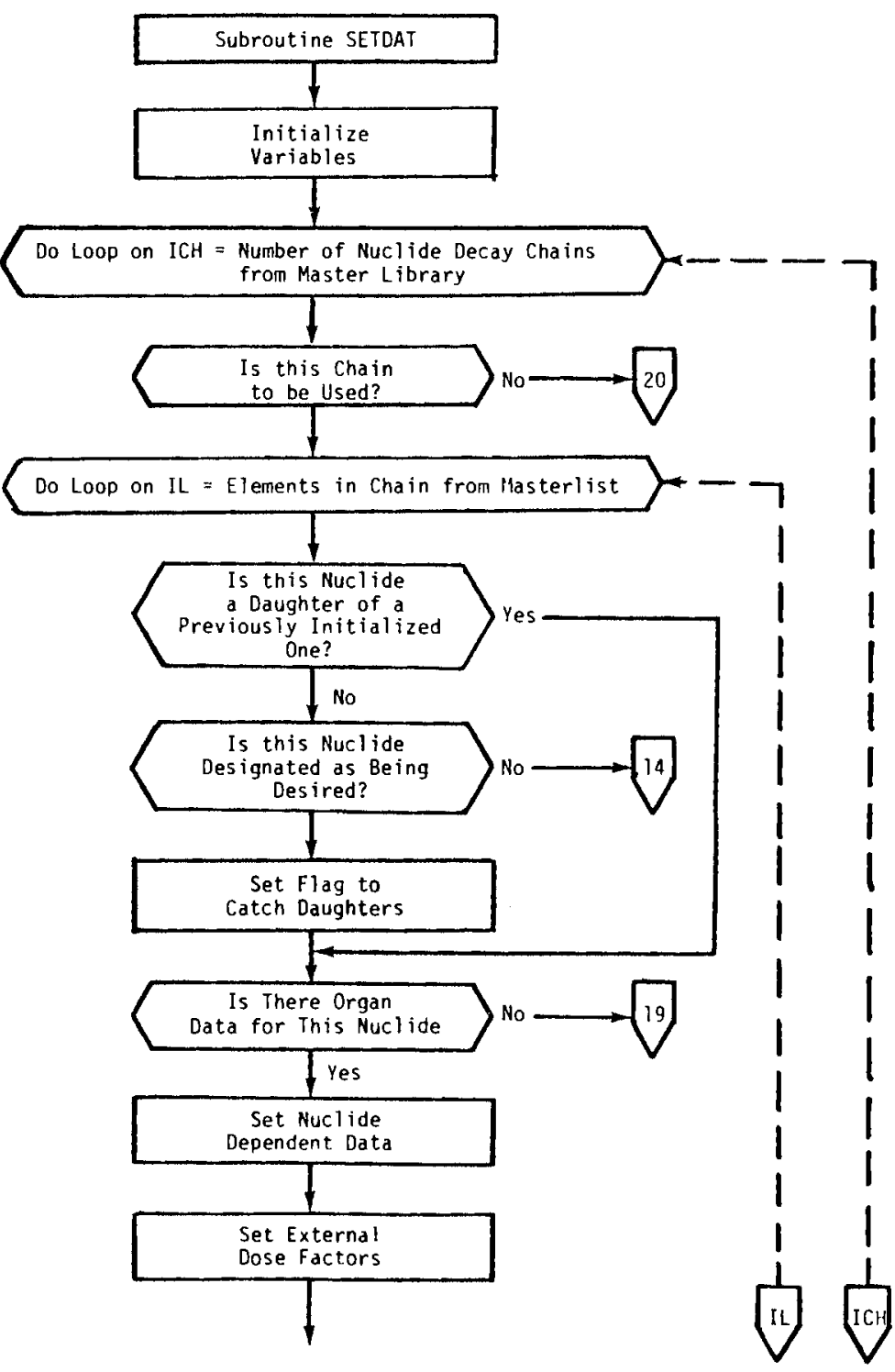




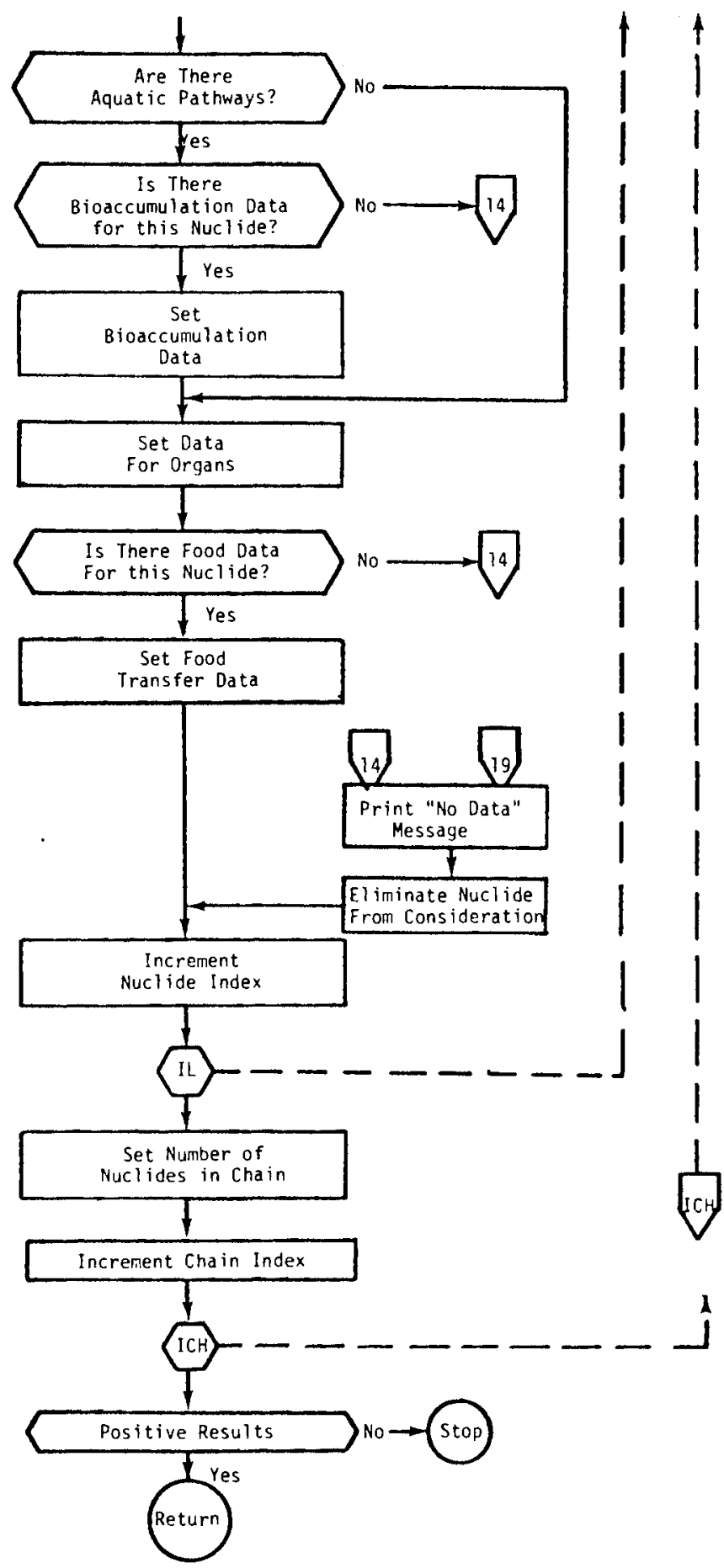



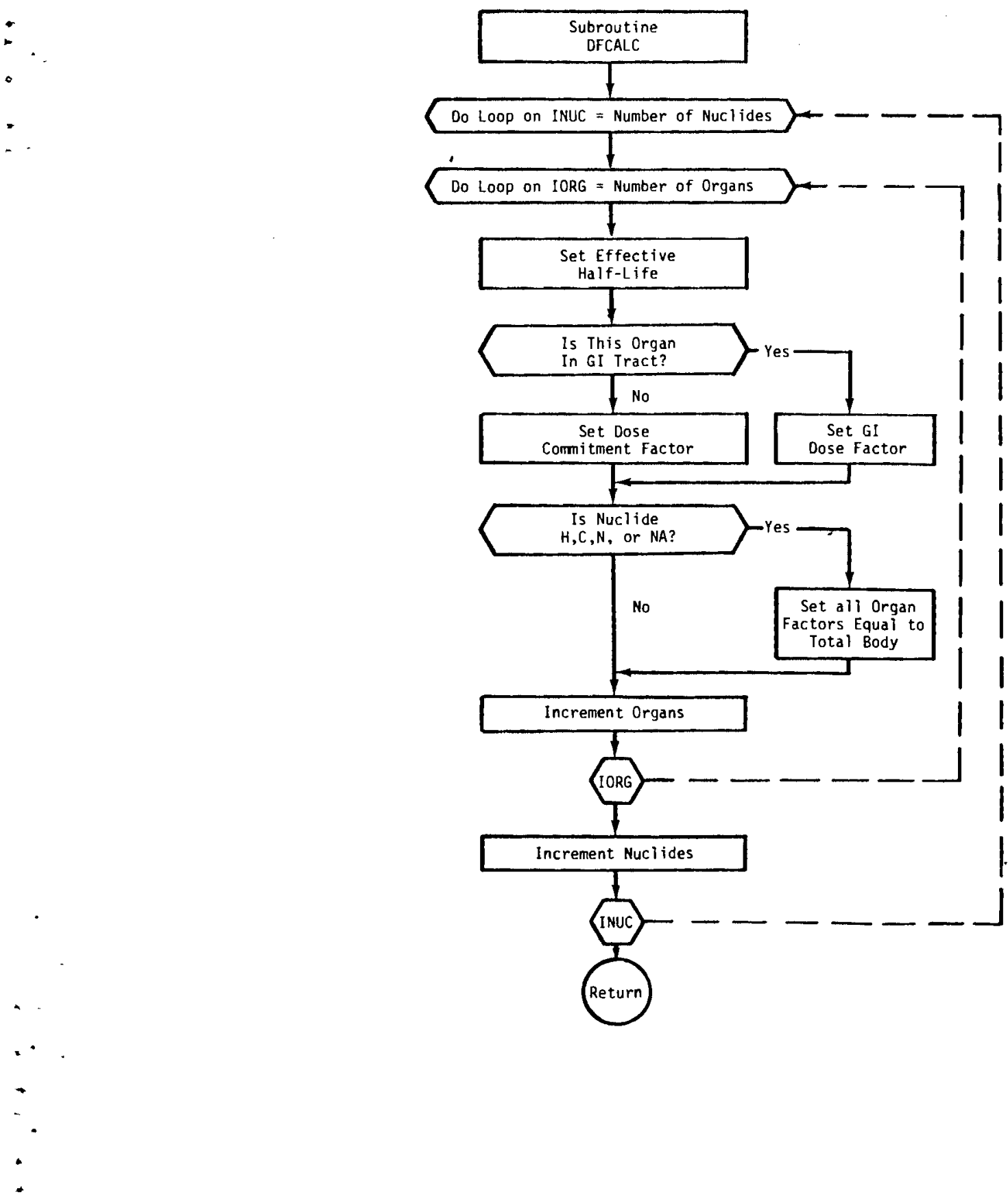


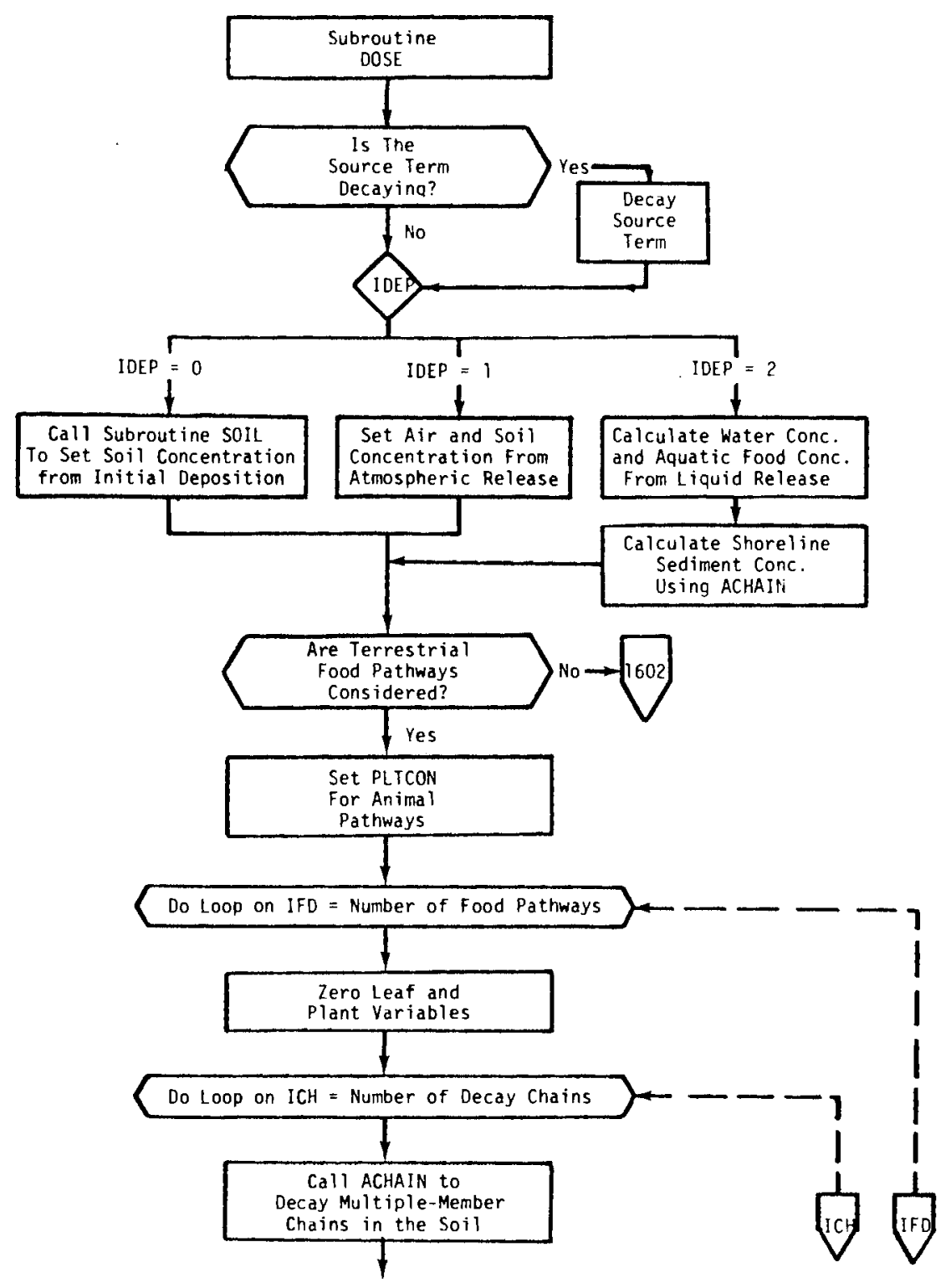




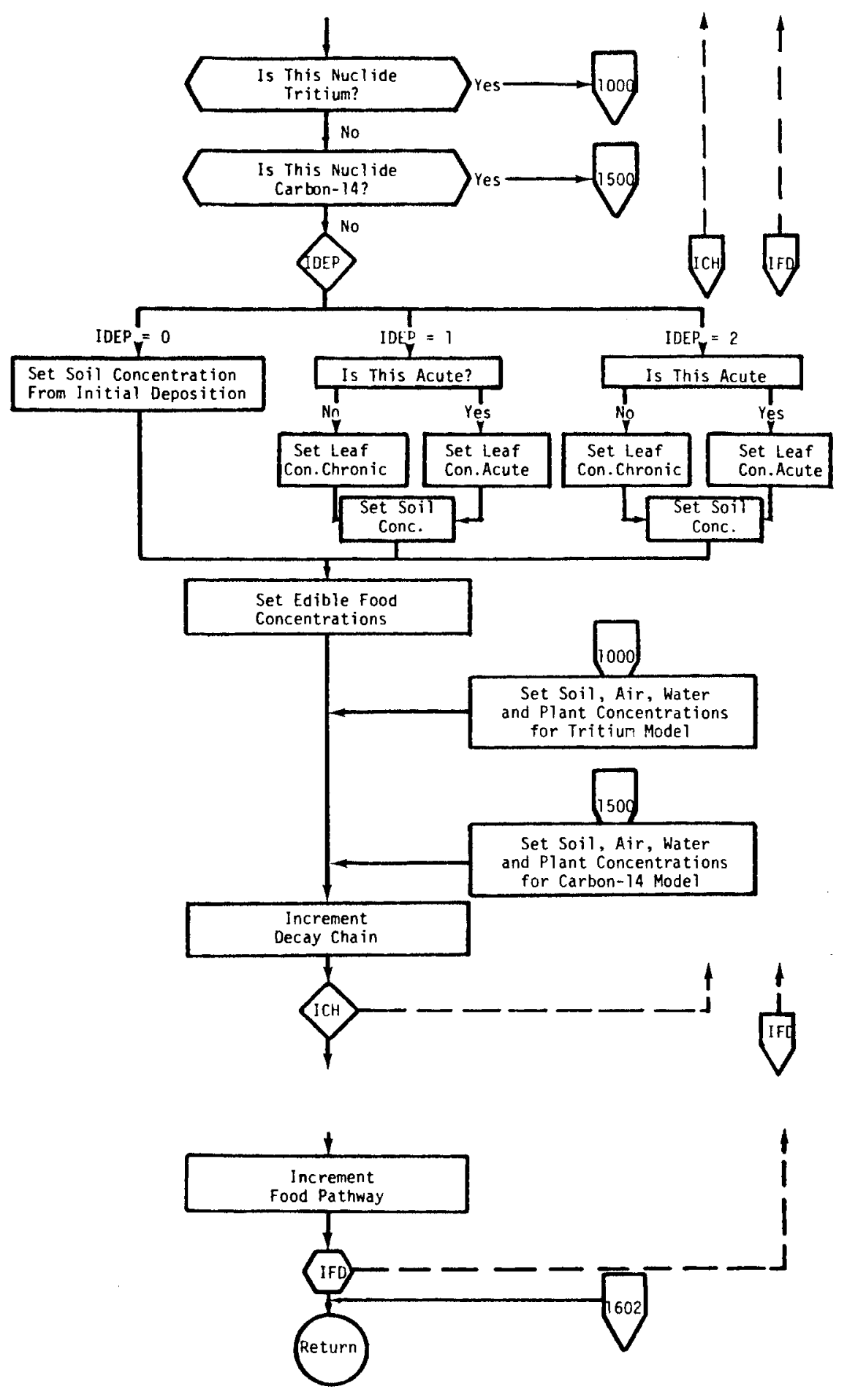

C-9 


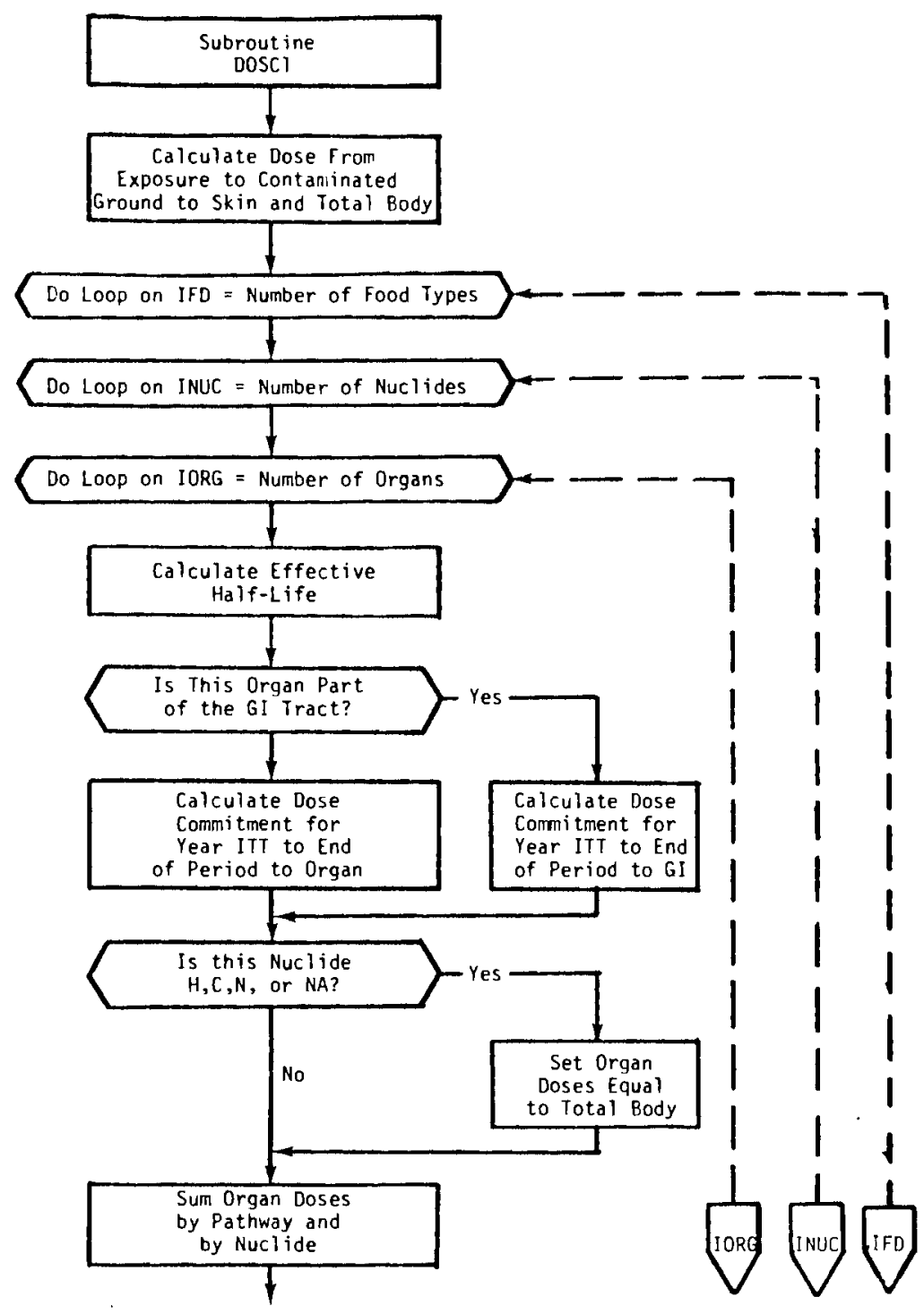




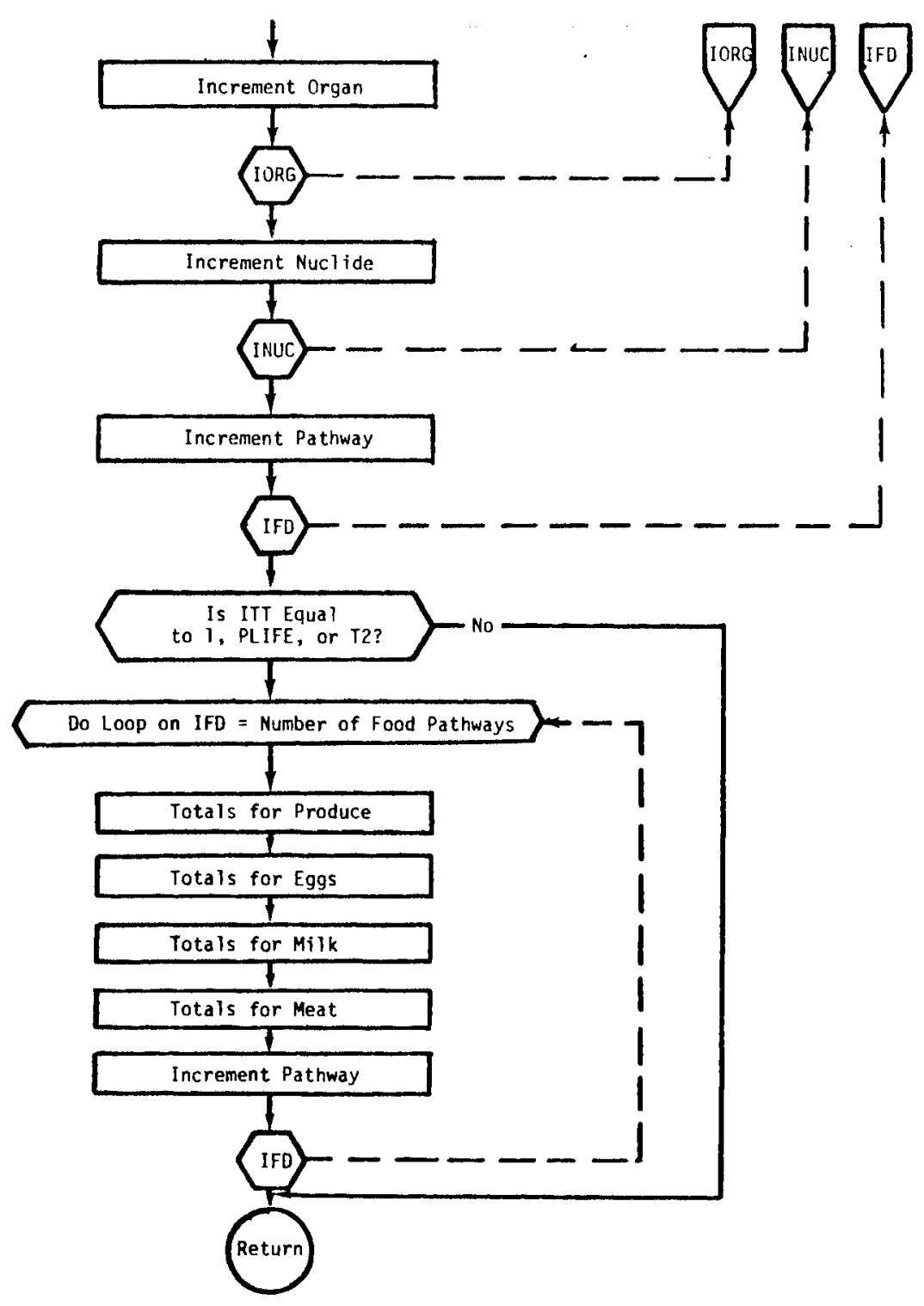




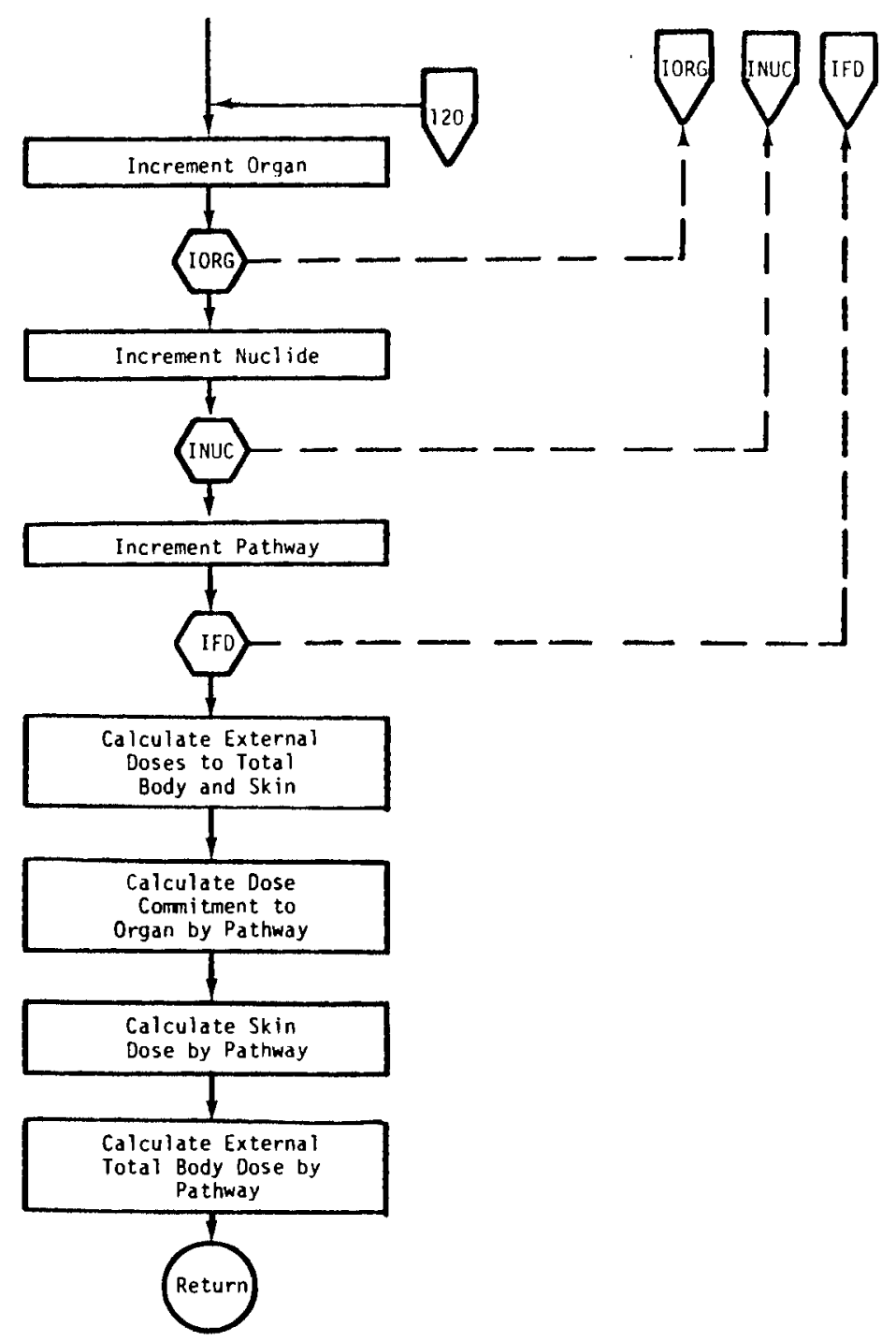




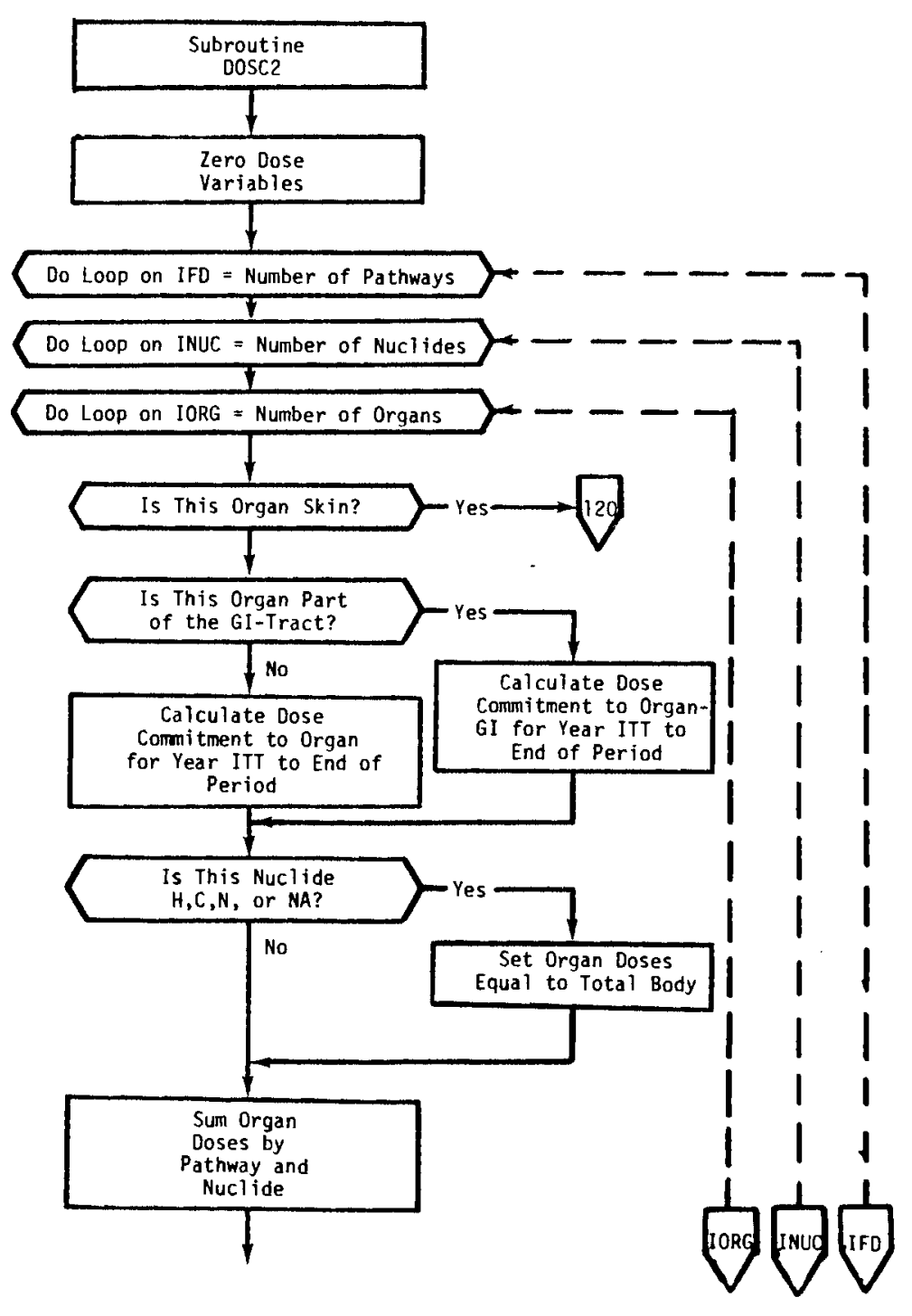


APPENDIX D

DATA LIBRARIES 
APPENDIX D

\section{DATA LIBRARIES}

Five data libraries are used by PABLM:

1. RMDLIB--radionuclide decay data library, read as 10 ,

2. FTRANSLIB--food transfer coefficient library, read as 12 ,

3. ORGLIB--organ data 1 ibrary, read as 11 ,

4. GRDFLIB--external dose factor 1ibrary, read as 16, and

5. BIOAC--aquatic bioaccumulation factor library, read as 14 .

The data in the libraries is set up such that additional data on changes to existing data may be entered with little difficulty. Listings of the libraries are given in Appendix E.

\section{RADIONUCLIDE MASTER DATA LIBRARY--RMDLIB}

The RMDLIB contains all radiological decay data used by PABLM. The library is organized into two sections. The first section contains radionuclides which are not members of decay chains, and also radionuclides singled out from chains with the " $+D$ " (plus daughters) designation. Radionuclides in the first section are arranged by increasing atomic number. The second section of the library contains radionuclides organized into decay chains ordered under the radionuclides highest in the chain. RMDLIB contains about 280 entries.

The data contained on each card of the RMDLIB library is as follows:

$\begin{array}{lll}\therefore & \text { Column 1 } & \text { Alphabetic element symbol } \\ \therefore & \text { Column 2 } & \text { Atomic weight, also metastable and/or " }+D \text { " designation } \\ \therefore & \text { Column } 3 & \text { Radiological half-life, days } \\ & \text { Column } 4 & \text { Relative position in decay chain } \\ & \text { Column } 5 & \text { Precursor in decay chain } \\ & \text { Column } 6 & \text { Branching ratio from primary percursor }\end{array}$


Column 7 Alternate precursor in decay chain

Column $8 \quad$ Branching ratio from alternate precursor

The RMDLIB FORTRAN format is (A2, A6, E10.2, 2I2, F7.4, I2, F7.4).

\section{FOOD TRANSFER COEFFICIENT LIBRARY--FTRANSLIB}

The FTRANSLIB contains factors used in PABLM relating concentrations of elements in soil to concentrations in farm products produced on that soil, and relating concentrations in animal feed to concentrations in animal products. The library has entries for 63 elements arranged by increasing atomic number compatible with the order of RMDLIB. The data contained on each card in the FTRANSLIB is as follows:

$\begin{array}{ll}\text { Column 1 } & \text { Alphabetic element symbol } \\ \text { Column 2 } & \text { Elemental deposition velocity, m/sec } \\ \text { Column 3-8 } & \text { Food transfer coefficients for plants, } \\ & \text { (pCi per gram plant (wet)/pCi per gram soil), milk } \\ & \text { (day/liter), eggs, beef, pork and poultry } \\ & \text { (day/kilogram). }\end{array}$

The FTRANSLIB FORTRAN format is (A2, 7E9.2).

\section{ORGAN DATA LIBRARY--ORGLIB}

The ORGLIB contains data used in PABLM for dose calculations to specific organs from ingested radionuclides. Data is arranged in blocks by nuclide. The blocks are ordered to be compatible with the RMDLIB chain order. Data in each block is arranged by organ index. The organs for which data are potentially available are:

\begin{tabular}{|c|c|}
\hline $\begin{array}{l}\text { Organ } \\
\text { Index }\end{array}$ & $\begin{array}{l}\text { Organ } \\
\text { Name } \\
\end{array}$ \\
\hline 1 & Total body \\
\hline 2 & Body water \\
\hline 3 & Kidneys \\
\hline 4 & Liver \\
\hline 5 & Spleen \\
\hline 6 & Bone \\
\hline
\end{tabular}




\begin{tabular}{|c|c|}
\hline $\begin{array}{l}\text { Organ } \\
\text { Index } \\
\end{array}$ & $\begin{array}{l}\text { Organ } \\
\text { Name }\end{array}$ \\
\hline 7 & Fat \\
\hline 8 & Lungs \\
\hline 9 & Adrenals \\
\hline 10 & Testes \\
\hline 11 & Ovaries \\
\hline 12 & Skin \\
\hline 13 & Brain \\
\hline 14 & Muscle \\
\hline 15 & Prostate \\
\hline 16 & Thyroid \\
\hline 17 & Pancreas \\
\hline 18 & Heart \\
\hline 19 & GI \\
\hline 20 & Stomach \\
\hline 21 & Small intestine \\
\hline 22 & Upper large intestine \\
\hline 23 & Lower large intestine \\
\hline
\end{tabular}

For most entries, only data for organs number $1,3,4,6,8,20,21,22$, and 23 are included. The data contained on each card in the ORGLIB 1ibrary is as follows:

Column $1 \quad$ Alphabetic element symbol

Column 2 Atomic weight, also metastable and/or " $+D$ " designation

Column $3 \quad$ Organ index $(1-23)$

Column 4 Biological half-life, days

Column $5 \quad f_{w^{-}}$fraction of ingested nuclide reaching organ of interest

Column $6 \quad f_{2}{ }^{\prime}$--fraction from blood to organ of interest

(not used by PABLM)(oniy for inhalation doses) 
Columns 7,8,9 Effective energy absorbed per disintegration in adult organs (MeV). Columns 8 and 9 are only used for Organ 8 (lungs).

The ORGLIB FORTRAN format is (A2, A6, I2, 6E8.2).

EXTERNAL RADIATION DOSE FACTOR LIBRARY--GRDFLIB

The external radiation dose factor file contains factors used in PABLM to calculate skin and total-body doses from exposure to radionuclides in the environment. There is a set for exposure from contaminated ground (which, when modified by a shore-width factor, is for exposure to river sediments), and a set for immersion in contaminated water used for swimming. There is also an unused set for air submersion doses. There are entries for 186 nuclides, arranged in the order of RMDLIB.

The data contained on each card in the GRDFLIB library is as follows:

Column 1 Alphabetic element symbol

Column 2 Atomic weight, also metastable and/or " $+D$ "

Columns 3-4 Soil contamination external dose factors for skin and total body, mrem/hr per $\mathrm{pCi} / \mathrm{m}^{2}$,

Columns 5-6 Swimming external dose factors for skin and total body, $\mathrm{mrem} / \mathrm{hr}$ per $\mathrm{pCi} / \mathrm{l}$,

Columns 7-8 Air submersion dose factors for total body and skin, $\mathrm{mrem} / \mathrm{hr}$ per $\mathrm{pC} \mathrm{i} / \mathrm{m}^{3}$.

The GRDFLIB FORTRAN format is (A2, A6, 6E9.2).

\section{AQUATIC BIOACCUMULATION FACTOR LIBRARY--BIOACH}

The bioaccumulation library contains the factors used by PABLM relating the. . concentration of nuclides in aquatic biota to the concentration of the nuclides in the water. These are separate factors for fresh and salt water. Also included is a factor for the cleanup of drinking water in water treatment plants. The library contains entries for 63 elements. 
The library is organized as:

Column 1 Alphabetic element symbol

Columns 2-5 Bioaccumulation factors for fish, crustacea, molluscs and algae for salt water ( $\mathrm{pCi} / \mathrm{kg}$ per $\mathrm{pCi} / \mathrm{l}$ )

Columns 6-9 Bioaccumulation factors as above for fresh water

Column 10 Fractional amount of radionuclide that passes through a water treatment facility.

The FORTRAN format is (A2, 9F9.1). 


\section{APPENDIX E}

\section{LIBRARY AND CODE LISTINGS}

1. RMDLIB

2. ORGLIB

3. FTRANSLIB

4. $B I O A C$

5. GRDFLIB

6. PABLM 
1. Radionuclide Master Data Library (RMDLIB)

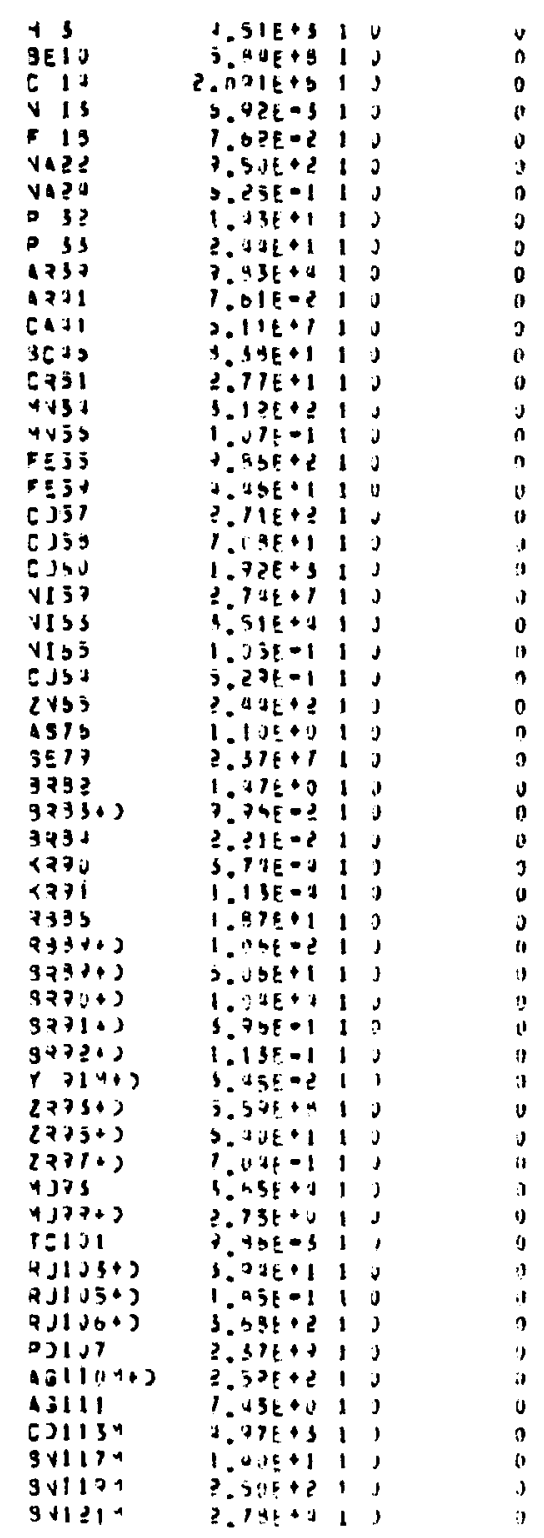


1. Radionuclide Master Data Library (RMDLIB)

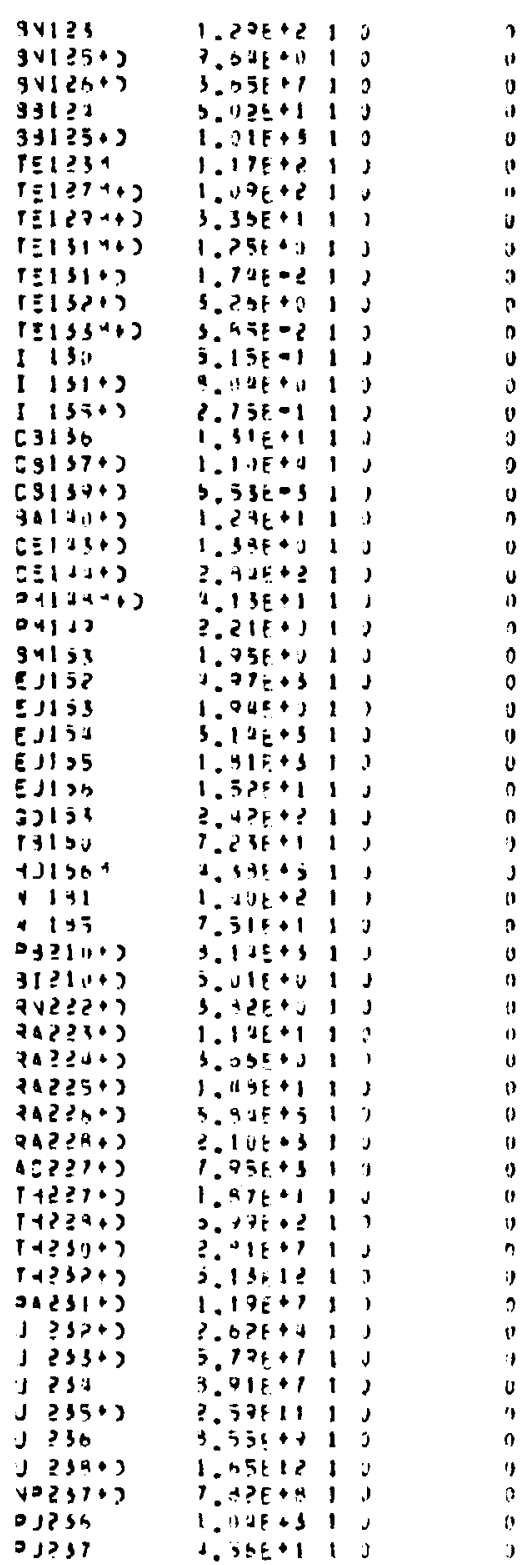

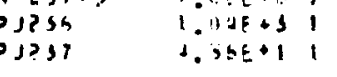




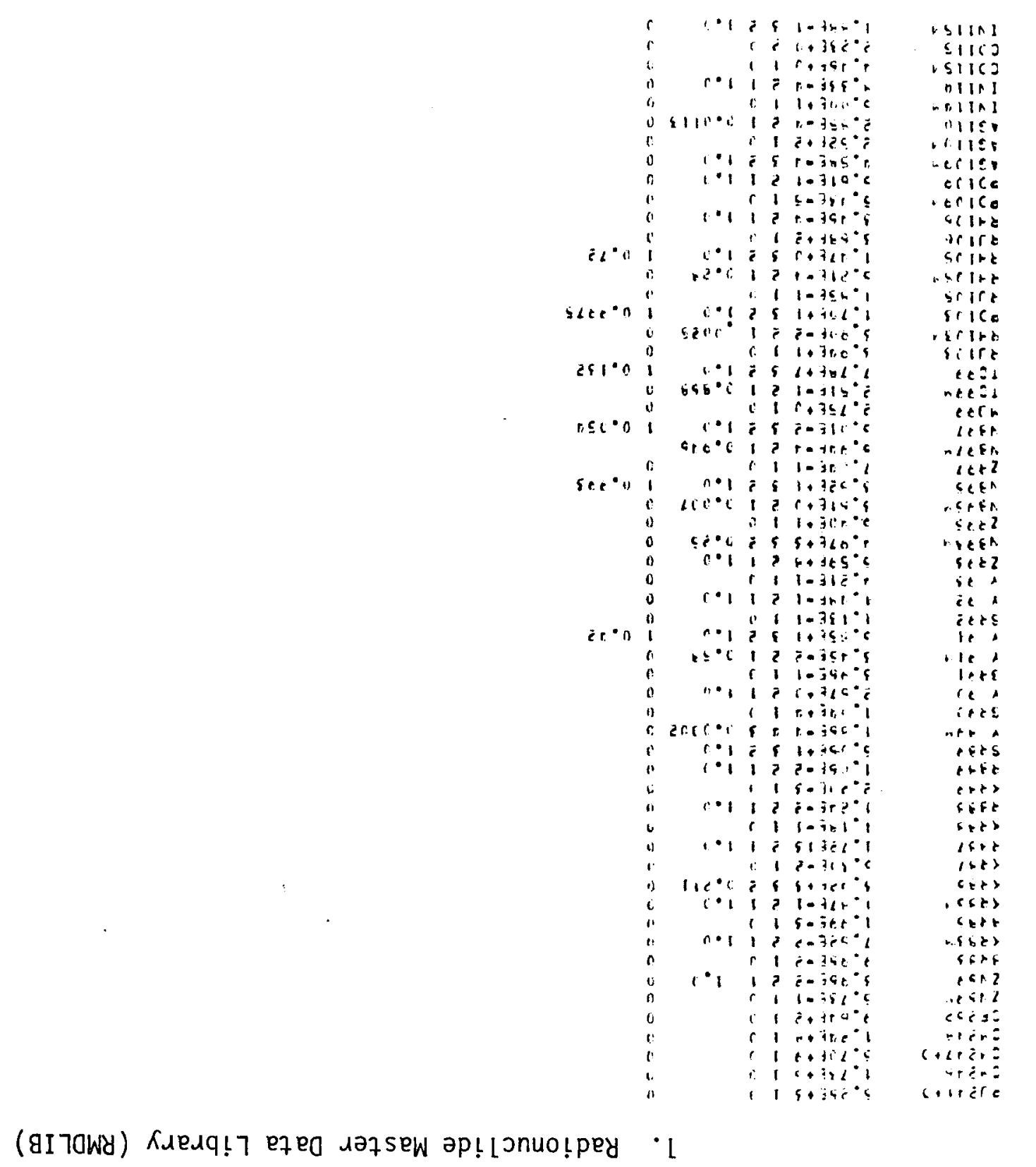


1. Radionuclide Master Data Library (RMDLIB)

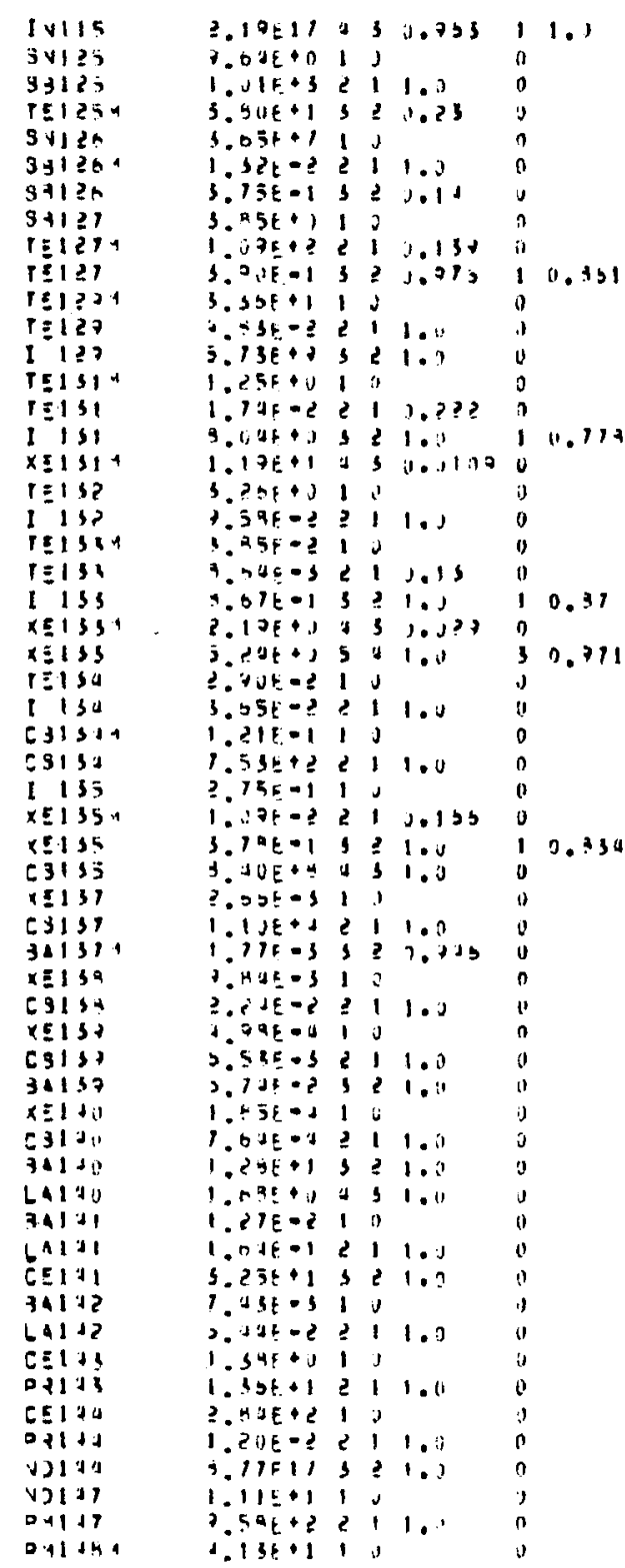


1. Radionuclide Master Data Library (RMDLIB)

\begin{tabular}{|c|c|c|c|c|c|}
\hline$=4119$ & $3.31 E+0$ & 2 1 & 11.1 & 9 & $\therefore$ \\
\hline Q4iji & $1.43 t+$. & 1 & j & 0 & \\
\hline $3 \times 131$ & $3.27 t+1$ & 21 & 1.0 & v & \\
\hline 4197 & $7.75 E-1$ & $1:$ & 1 & 0 & \\
\hline QEI31 & 1.9 if is & ? 1 & 11.9 & 0 & \\
\hline $11 \geq 30$ & $2,+1 E+1$ & 10 & & 0 & \\
\hline 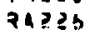 & 5.SUE+S & 21 & 11.1 & 0 & \\
\hline २ข??? & 3.42E+0 & s? & 21.0 & & \\
\hline 23210 & $9.1 U E+3$ & 13 & 1.1 & 18 & \\
\hline 31210 & $3.6 .1 E+1$ & 5 & 1.0 & J & \\
\hline D jeiti & $1.3910+2$ & 5 &, 1.3 & 0 & \\
\hline I 23? & $302 t+0$ & i. & , & $n$ & \\
\hline $1+? 32$ & J I DE IS & ? & & 0 & \\
\hline 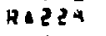 & $2.111+3$ & 3 & 1.0 & 0 & \\
\hline $1=\geq ? \pi$ & $2.55 E-1$ & 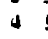 & 31.0 & $"$ & \\
\hline$T+? \geq 9$ & $3.7764 ?$ & $5:$ & $1, i)$ & 1 & 1,1 \\
\hline Q42?] & $5.66 k+j$ & 5 & ; 1.0 & i & \\
\hline D321? & $3.43 t-1$ & $i:$ & 31.0 & 0 & \\
\hline $3121 ?$ & $3.20 k=2$ & 91 & $1,1,0$ & 0 & \\
\hline J涪 & ? SPEII & $i j$ & 10 & 0 & \\
\hline$|t \geq 3|$ & $1.068+0$ & 21 & 1.0 & $a$ & \\
\hline 24251 & $1.17 k+7$ & 3 & 21.0 & j & \\
\hline 10227 & $1.05 i+3$ & 43 & 31.0 & 1) & \\
\hline $\mid 1 ? ?\}$ & $1.47 E+1$ & 5 & 40.9302 & 0 & \\
\hline$F \geq \geq ?\}$ & 1.5140 ? & is & $12.313 a$ & $j$ & \\
\hline Q4?? & $1.1+1+1$ & 7 & 51.1 & $b$ & 1.1 \\
\hline$J 237$ & $3.735+0$ & i & 4 & $"$ & \\
\hline vo?st & $1 .+2 \beta+y$ & 21 & 11.0 & $\mathfrak{a}$ & \\
\hline 94233 & $\therefore P E+1$ & 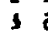 & (1.) & , & \\
\hline$J \geq 33$ & $3.17 t+1$ & a & 11.0 & í & \\
\hline $1+2 ? 0$ & $\because n 9 E+0$ & 3 & 1,3 & 0 & \\
\hline$+4 \geq \geq 5$ & $1.096+1$ & o 5 & $51, i$ & i" & \\
\hline$\Delta<\geq \geqslant 5$ & $1.008+1$ & 13 & 1.0 & 0 & \\
\hline$J \geq 5 x$ & $1.95 E 12$ & 10 & 30.3 & 1) & \\
\hline $1+251$ & $2.416+1$ & 21 & 11.0 & j & \\
\hline PA53यx & $3.13 E-1$ & ; & 21.1 & 3 & \\
\hline PA?s0 & $? A \mid F-1$ & 4 & 53,5118 & 7 & \\
\hline 4 प? 124 & $5.55 \mathrm{E}$ & $1:$ & J & $n$ & \\
\hline $4 \times ? d ?$ & $5.6+E-1$ & 21 & 11.1 & a & \\
\hline C4? ? & $1.33 t+2$ & 3 & $2 x, \pm \geq 1$ & n & \\
\hline DJ? & $1.415+9$ & 4 & 3.113 & !) & \\
\hline$V=2 \mathrm{SN}$ & tat 10 & 50 & & 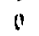 & \\
\hline 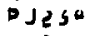 & $5.21 E+1$ & , & 51.1 & is & 1.3 \\
\hline$=x \geqslant+4$ & $3.61 E+5$ & $i j$ & jo & $n$ & \\
\hline DJ?נU & $3 . \because \geqslant E 10$ & c & 1 & 0 & \\
\hline$J \geqslant 40$ & $3.44 E-1$ & 3 & $2,1+1$ & n & \\
\hline 0 ग ग & $\because 32 E+6$ & 43 & 31.9 & 1 & $1,$. \\
\hline Cस24 & $5.7 B E+1$ & 10 & 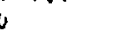 & 0 & \\
\hline$C \times 2+3$ & $1.112+1$ & 25 & 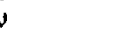 & jo & \\
\hline $0 J ?+3$ & $? .105-1$ & 31 & 1.1 & 0 & \\
\hline $4+2+3$ & $3.718+2$ & 5 & 63 & 2 & 0.032 \\
\hline$y=230$ & $? 350+3$ & 3 & 1.1 & $"$ & \\
\hline D J53 & $3.91 k$ os & 35 & 51.9 & $?$ & ח. \\
\hline$C 4 ?+5$ & $3.10 t+3$ & 12 & & $n$ & \\
\hline | ונगנ & $5 .{ }^{3}$. & 21 & 1.1 & 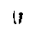 & \\
\hline $4 \times 2+1$ & $1.5 \theta_{t}+3$ & 36 & 21.1 & 1 & \\
\hline
\end{tabular}


2. Organ Data Library (ORGLIB)

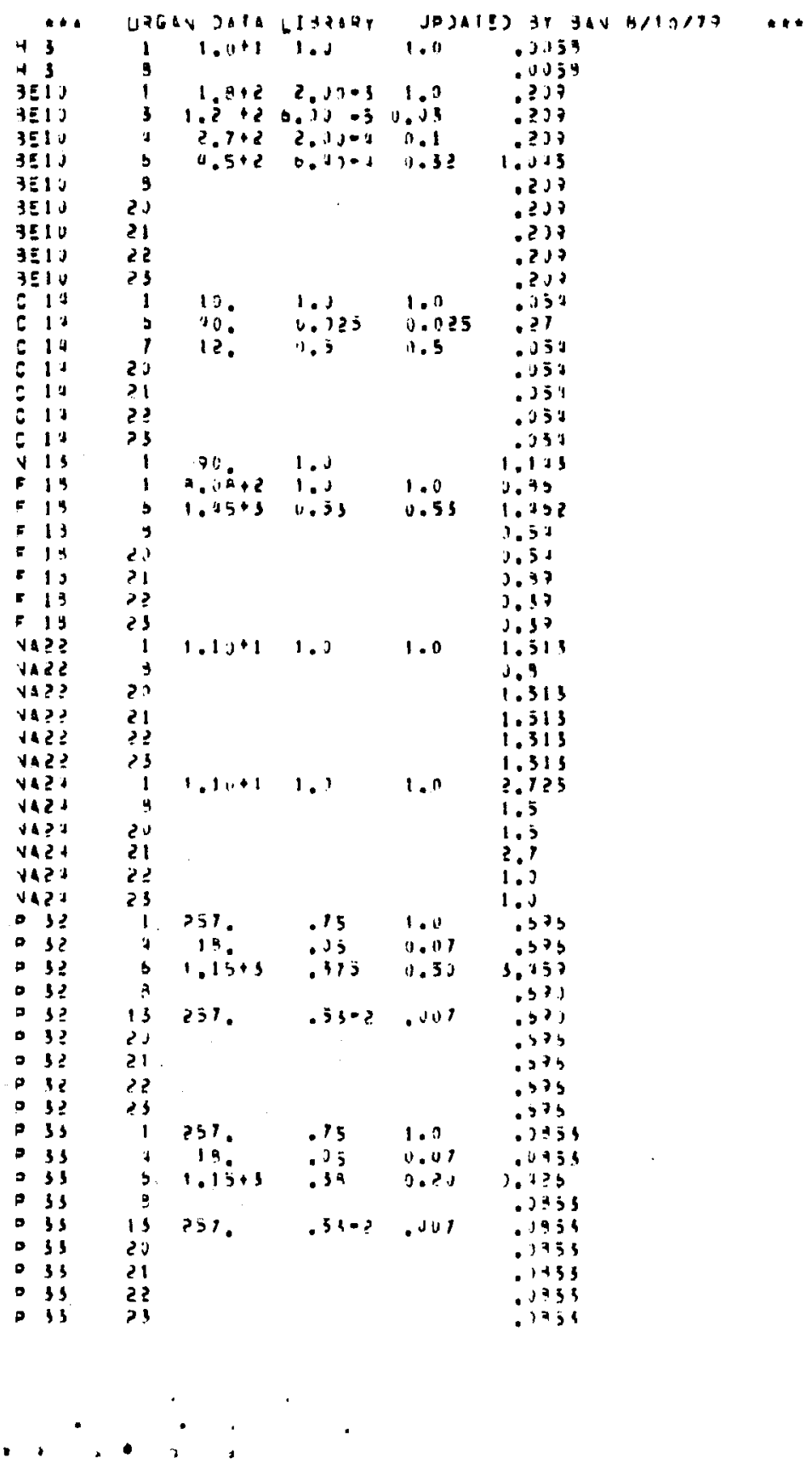


2. Organ Data Library (ORGLIB)

\begin{tabular}{|c|c|c|c|c|c|}
\hline CAMI & 1 & $1.69+4$ & - ba & 1.0 & . JJ3s \\
\hline $\begin{array}{l}C 491 \\
64+1\end{array}$ & 3 & 1.24 .1 & .51 & 0.0 & $\begin{array}{l}.0335 \\
\text { OJj30 }\end{array}$ \\
\hline 6441 & 20 & & & & .0335 \\
\hline$=491$ & ?1 & & & & . \\
\hline 6491 & 22 & & & & .035 \\
\hline$C 421$ & 23 & & & & .3035 \\
\hline $5=13$ & 1 & 30.11 & $.1: 1 \cdot 3$ & 1.0 & 1.333 \\
\hline 9015 & 1 & 75.0 & $.21 \cdot 5$ & .02 & .31? \\
\hline$s=1 s$ & 1 & 56.0 & $.1 ;=1$ & .15 & .351 \\
\hline $3=45$ & b & $(3.1)$ & נ. & .20 & 1.131 \\
\hline 35$] 5$ & 9 & & & & .541 \\
\hline$s=16$ & $? 11$ & & & & . \\
\hline $5=45$ & 21 & & & & 1.5 \\
\hline $9=25$ & 22 & & & & .219 \\
\hline 9200 & 23 & & & & .917 \\
\hline 6251 & 1 & 313. & (נ) & 1.0 & .213 \\
\hline 8731 & 3 & bis. & $.13-1$ & .21 .3 & .031 \\
\hline$=751$ & $y$ & 0150 & $(2)=3$ & .02 & . vid \\
\hline Eर31 & 13 & B.s. & $.15 \div 5$ & $.93=3$ & $.031-1$ \\
\hline 6751 & 15 & 610. & $10.45=5$ & $. \neg \nu=3$ & $3.5-3$ \\
\hline $\begin{array}{l}731 \\
0751 \\
071\end{array}$ & ह.) & & & & .119 \\
\hline $6+51$ & 3 & & & & 025 \\
\hline 2751 & 3 & & & & . \\
\hline $4 \sqrt{56}$ & 1 & 11. & .13 & 1.0 & .512 \\
\hline $4 \times 52$ & 1 & 23 & . 1? & .24 & .221 \\
\hline Aขร4 & 9 & & & & . 2333 \\
\hline $4 \sqrt{52}$ & 17 & 5,30 & .019 & .103 & .133 \\
\hline $4 \sqrt{5} 1$ & 2j & & & & .230 \\
\hline 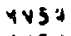 & 21 & & & & .513 \\
\hline 4.151 & ?? & & & & ? \\
\hline $45 ;$ & 23 & & & & 12? \\
\hline $4 \times 53$ & 1 & 17. & .13 & 1.1 & 1.913 \\
\hline מנפ & 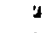 & 23. & ? & .21 & 1.235 \\
\hline yvis & 9 & & & & 1.31 \\
\hline 4 453 & 11 & 5.11 & Sנos & .03 & 1.13 \\
\hline 4レう & 21 & & & & $i 3$ \\
\hline 4 453 & 21 & & & & 1.7 \\
\hline tVis & 2 रे & & & & 1.33 \\
\hline 4V53 & 23 & & & & 1.23 \\
\hline$F[3$, & 1 & a 10. & .10 & 1.9 & $0,5 \cdot 3$ \\
\hline FES & 7 & $55 \%$ & .113 & .15 & 0.3 .3 \\
\hline FEj, & ; & a.xu. & .32 & .02 & $0.5 \cdot 3$ \\
\hline *5うj & $b$ & $\left(b n_{1}\right)$. & .110 & .10 & $4, ?$ \\
\hline FEs, & $\exists$ & s? : & . & ."? & 7.3 .3 \\
\hline FE5; & $2 \%$ & & & & .0335 \\
\hline हรว & I & & & & $0: 355$ \\
\hline FE5; & 2? & & & & .0353 \\
\hline EEj & 25 & & & & $3.3=3$ \\
\hline$F 557$ & 1 & avv. & .12 & 1.0 & .933 \\
\hline$E=53$ & J & $55 \%$ & .1113 & .13 & .137 \\
\hline$F \equiv j 7$ & 5 & $5 \%$ & $.012 ?$ & $.0 ?$ & .301 \\
\hline FEう] & 3 & $150,0$. & . & .12 & .145 \\
\hline$F \equiv 53$ & $y$ & $32 \div 6$. & . 1012 & . :? & | \\
\hline FE5? & $2 J$ & & & &.+20 \\
\hline$F \equiv 51$ & 21 & & & & .411 \\
\hline
\end{tabular}


2. Organ Data Library (ORGLIB)

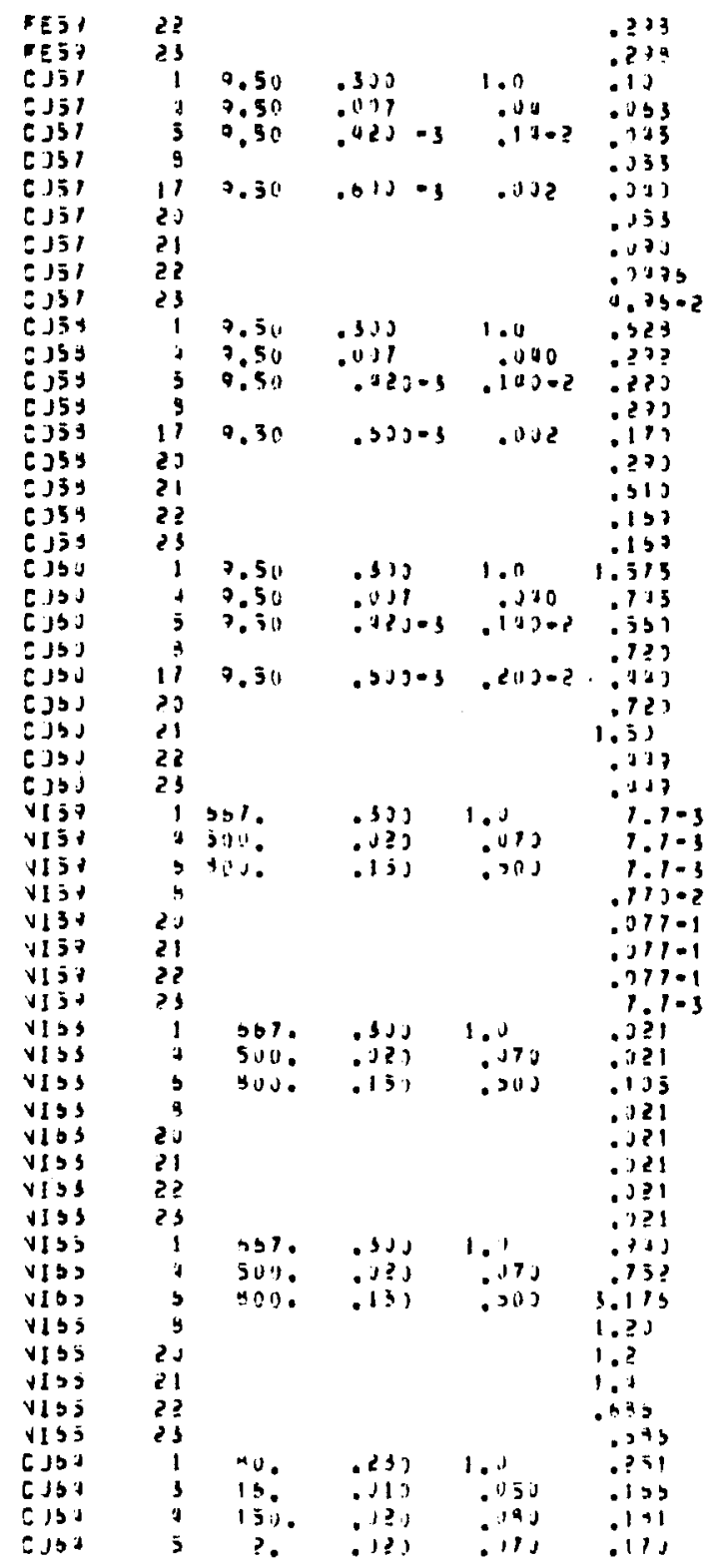


2. Organ Data Library (ORGLIB)

\begin{tabular}{|c|c|c|c|c|c|c|}
\hline Cus: & $\stackrel{8}{\therefore}$ & & & & .13 & \\
\hline 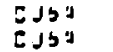 & $\begin{array}{l}13 \\
19\end{array}$ & $\begin{array}{l}\text { Puove } \\
\text { Hijo }\end{array}$ & 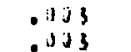 & 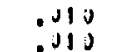 & . 21' & \\
\hline Cנ4 & 210 & & .003 & .010 & $: 177$ & \\
\hline ES4 & 21 & & & & $.2 j$ & \\
\hline $\begin{array}{l}\text { Essa' } \\
\text { EJb' }\end{array}$ & $\begin{array}{l}23 \\
23\end{array}$ & & & & $\begin{array}{l}135 \\
: 1 ; 5\end{array}$ & \\
\hline & & 733. & .110 & 1.9 & .311 & \\
\hline $2 \times 55$ & 3 & 197. & .393 & & .111 & \\
\hline $\begin{array}{l}2 \times 53 \\
2503\end{array}$ & ' & 11 & .135 & .353 & .153 & \\
\hline $\begin{array}{l}2 \text { 2vos } \\
2 v 5 j\end{array}$ & 3 & 1300. & .113 & .151 & .133 & \\
\hline Zvo3 & 10 & 210. & 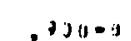 & $+0)=5$ & 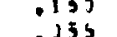 & \\
\hline Zusi & ii & 1.17 & (גנ & $0.003-3$ & .נ535 & \\
\hline 2vo & $1 \%$ & 19600. & .j3" & Soj & .321 & \\
\hline Zvbs & 13 & 14 & Sטos & .065 & 353 & \\
\hline $2 \times 5 j$ & 11 & 23. & . Jss & .083 & .094 & \\
\hline $2 \times 55$ & 20 & & & & .13 & \\
\hline $\begin{array}{l}2 \times 53 \\
2 \times 53\end{array}$ & 21 & & & & .32 & \\
\hline $\begin{array}{l}2 \times 35 \\
2 \times b 5\end{array}$ & ?द & & & & $\begin{array}{r}0.194 \\
0.041\end{array}$ & \\
\hline 4975 & $i$ & $? 90$. & . 13\% & & $1: 3$ & \\
\hline 4575 & 3 & 530. & $(3 J)=3$ & .010 & 1.1 & \\
\hline 4575 & i & 530. &.$+5 ;-3$ & .030 & $i .1$ & \\
\hline 4975 & 9 & & & & 1.13 & \\
\hline $\begin{array}{l}4973 \\
\text { ist5 }\end{array}$ & ?3 & & & & 1.1 & \\
\hline $\begin{array}{l}4915 \\
4975 \\
495\end{array}$ & 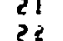 & & & & 1.3 & \\
\hline ists & $? 3$ & & & & 1.1 & \\
\hline SEIt & 1 & 11. & .7 & 1. & בנין & \\
\hline $951 \%$ & 3 & 11. & . J & .00 & ב? & \\
\hline 357 & ! & 24. & $.0 \mathrm{~b}$ & .07 & .04 ? & \\
\hline 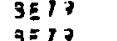 & 3 & & & & . 11? & . (4)? \\
\hline 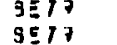 & $\begin{array}{l}23 \\
21\end{array}$ & & & & - $0 x+2$ & \\
\hline SEา & 2? & & & & 092 & \\
\hline SEYt & 33 & & & & 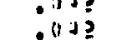 & \\
\hline 3232 & 3 & 4.0 & 1.2 & 1.0 & 1,713 & \\
\hline $379 ?$ & 3 & & & & .333 & \\
\hline $\begin{array}{l}329 ? \\
3737\end{array}$ & 2) & & $3.1=2$ & & .35 & \\
\hline 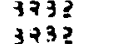 & $\begin{array}{l}21 \\
2 ?\end{array}$ & & $3.1-2$ & & 1.3 & \\
\hline $\begin{array}{l}3+372 \\
3740\end{array}$ & 23 & & $\begin{array}{l}3.30 ? \\
3: 1=?\end{array}$ & & 隹 & \\
\hline 2935 & $i$ & 4\$. & & 1. & :3? & \\
\hline 9335 & I & 03. & .15 & is & .31 & \\
\hline 7435 & 3 & 45. & נינט & .0101 & .53) & \\
\hline 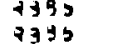 & , a & 40. & & & (3)? & \\
\hline 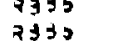 & in & $\because$ & . 13 & .253 & .13 & \\
\hline$x+1$, & 23 & & & & 653 & \\
\hline 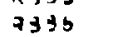 & 21 & & & & 0.39 & \\
\hline 7396 & 2? & & & & & \\
\hline PAYS & 23 & & & & 33 & \\
\hline (9781+1 & 1 & प0र०ण. & & 1.0 & 1.131 & \\
\hline (977161 & & $000 \%$ & 3201. & $.3>0$ & 5.5i1 & \\
\hline 9770. & $y$ & & & & 1.905 & \\
\hline & & & & & & \\
\hline
\end{tabular}


2. Organ Data Library (ORGLIB)

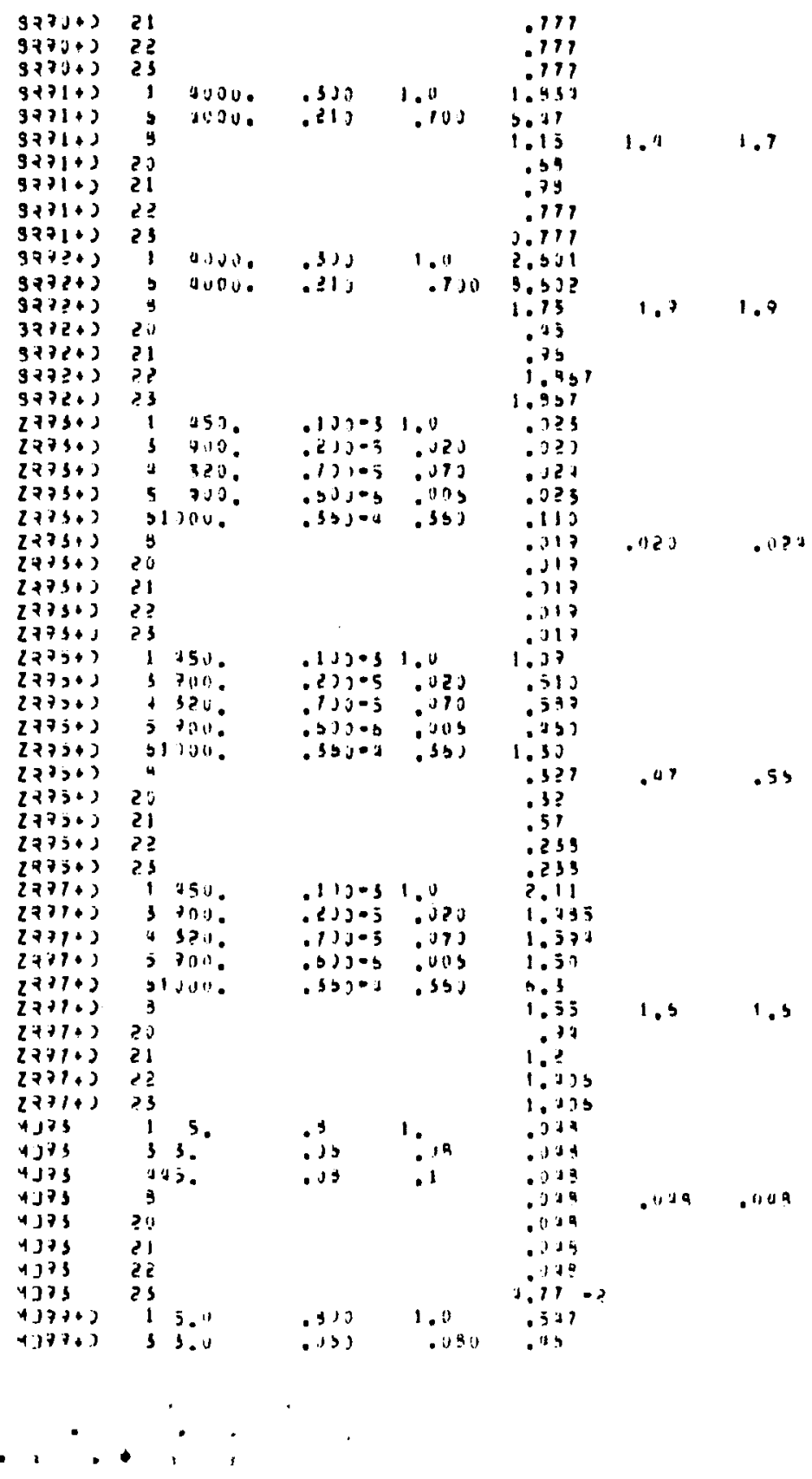




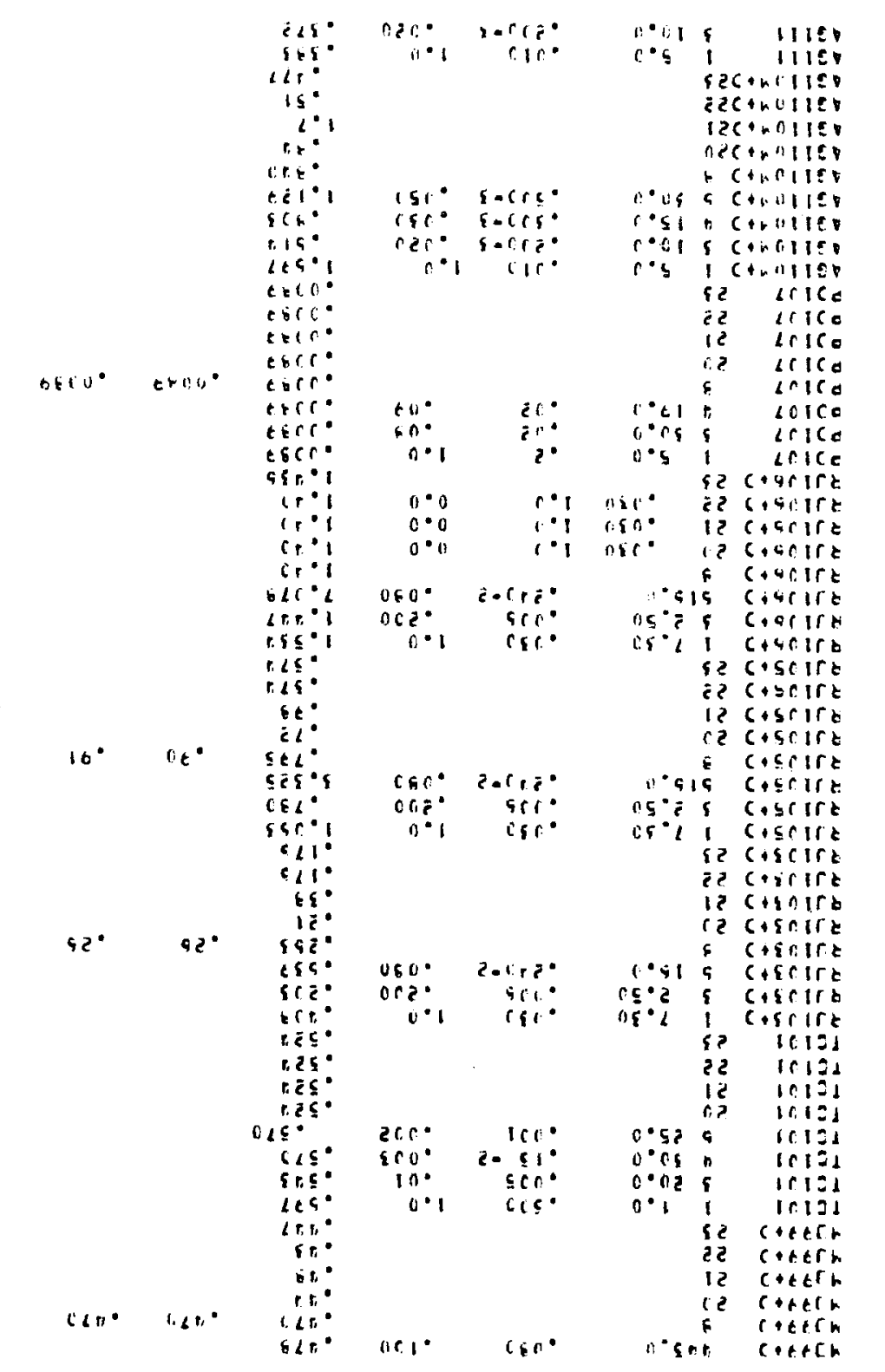

(घIาפу0) Kuesq!7 ezed uebso 
2. Organ Data Library (ORGLIB)

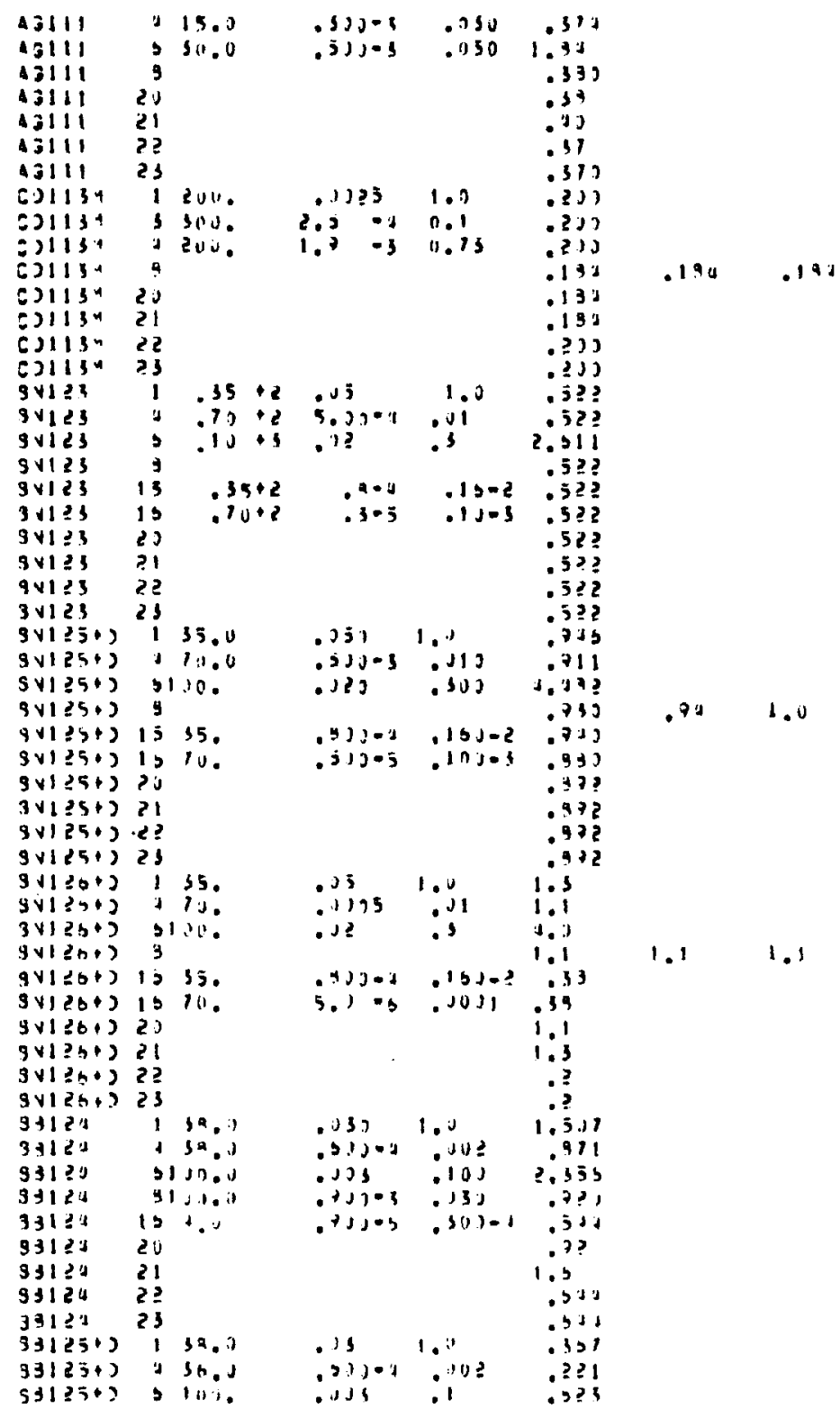




\section{Organ Data Library (ORGLIB)}

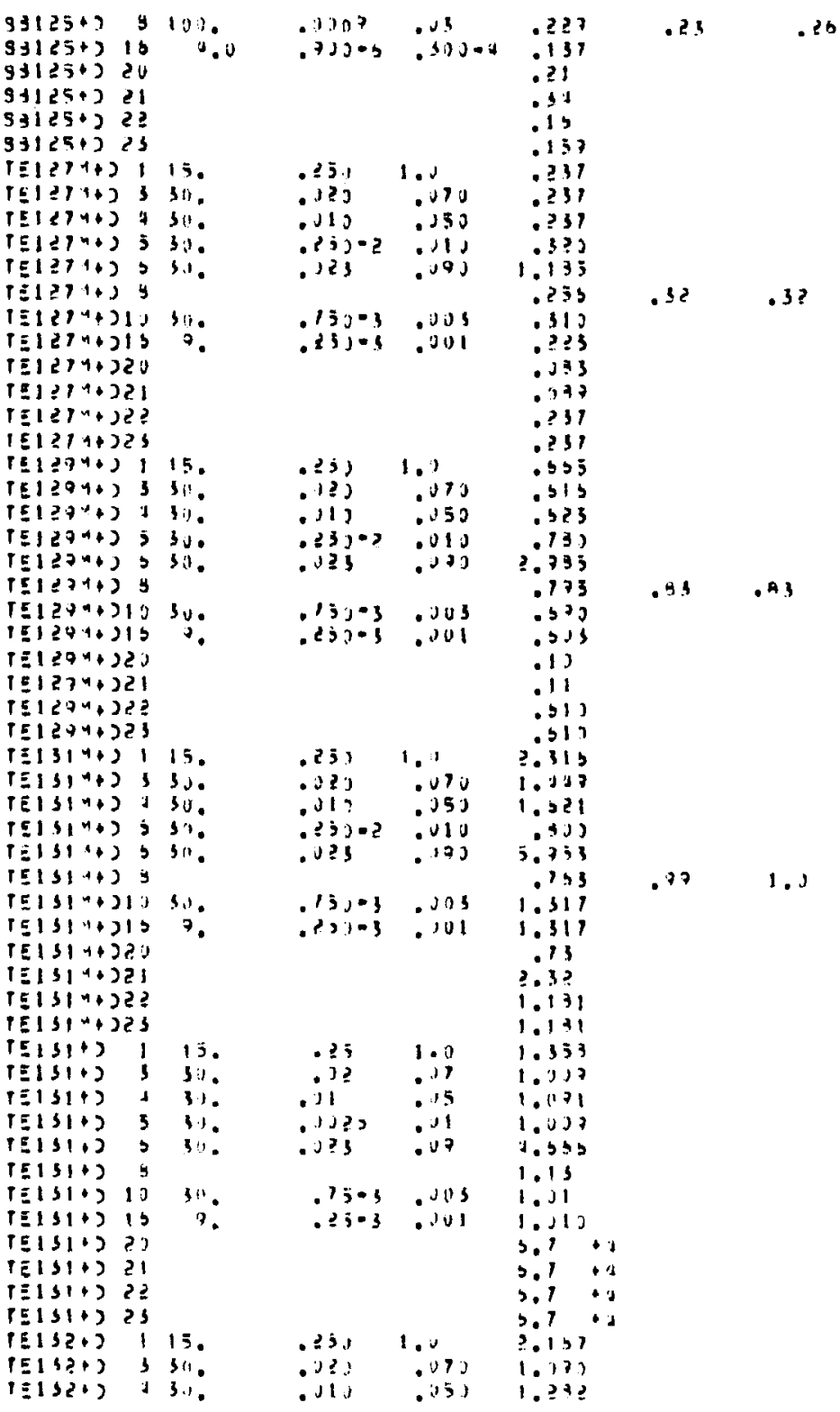




\section{Organ Data Library (ORGLIB)}

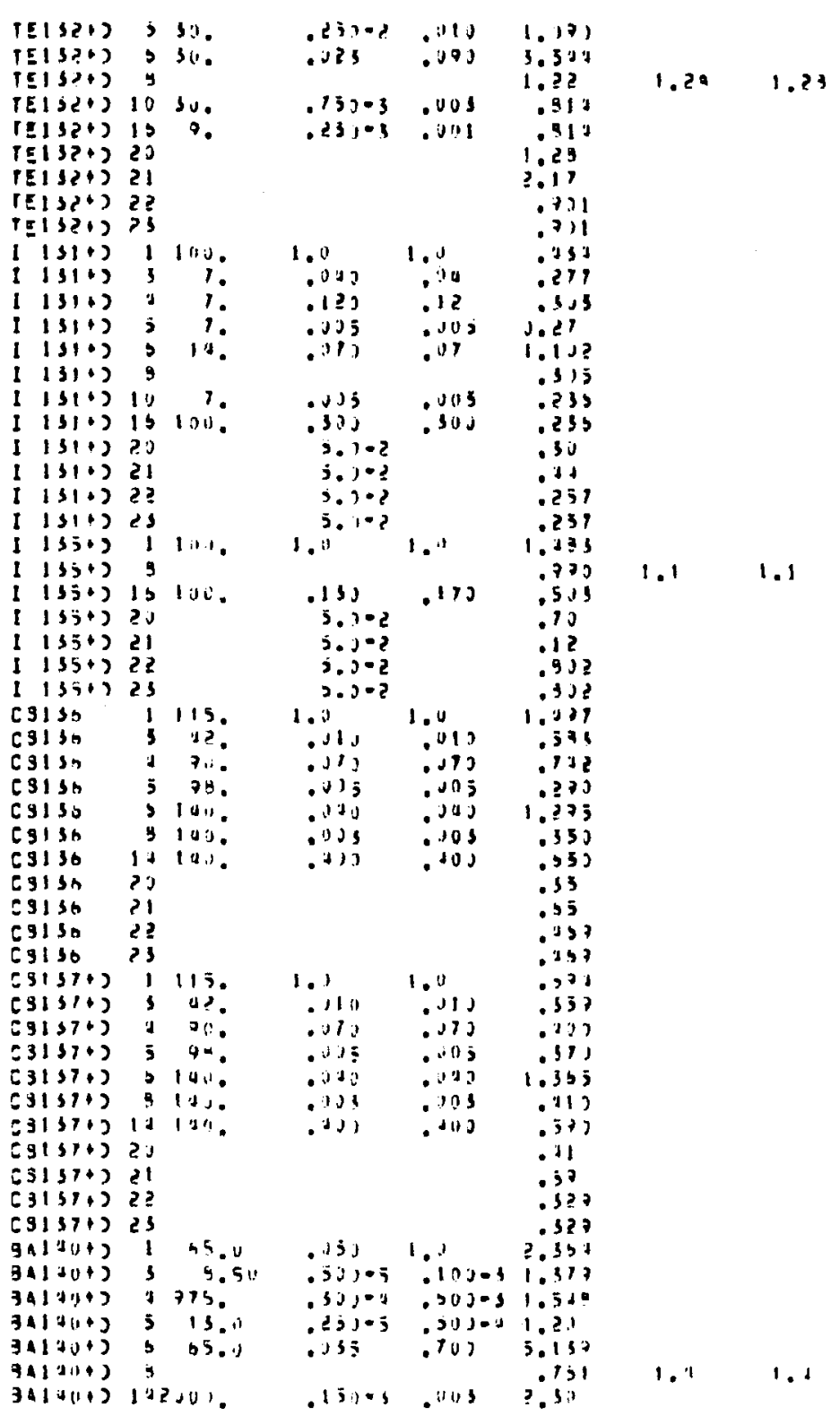


2. Organ Data Library (ORGLIB)

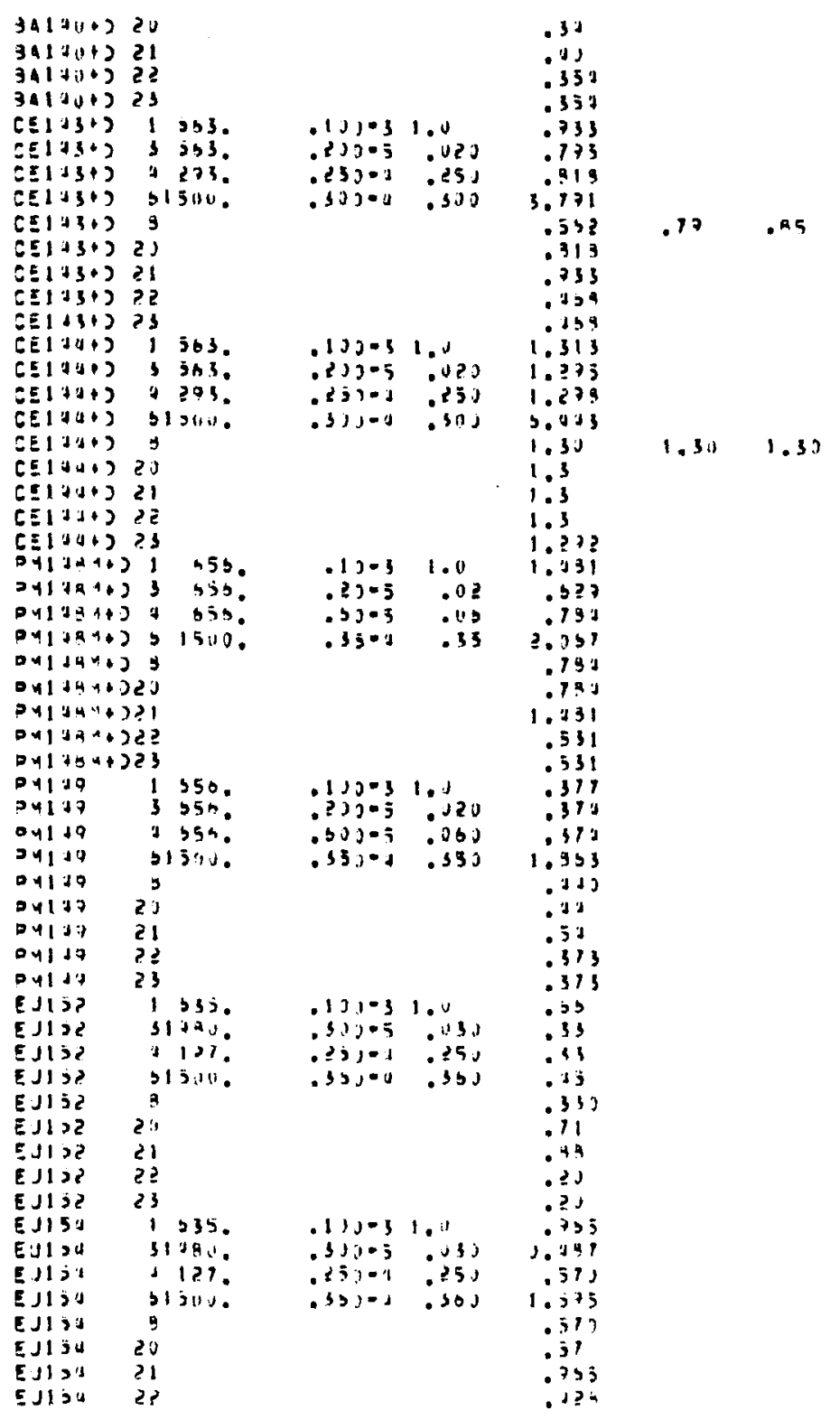


2. Organ Data Library (ORGLIB)

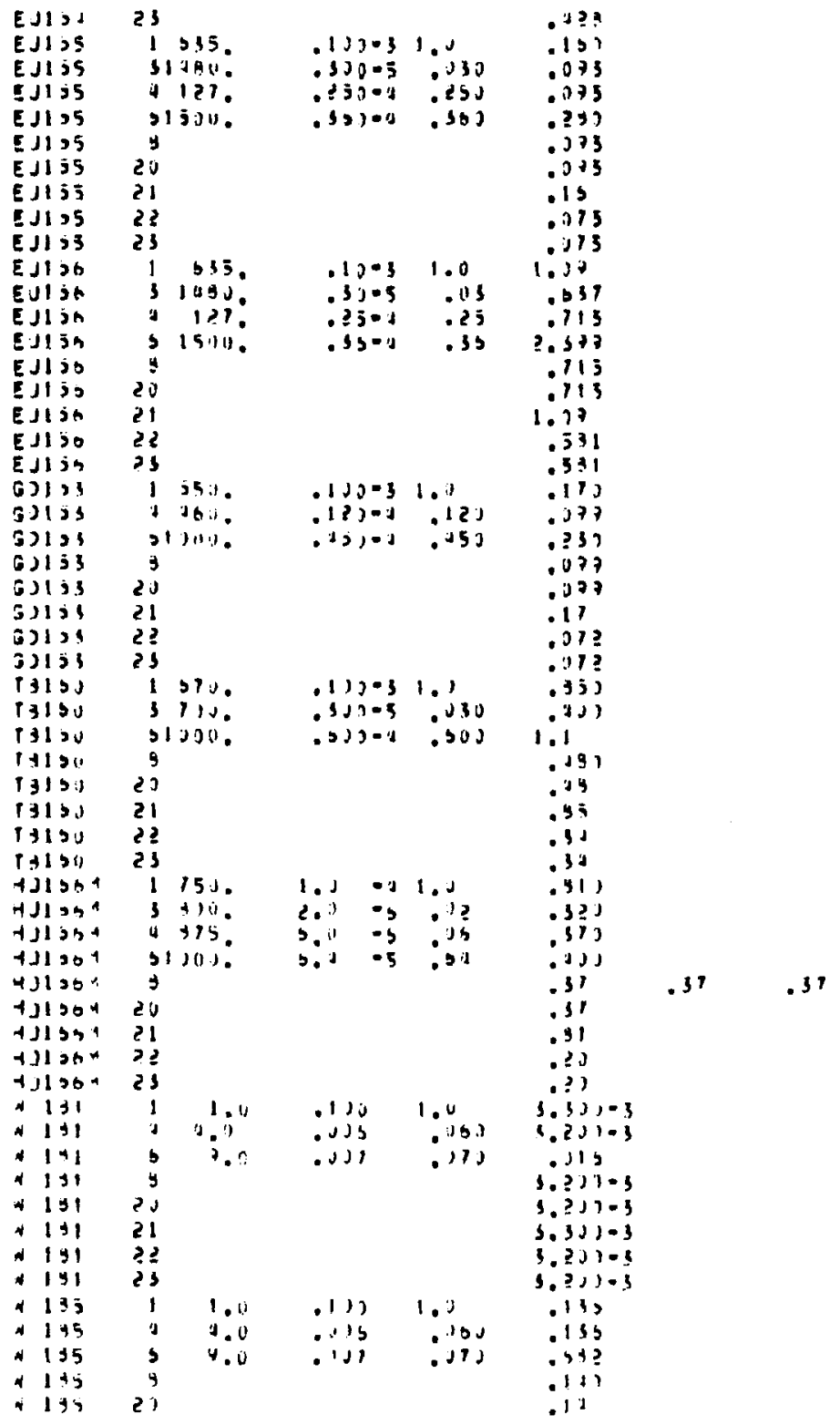




\section{Organ Data Library (ORGLIB)}

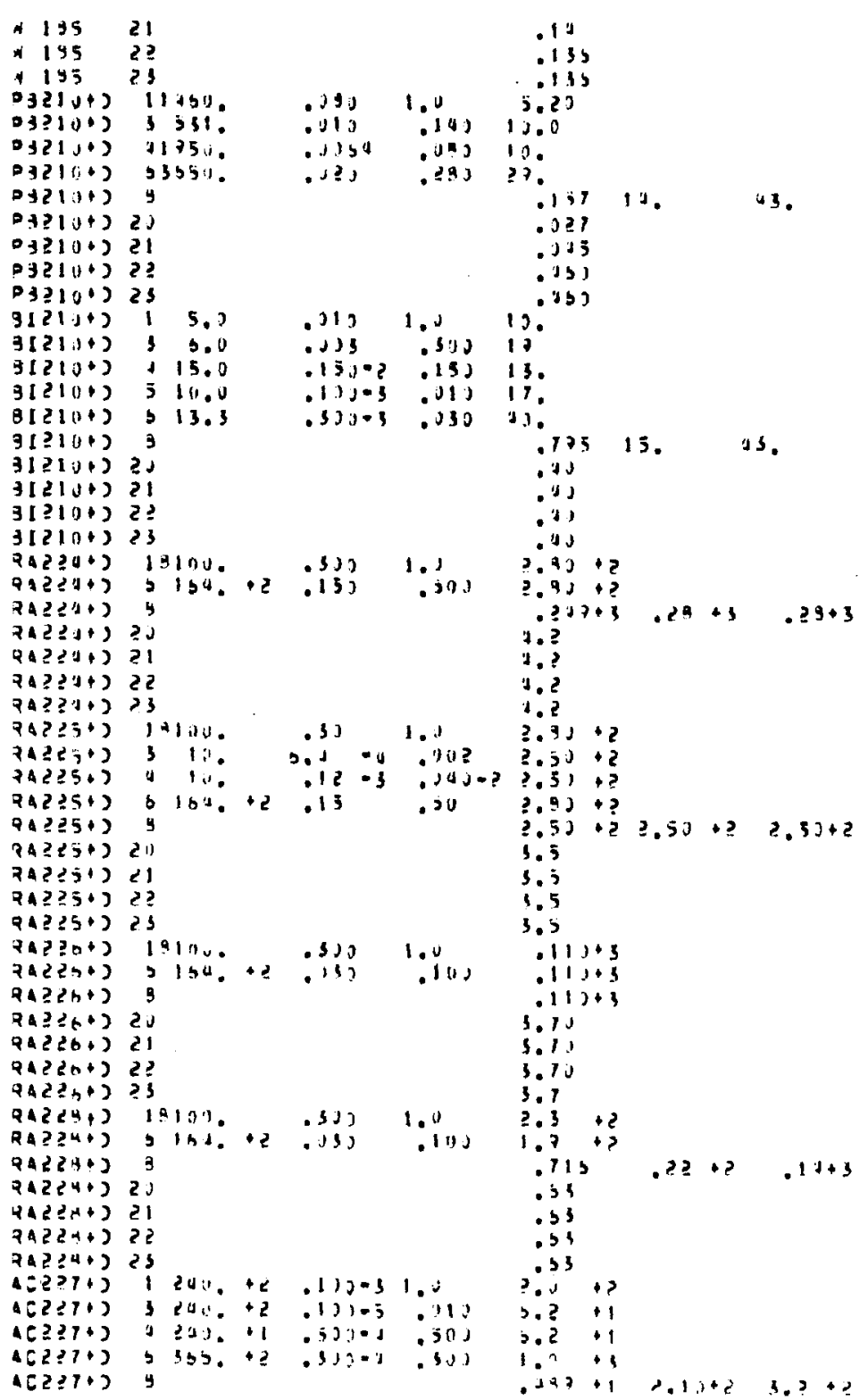


2. Organ Data Library (ORGLIB)

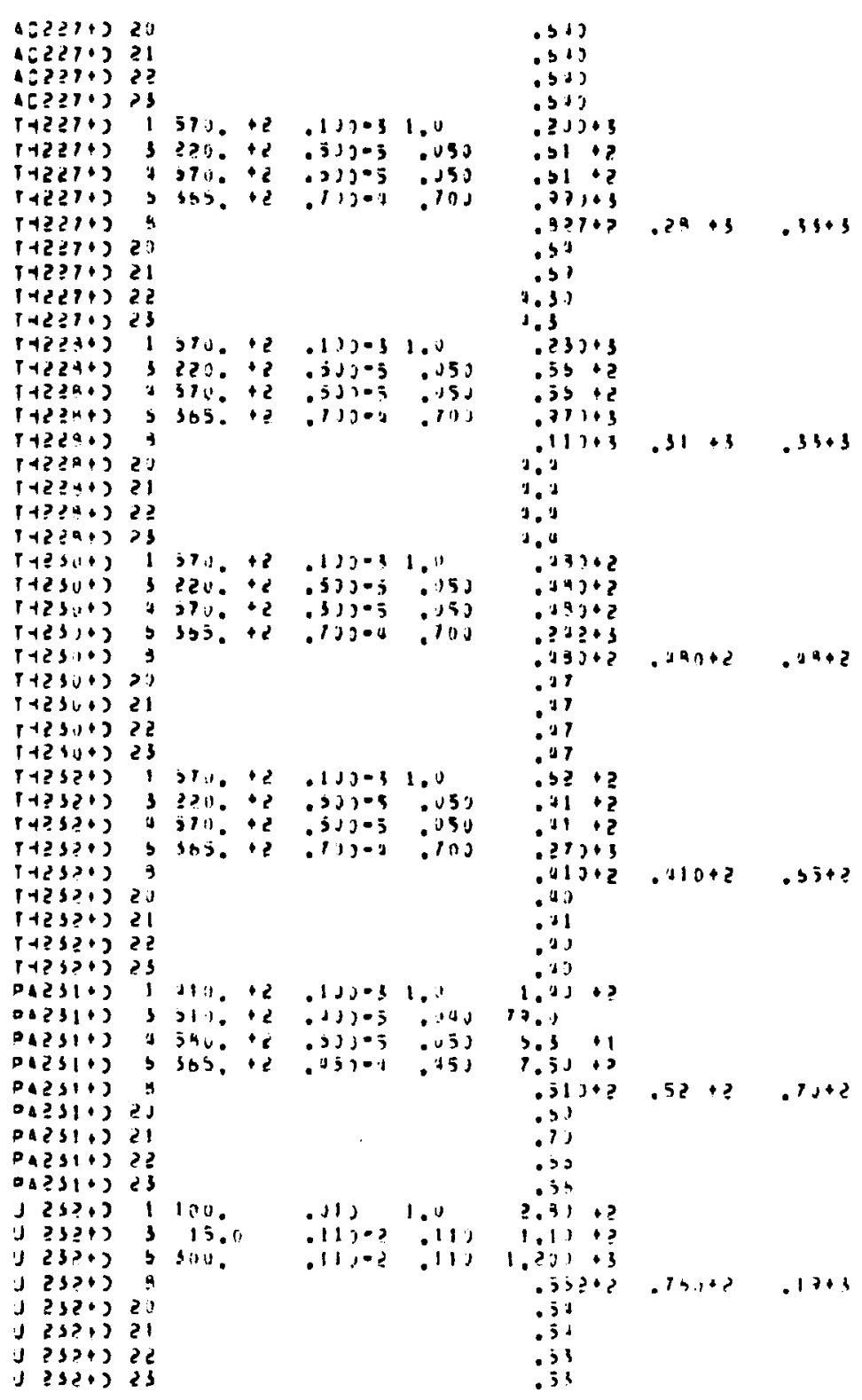




\section{Organ Data Library (ORGLIB)}

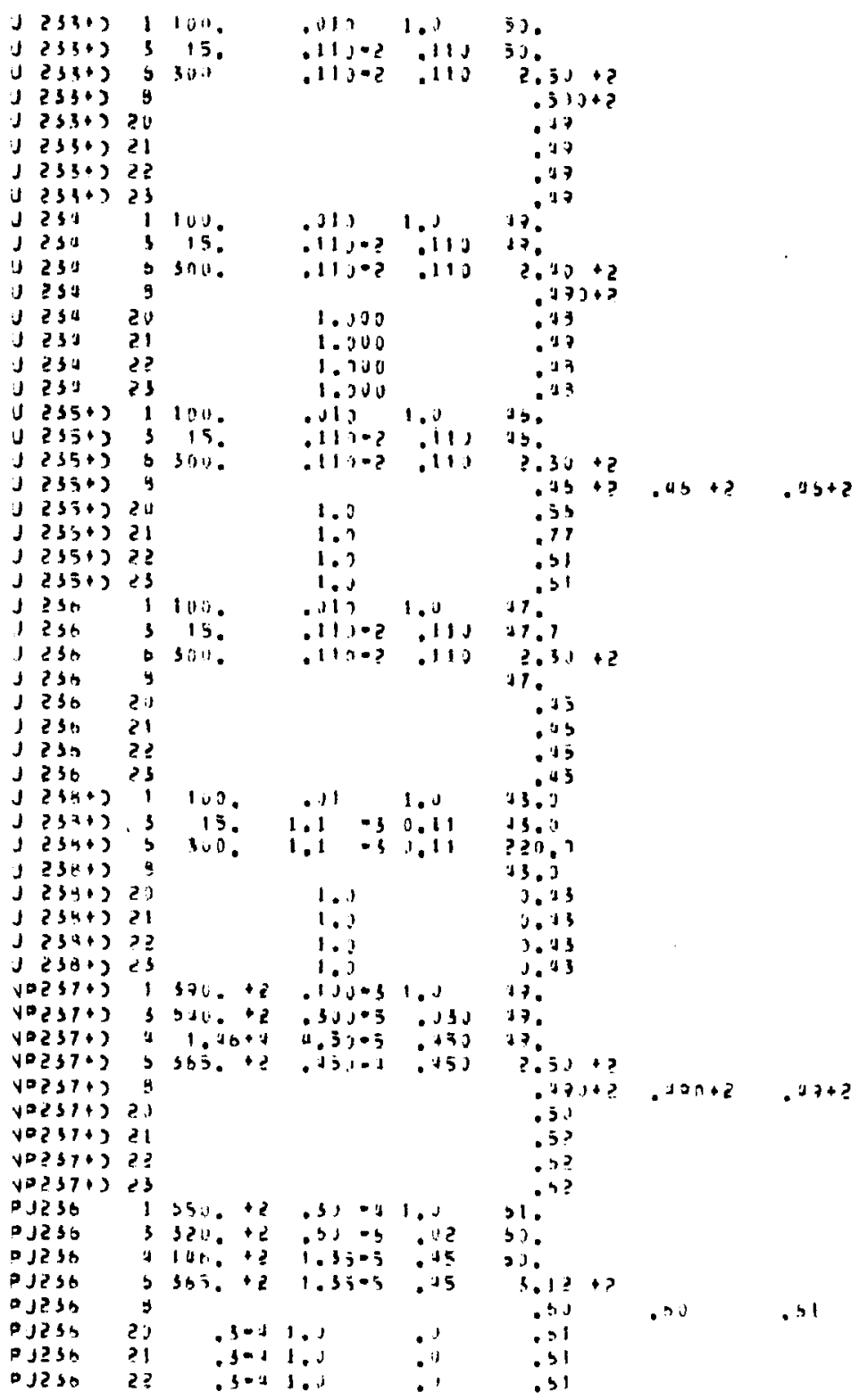




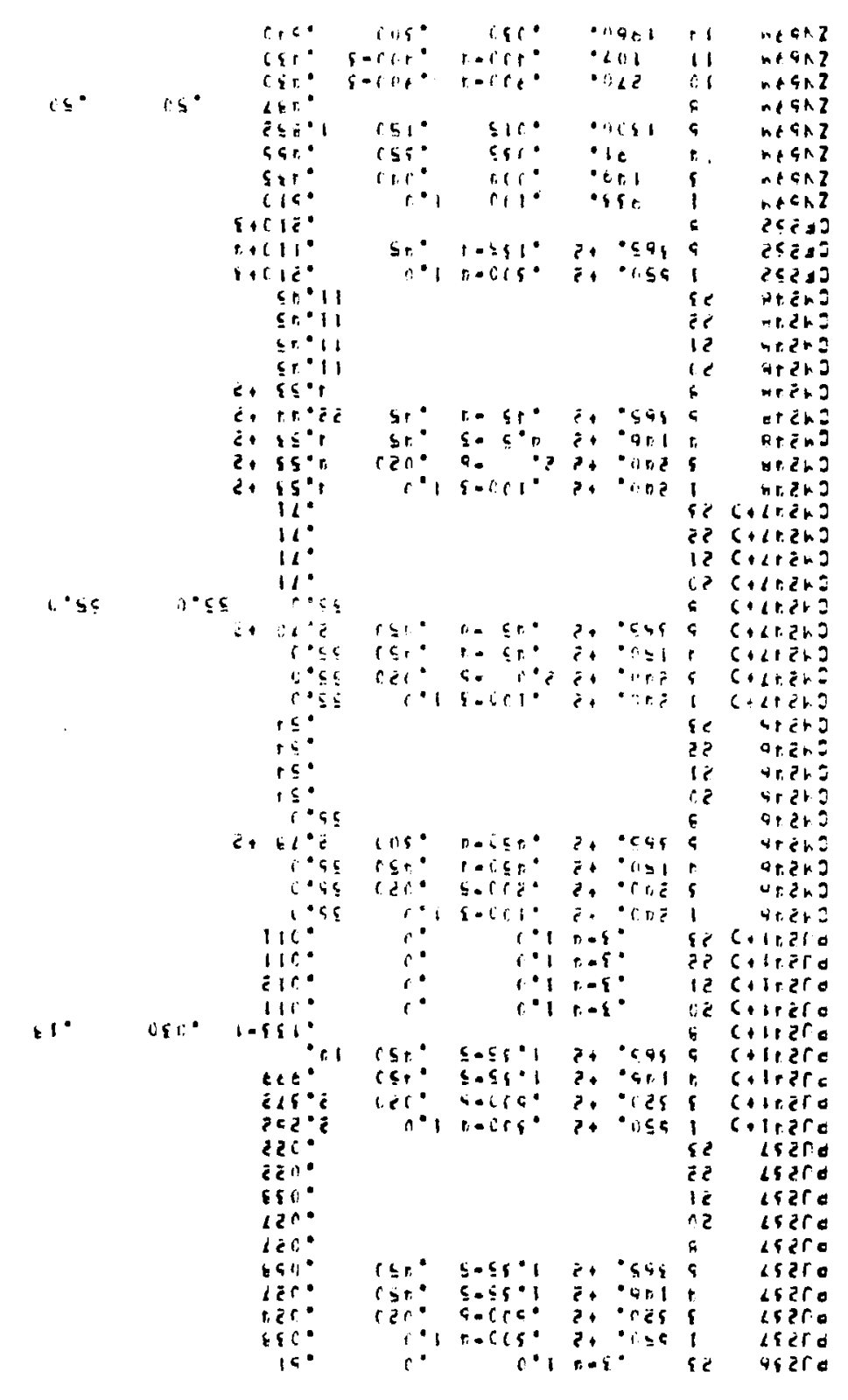

(8I75yo) Kaedq!7 eqea ueguo • 
2. Organ Data Library (ORGLIB)

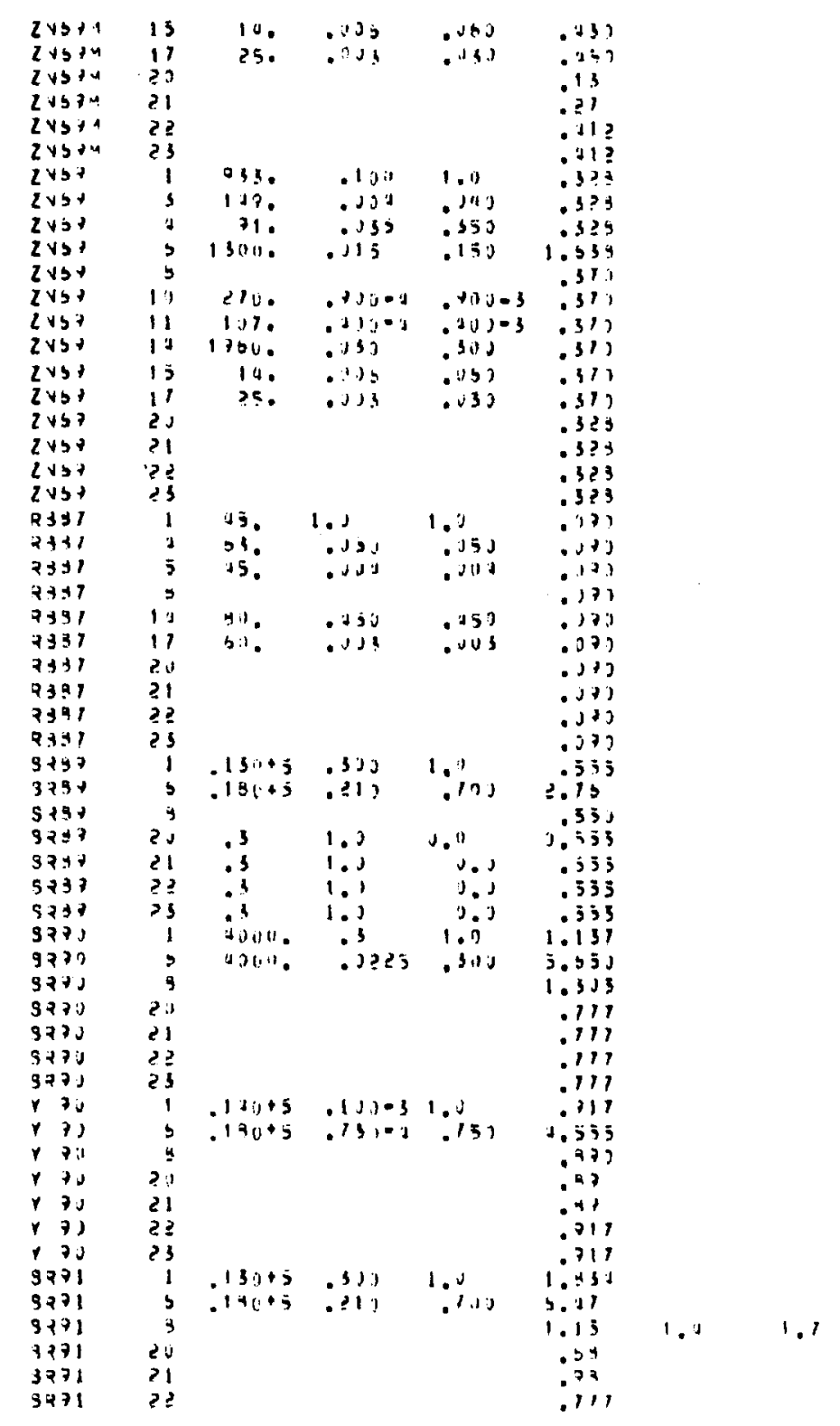


2. Organ Data Library (ORGLIB)

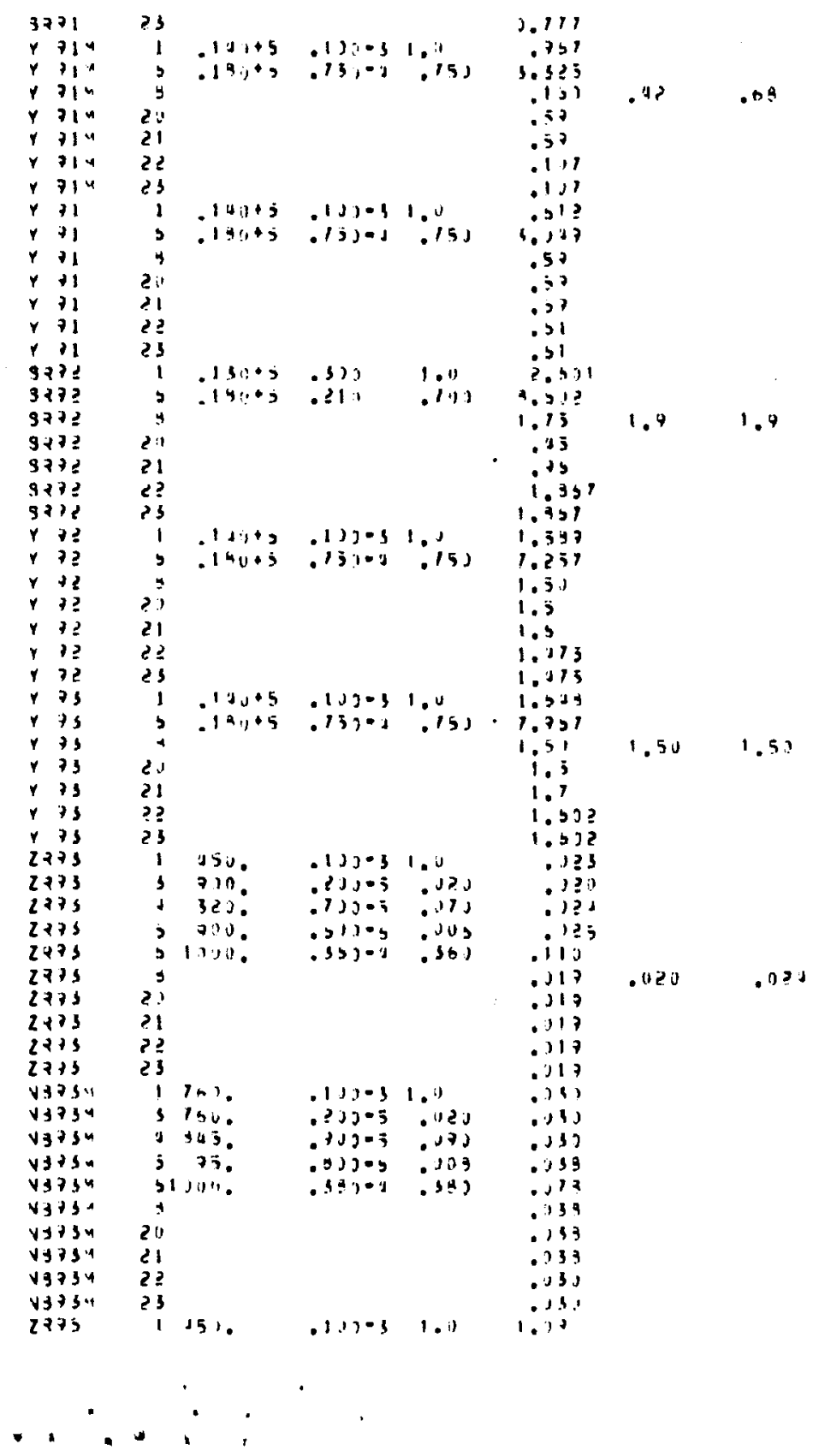




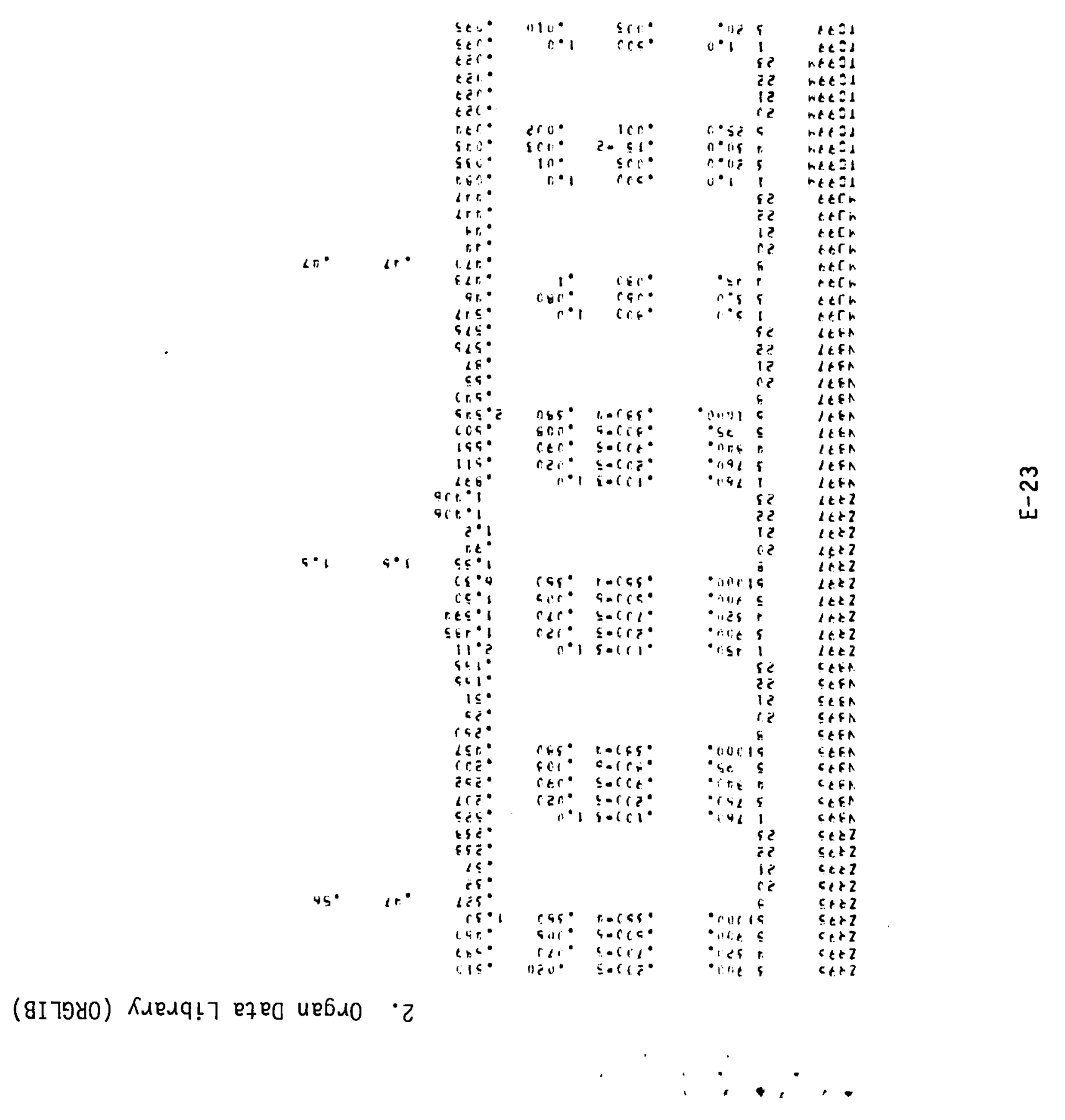




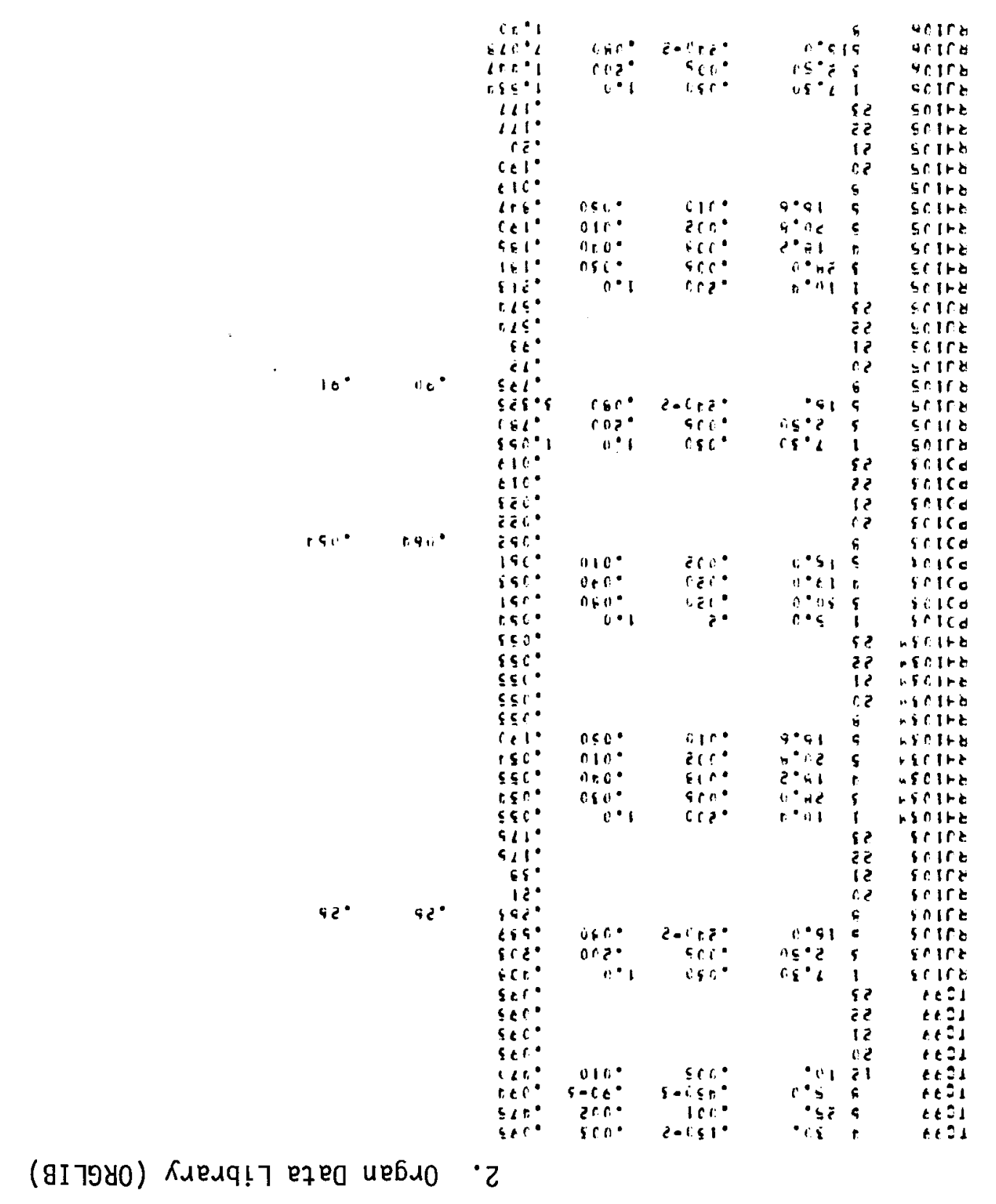




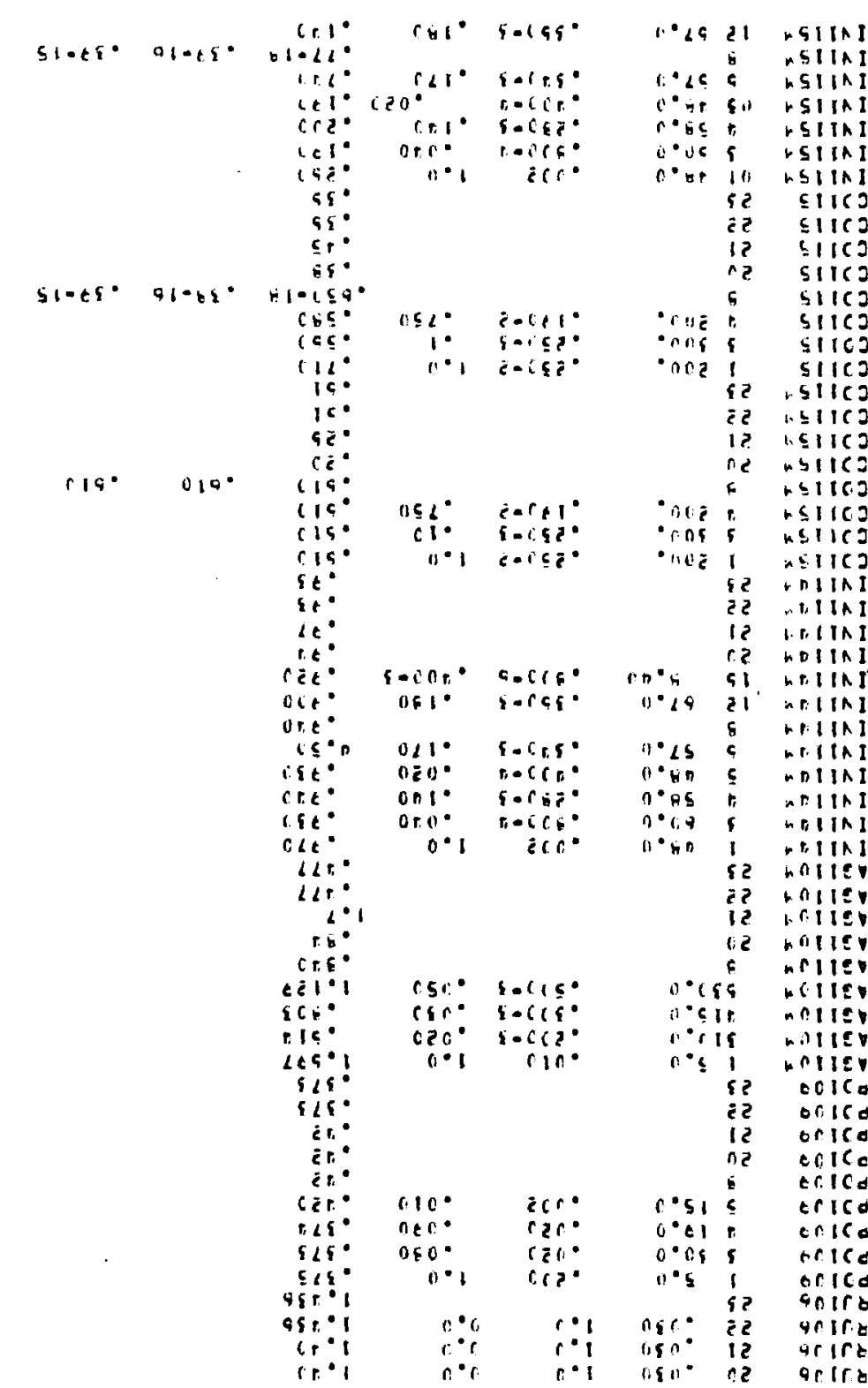

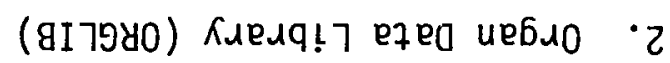




\section{Organ Data Library (ORGLIB)}

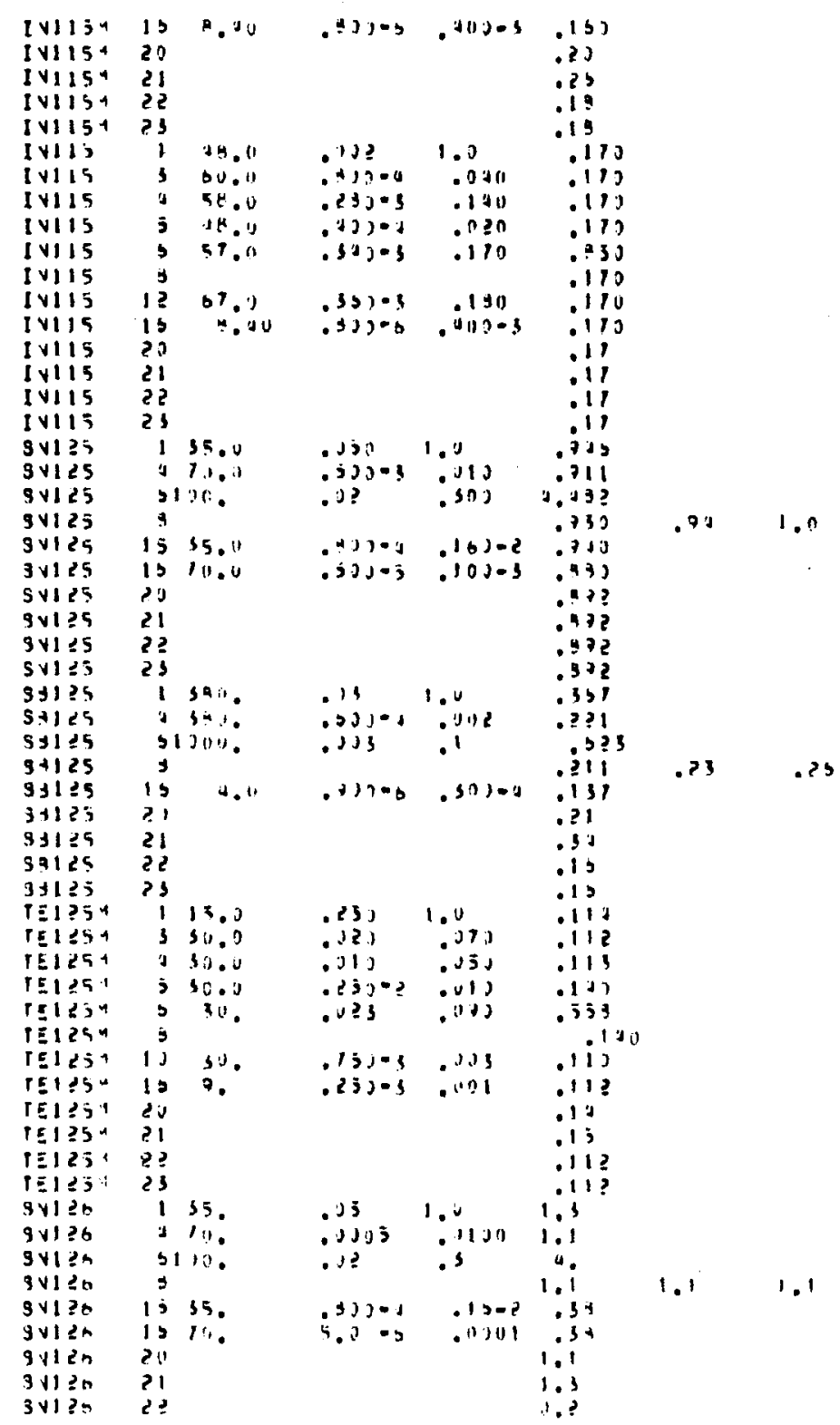




\section{Organ Data Library (ORGLIB)}

\begin{tabular}{|c|c|c|c|c|c|c|c|}
\hline $3 \vee 1 ? 6$ & 25 & & & & 0,2 & & \\
\hline 93126 & & SH. & .us $=$ & 1.0 & 1.9 & & \\
\hline 391?6 & & & 0 & 0.02 & 3.3 & & \\
\hline $351 ? 3$ & $y$ & & & & .93 & .05 & .95 \\
\hline $351 \geq n$ & 15 & u. & จ. -7 & $3.0-5$ & .7 & & \\
\hline $\begin{array}{l}331 \geq 6 \\
53126\end{array}$ & $\begin{array}{ll}5.1 \\
51\end{array}$ & & & & .75 & & \\
\hline 5) & 2? & & & & 74 & & \\
\hline ज्ञात? & is & & & & 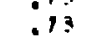 & & \\
\hline कासी & $i$ & 34. & .04 & 1.0 & .713 & & \\
\hline $331 \geq 7$ & j & $3 \approx$. & 0.105 & .002 & | & & \\
\hline 941? & b & $10 \%$ & .033 & .1 & 2.233 & & \\
\hline $331 \geq 7$ & 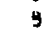 & & & & $b \geq 1$ & & \\
\hline $991 \geq 1$ & is & 1. & $7 .-1$ & $5.3 \cdot 5$ & .13 & & \\
\hline $931 \geq 7$ & 2.) & & & & , & & \\
\hline $931 ? 1$ & 21 & & & & 1.1 & & \\
\hline 9y1? & 2? & & & & 5?4 & & \\
\hline 53ij7 & 25 & & & & $3 \geq 1$ & & \\
\hline$T \equiv 1 ? 74$ & i & 15.0 & $.85 !$ & 1.0 & . & & \\
\hline TEI? & ; & 39.0 & j & . oro & .231 & & \\
\hline$P E 1 \geq 7$ & 4 & $3(0)$ &. iij & .050 & . 231 & & \\
\hline rEI?74 & j & 30.0 & . $231=2$ & .jis & (32) & & \\
\hline$r \leq 1 \geq 74$ & , & 3i1. 0 & J 13 & .073 & 1.195 & & \\
\hline$T \equiv 1 \geq 7$ & 4 & & & & .253 & 32 & 3? \\
\hline TEizin & 10 & bi). 0 & $.15-5$ & .003 & .313 & $\cdots$ & $9=$ \\
\hline$T E 1274$ & is & 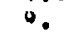 & $.25,-3$ & . (ग) & $? \geqslant 3$ & & \\
\hline TEI?TA & i.) & & & & .033 & & \\
\hline$T E ! ? 14$ & 1 & & & & 097 & & \\
\hline$T \equiv 1 \geq 74$ & 2? & & & & 1918 & & \\
\hline$T \equiv I \geq 74$ & 23 & & & & (3) & & \\
\hline rEis) & $i$ & 15. & . & & ? ? & & \\
\hline $1 \leq 1 ? 1$ & 3 & $\mathrm{Sit}_{\mathrm{i}}$ & . ग? & כ. & $? 35$ & & \\
\hline$r \equiv 1 \geq 7$ & 4 & 31. & $.3 i$ & .153 & .233 & & \\
\hline$T \leq i ?$ & j & 30. & ?3-? & .31 & (29) & & \\
\hline$|E| R \mid$ & s & sin. & $\therefore \geqslant 5$ & .103 & 1.115 & & \\
\hline$T E 1 ?$ & y & & & & ? & & \\
\hline TEI? & 10 & $3 w$. & .151 .3 & .0us & (3) & & \\
\hline$r \equiv 127$ & is & 3.0 & . (5j) & (D)1 & .235 & & \\
\hline rÊ $1 \geq$ & 20 & & & & :1 & & \\
\hline TEli? & al & & & & .3 & & \\
\hline TE्धार7 & 22 & & & & $?$ & & \\
\hline$T \leq 1 ?\}$ & 23 & & & & $? 33$ & & \\
\hline TE1EA4 & 1 & 15. & (25) & 1.0 & .353 & & \\
\hline TEISकण & ; & 31,0 & $\therefore \geq 3$ & נ. & . bls & & \\
\hline TE1200 & 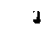 & so. & .013 & .050 & (3) & & \\
\hline TEIZOA & j & 311. & 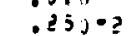 & 110 & 33 & & \\
\hline reieon & s & 30. & . 0?3 & .091 & $\therefore 7+j$ & & \\
\hline$r \equiv 1 ? 41$ & $y$ & & & & .73 & .45 & .43 \\
\hline TEleq & $1 \%$ & 50. & $.15,7 \cdot 3$ & S0 &., 73 & & \\
\hline TEI 274 & is & 9.3 & $.231-i$ & .001 & .313 & & \\
\hline$T E 1294$ & 21 & & & & .11 & & \\
\hline TEI?04 & (2) & & & & .11 & & \\
\hline$T E[5+1$ & ?ֶ? & & & & , bil & & \\
\hline TEIZOU & 23 & & & & . & & \\
\hline TEI & $i$ & 15.0 & ) & 1.9 & .573 & & \\
\hline TEiह? & 3 & $31: 0$ & .120 & $\therefore 71$ & .532 & & \\
\hline
\end{tabular}




\section{Organ Data Library (ORGLIB)}

\begin{tabular}{|c|c|c|c|c|c|c|c|}
\hline $\begin{array}{l}r=1 \leq 0 \\
T E 1 \leq 7 \\
T E 1<0 \\
T \equiv 1 \geq 0\end{array}$ & 5 & $\begin{array}{l}30 . \\
3 n: \\
3 i 1 .\end{array}$ & $\begin{array}{l}.011 \\
013102 \\
.323\end{array}$ & $\begin{array}{l}.053 \\
.012 \\
.095\end{array}$ & $\begin{array}{r}531 \\
53101 \\
9353 \\
.133\end{array}$ & .73 & .73 \\
\hline$T E 1 \geq 4$ & 10 & so. & (15)-3 & .005 & .51 & & \\
\hline $\begin{array}{l}T E 1<0 \\
r=1\end{array}$ & $\begin{array}{l}10 \\
23\end{array}$ & D.J & $.253 \cdot 3$ & .001 & $\begin{array}{l}.557 \\
.75\end{array}$ & & \\
\hline $1 \leq 1 \geq 7$ & 21 & & & & .79 & & \\
\hline $151 \leq 7$ & 22 & & & & 535 & & \\
\hline PE12? & 23 & & & & .513 & & \\
\hline 1127 & 1 & $10 \%$ & 1.0 & 1.0 & $3,1 \geq-2$ & & \\
\hline 1129 & 3 & 1.0 & | (1) & .040 & $3.15 \div 2$ & & \\
\hline $11 \geq 9$ & 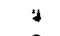 & 1.0 & $.1 \geq j$ & . 121 & $1,57=2$ & & \\
\hline I 129 & j & 7.0 & .005 & .015 & .011 & & \\
\hline 1129 & b & 14.5 & j & .070 & .315 & & \\
\hline $11 \geq ?$ & $y$ & & & & is? & & \\
\hline 1129 & 12 & 1.11 & .125 & ز زارد & .053 & & \\
\hline $11 \geq 0$ & 13 & ivo. & $.30 \mathrm{~J}$ & .200 & $3.52=?$ & & \\
\hline I 120 & P & & & & $0 \div 2$ & & \\
\hline I 129 & 21 & & & & 397 & & \\
\hline I $1 \geqslant 0$ & 22 & & & & . Jb7t & & \\
\hline I 120 & 23 & & & & .6574 & & \\
\hline $15131^{4}$ & 1 & 15. & .25J & 1.0 & 1.33 & & \\
\hline$r \equiv \mid s i r$ & 3 & Sil. & . $0 ? 3$ & .010 & (1) & & \\
\hline $\operatorname{TE} 1314$ & 1 & sis. & .313 & .051 & .710 & & \\
\hline$T \equiv \mid$ sia & j & $3: 3$. & ?3j=2 & .013 & .303 & & \\
\hline iElsin & b & sn. & . nes & $.0+0$ & 2,31 & & \\
\hline$I \leq\left. 1 \mathrm{~s}\right|^{4}$ & y & & & & .753 & .07 & 1.1 \\
\hline$T E 1314$ & 1.1 & s:s, & $.150+1$ & $.00 s$ & .37 & & \\
\hline $1 E 1314$ & 15 & 7. & $.253=3$ & .001 & כילנ. & & \\
\hline$t \leq 131$. & נग & & & & .73 & & \\
\hline$T \underline{E} 1314$ & 21 & & & & $1 . ?$ & & \\
\hline $\begin{array}{lll}T \\
r \\
0\end{array}$ & 23 & & & & .53 & & \\
\hline$P=1314$ & 23 & & & & .35 & & \\
\hline IE $1 \$ 1$ & 1 & 13. & .25 & 1.0 & 1.359 & & \\
\hline$T E|3|$ & 3 & $3: 1$. & $x ?$ & .07 & $1.0 \mathrm{JP}$ & & \\
\hline TEISi & + & $3 i 1$. & .31 & .05 & 1.571 & & \\
\hline$T \leq 131$ & s & 30. & $0 \geq 3$ & $\therefore 4$ & A.sbs & & \\
\hline$T \equiv \mid S 1$ & $y$ & & & & 1.13 & & \\
\hline$T E \mid B i$ & 15 & $3 \cdots$ & $.75-3$ & .003 & 1,01 & & \\
\hline$|E| S \mid$ & 13 & 3 & $.23-3$ & .001 & 1.119 & & \\
\hline$T \equiv 1 S 1$ & ?!) & & & & 1.13 & & \\
\hline$I E 13 i$ & 21 & & & & 1.35 & & \\
\hline$T E 131$ & $2 !$ & & & & .053 & & \\
\hline IEISi & 23 & & & & .913 & & \\
\hline $1|3|$ & 1 & 10.1. & 1.1 & $1 . J$ & .334 & & \\
\hline $1 \mid s 1$ & 3 & 7. & .01 & 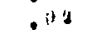 & וי??. & & \\
\hline I isi & $i$ & $i$ & .12 & .12 & .305 & & \\
\hline i 13i & $\mathbf{j}$ & 7. & .11; & .203 & 2.27 & & \\
\hline $\mid 131$ & 3 & 1. & וני & .07 & $(1,1) ?$ & & \\
\hline 1131 & y & & & & $.3+3$ & & \\
\hline$I \mid \$ 1$ & 10 & 7. & . 015 & 55 & .23 & & \\
\hline 1131 & 13 & 101. & .330 & .301 & .335 & & \\
\hline 1131 & 2J & & $5.1=?$ & & $.3 \mathrm{~J}$ & & \\
\hline 1131 & $2 !$ & & 5. $1=2$ & & .14 & & \\
\hline $113 i$ & $? 2$ & & $3,1=?$ & & |?31 & & \\
\hline 1151 & ?3 & & j.1.? & & ? ?57 & & \\
\hline
\end{tabular}




\section{Organ Data Library (ORGLIB)}

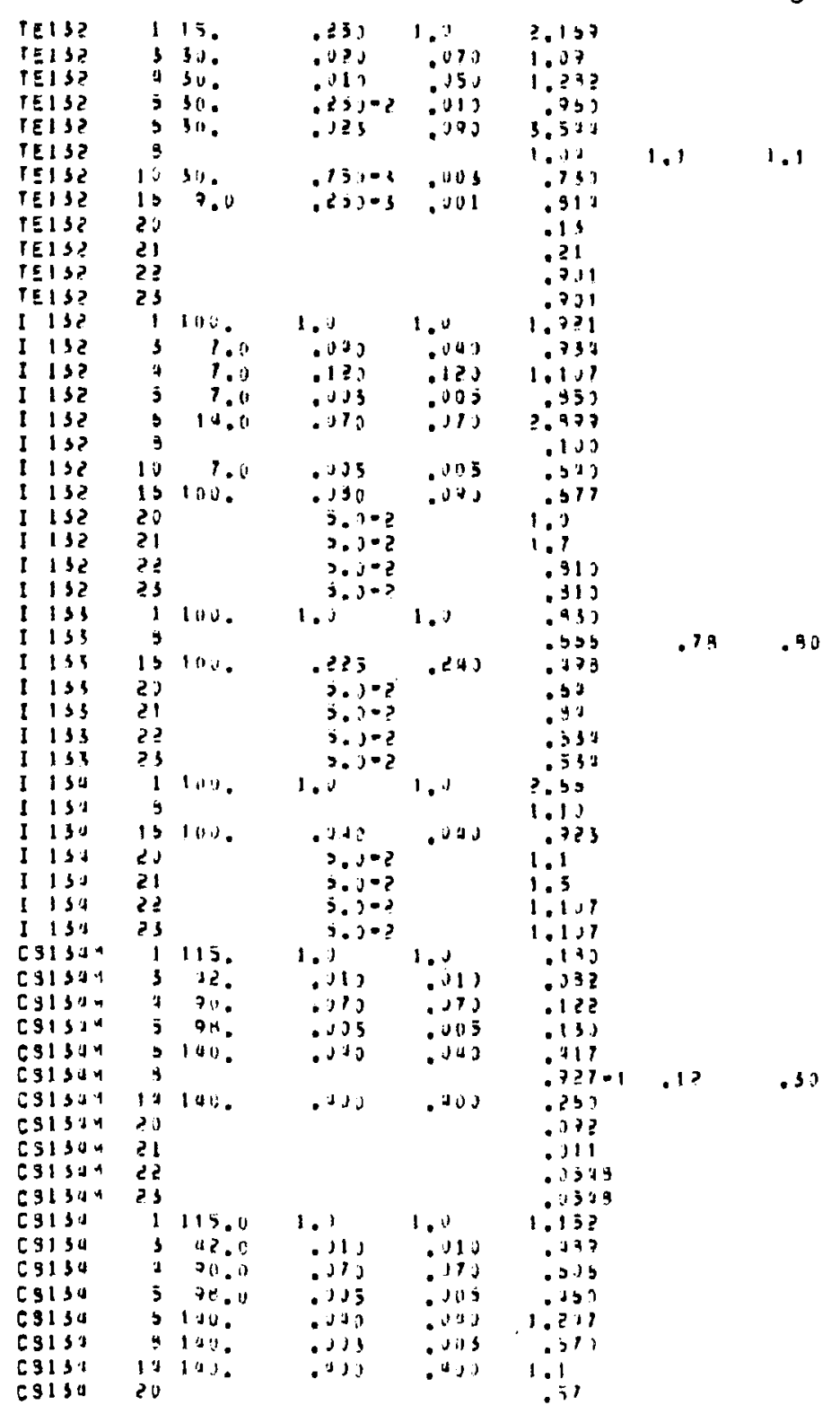


2. Organ Data Library (ORGLIB)

思

\begin{tabular}{|c|c|c|c|c|c|c|c|}
\hline C 3134 & 21 & & & & 1.1 & & \\
\hline C5151 & ?2 & & & & .233 & & \\
\hline $\begin{array}{lll}1 & 135\end{array}$ & 3 & 1900. & 1.1 & 1.1 & $\begin{array}{l}0303 \\
1 . x+3\end{array}$ & & \\
\hline i 135 & 9 & 1.1 & 152 & יד & 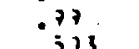 & 1.1 & 1.1 \\
\hline 1 iss & 30 & & $\begin{array}{l}n, j, 3 \\
j . j=?\end{array}$ & .173 & $: 333$ & & \\
\hline & 21 & & j. $)=2$ & & & & \\
\hline 1135 & $2 ?$ & & 3.102 & & .93? & & \\
\hline $\begin{array}{l}11135 \\
C 3135 \\
C 3\end{array}$ & 23 & 115 & $\stackrel{5.9=?}{1.5}$ & & 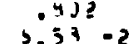 & & \\
\hline 63135 & 3 & 11?. & .110 & :jo & $3,54=?$ & & \\
\hline 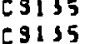 & 5 & 7.0. & 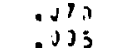 & $.07 \%$ & $\begin{array}{l}3.53 \\
0.359\end{array}$ & & \\
\hline E3155 & s & 19: & 010 & (X) & $: 327$ & & \\
\hline 59113 & $y$ & Iय. & .113 & . sus & . Oss & & \\
\hline C3135 & 1.1 & 1.80. &.+119 & 79? & $\therefore 33$ & & \\
\hline 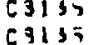 & $\begin{array}{l}21 \\
21\end{array}$ & & & & • & & \\
\hline C9iss & 2? & & & & לss & & \\
\hline E3135 & 23 & & & & Sלs & & \\
\hline 5137 & 1 & 115. & 1.1 & 1.1 & , & & \\
\hline$[913]$ & 3 & 12. & נו & .010 & .353 & & \\
\hline 69131 & 1 & 70. & 313 & ניני & .203 & & \\
\hline $\begin{array}{lllll}5 & 9 & 1 & 1\end{array}$ & 5 & 79. & 0115 & 5 & .573 & & \\
\hline 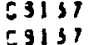 & 5 & $\operatorname{lan}$. & - ग2? & . 0408 & 1.355 & & \\
\hline 年 & 1. & 100: & :4) & : & 0 & & \\
\hline [ais] & 23 & & 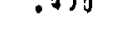 & & 0 & & \\
\hline$=3137$ & 21 & & & & 33 & & \\
\hline $\cos 131$ & ?? & & & & 3? & & \\
\hline $\begin{array}{c}6 \\
6\end{array} 137$ & 23 & & & & .327 & & \\
\hline 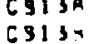 & 1 & 115. & 1.1 & 1.0 & ?.297 & & \\
\hline $\begin{array}{l}03134 \\
\text { CSISB }\end{array}$ & 3 & $7 ?$ & . & .01 & 1.431 & & \\
\hline Cgija & j & ${ }_{P R}:$ & (30j & .025 & 1.95 & & \\
\hline 63134 & 3 & 120. & גיני & . 11 & 5.421 & & \\
\hline 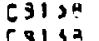 & $y$ & & & & 1.5 & & \\
\hline $\begin{array}{l}53138 \\
c 3198\end{array}$ & 11 & $14:$. & . 11 & .00 & ?.207 & & \\
\hline C\$139 & 21 & & & & $\begin{array}{l}1.95 \\
3: 3\end{array}$ & & \\
\hline Eg/se & $? 2$ & & & & i. 15 ? & & \\
\hline C3154 & 23 & & & & 1.353 & & \\
\hline ( 3159 & 1 & 113. & I. & 3. & ?.111 & & \\
\hline cy1s? & 1 & 4i. & .11 & .01 & 2.551 & & \\
\hline c31s, & & P11. & . & .n! & 2.594 & & \\
\hline C31s, & 3 & ${ }^{7 H}$. & .103 & .025 & $?, 56$ & & \\
\hline $\begin{array}{l}\text { C9139 } \\
\text { c9199 }\end{array}$ & $?$ & 191". & . & .01 & $1 ! 35$ & & \\
\hline $\begin{array}{l}69137 \\
63139 \\
6\end{array}$ & 13 & 100. & . & .4 & $\begin{array}{l}2.33 \\
2.11\end{array}$ & & \\
\hline Csiso & 2. & & & & 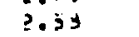 & & \\
\hline$(31 s 0$ & 21 & & & & 3.11 & & \\
\hline 63157 & $? ?$ & & & & ליכ.jo & & \\
\hline 69139 & 23 & & & & 2.539 & & \\
\hline 34190 & 1 & 65.1 & .120 & 1.1 & ?.931 & & \\
\hline $34 \int d_{3}$ & 3 & & 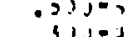 & - $1110=3$ & 1.917 & & \\
\hline & & is. & . 31) & $.511)=3$ & 1.026 & & \\
\hline & & & & & & & \\
\hline & & & & & & & \\
\hline
\end{tabular}




\section{Organ Data Library (ORGLIB)}

\begin{tabular}{|c|c|c|c|c|c|c|c|}
\hline $\begin{array}{l}34191 \\
341019\end{array}$ & $\begin{array}{l}3 \\
b\end{array}$ & $\begin{array}{l}13.2 \\
45.2\end{array}$ & $\begin{array}{l}.25305 \\
.235\end{array}$ & $\begin{array}{l}50304 \\
100\end{array}$ & $\begin{array}{l}1.20 \\
3.130\end{array}$ & & \\
\hline 34104 & $y$ & & & & .31 & 1.4 & 1. J \\
\hline $941+0$ & $1+2$ & 1011. & $.15 .7=4$ & .003 & $2.3 j$ & & 1.0 \\
\hline 34120 & (2) & & & & 32 & & \\
\hline 341211 & 21 & & & & IJ & & \\
\hline $3+1$ । & 2? & & & & .351 & & \\
\hline $341+3$ & 23 & & & & .351 & & \\
\hline$|a|+\mid$ & 1 & 300. & . & 1.0 & 1.997 & & \\
\hline$[A \mid d u$ & I & נove. & $.13,04$ & .150 & 1.150 & & \\
\hline$[4 \mid+\|$ & b1 & 2181. & $.2 \mathrm{JjO}$ & Anj & 3.333 & & \\
\hline $611+6$ & 9 & & & & 1.10 & & \\
\hline$L A l u d$ & 20 & & & & 1.1 & & \\
\hline $641+0$ & 21 & & & & 1.7 & & \\
\hline$[A \mid J 0$ & 2? & & & & .703 & & \\
\hline Lal 10 & 23 & & & & $.7 ? 3$ & & \\
\hline 34121 & 1 & 65. & .13 & 1.0 & 2,353 & & \\
\hline $3+i+i$ & 3 & 3.5 & -5נ30. & $.11-3$ & ?.115 & & \\
\hline 34121 & 1 & 715 & (3)נJ-j & $.3 j=3$ & 2.147 & & \\
\hline 34121 & j & 13. & .23j-5 & .5304 & 2.11 s & & \\
\hline $341+1$ & b & 65. & .035 & .1 & 10.01 & & \\
\hline 34131 & 9 & & & & $? .1+1$ & & \\
\hline 94121 & 122 & 100. & $.130=3$ & .003 & 3,355 & & \\
\hline $341+1$ & $2 j$ & & & & $2.1 \pm 7$ & & \\
\hline $34 \mid+1$ & 21 & & & & $? .353$ & & \\
\hline 94111 & ?? & & & & 1.127 & & \\
\hline 34121 & 23 & & & & 1.127 & & \\
\hline$|A|+\mid$ & 1 & 53 & וננ口 & 1.0 & .331 & & \\
\hline$(4)+1$ & + & मा & $15 j=4$ & j & ב2 & & \\
\hline$[4121$ & 1 & נगU. & $.+J j=1$ & .25 & $2.05 j$ & & \\
\hline$[41+1$ & 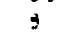 & & & & (ㄱ? & & \\
\hline La1di & (2) & & & & .713 & & \\
\hline$\left[\begin{array}{llll} & 1\end{array}\right.$ & 21 & & & & .831 & & \\
\hline LAd & ?? & & & & .749 & & \\
\hline $641+1$ & 23 & & & & .733 & & \\
\hline$C E 1+1$ & 1 & SbS. & $.(1) 1=3$ & $1.00 \mathrm{~J}$ & .2?1 & & \\
\hline$C E 1+1$ & 3 & jes. & $.22 j=5$ & . ग? & 171 & & \\
\hline$C E I+i$ & 1 & 993. & 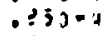 & (5) & .177 & & \\
\hline$E E 1+1$ & 31 & 500. & .51304 & .301 & . 7?9 & & \\
\hline CEIAI & 9 & & & & (11) & & \\
\hline CEI I I & 2:1 & & & & 13 & & \\
\hline CEIJi & 21 & & & & ??? & & \\
\hline CEIAI & $2 ?$ & & & & $1 \geqslant 1$ & & \\
\hline CEIJ & 23 & & & & .171 & & \\
\hline 341 ? & 1 & b5. & .05 & 1.3 & 1.417 & & \\
\hline $341 \% ?$ & 3 & $\$ .5$ & 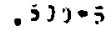 & $.102-3$ & ?? ? & & \\
\hline BAIग & 2 & 715 & (\$ ג & : ovses & 7? & & \\
\hline $\begin{array}{l}3412, \\
34112\end{array}$ & j & 13. & 5 & $=303=1$ & ?.12? & & \\
\hline $\begin{array}{l}341 \text { ? } \\
\text { 941ग? }\end{array}$ & 3 & b5. & & .7 & $\begin{array}{l}1.753 \\
2.851\end{array}$ & & \\
\hline 341 ग2 & 17 & $?$ & 3 & S ום & 3.197 & & \\
\hline 34142 & 26 & & & & 2.231 & & \\
\hline $341+2$ & ? & & & & $3.4: 3$ & & \\
\hline $341+2$ & 2? & & & & 1.953 & & \\
\hline $341 \mathrm{~d}$ & 23 & & & & 1.953 & & \\
\hline $641+7$ & 1 & suj. & וונ, & 1.0 & 2.133 & & \\
\hline LA1 & 1 & w wi. & 150. & .13 & 1.97 & & \\
\hline
\end{tabular}


2. Organ Data Library (ORGLIB)

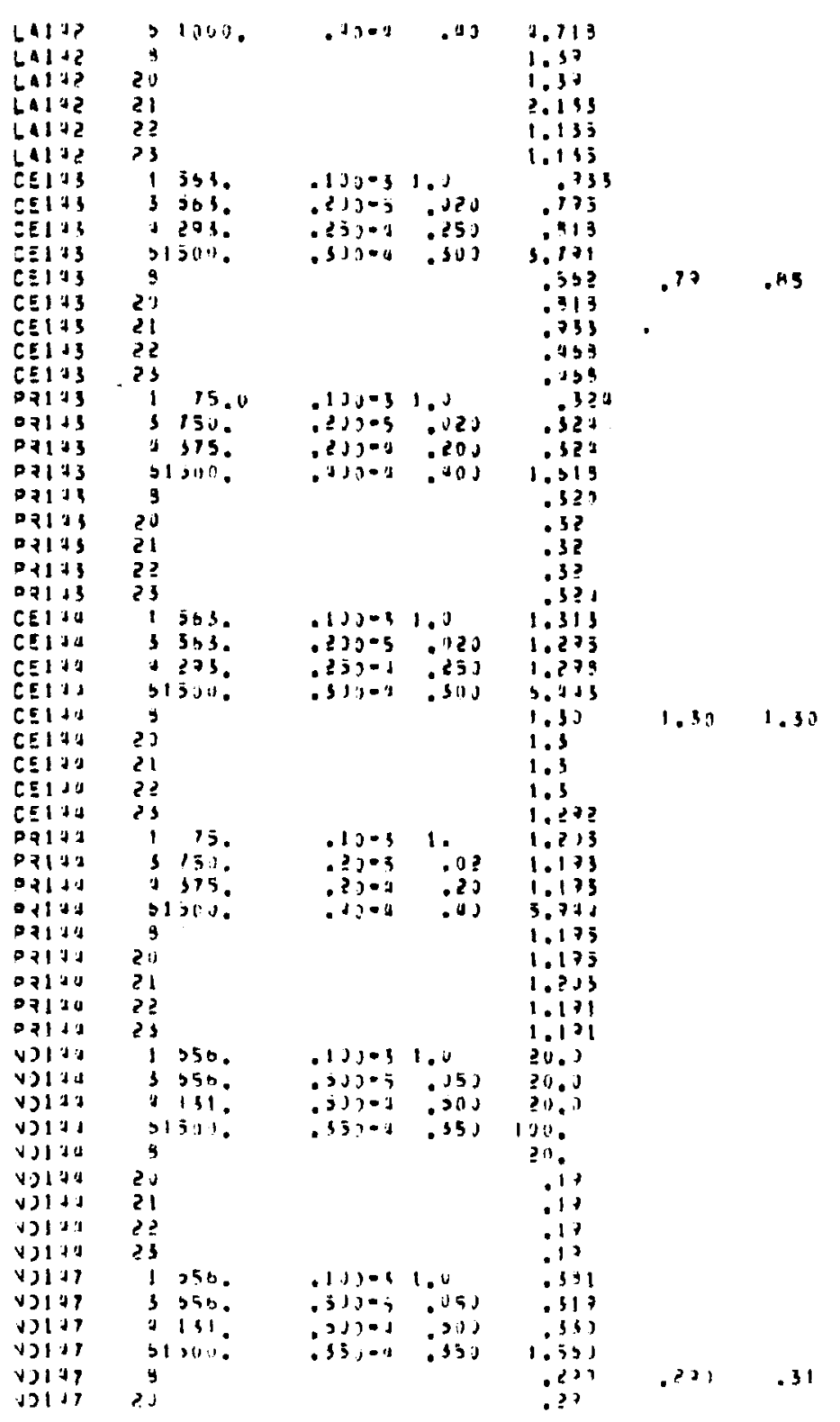




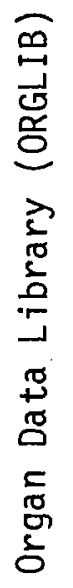

$\stackrel{?}{\sim}$

$\stackrel{2}{?}$

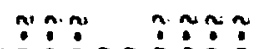

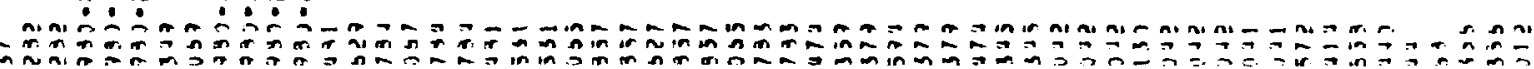

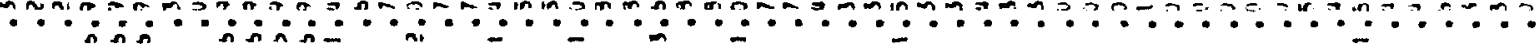

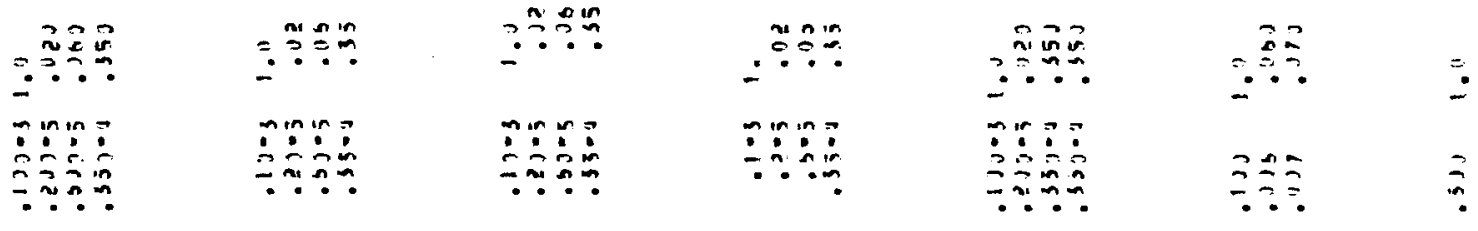

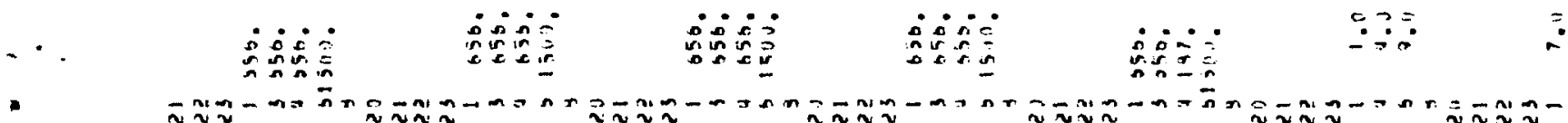


2. Organ Data Library (ORGLIB)

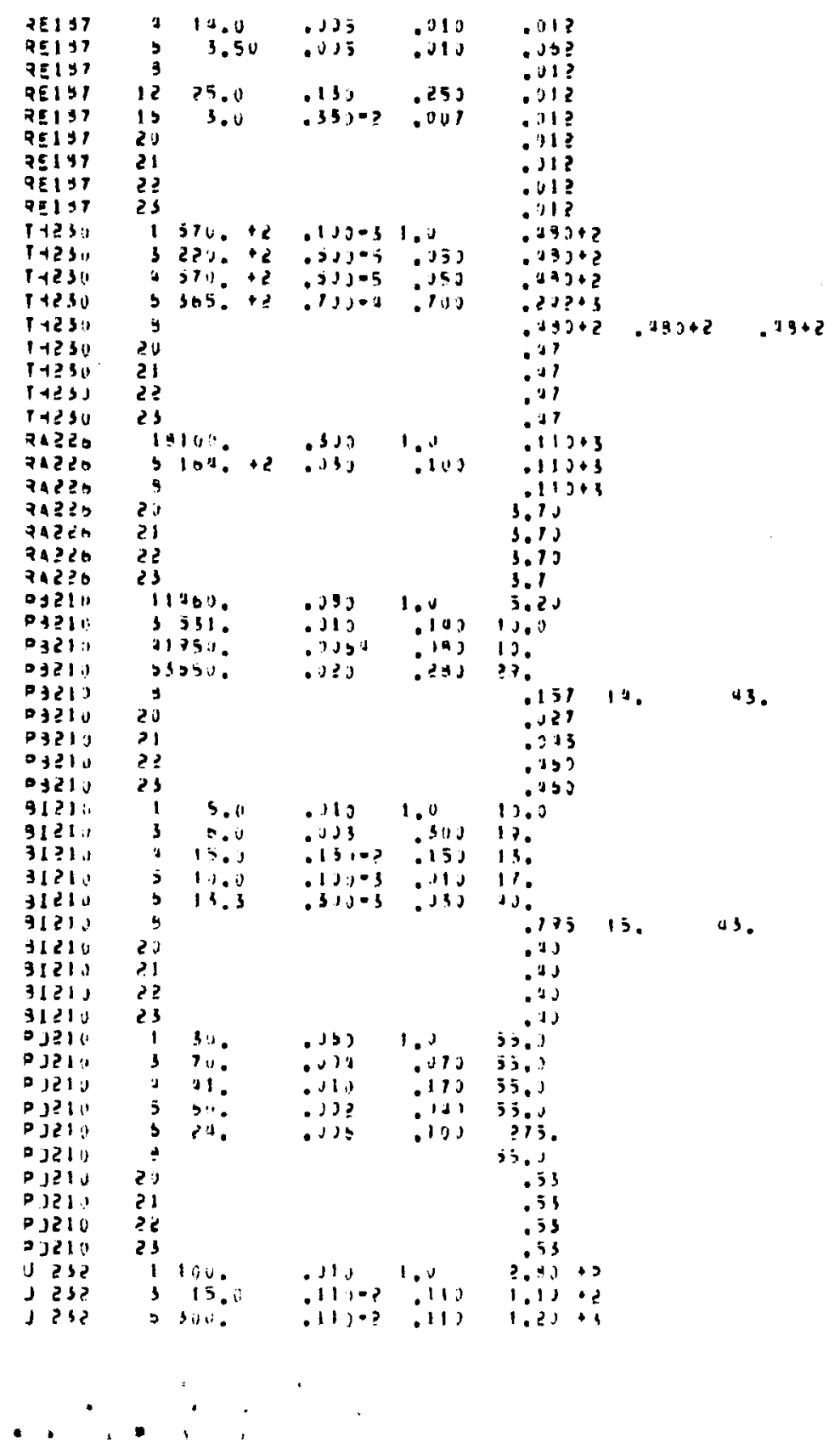



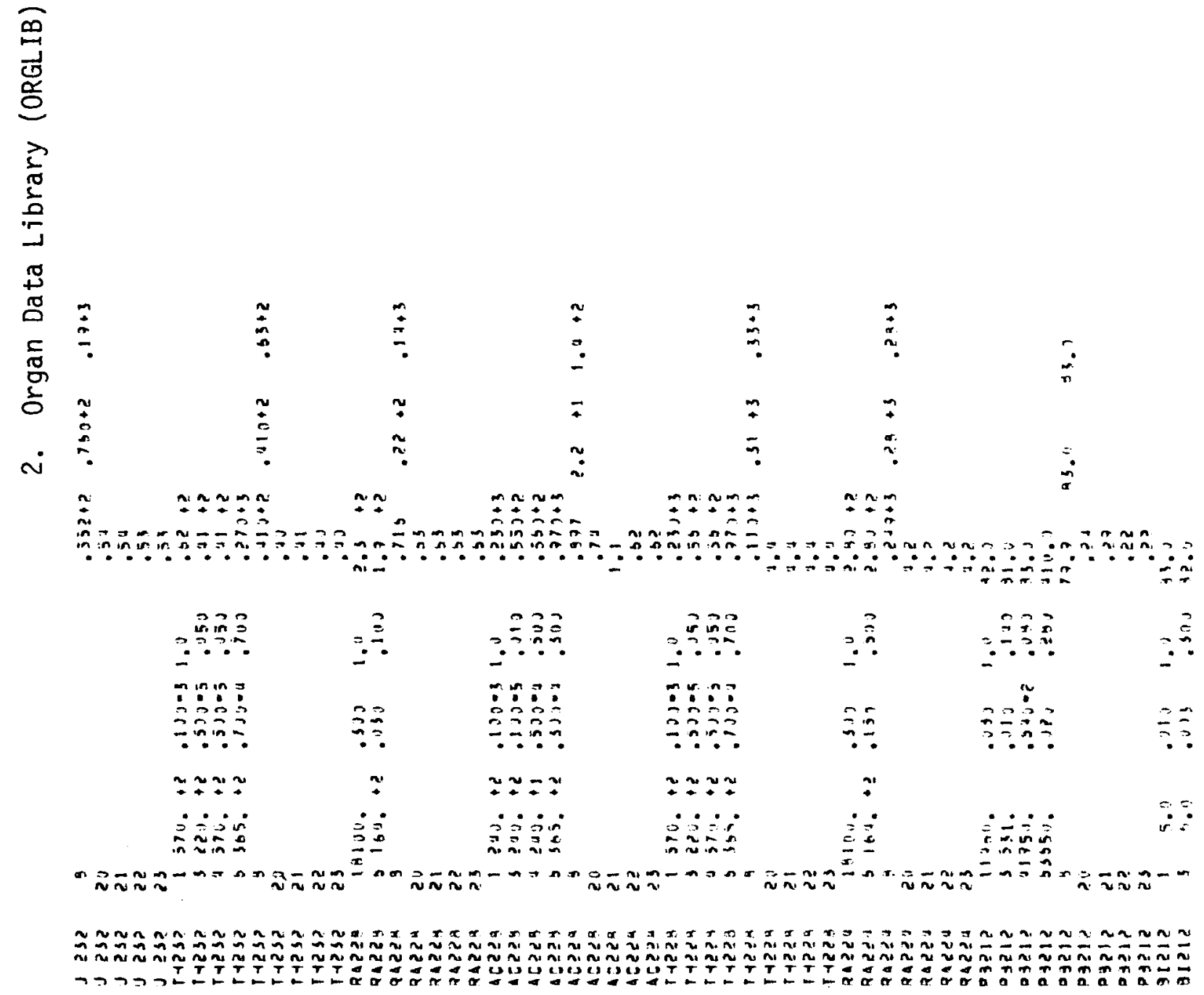


\section{Organ Data Library (ORGLIB)}

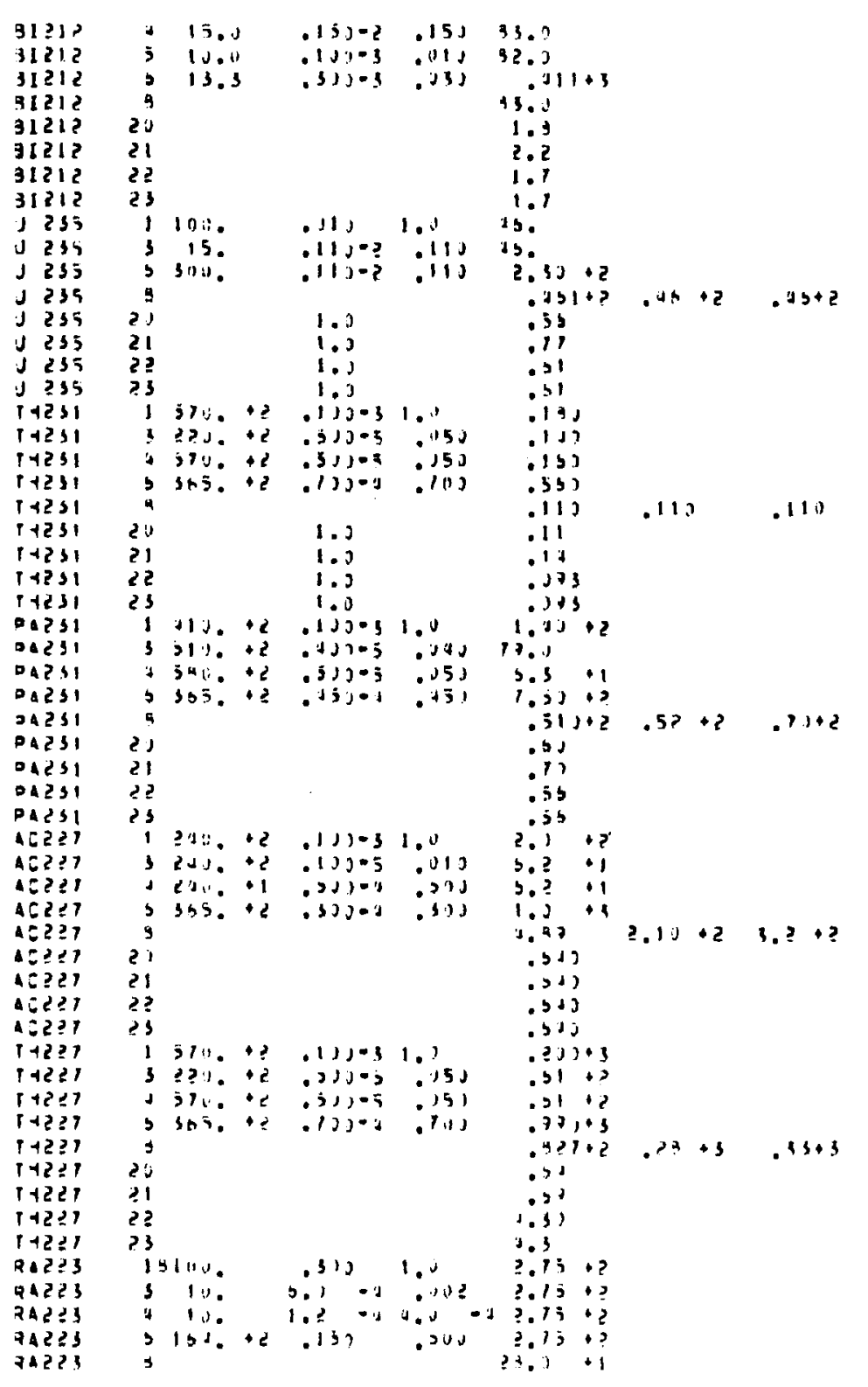


2. Organ Data Library (ORGLIB)

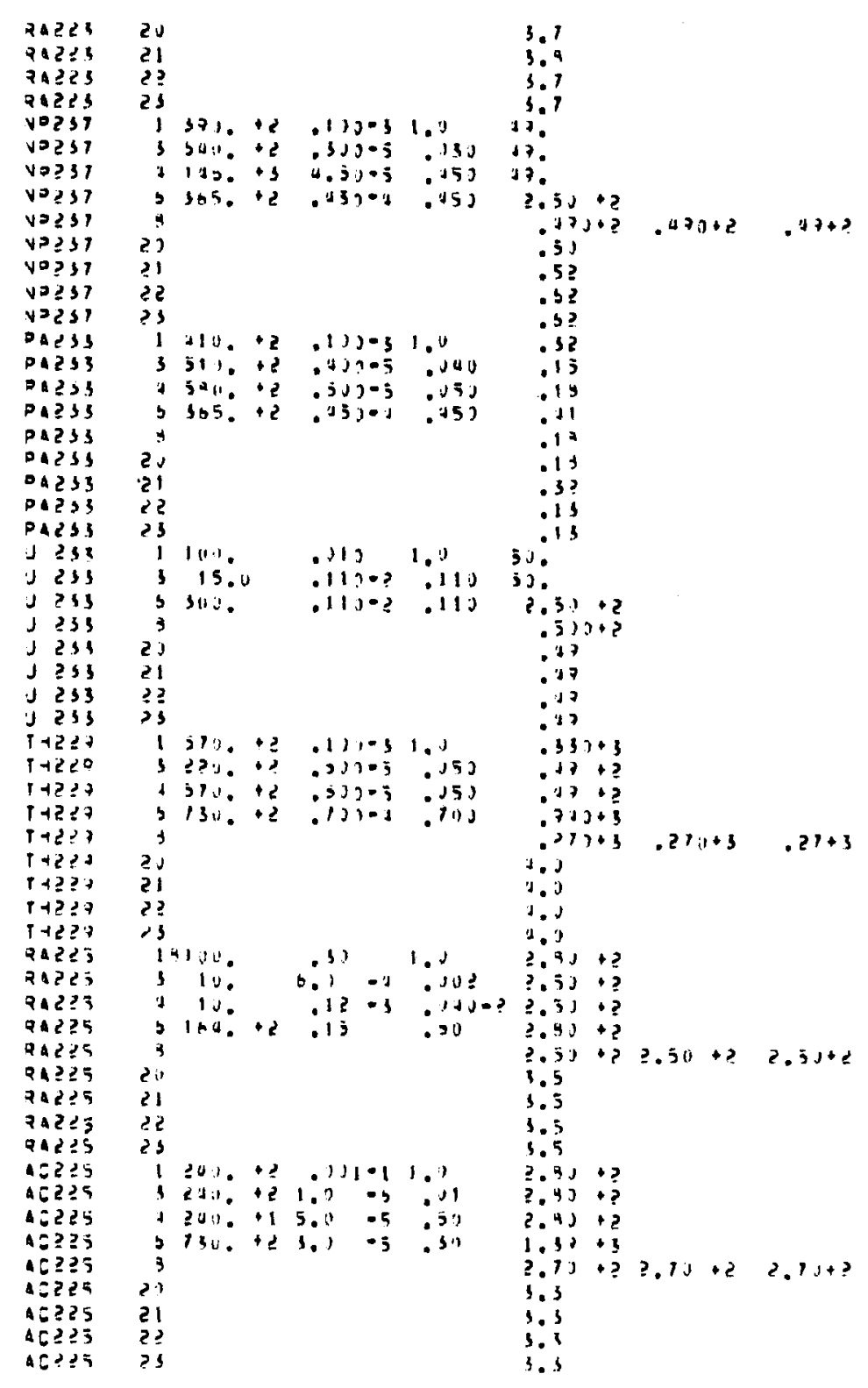




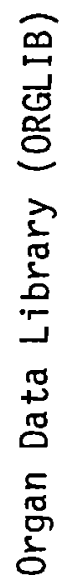

i
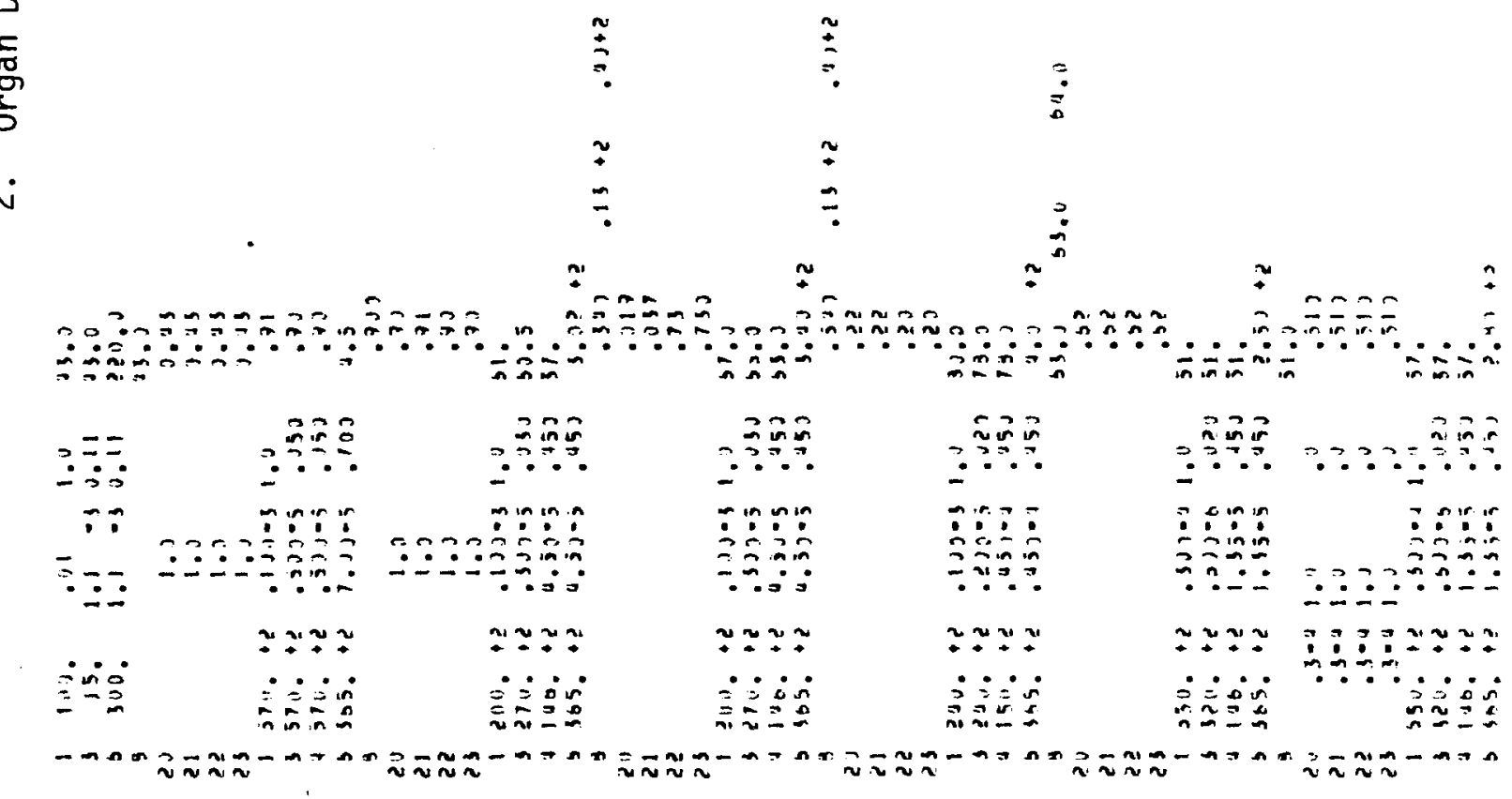

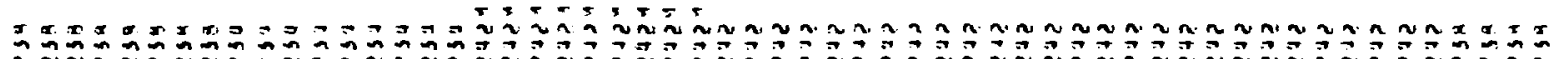

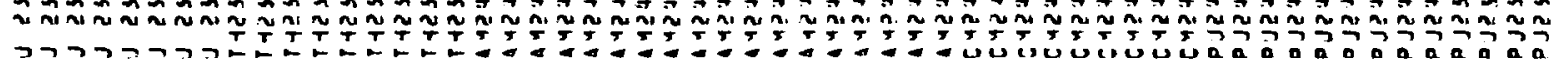


2. Organ Data Library (ORGLIB)

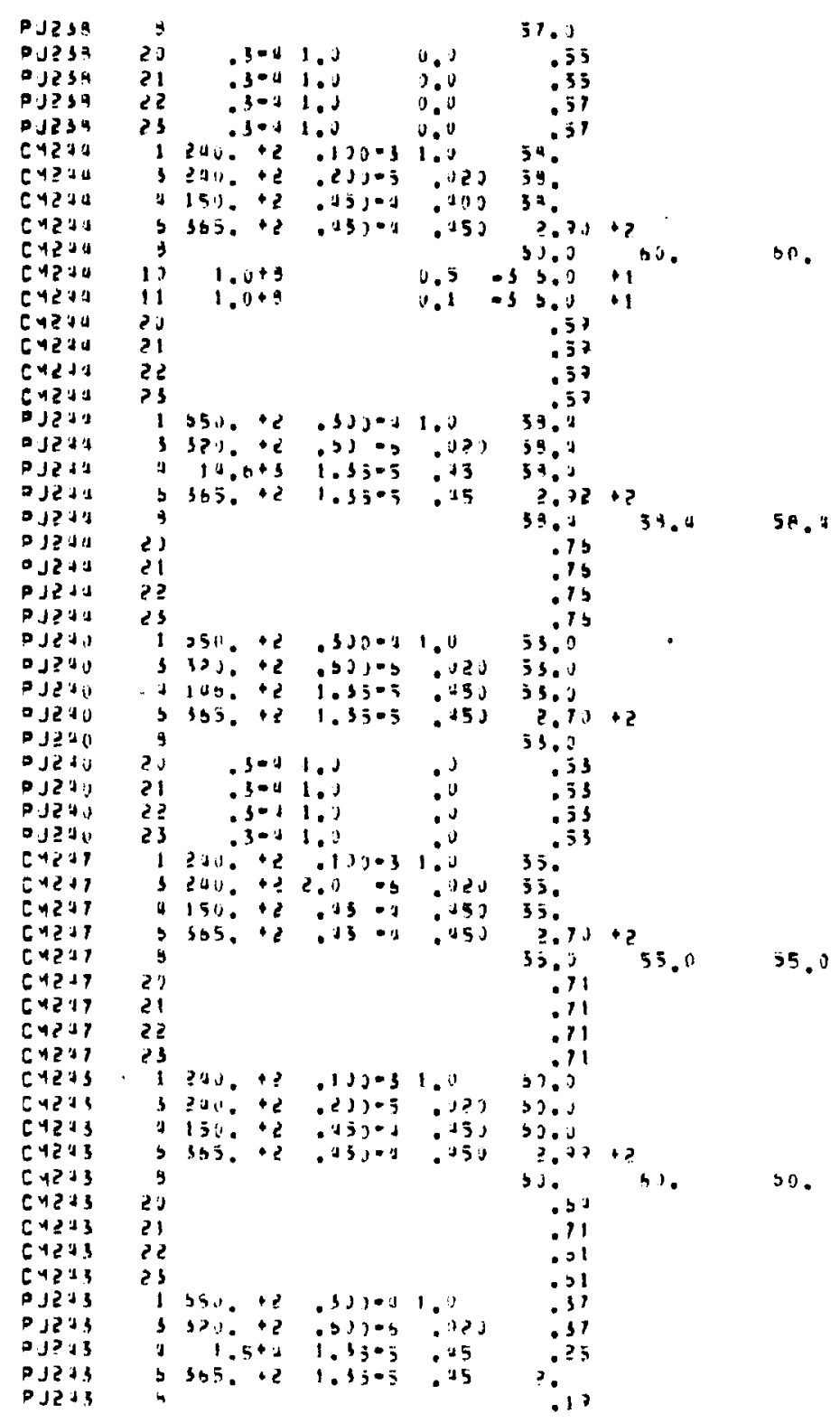




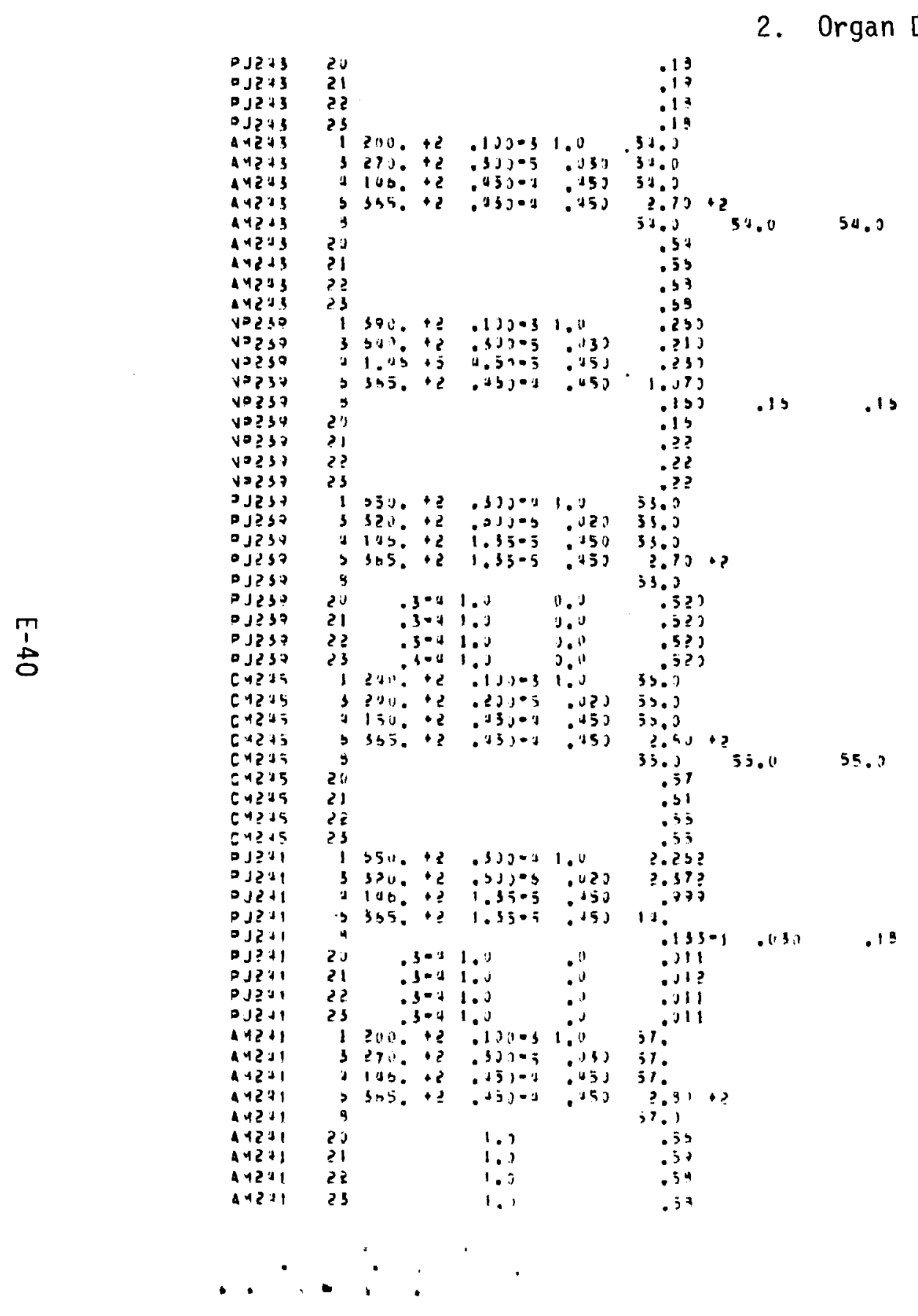




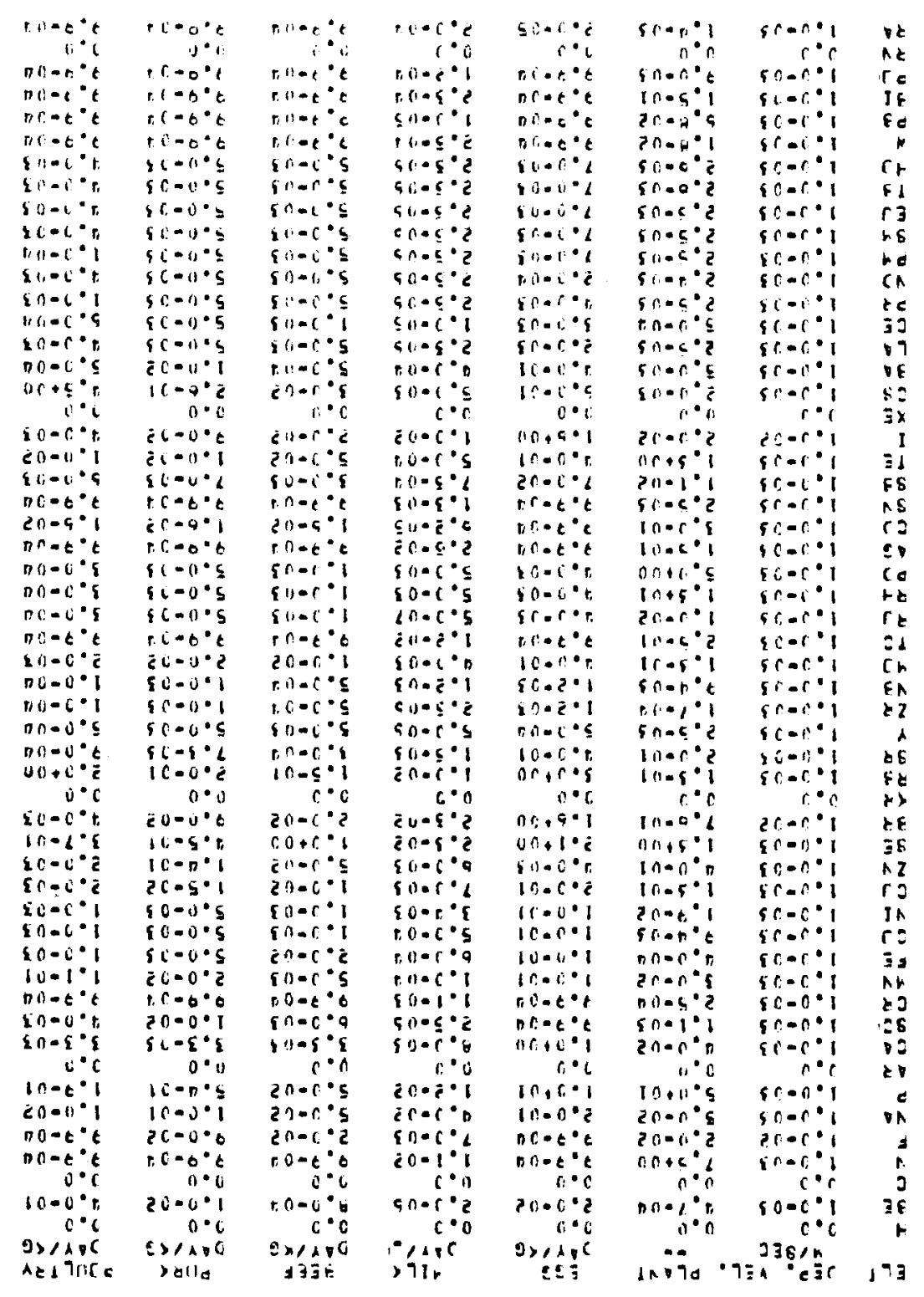


3. Food Transfer Coefficient (FTRANSLIB)

\begin{tabular}{|c|c|c|c|c|c|c|c|}
\hline A: & $1.0=33$ & $2.3-03$ & $? \cdot 1+03$ & $2.5=00$ & $5.1-1,3$ & $1.11-0 ?$ & $7 . .7=03$ \\
\hline $1+$ & $1.0-13$ & $1.2-: 33$ & $3.0 \cdot 03$ & ?.5010 & $9 . J-113$ & $1.9-3 ?$ & $4.0-13$ \\
\hline 1 & $1.0 \cdot 03$ & 2.5003 & 3.0 .03 & 2.5.us & $5.1-03$ & $1 \cdot 0-1) ?$ & $4.0-03$ \\
\hline$J$ & $1.0=03$ & $2.5-03$ & $3.2=(11)$ & $0.3 \cdot 01$ & 5. $1=05$ & 3.10 .31 & $1.2-03$ \\
\hline vo & 1.2003 & 2.5 .03 & $? .11=03$ & . 3.05 & $3.3 \bullet 113$ & $1.0-12$ & $1.7-33$ \\
\hline PJ & $1.0=-13$ & $2.5-114$ & ?. & 2.3 .03 & $a=03$ & $1 \cdot 0-0 ?$ & $1.9=03$ \\
\hline 1* & $1.2-33$ & $2.5-0.4$ & $?, 0.03$ & & 5.1003 & $1,11-3 ?$ & $4 . n-113$ \\
\hline 7 & $1,3-33$ & $2,5.113$ & $? \cdot 1 \cdot 0.3$ & $? \cdot 3-0,3$ & $5.7-03$ & $1.0=0 ?$ & $100=03$ \\
\hline CF & $1.2-13$ & $2,5.45$ & $2.0-13$ & 7.3 .01 & $5.0=113$ & $1,(1-2) ?$ & $1.0-.13$ \\
\hline
\end{tabular}




\section{Bioaccumulation (BIOAC)}

\begin{tabular}{|c|c|c|c|c|c|c|c|c|c|}
\hline$\varepsilon_{L}$ & IT $=13 \mathrm{~m}$ & $\begin{array}{l}\text { ALI HIEL } \\
C Q U S .\end{array}$ & 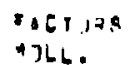 & & 194 & CRUS. & $M_{L} L_{1}$ & & \\
\hline+ & 1.0 & i.u & i. 0 & i. 3 & .7 & & & .7 & 1.0 \\
\hline JE & $\begin{array}{r}1100.0 \\
1.0\end{array}$ & 100000 & $170 n \frac{0}{1.0}$ & נ. 1003$\}$ & $\begin{array}{r}2.0 \\
4600.0\end{array}$ & 111.9 & 10.0 & 20.1 & $\therefore$ \\
\hline & ." & .0 & .0 & . J & & & n & Jition & 10 \\
\hline & 4.0 & $\$ .0$ & $\$ .0$ & 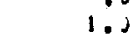 & 10.0 & 10000 & 100.0 & 20 & .9 \\
\hline VA & 1.0 & 1.0 & 1.0 & 1.0 & 100.0 & 2000 & $230 . n$ & 500.3 & \\
\hline & 13300.0 & 10000.0 & 10001.11 & 120,0000 & 100000.0 & 200010,1 & ? 23000.0 & 501000.0 & \\
\hline 42 & 1.2 & 1.0 & 1.0 & 1.1 & 1.1 & $1 . j$ & I.n & 1.0 & \\
\hline ea & 10.0 & 10.0 & 11.0 & 1.0 & 410.1 & 330.0 & 330.0 & 130.0 & \\
\hline 3i & 100.0 & 300.0 & 300.0 & 1030.0 & 2. & 1000.1 & $1000 . n$ & 10000.3 & \\
\hline 62 & 100.0 & (640, & 1003 & $13,3,0$ & $211 . \mathrm{J}$ & 2300.3 & 300,0 & 4 J00.0 & \\
\hline $4 \mathrm{v}$ & 35.00 .0 & 10000.0 & 39000.0 & 1030200 & 400. & outun. & דingn: & 10100.0 & \\
\hline$F E$ & 100000 & Jou.j & 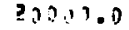 & b.) 10.0 & 1310.0 & 3200.1 & 3210.0 & 1000.0 & \\
\hline CJ & i Jo. i & 100000.0 & (1) J.0 & 130.0 & 50.0 & 201.3 & 300.0 & 200,0 & \\
\hline VI & 300.0 & 100.0 & 131.0 & 100.0 & 100.0 & $\ln 11.0$ & 100.0 & 53.0 & \\
\hline CJ & 1500.0 & 5000.0 & n. & 1003.0 & 30.0 & 400.0 & 000.0 & 2000,0 & \\
\hline & o Ju. & 5000.0 & $3000) .0$ & (3.3.1 & 50 & 10000.3 & ח. & $2030 n .0$ & \\
\hline BE & 10.0 & 10.0 & $1 ! .1$ & 130.0 & 180.0 & 170.3 & 170.0 & $100 n .0$ & \\
\hline 32 & 3.2 & 11.0 & 11.0 & 123.0 & a? 0 & 330.0 & 331.0 & 50.3 & \\
\hline$x$ & 1.0 & 1.0 & 1.0 & 1.0 & 1.1 & $1 . J$ & 1.0 & 1. & \\
\hline 75 & 30.7 & SU. & 11.0 & 1,0 & 2000.0 & 100.0 .3 & 1000.01 & $\ln 00.0$ & \\
\hline 32 & 1.0 & 1.0 & 1.0 & ?נ. J & 30.0 & 100.0 & 100.0 & $\sin 0.0$ & \\
\hline & $30 . J$ & 100.0 & 100.0 & $30 \mathrm{J.V}$ & 25.0 & I Uno.s & 1000.0 & $500 n .0$ & \\
\hline 27 & 30.0 & 100.0 & $10 \% .0$ & $(i, J 0.0$ & 3.3 & 6.7 & 5.7 & 1000.0 & \\
\hline$\sqrt{3}$ & 100.0 & 2uv.u & $? 03.0$ & 100.0 & 30000.0 & 100.0 & $\ln 0.0$ & Q0.0.0 & \\
\hline 4J & 10.0 & $1 \mathrm{OJ} . \mathrm{J}$ & 103.0 & 100.0 & 10.1 & 10.0 & 10.0 & lonn. & \\
\hline$T:$ & 10.0 & 100.0 & 100.0 & 160300 & 15.3 & 5.3 & 5.0 & 20.0 & \\
\hline ₹J & 3.0 & 100.0 & 101.0 & o & 10.0 & 300.2 & $3 \cap 0.0$ & 2900.0 & \\
\hline R- & 16.0 & iJu. & 101.0 & 131,0 & $10 . \mathrm{J}$ & 301.9 & $300 . n$ & Por. & \\
\hline & 11100 & 100.0 & 10100 & 103.0 & 10.2 & 300.0 & 100.0 & 200.0 & \\
\hline 43 & 1000.0 & 5010.0 & 3000.0 & 1020.0 & 2.3 & 770.0 & 770.0 & 200.3 & \\
\hline CJ & 100.0 & 30100.0 & 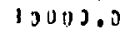 & 10003.0 & $2 \mathrm{Jj} .3$ & 3000.0 & $2003 . n$ & 1900. & \\
\hline & 3.: & 3.0 & 3.0 & 13.0 & 30411.0 & 000.3 & 1000.0 & 100. & \\
\hline 93 & 1300.0 & 100000 & $109: 0$ & ט. & 1.0 & 10.3 & 10.0 & 1500.3 & \\
\hline TE & 10.0 & 10.0 & 101.0 & 1000.0 & 490.3 & 75.3 & 75.7 & 100. & \\
\hline 1 & 20. .19 & 103.0 & 1.3 .11 & כ. בנננט & $15 . \mathrm{J}$ & 5.3 & 3.0 & w1. & \\
\hline$x E$ & 1.0 & 1.0 & 1.0 & 1.0 & 1.0 & $1 . j$ & 1.0 & 1.7 & \\
\hline 63 & 30.0 & 53.0 & $1 \%$ & 10.0 & 030.0 & 100.0 & $130 . n$ & 500. & \\
\hline 34 & 3.0 & S. 0 & 3.0 & 130.0 & 4. & 00.0 & 200.0 & 500.1 & \\
\hline 64 & 30.0 & 100.0 & 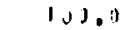 & 10.0 & 25.4 & נו & $\ln 000$ & 5000.8 & \\
\hline cE & $3 v .0$ & $(11) .8$ & 1.12 .0 & ננ.נ & 1.2 & & 1000.11 & $\omega_{0}$ & \\
\hline ?२ & 100.3 & 10000 & 13020 & $1,13.7$ & 25.1 & $\operatorname{linu.j}$ & $\ln 00.0$ & 5 anc. & \\
\hline v) & 130.1 & 110.0 & 1.01 .11 & 1) 110 & $\geq 5.0$ & 1000.0 & $(900.1)$ & i. & \\
\hline 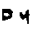 & 150.1 & 10.000 & 1000.11 & 103 & 25 & & ח. חט 10 & 7. & \\
\hline 34 & 100.0 & $1(1) 0.0$ & (1): $)$. & (1) J J & $\geq 5.0$ & , & $10,0.0$ & $5 n$ & \\
\hline EJ & & 1) 100 & & & 25.0 & & & 50 & \\
\hline 13 & i.j & 1.0 & i) 1.0 & & & & 1030.0 & $3.100 . \mathrm{J}$ & \\
\hline+1 & 100.0 & 100000 & 1091.0 & 1111.0 & $25 . \mathrm{J}$ & ljon. & 1200.11 & 5900.9 & \\
\hline & 10.0 & 13.0 & 12.0 & $1) .0$ & $(? 3), 1$ & 11.2 & $10 . n$ & 1500. & \\
\hline$p_{3}$ & 300.3 & 10000 & 1001.0 & 5.20 .1 .10 & 120.0 & $10 \%$, & 1.30 .0 & 2.0 .0 & \\
\hline$A I$ & 15.0 & 100000 & iosion & $1037 .$. & 15.1 & In. & $10 . n$ & 1500.0 & \\
\hline & 30.0 & 340.0 & 5000.0 & 2000.0 & $57 \cdots, 0$ & 211:010. & 23010.401 & $\operatorname{egn} n . x$ & \\
\hline av & 1.0 & 1. & 1.0 & 1. & 57.1 & 1.1 & $1 . n$ & 1.0 & \\
\hline Q4 & 50.0 & $(1) .0$ & 101.0 & 13300 & 50.1 & , , & 250.0 & $2 \sin 0.1$ & \\
\hline $4 E$ & 25.11 & $1(1 ; 1,0,1$ & 100300 & ים, & $25 . \mathrm{J}$ & (1, & 1930.19 & 31) & \\
\hline
\end{tabular}




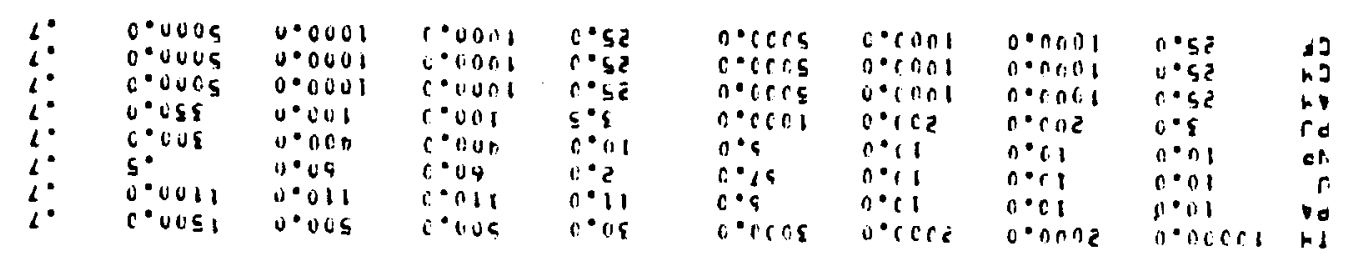

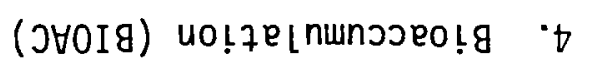


5. External Dose Factors (GRDFLIB)

\begin{tabular}{|c|c|c|c|c|c|c|}
\hline $\begin{array}{l}-1 \\
3\end{array} 510$ & $\begin{array}{l}-0 E+q u \\
0 E+0 u\end{array}$ & 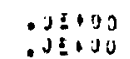 & 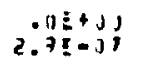 & 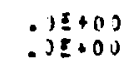 & $\begin{array}{l}O E+i 0 \\
? D E+W 0\end{array}$ & 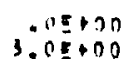 \\
\hline & & & $3.95-10$ & .JE०00 & $1: 4 E-11$ & $3.5-0 ?$ \\
\hline 13 & $3.4 t \in 01$ & 7. & 2.6E-Us & $1.3 \varepsilon-n b$ & $5 E-v^{2}$ & $1.48=00$ \\
\hline is & $9.0 E=04$ & 5.41 .07 & $2.35-00$ & $1.95-03$ & .2E-ग & $1.1 \bar{E} .0 \mathrm{~b}$ \\
\hline Vu?? & . $95 \cdot 18$ & 1.05009 & $4.9 \equiv-2,5$ & & $.9 E=U t$ & $2.3 E-06$ \\
\hline 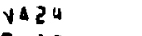 & $? . O E=118$ & $2,35=019$ & 7,3 & 7.9 & $3.5 E=16$ & J. $5=11 \mathrm{~h}$ \\
\hline a s? & $.35+40$ & $.3 \geq 000$ & $b, 95)$, & B. AE - & $3 . M E-U Q$ & $5.28-07$ \\
\hline$\Rightarrow 33$ & . $O E \bullet(B)$ & . $150+03$ & $2.2 \equiv-19$ & $7.7 \leq-11$ & $4 B E=11$ & $\geq 0=0$ \\
\hline 425 & . IE $+U .1$ & . $0 \vdots 000$ & 1.50 .17 & $3 . \geq-10$ & $3.35-10$ & $1 . \geq 0$ \\
\hline परगा & $0.0(0)$ & $.05+30$ & $3.25-03$ & $? .45$. & $1.16 \cdot 00$ & $1.0 E-n b$ \\
\hline $64+1$ & A. OE-UD & 3.4007 & A. $5 \div-01$ & 7.3 & ?.3e+un & $3.08+00$ \\
\hline $9=23$ & $1.5 E-14 \%$ & $1, S 5-39$ & ט. & 3.7 & $1.1 E-u_{n}$ & $R, n g-n b$ \\
\hline 231 & A AE & $2, \geq \vdots-10$ & $6.45=0.3$ & 3.? & Z. JE= IIA & $2.7 E-119$ \\
\hline V5d & $3.9 E=0.0$ & $5.55-47$ & $1.4 E-J b$ & 1.5 & $=07$ & 9.18007 \\
\hline 4 453 & $1.3 E=0.9$ & 1.15 .19 & $0.05=0 \%$ & & & $3.4 \xi 0 \mathrm{~b}$ \\
\hline Eミ5j & & .110 & $3, n-10$ & 3.3 & $3.5 E=11$ & $1.05-07$ \\
\hline rミ5t & D.ME & $5.1: 0$ & $2.6 \vdots$ & ?.? & & 1.2505 \\
\hline$=351$ & $1.1 .1 E$. & $+1=$ & $? .1$ & & & \\
\hline & 9.26 & $1.75-17$ & $2.15-u b$ & & & $1.18-0 b$ \\
\hline : 100 & $2,0 \mathrm{c}-(1)$ & 1.15 .61 & 5.4 & 3.3 & & 2.58 \\
\hline VIST & $.3 E+(1)$ & . $0 \vdots$ & $3.45-313$ & 2.3 & & on \\
\hline VIbs & & & & & & \\
\hline VIsj & J.SE-JP & 4.15 .07 & $1.7 E$ & 1.3 & $\triangle . A E$ & 1.18 \\
\hline C J J & 1. TE.0. & $1,5 \vdots-0$, & $5 . ?$ & & & \\
\hline ivss & $2.5 E$ & $4.0 三$ & & 1.1 & & 5.50107 \\
\hline 3517 & JEA & . & 3.23 & 3.1 & 16 & $3.35=05$ \\
\hline 374? & ?.? $\{-1) d$ & $1.1 \%=$ & 0.35 & 5.3 & ve & \\
\hline 92y54 & & $0.0 三$ & & & -69 & $2.75=07$ \\
\hline 324J & 1.21 & $1.2 \vdots$. & 5.3 & 3.5 & $1.5 E-1.0$ & $1.0 \overline{5}-0 b$ \\
\hline 7535 & T.2k. & $0,1 \equiv 0$ & $9.5 \equiv$ & & & \\
\hline & $1.4 \mathrm{E}$ & 1.350 & & 9.5 & & (i) 3 \\
\hline $92+7+2$ & $0.5 c-15$ & 5.950 & $5.45=$ & J. & 2.18 & 1.78 \\
\hline 3२7००2 & & . & 1.5 & 3.1 & & 1.3 \\
\hline & & $7.1 \equiv$ & & & & \\
\hline $927 ?+2$ & 1.16 & $+.0=$ & 3.15 & 2.3 & $1.1 E=U t$ & $1.35 \cdot 30$ \\
\hline$y+1 * 1)$ & \pm .48 & 3.350 & 1.2 & & & \\
\hline 227 & & .1 & & & & $1.5 E-05$ \\
\hline & 5.4 & 5.01. & 1.2 & & 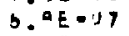 & $3.0=09$ \\
\hline 277 & 0.48 & 5.55 & 2.1 & 1.5 & 7 & $1.08-06$ \\
\hline 137 & 0.35 & 2. 15 & 2.9 & $1 . ?$ & 2. OE & S. $\quad$ I on 0 \\
\hline & & & & & & 3.93 \\
\hline$i=1$ & 3.31 & $? .1 \vdots=$ & 1.? & 3,3 & & \\
\hline & & $3.3 \vdots$ & & & & \\
\hline & 5.1 & $1.5 \vdots$ & $1.4 \vdots$ & & & $1.050 \mathrm{~b}$ \\
\hline & 1.9 & $1.5 \vdots$ & 1.7 & 1.9 & & \\
\hline & & & & & & \\
\hline $4311 ; 1+2$ & $2.15=$ & 1.4. & 5.3 & $\triangle 7 E$ & & $\therefore 0$ \\
\hline & $2.15=10$ & $1 . \pm \equiv-1)$ & 3.9 & 3.35 & 2.25 & 3. \\
\hline & e.bE. & $2,3 \equiv-1$ & $1.15-$ & $5.7 !$ & & 1.45 \\
\hline & $5.5 t=0 t$ & & $5.3 E-17$ & & & \\
\hline $3 \times 123+3$ & S. SE - 11 & $3.1 \leq-1 \mathrm{~J}$ & 1.150 .16 & $1.3 E$ & TSE & \\
\hline$S \times 1 ?$ ? & $1.0 t=3 x$ & $7,0:-$ & $6.05-0$, & & & \\
\hline $9+1 ? 4$ & $1,5 E-101$ & $1.35 . .24$ & נ. $5:-102$ & G, SE. & & \\
\hline $931 \geq 54$ & $3.5 t-6 t$ & $3.1 \equiv \cdot 07$ & $7.5 \equiv-3)$ & $1.35=111$ & 3. . EE $=U 7$ & $1.5 E-117$ \\
\hline$(\equiv 1274+)$ & $1.3 E-1 ?$ & $1,15-12$ & $1.55-10$ & $2.35-13$ & $1.25=1 n$ & $1.3 \equiv-17$ \\
\hline
\end{tabular}


5. External Dose Factors (GRDFLIB)

\begin{tabular}{|c|c|c|c|c|c|c|}
\hline$T E \mid \geq \cap 4\}$, & $7.05-10$ & 15.10 & $7.45 \cdot u 1$ & $2 .|\varepsilon-n|$ & $P, J E=J B$ & $5,1=-01$ \\
\hline$\left.\left.|E| 3\right|^{4}+\right)$ & P. $J E-114$ & 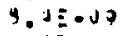 & 2.15-19, & ט & $1.0 E \cdot u n$ & $1.35-05$ \\
\hline Fis & DE & $2.25-17$ & $1.0 E-0 s$ & I. & $1, \triangle E=1) 7$ & $1.1 E \cdot c s$ \\
\hline $\mid E(s ?+)$ & 2. JE-OI & & $4.9 \vdots-11$ & J. JE-0I & I. $A E \cdot U 7$ & $2.35=07$ \\
\hline PE(33xt) & I. IE.UA & $1.5 \equiv .03$ & $5.05 .0 \mathrm{~S}$ & $3.7 E=05$ & $1 . A E-U_{6}$ & 政 \\
\hline $\begin{array}{l}\text { iso } \\
131+3\end{array}$ & $\begin{array}{l}1.7 E-115 \\
3.0 E-1)^{4}\end{array}$ & $\begin{array}{l}1.28-74 \\
5,45-1,3\end{array}$ & $\begin{array}{l}4.95-0\} \\
0.3 \leq-01\end{array}$ & $\begin{array}{l}3.75-04 \\
9.95-1)\end{array}$ & $\begin{array}{l}98-16 \\
3,1 E-197\end{array}$ & $\begin{array}{c}3000 \\
3,90-0)\end{array}$ \\
\hline $1(35+3$ & $1 . \triangle E=0$. & 1.25 .19 & a.jI-us & $3 . S E-n S$ & $1.5 E-06$ & 2.000 \\
\hline & $1 . T E-V O$ & & 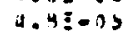 & $4.1 E-0 \mathrm{~s}$ & $Q E=-16$ & $2 . \geq 805$ \\
\hline & J. $.7 E-u t$ & :.47 & 1. JE-J & & $\therefore J E=O Y$ & $1,05-11$ \\
\hline & $1.2 E$ OU & -17 & & & & $18-0 \mathrm{~s}$ \\
\hline $341+10+3$ & (2.JE & 2.10 .07 & $1.65-31$ & $90-7=01$ & ग? ?E-U & $\begin{array}{l}30-05 \\
\text { y }\end{array}$ \\
\hline CEI: & $2.5 t \cdot t)$ & $5.5:-70$ & I. & $3.18-01$ & $2, A E=J 7$ & 3.35007 \\
\hline & & $2 \vdots-10$ & ט & 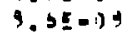 & $A, 1) E-\cup B$ & 1. $2 E=0$ S \\
\hline 124 & $5 .>E=64$ & I.JE & D. I.5E & $3.15-05$ & $2.0 E+\cup 0$ & 3. $\bar{E}+00$ \\
\hline 0 प1 के & $2.75-11$ & $2.3 \pm=11$ & $1.5 \equiv-117$ & $1.55-01$ & $\rightarrow, D E=\| ?$ & $3.18-01$ \\
\hline 94153 & 3. $1 E-11$ & $-1 j$ & ? & $3,5 \equiv-09$ & $3, J E=0$ & ד) \\
\hline EJIS? & $9.5 E=n d$ & 1. & $2.1 \equiv-1) 0$ & $1.3 E-03$ & $1.3 E=05$ & $3.5 \leq-04$ \\
\hline$E \mathrm{Jl}>\mathrm{u}$ & $9.1 t=04$ & $1.5 \equiv .07$ & 3. & 2 & $\because 65-1 ; 5$ & נימנ \\
\hline & 'J $3 t=10$ & $3 .+5.10$ & $1.15-11$ & & & 3.b \\
\hline EN135 & $9,1 \leq-1: 0$ & 1.05.17 & S.AE & $2.15-0 \mathrm{~s}$ & $\rightarrow . A E=U Y$ & 1.5500 \\
\hline Tisu & $1 . t, E=0 B$ & $y_{0}, 5 \leq \cdot 17$ & ? & 2.43 & $\because O E+O O$ & $3.0 ?+113$ \\
\hline A J 50 A & $1 . .1 k$ & 3.100 .07 & 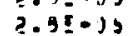 & ?.AE. & & $3.08+n 1$ \\
\hline 14 & R. FE-1L & ट.। $13 \cdot 12$ & $6.35-1\}$ & 535. & $250-10$ & $1.2=10$ \\
\hline$\wedge 155$ & -uetju & 西, & 1.95-0. & $3.2 E-10$ & $1: \triangle E-10$ & i.? \\
\hline (2) & 1. TE-11 & $1.5=-11$ & $3.5 \equiv=01$ & $3.35=$ & TE-UQ & \\
\hline उदाधी: & .ne+uo & 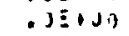 & $3.55-37$ & $2.15-72$ & $1.3 E=110$ & $3.3 E-01$ \\
\hline จห???+) & $1.5 E-11$. & $1,3 \equiv .04$ & $5.0 E-i)$ & $3 . \geq E-1\}$ & I. SE-UG & 2.75000 \\
\hline & $1 . a_{E}=(t) t$ & $1,3 \equiv-$ & $1.3 \Sigma-0 s$ & & & $3.0 \mathrm{~s}+0$, \\
\hline $942+40$ & $1 ..) E-14$ & $\$ .1 E .07$ & $3.5 E-v$ & 2.3g-Jo & ?. UE + UO & 3, anton \\
\hline Q४??3+3 & 1 . $E E-10$ & $9.1 \equiv$ & $0.35-1,3$ & $1.7 \mathrm{E}=$ & ?. nE + Un & $3.18+00$ \\
\hline$a 4 ? ? b+3$ & $1.5 \mathrm{E}$ & $1,5 E .19$ & $5.08 \cdot 115$ & 3.3 & & $2.98-14$ \\
\hline & $1.4 E=18$ & $1 . \geq \geq-45$ & A. & 3.150 & ? nE & $3.00+00$ \\
\hline $1=2 ? 7+3$ & ?. QE०UT & 2.0507 & $0.350,1$ & I. JE- 77 & COE UO & 3. \\
\hline $1+2 \geq 1+3$ & b. If-li & 5.1 & $1.0 \leq-01$ & & & $3.0+01$ \\
\hline & & & ל ניט-5E & & & $3.0+0$ \\
\hline $1+231, \ldots$ & $1 . n E-10$ & $1,5 \vdots .1 ?$ & 4.4500 & $1.2 E-07$ & $5.5 E-10$ & $1.98 \cdot 07$ \\
\hline $1+232+3$ & & $3 . J \equiv .17$ & 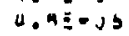 & 3.4 & & $5.15+00$ \\
\hline 0 a $33 i+3$ & ?.1E-Ut & $2 . ?$ & $1.15-111$ & 5.7 & 10 & $3.15=00$ \\
\hline$j ? 3 x+3$ & ZIE-II & 2.0 & $1.1: 07$ & $\therefore 5=-10$ & $E=10$ & $4.95-13$ \\
\hline $2,3+3$ & $7.5 \mathrm{E}$ & & $2.0[0,1$ & & & \\
\hline & & & & 135. & & $33=-07$ \\
\hline J 2354 & 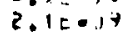 & $1.95-37$ & $3.5=11$ & S. & 0. & $1.78-01$ \\
\hline J esn & $1.3 t=10$ & 2.1E. & $3.1 \equiv-01$ & & & $1.38-07$ \\
\hline & & & & & 4 & $18=0$ \\
\hline & $1.91-04$ & & I. & 3,35007 & $1.4 E-(17$ & I. \\
\hline QJ & $b_{0} A E=1$ ? & 4.0 & & & & $3.28-11$ \\
\hline & $1.5 t-11$ & $-1 ?$ & 3.350 & & & $18-0 ?$ \\
\hline & & & & & 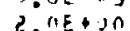 & (1) \\
\hline Cx? & & 0,4 & $4.75-11$ & 3.15. & $\therefore \| t$ & $1.0 \leq 011$ \\
\hline$(152)$ & $7.35-35$ & $5,0 \equiv .14$ & $1.75-05$ & 1.15 & & \\
\hline Evisin & 3. At $\cdots$ & $2,+0.17$ & $1.25=10$ & & 34 & {$\left[\begin{array}{l}-.1 \\
\end{array}\right.$} \\
\hline zyst & & & 2.45 & & $\ln$ & \\
\hline & & & จ.Uอ- & & & \\
\hline 394 & $.05+$ & 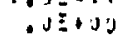 & 1.15 & & 6.7 & 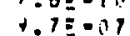 \\
\hline & & & $=-01$ & & & $3.25-01$ \\
\hline & & & $\because 1$ & -03 & a & $1.5 \equiv-(1)$ \\
\hline
\end{tabular}




\section{External Dose Factors (GRDFLIB)}

\begin{tabular}{|c|c|c|c|c|c|c|}
\hline$\{29\}$ & $.0 E+110$ & $.0 \leqq+00$ & $J . b I=U b$ & $2.15-95$ & $1.3 E-U B$ & $2.1 \equiv=06$ \\
\hline จงy & . UE QUU & $. \Delta \Xi+00$ & $2.5 \leq 0.03$ & $1.2 E-10$ & & \\
\hline $29 y$ & $.12 k+0 u$ & $.0 \equiv 1.00$ & $.7 \equiv-J \mathrm{~J}$ & $1.5 E-05$ & $? .1 E=-16$ & $1.7 \bar{s}-n_{b}$ \\
\hline is 5 : & $4.0 \leq-29$ & S. $5 E-77$ & $3.6 \equiv-u b$ & $1 . \geq E-0,5$ & 5. $D E-U 17$ & $2.15-n b$ \\
\hline$\{79\}$ & . UE +uU & $.35+00$ & $6.8 \equiv-05$ & J. $9 E-0 \rightarrow$ & $=06$ & 25015 \\
\hline $37 \mathrm{~J}$ & D $A E+Q y U$ & $.0 \div, 10$ & $1.5 E-07$ & $5 . J E-10$ & $E-10$ & $1.5=07$ \\
\hline $7 \mathrm{~J}$ & $.05-12$ & $2.2 E=12$ & & $1.35-0 a$ & & $3.5=-17$ \\
\hline ji & $.7 t=11$ & $2.1 \pm .11$ & $5.75-41$ & 0.18 & $1 E-09$ & $3.2 \bar{E}-01$ \\
\hline $7 ?$ & $1, J E-B t$ & $1,35.17$ & $2.0 \equiv-i b$ & I. SE. & $E-v^{\prime}$ & $1.5 \equiv 0 \mathrm{~s}$ \\
\hline 39 & $1, H E-10$ & 5.15 .13 & $1.000,3$ & $(175-0)\}$ & & $-n$ \\
\hline valus & $1.01=10$ & $5,29-13$ & (3) & $\geq 2 E-11$ & $7, ? \mathrm{e}-1 ?$ & \\
\hline$v+5$ & $0.3 E \cdot 11^{7}$ & 5.15 .07 & $1.0 \equiv .0 \mathrm{~s}$ & & 3, DE $=17$ & $1.5=-01$ \\
\hline $43 \geqslant 1$ & 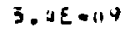 & 9.05 .07 & & & & \\
\hline$T=8+4$ & $1.15 \cdot 04$ & $7.3 \vdots-10$ & $2.75-57$ & $2.3 \equiv$ & $1.1 E=07$ & $1.3=$ \\
\hline re? & $.0 E+9 U$ & 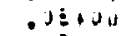 & $2.05-11$ & $1.35-13$ & & 3.4 \\
\hline $7+1$ J5 & $7.75-10$ & $0.3 \vdots-1 \mathrm{~J}$ & 3. $0 E-01$ & 1.1 & & \\
\hline Q J1 10 & $1.4 E=U t$ & $1.55-07$ & $1.75-, 6$ & 3.3 & 17 & 1.5500 \\
\hline $231 \mathrm{~J}=$ & ग. B)E-11 & $5.5 \pm-11$ & (. & 7.3 & $\therefore 3 E=10$ & 3.0 \\
\hline$=2113^{\circ}$ & .) E+01$ & . Jミな」 J & . $13+00$ & חת ה & & \\
\hline$P \leqslant 1254$ & $20 t-11$ & & $1.5 \equiv-09$ & & & $1.1 \mathrm{E}$ \\
\hline gVI? & $1.0 E-1.4$ & $7.0 \sqsubseteq .07$ & $6.015-21$ & $1, A E-n y$ & $1.3 E-U 5$ & 3.5 \\
\hline $3 \pm 1 \geq 0$ & $1.0 E=0 M$ & 9.7 & 3.35 & 2. 4 & & \\
\hline $931 \leq 7$ & $\rightarrow . B C$ & 5.1 & $1.0-19$ & & & \\
\hline$T \equiv 1 \geq 7$ & $1.1=$ & $1,0 \equiv-11$ & $1,7 \leq-51$ & द. $9 E=\cap 7$ & $12 E$ & $1, b E-01$ \\
\hline$T \equiv 1 \geq 2$ & $3.0 \mathrm{E}$ & $7,1=-13$ & $700=07$ & 1.7 & 9.9 & \\
\hline 1127 & 1.5 & 4.5 & $3.3 \pm=05$ & & & \\
\hline$x \equiv 1$ & & & $5.6 \vdots-03$ & $3, ? 5=0$ ? & 3.9 & 3.9 \\
\hline 1152 & z. OE & $1.7=19$ & $5.5 \equiv-15$ & 7. & 2.0 & 2.7 \\
\hline 1133 & $4.55 \cdot y t$ & $3.1 \equiv .07$ & $1.5 \equiv-0 \mathrm{~s}$ & & & \\
\hline & & . UE bila & & & & ग. 0 \\
\hline$x=153$ & $.0 E+0.9$ & 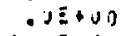 & $1.1 \pm-07$ & 5.1 & $2.5 \mathrm{E}$ & \\
\hline $1 \equiv 130$ & $1.2 E-11$ & 1.05 .00 & $3.5 \leq-177$ & & & \\
\hline & $1.9=-00$ & 1.5509 & $3.5 \Sigma-0\}$ & u. 25 & 2.0 & $2.92-06$ \\
\hline & $1.3 E-11$ & D. $2 \pm .10$ & $1.7 \pm-1 i$ & & & 3.1 \\
\hline Es/5, & 1.UE $=0$ C & 1.25 .09 & $3.5 \equiv-04$ & & & \\
\hline & & $.98+00$ & & & 3.5 & $3.0 E=07$ \\
\hline & & $.0 \vdots 40 \%$ & $7.9 E-07$ & 1. & & .07 \\
\hline Cs1s & $.0 B$. & $. j \equiv+j !$ & 1.150 .13 & & & \\
\hline$x \leq 137$ & & & & & & \\
\hline$=5 \mid 3\}$ & $\triangle .7 E-U 7$ & $1 . ? \vdots 0$ & $1.15-25$ & i. & & 1. $15-01$ \\
\hline$x \leq 13$ & oftiju & & $3.45-03$ & & & \\
\hline$=\$ 131$ & & & & & & \\
\hline & & 2.13 & & 7.1 & 1.7 & 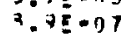 \\
\hline $6=1$ & $1.7 E \cdot 10$ & 1.55 & $5.3 \mathrm{E}=1.9$ & & & \\
\hline & $4 . J E-D 4$ & 1. & 2.05 .05 & & & \\
\hline $641+$ & $2 . D_{E}-11$ & $2.5 \pm-10$ & & & & $3.2=-0$ \\
\hline CEId & 3.?E & 5.j & & & & \\
\hline & & $7.7 \pm 0.12$ & 3.03 & & & \\
\hline & & & & & & \\
\hline & $.0 E$ & & & & & \\
\hline & & & 1. $\Delta$ - & & $\therefore .0$ & \\
\hline & & & & & & \\
\hline vol 17 & $1.2 E$. & & $3.05-47$ & & & \\
\hline & & & $1.3 E-J^{3}$ & & & \\
\hline & & & & & & $1.25-0$ \\
\hline & $2.3 E=? t$ & $2 . ? 0.010$ & H. $4 \equiv=37$ & & & \\
\hline $9 \times 151$ & $2.1\{-1)$ & $1.3 \pm .11$ & $1.75-17$ & ?.SE-11 & 2. $7 \mathrm{E}-\mathrm{Ut}$ & 3. \\
\hline
\end{tabular}


5. Externa1 Dose Factors (GRDFLIB)

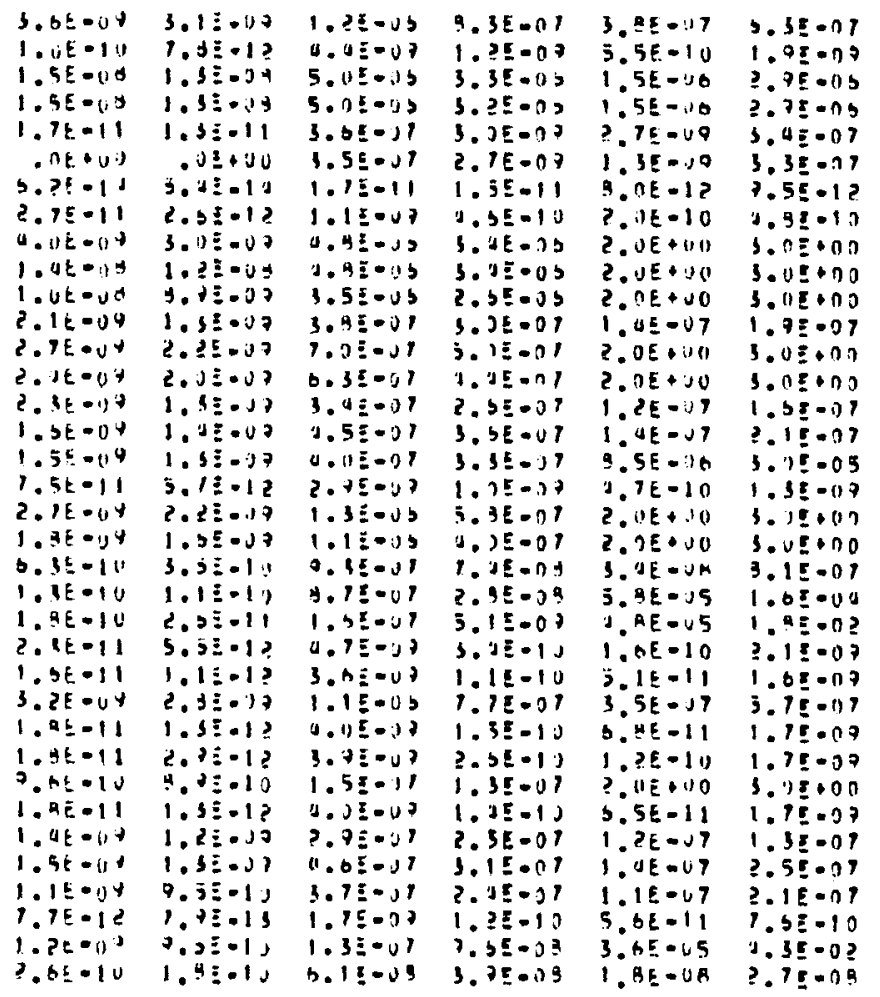




\section{PABLM}

\section{OF TN,SO AA .MAIN}

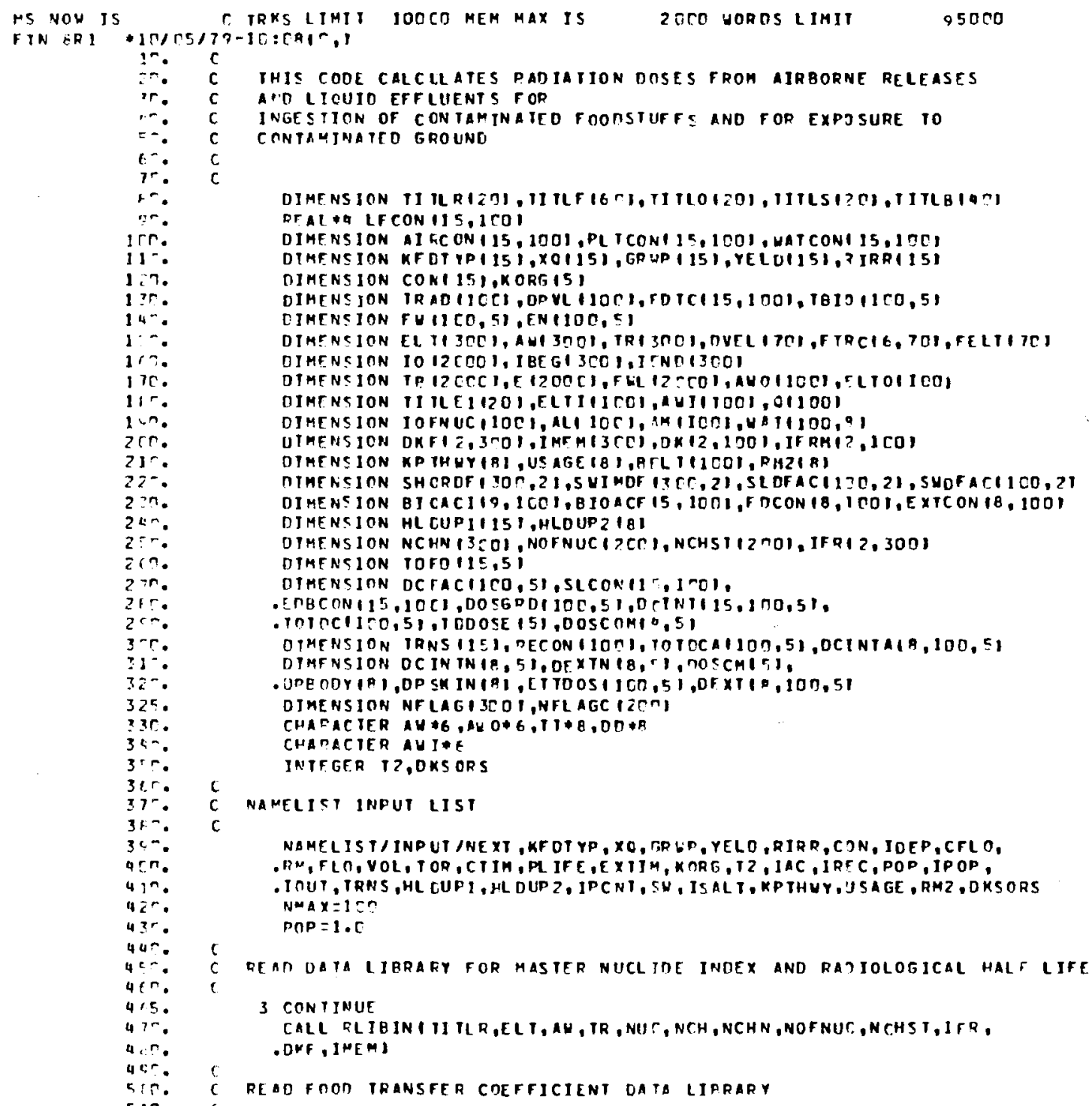

95000

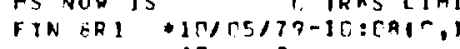

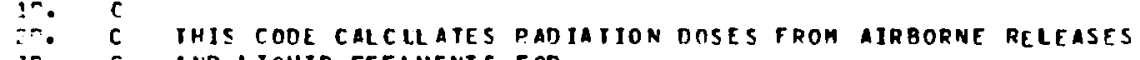

ir. C AO LICUIO EFFLUENTS FOR

..- C INGESTION OF CONTAMINATEO FDONSTUFFS ANO FOR EXPJSURE TO

C CONTALINATCO GROUNO

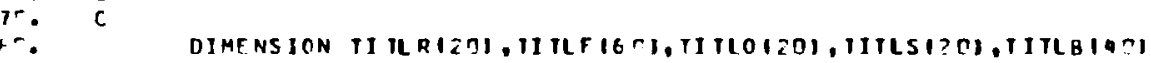
Pr. PTAL LA LCONIIS,ICOI

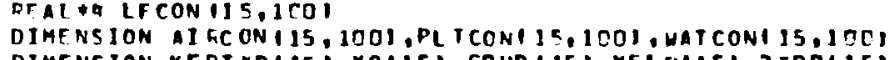
DIMENSION CONI 15I OKORG 15 I

DIMENSION IRAD IICCI, OPVI

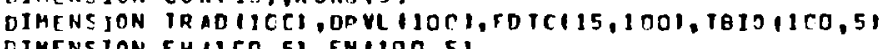

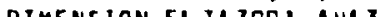

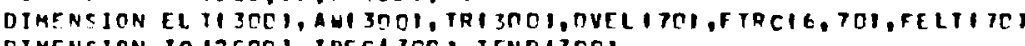

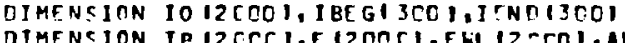

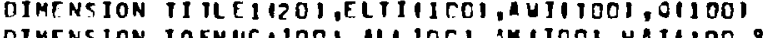

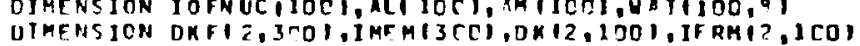

DIMENSION KP THUY TRI, US AGEIBI, RTL IIICOI, PHZ(B)

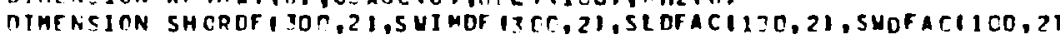
DIMENSION BICAC119,1COI,B10ACF 15, 1001, F DCON18, ICOI, EXTCON18, 1001 DIMENSION HL CUP1 115$\}$, HLOUP Z 181

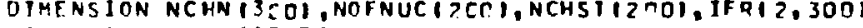

DIMFNSION TOFOIIE,5I

OTMENSION DCTACIICO,5I,SLCON11T.1 OOI.

-ERBCONI15,10C1,DOS6RDI10C,51,0CIN1115,170,51.

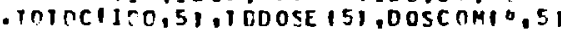

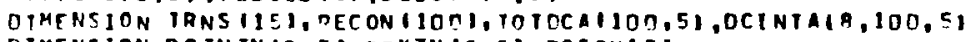

DTMFNSION OCINTNTE, 5 T.OEXTN

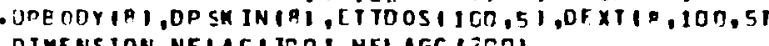

DIMENSION NFLAGISC D T, NFL AGC TZCTI

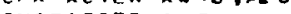

TNTFGE $12,0 \times 5$ OR

C NAMELIST INPUT LIST

c

NAMELIS T/INPUT /NEXT, KFOTYP, XO, TPRLP, YELO, , IRR, CON, IDEP, CFLO,

-HM, FLO, YOL, TOR, CTIM, PL IFE, EXIIM, KORE,TZ, IAC, IREC, POP, IPOP,

IINUT, TRNS, HL CUPI, HL DUP Z, IPCNI, SW, ISAL T, KPIHUY, JSAGE, RMZ, DKSORS

$\operatorname{RM} A X=12$
$P O P=1 . C$

REAT DATA LIBRARY FOR MASTER NUCLIDE INOEX AND RAJIOLOGICAL HALF LIFE

3 CONTINUE

CALL RLIBINIII ILR,ELT, AH, TR, NUT, NCH, NCHN, NOFNUC, NCHST,ITR,

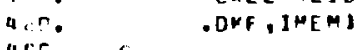

SIF. C REDO FOON TRANSFER CDEFFICIENT OATS LIPRARY 


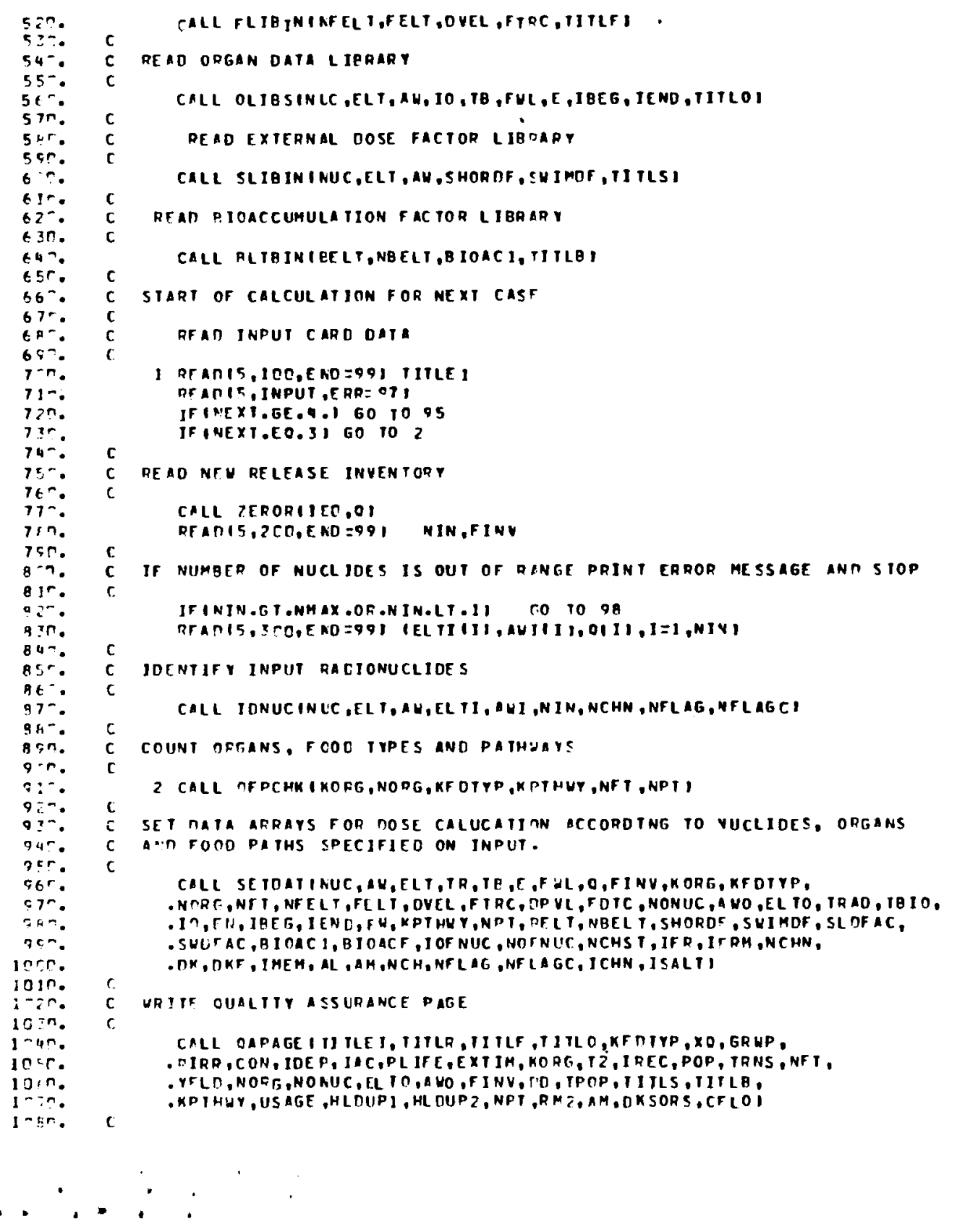




\section{PABLM}

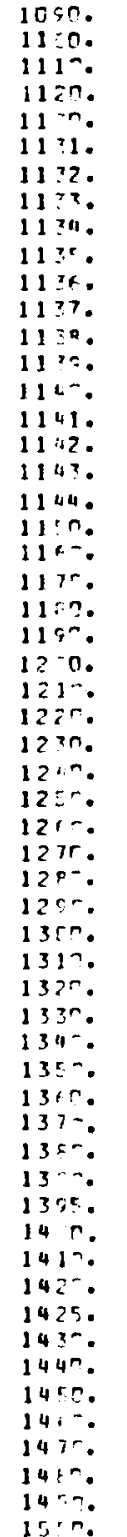

C CALC"LAIF DOSE FACTOR FOR CURREHT INYEMTORY AND ORGANS -

CALL OFCALCITRAD, TBIO,FW,EN, NONUC, NORG, DCFAC,KORG, - Elini

CALL TEROPI75OC,OCINT

CALL TERORISCODOOSGR

COLL TEFORISCO.TOTOCI

CALL ZEPOR 2 C, DOSCOM?

CALL TEPOPIS, TODOSE I

CALL 7CDORI75, TOFDI

CALL TERORIGCEC,DCINTA)

CALL TEFORTSCe, i.THOOSI

CALL TEFORIBCO,EXICONI

CALL TEPORTSCO,TOTOCA

CALL TERORIAC, CCININI

CALL TEROR I C C, DEXTH

CALL TERORIISOC,SLCONI

CALL ZEFORIGCCC,DFXTH
C IIMF LOOPFOR FA RLM

00 $50 \quad 111=1,12$

CALCULATF FOOD CONCENTDATION FACTORS

CALL DOSE IIOEP, NF T, NONUC, IREC, CFLO,FLO, VOL, TOR, CTIM, PLIFE, RM . SLCON, EDBCON, KFDT YP, EL TO, XO, TRAD, YELD, GPUP, DPVL, TRNS,

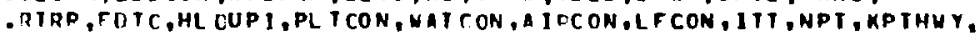
- TXICDN, FDCON, RM 2, AH, WAT, BIOACF, HL TUPZ,SW,

$\mathrm{C}$

-RECON, ICHN, I OF NUC, $A$, DM, IFGM, DKSOES, IAC,

C CALCULATE. DOSF FROM FOOO CONCENTRATION AND DOSE TACTORS

JFINFT.GT.OS

CALL MOSCITNCNUC, NORG, KORE, NFT, C CN, POP, EXTIM, SLCON, EDBCON,

- OOS FRD, TOTOC, OCFAC, SLDFAC, KFOTYP, COSCOM, TODOSE, EL TO,

.TPAN,TBIO,OC IN T, ITT, PLIFE, TCFD, T

TFinPt. TT.0I

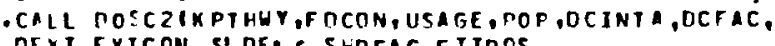

-OFXT, EXICON, SL DFA C, SWDFAC,ETTORS,

-NORG, NONOC,TOTOCA, KOAS, NPT, DCINTN,DEXTN,

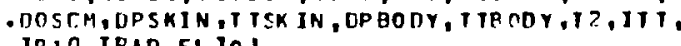

c

WRITE TUTPUT REPORTS

LIFE $=$ PLIFE

IFIITT.50.1160 in 52

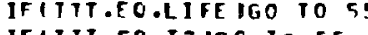

go to 5 is

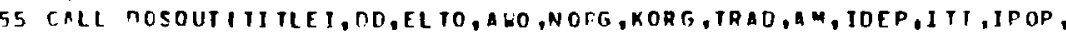

-PLIFE, NONUC, IOUT,IPCNT, NFT, CON, XO,RIRR, HLDUP I, TRNS, TOTDC,

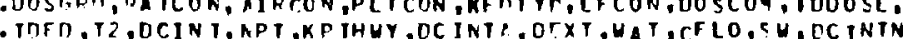


6. PABLM

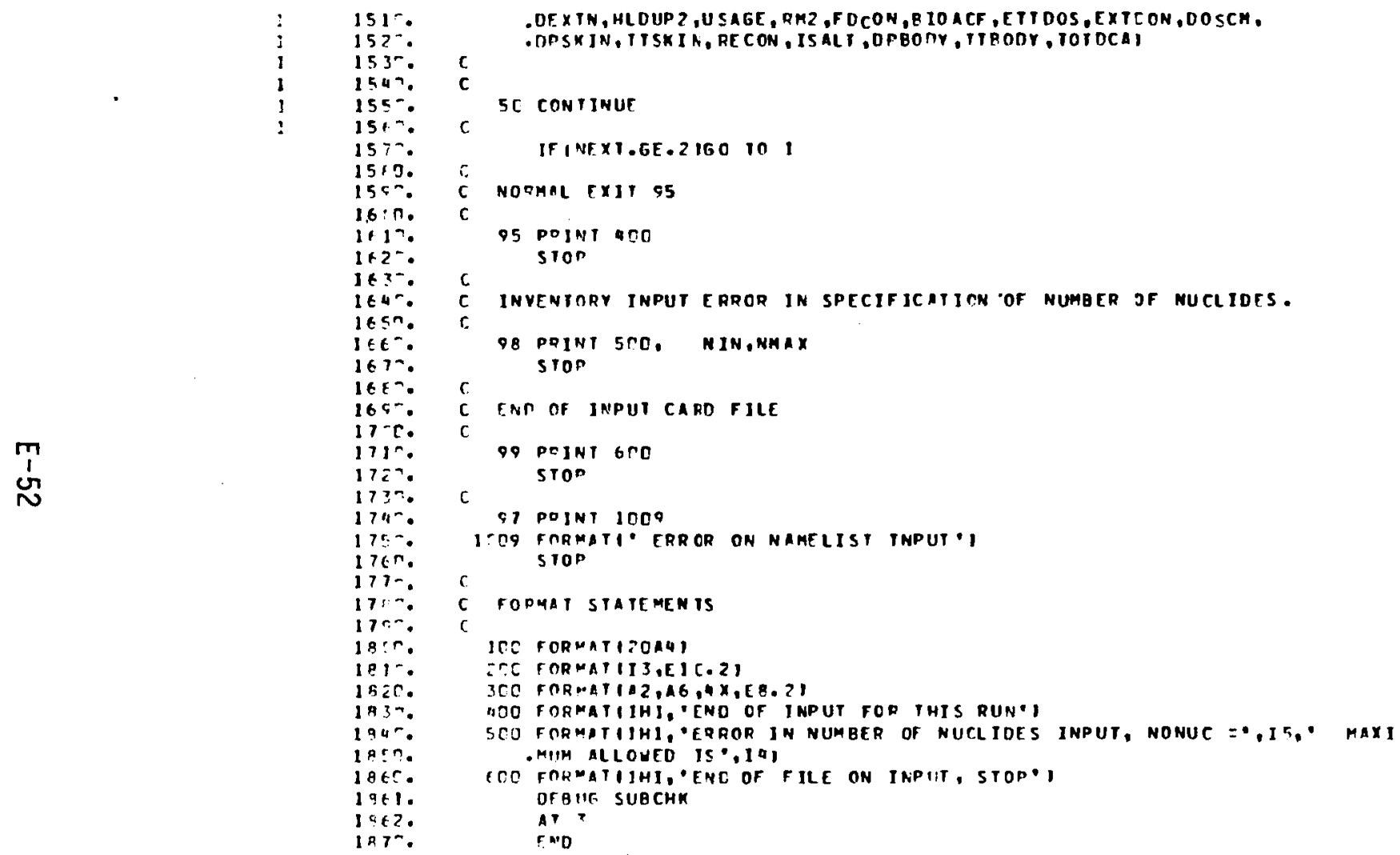




\section{PABLM}

i.F IN,SO AM,OLIOIN

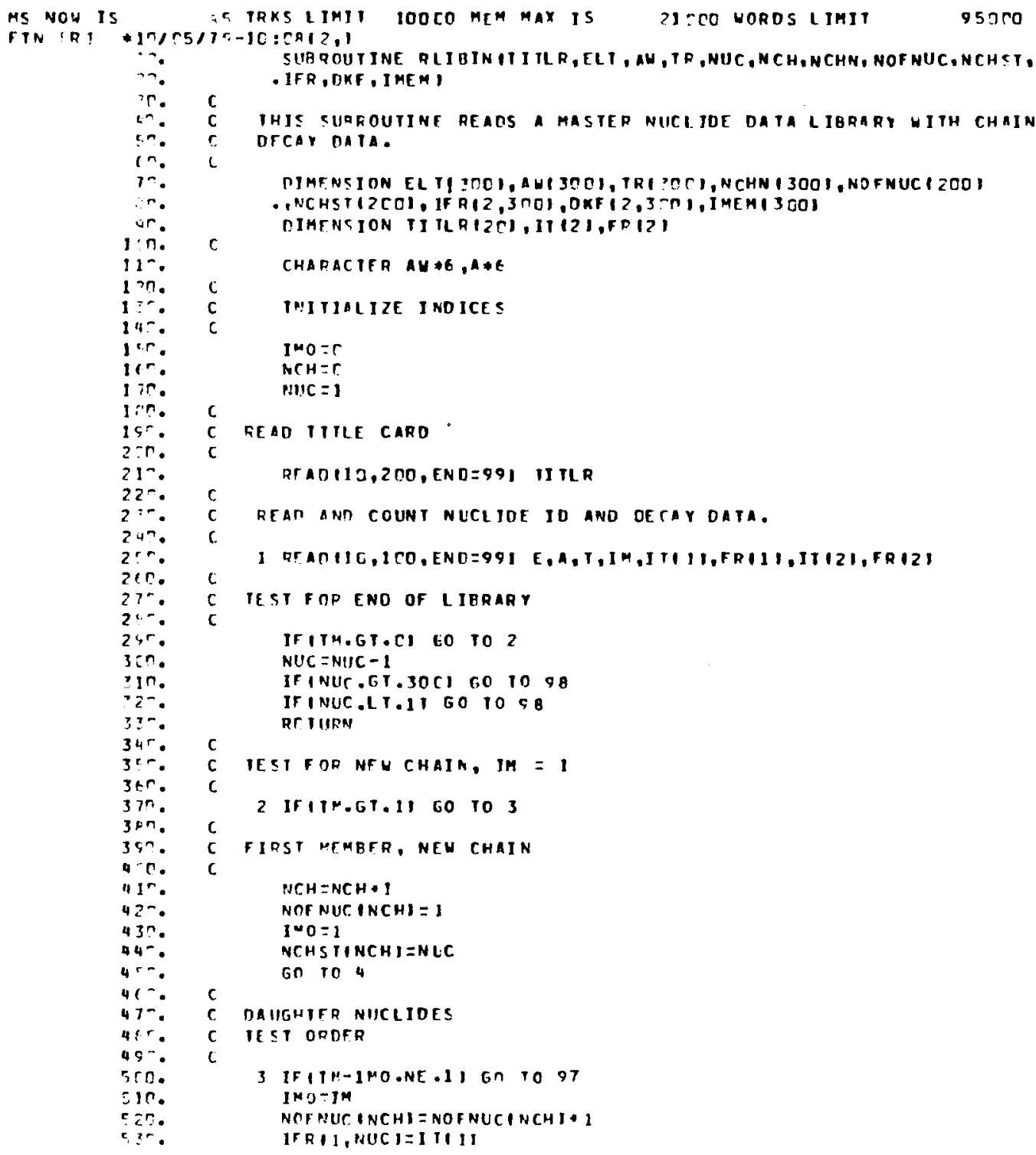




\section{PABLM}

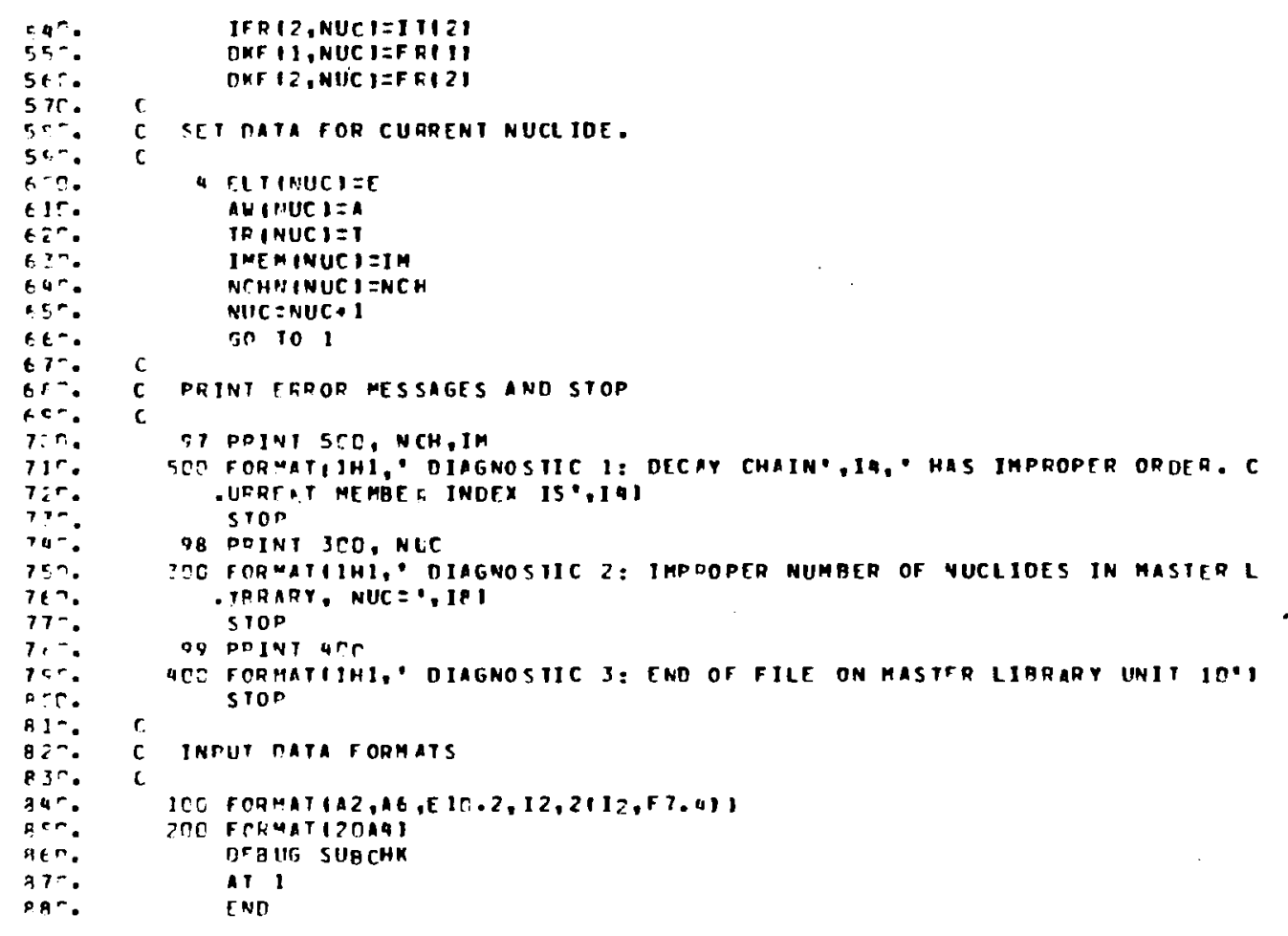

ENC FTH 30 - 19ANK 228 ORAM:K 


\section{PABLM}

DFTN,SO AA OFLIEIN

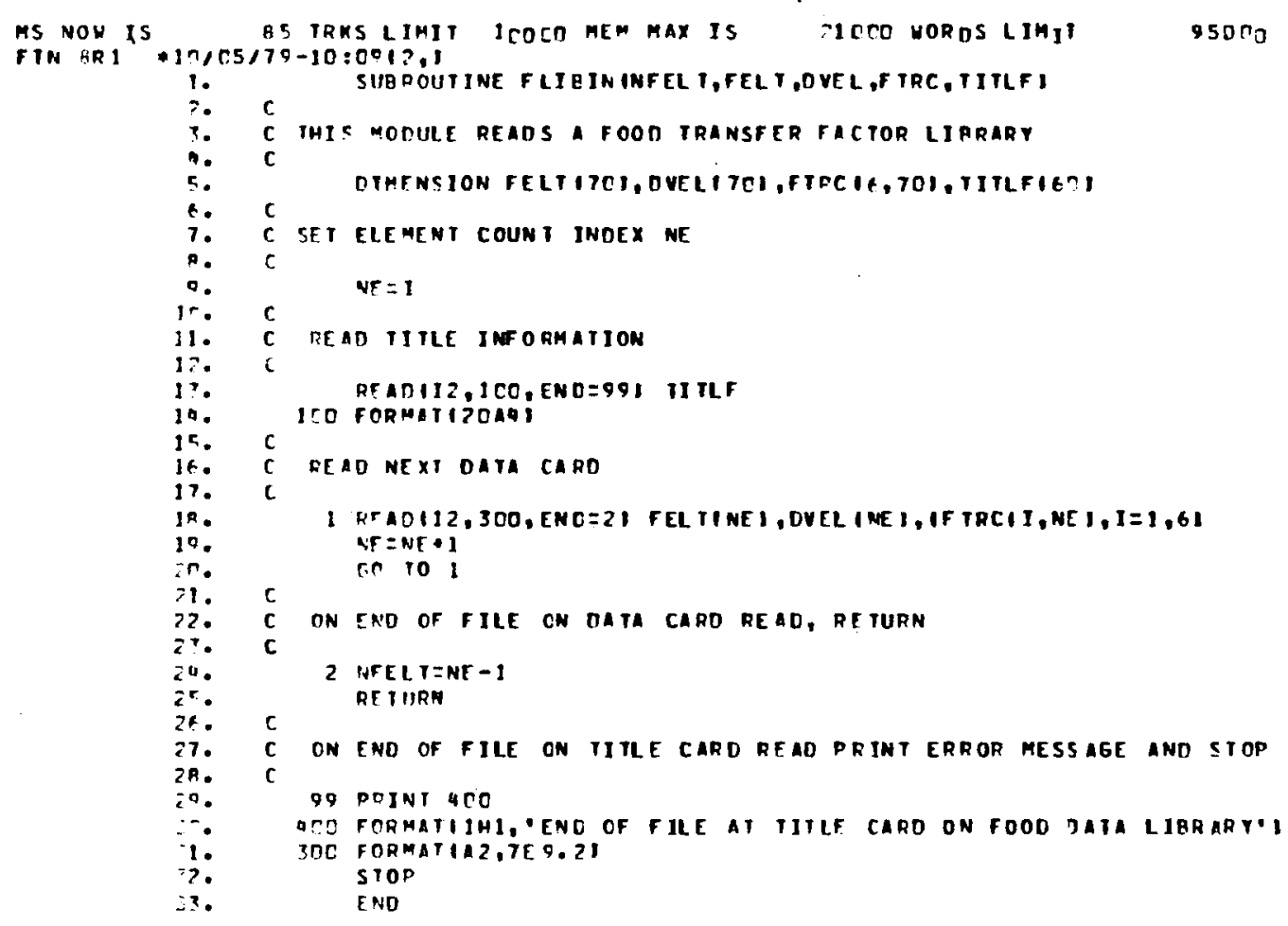

END FTH G 5 TBANK 9 DOANK 


\section{PABLM}

DF IN, SO AA . DL IBS

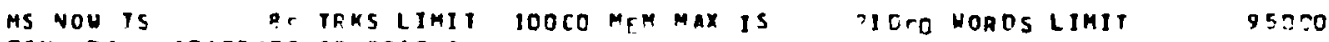

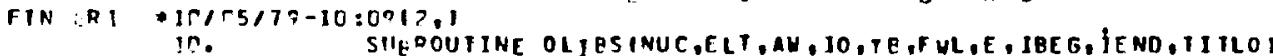

:- C THIS MOOULF REAOS DATA TROH THE OPGAN BATA LIBRABY

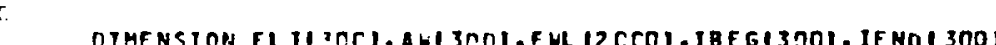

DIMENSION TB $12(00)$, E 120001,10120001

OIMENSION TITLCIZTI,EIISI

CHARACTHA AH O6, A*A.

AL $z=A L O G 12.1$

C. SET TATA ARRAYS TO ZERO

C SET RATA ARRAYS TO ZERO

CALL PEROIISCOC, IOI
CALL TEPOIINLC, IENO

CALL TEDOIGLE, IENO I

CALL PEROITNLC,IEEG
CALL PEPORITCCC,FUL

CALL ZERORI2 COC,IP

CALL TEDORIZLCCOEI

INIIIALIJE CONTROL INIEgERS

NC: $=1$

IP $=n$

C REAO ORGAN LIERARY IITLE CARO

GrAO111,100,ENO=\$91 11720

ITO FORMATIZOAG

C DESOFIRSI OATA CAPO

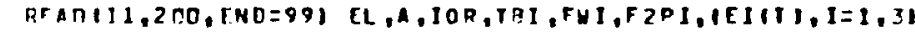

2TE FOR MATIA2,A6,12,6EB,Z1

1 ITIEL.NE .ELTINCI.OR.A. NE . RH INC II 60 TO 6

IF I OOR.FO.11 GO 10 ?

IF INOR D.NE.NCI 6010

Gn 00

5 IFINC.GT.PI IEADINOLDI=IP

NOL $D=M C$

IPE GINCI I IP.

3 IF $=I F \cdot 1$

c

set tata for curaeni nuClide ano trgan

FVLIIPI $=F U I$

TQ TIPI TB

$\operatorname{lin} 1151=108$

EIIDEETI1

DEAO NTXT DATA CADO 


\section{PABLM}

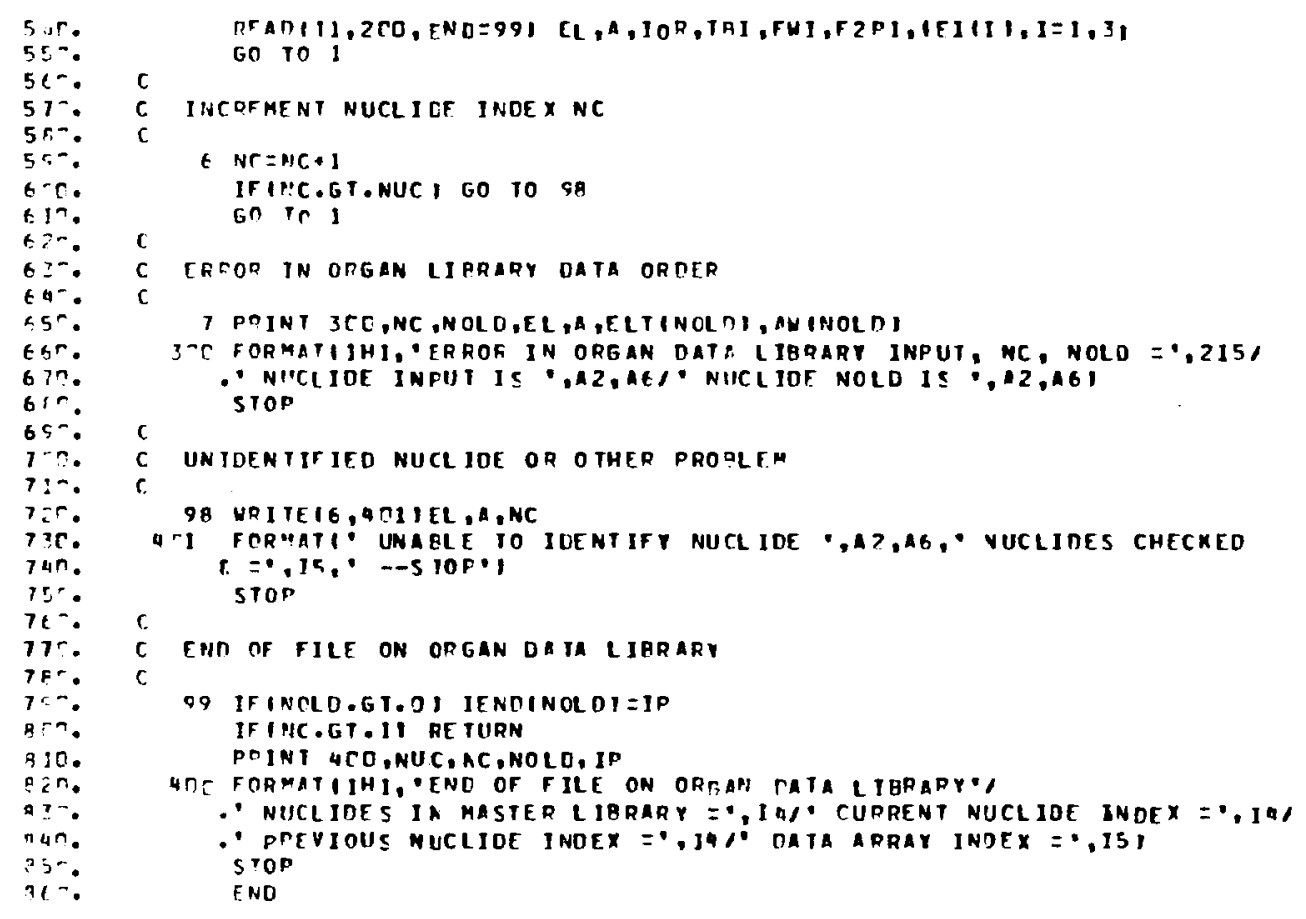

ENO FIN $21 Z$ IRANK ZGG DOA VMK 


\section{PABLM}

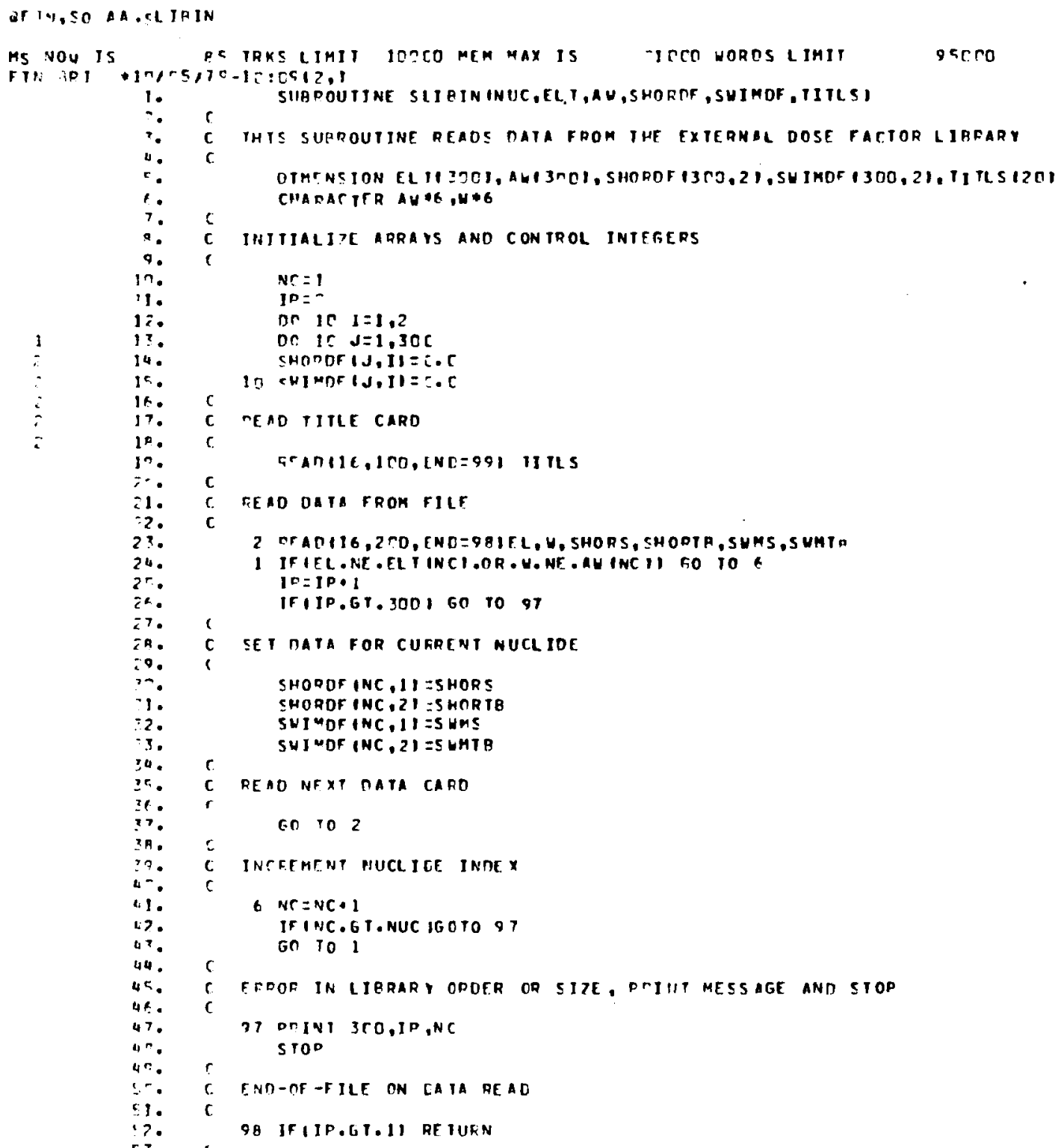




\section{PABLM}

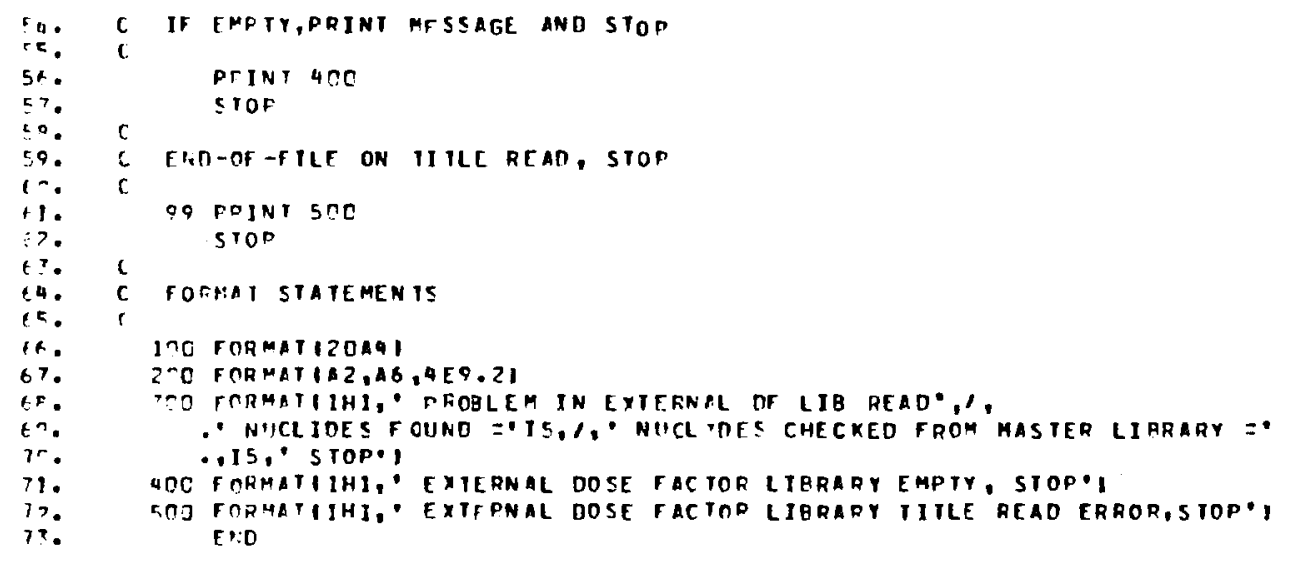

LND FIN 149 IPANK 194 ORANK 


\section{PABLM}

OFIN,CO AM.ALIBIN

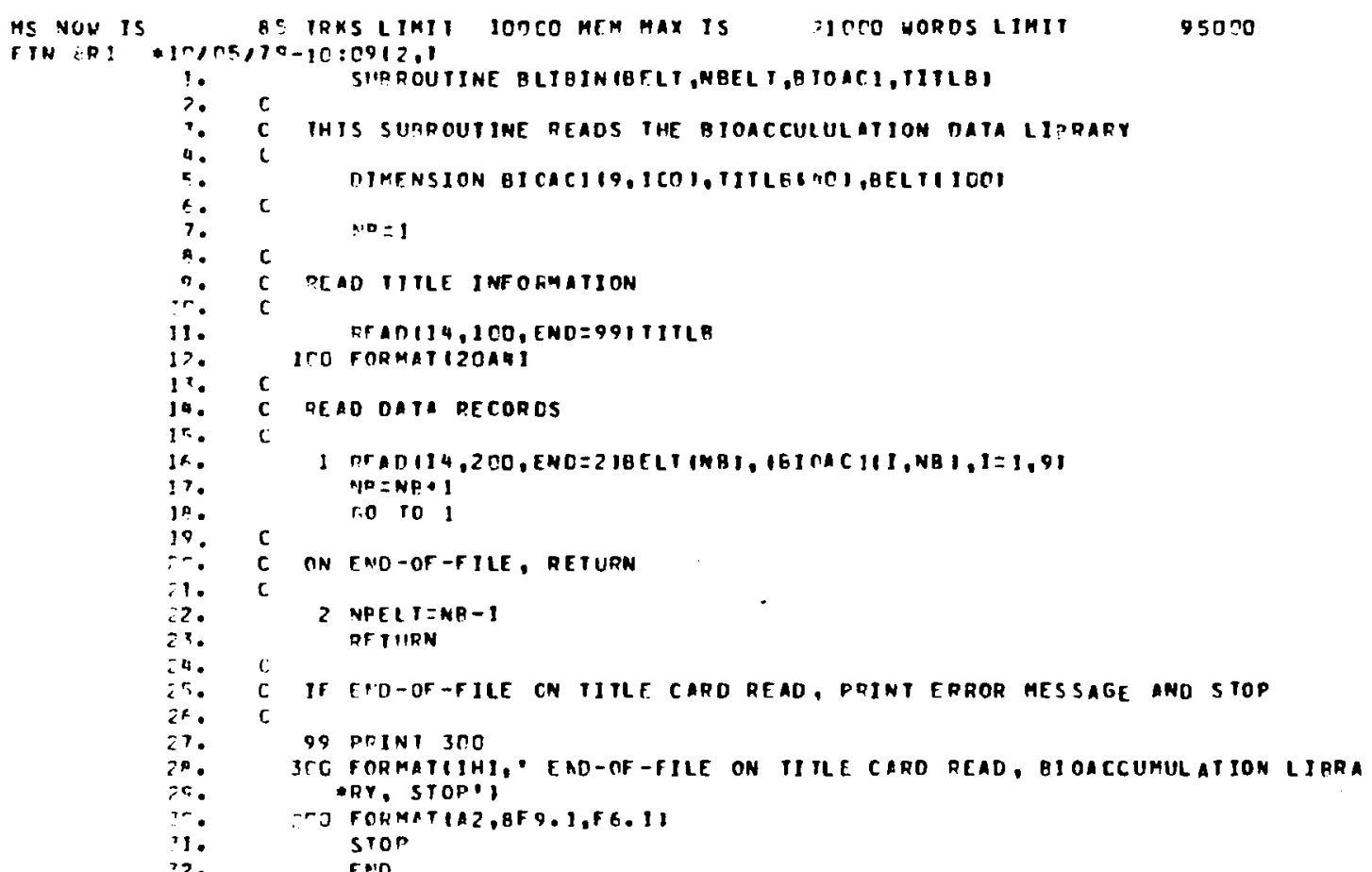

ENO FIN $5 B$ JBANK \& 7 DPANK 
6. PABLM

$m$
1
$a$

DF IN,SO AA.TRDOR

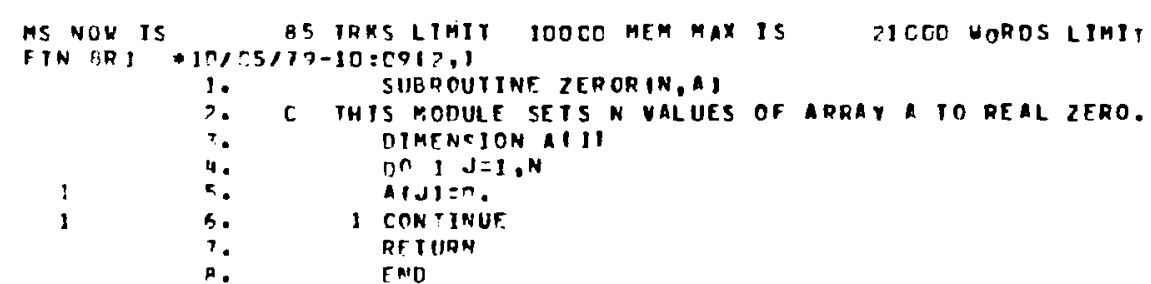

ENO FTN 34 IB ANK, 


\section{PABLM}

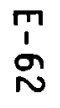

ariv, 50 Aa.TEROT

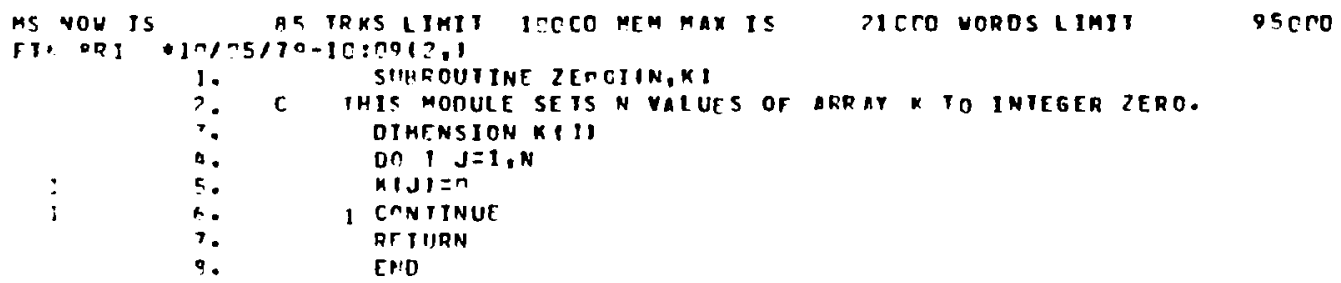

FNO FIM 34 JQANK 1 = DRANK 


\section{PABLM}

aFtN, SO AA .TONUC

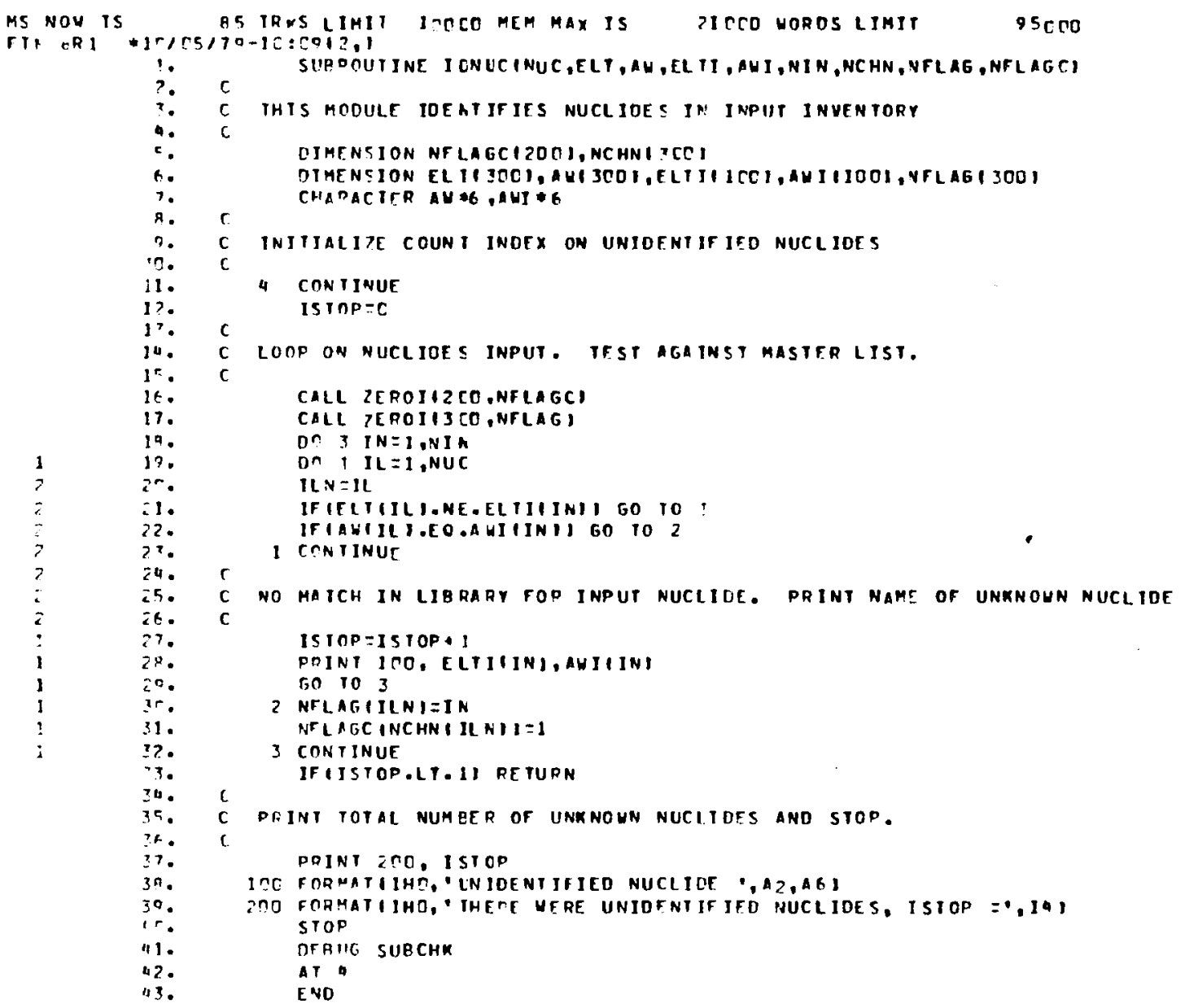

ENE FIN 275 IBANK 130 DAAMK 


\section{PABLM}

\section{arIN.5O AA.OTPCHK}

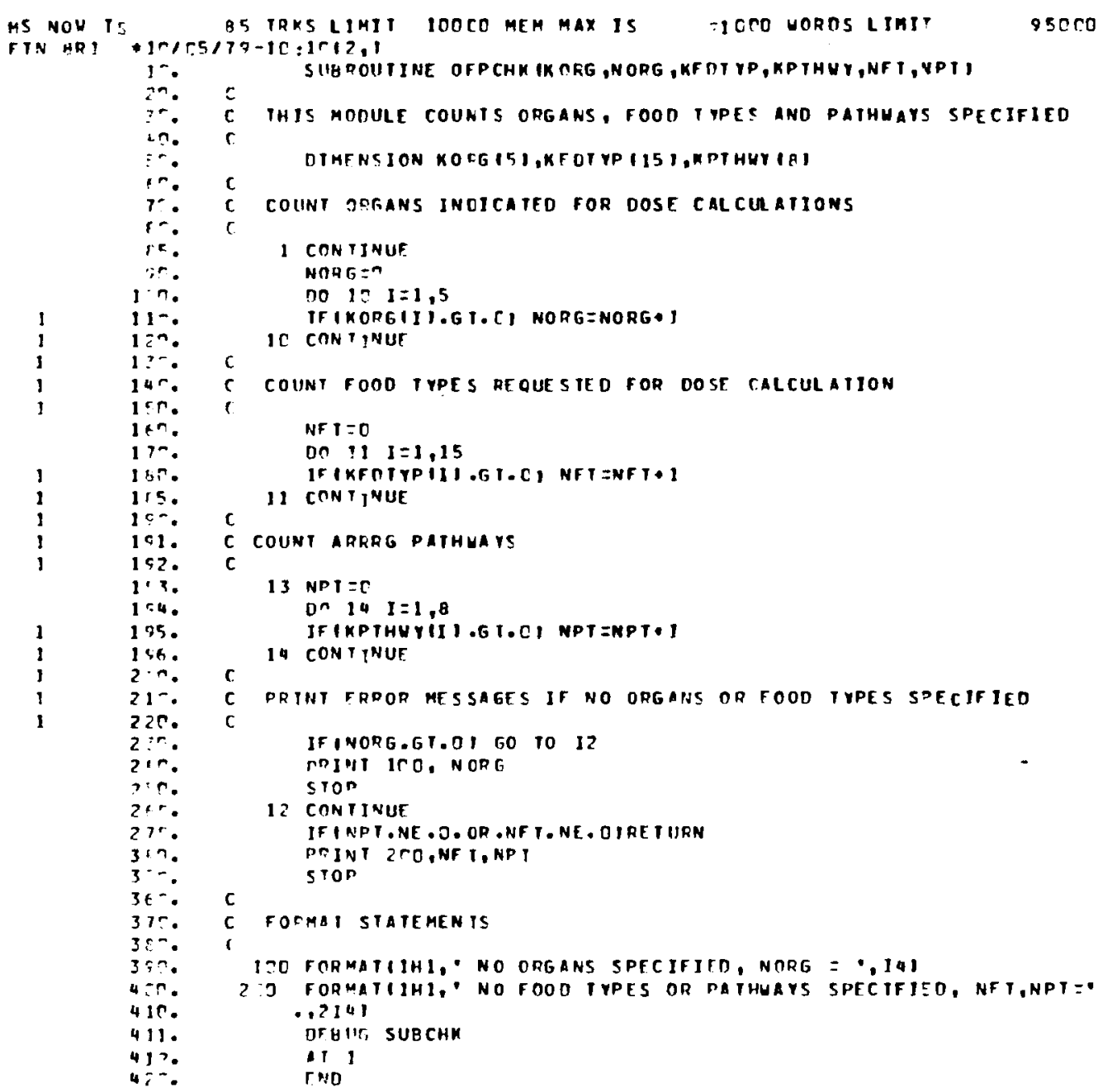

END FIN 14 A IRAISK BI THANK 


\section{PABLM}

arin.SO AA.SETDAT

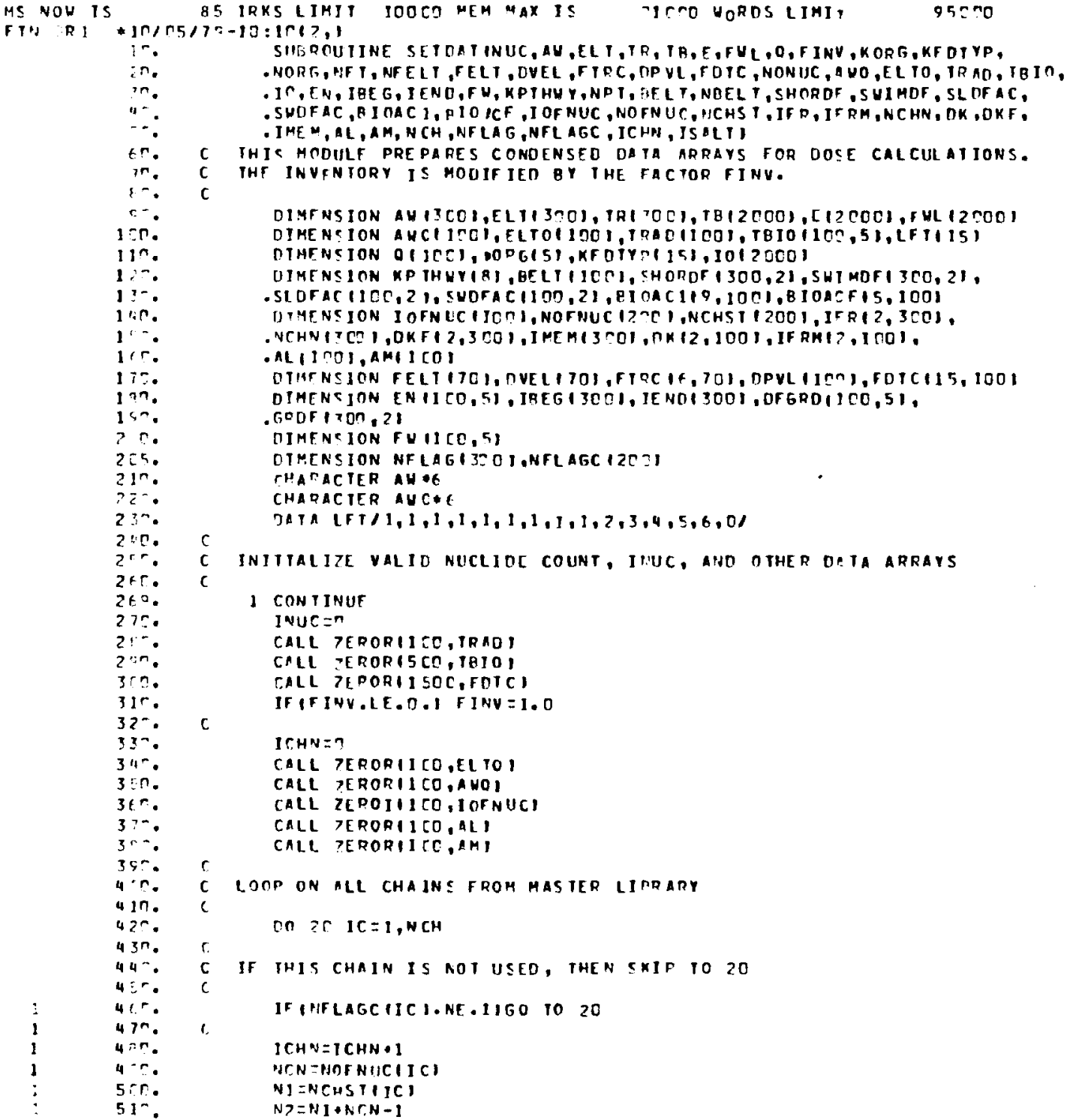

1 CONTINUE

NUC $=n$

CALL TERORIICO, TRAOI

CALL TEROR(5CO,1810)

TALL TEPORIISOC,FOIC

IFIFINV.LE.D.I FINV=I.0

c

ICHN=?

CALL TERORIICO,ELTOI

CALL TERORIICO,ANOI

CALL ZEPOITICO,IOFNUCI

CALL TERORIICO,ALI
CALL TERORIICC,AMI

C LOOP ON ALL CHAINS FROM HASTER LIPRARY

On $P C \quad I C=1, N C H$

IF IHIS CHAIN IS NOT USED, THEN SXIF TO 20

ifimflagcitci.ne.11G0 To 20

CHN=ICHNO1

DSN = MOR NUICII CI

NI $=$ NCHSTIICI

$N T=N+N, N-1$ 


\section{PABLM}

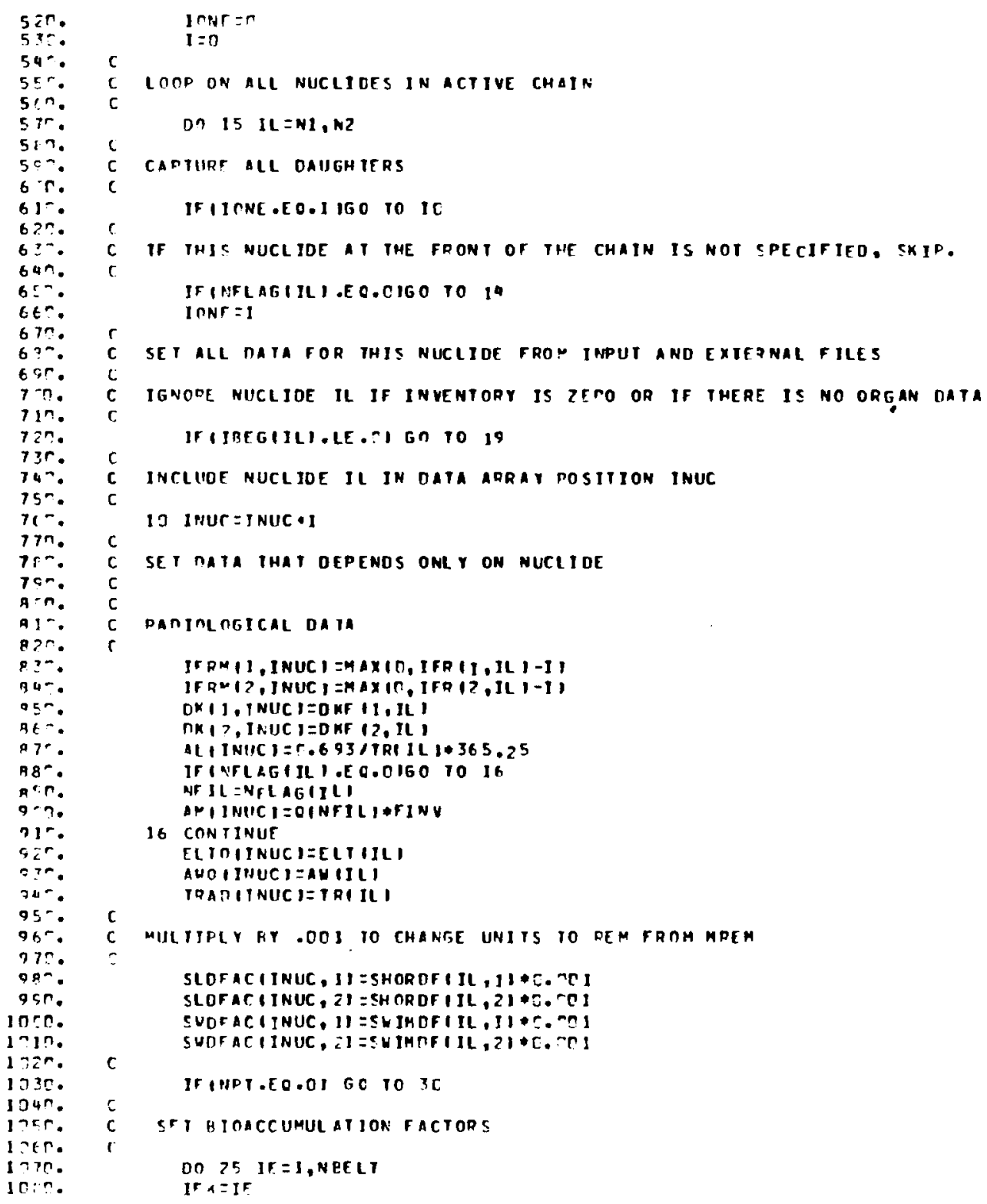


6. PABLM

IFICLTOEINUC J,EO.BELTIE IJGO TO 26

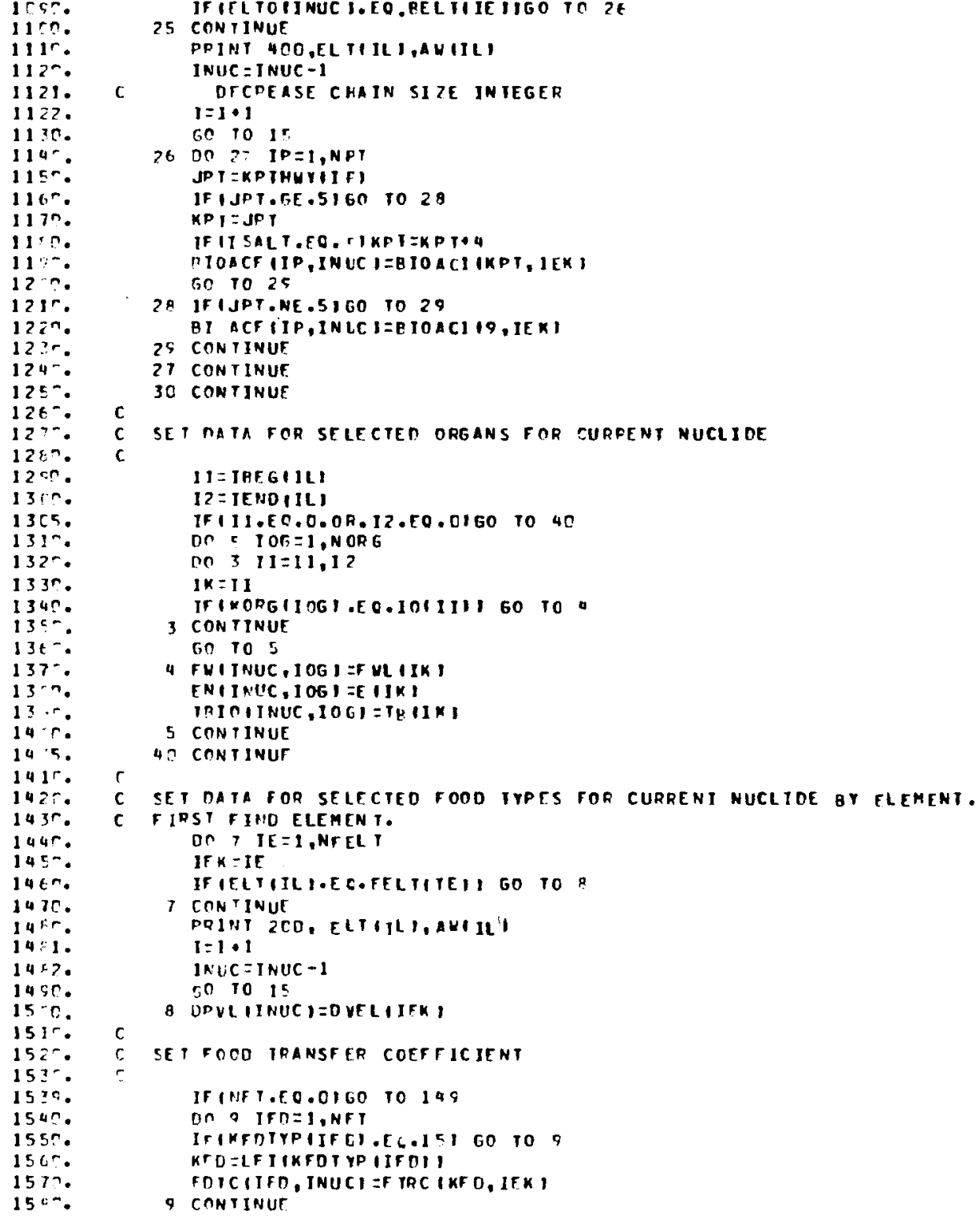

5 CON TINUE

PPINT $400, E L T I I L I, A N I I L$

INUC = INUC-1 


\section{PABLM}

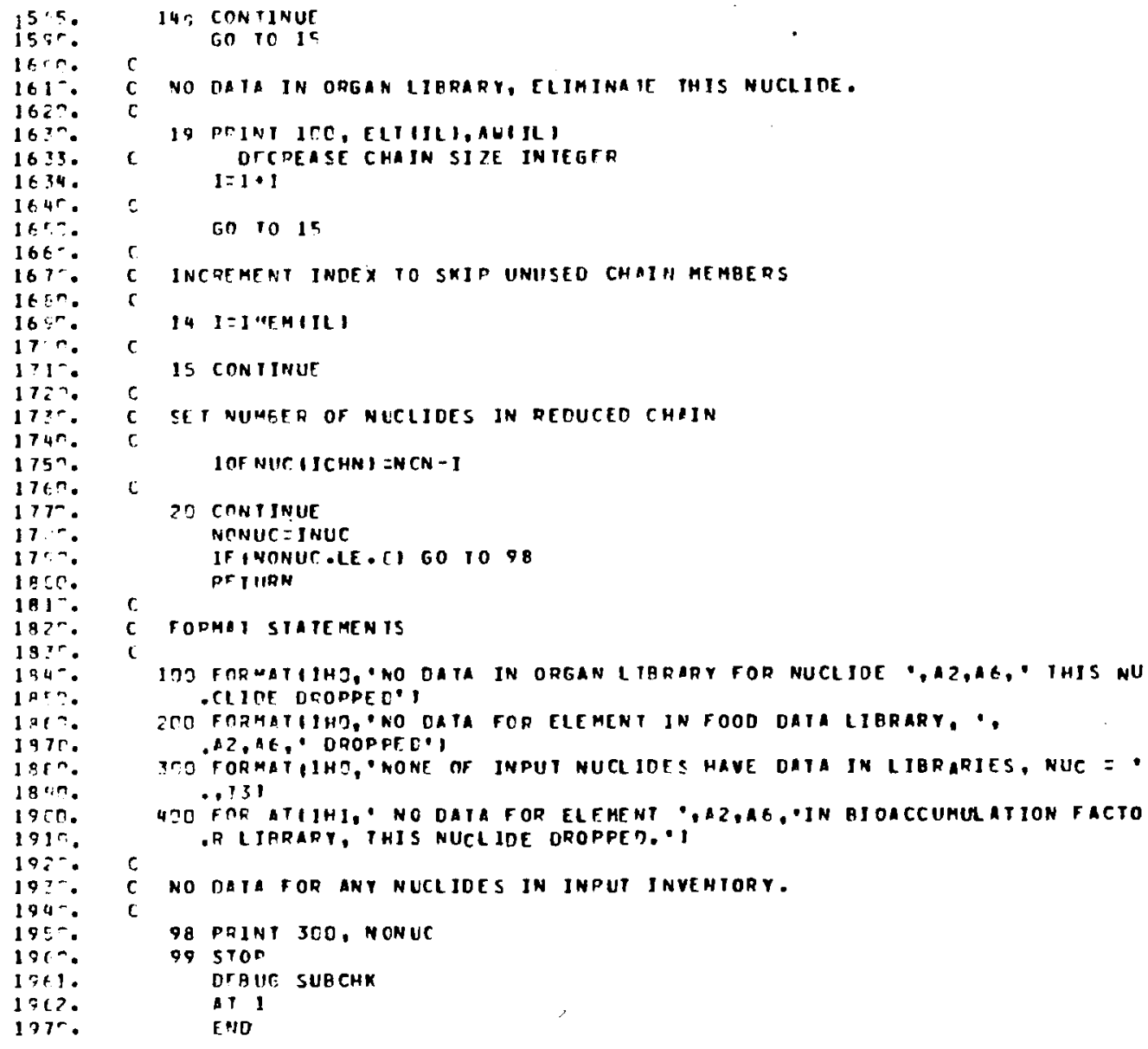

END FIN 12 EG IAANK 1573 DRANK 


\section{PABLM}

GF TV,SO AA.OAPATE

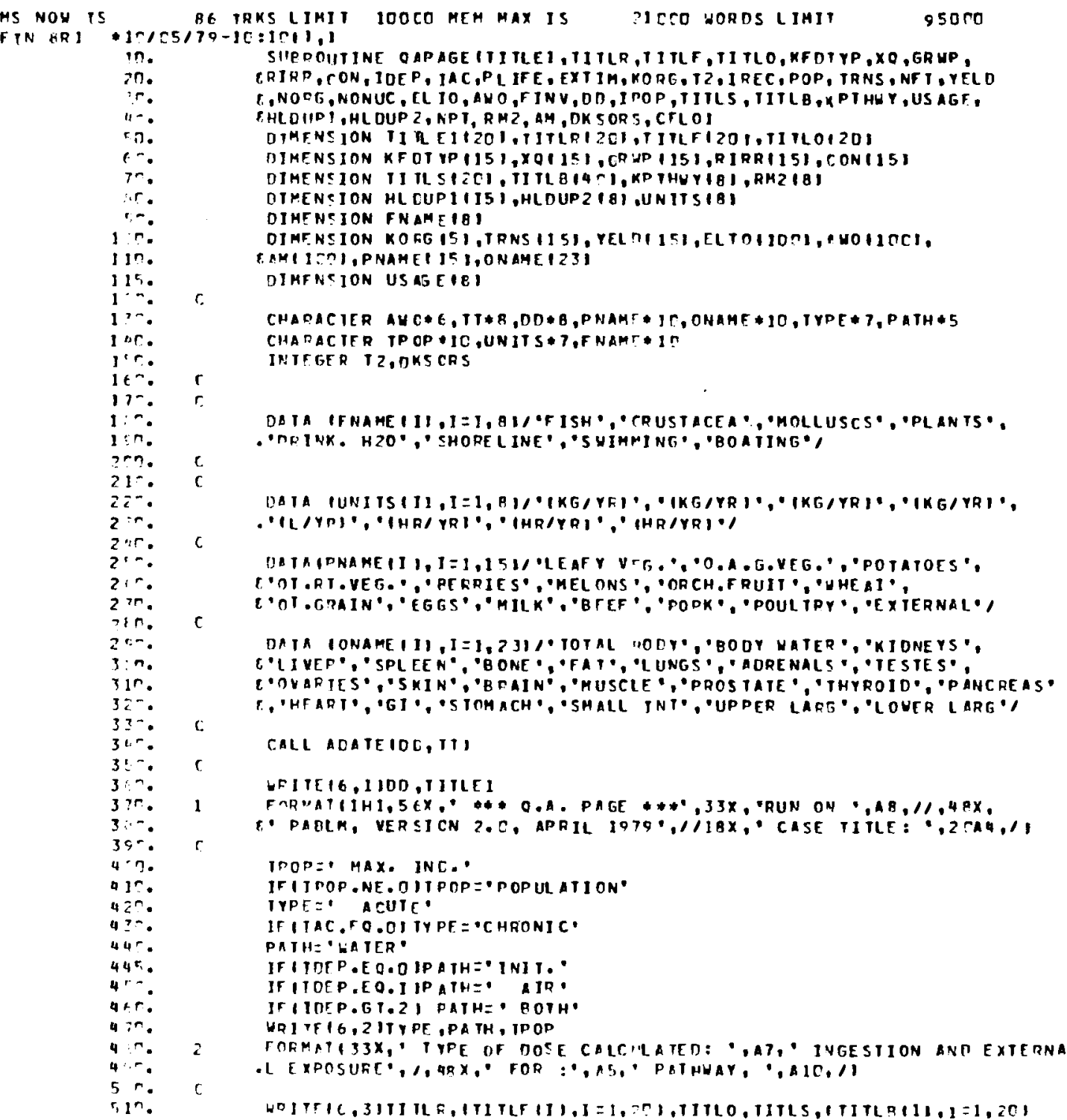

$950 \mathrm{CO}$

TH KR I

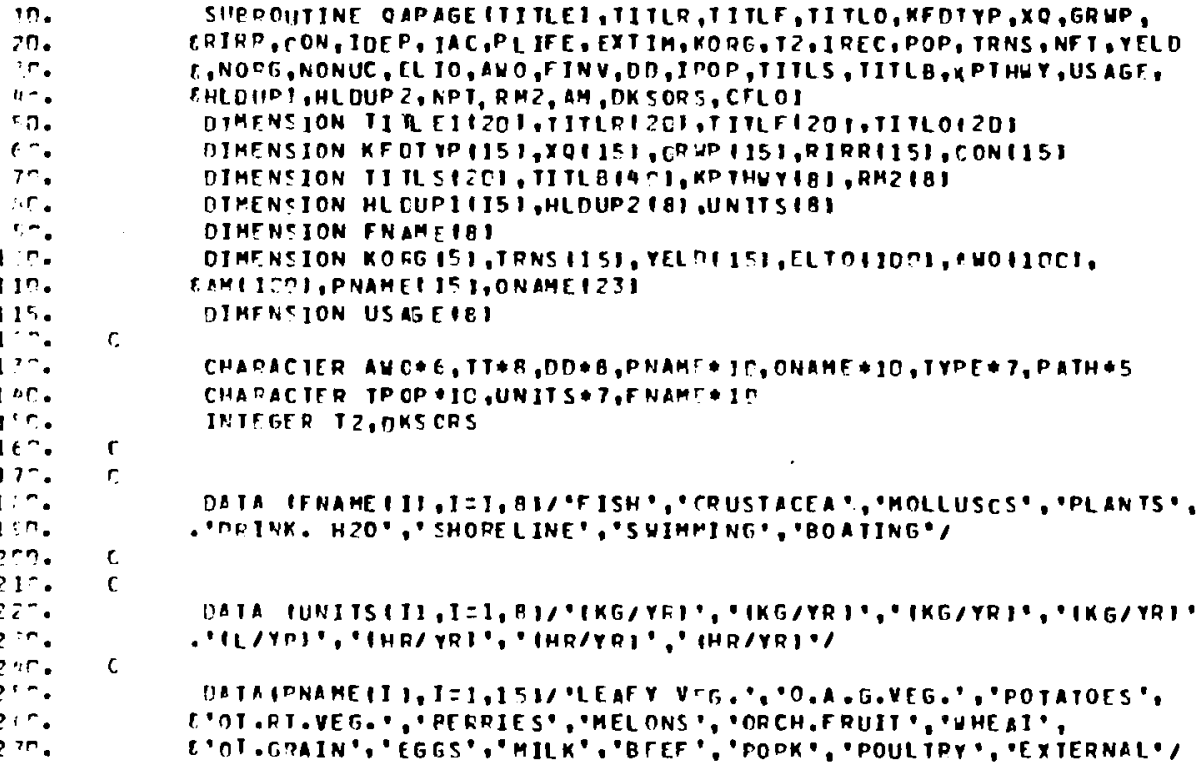




\section{PABLM}

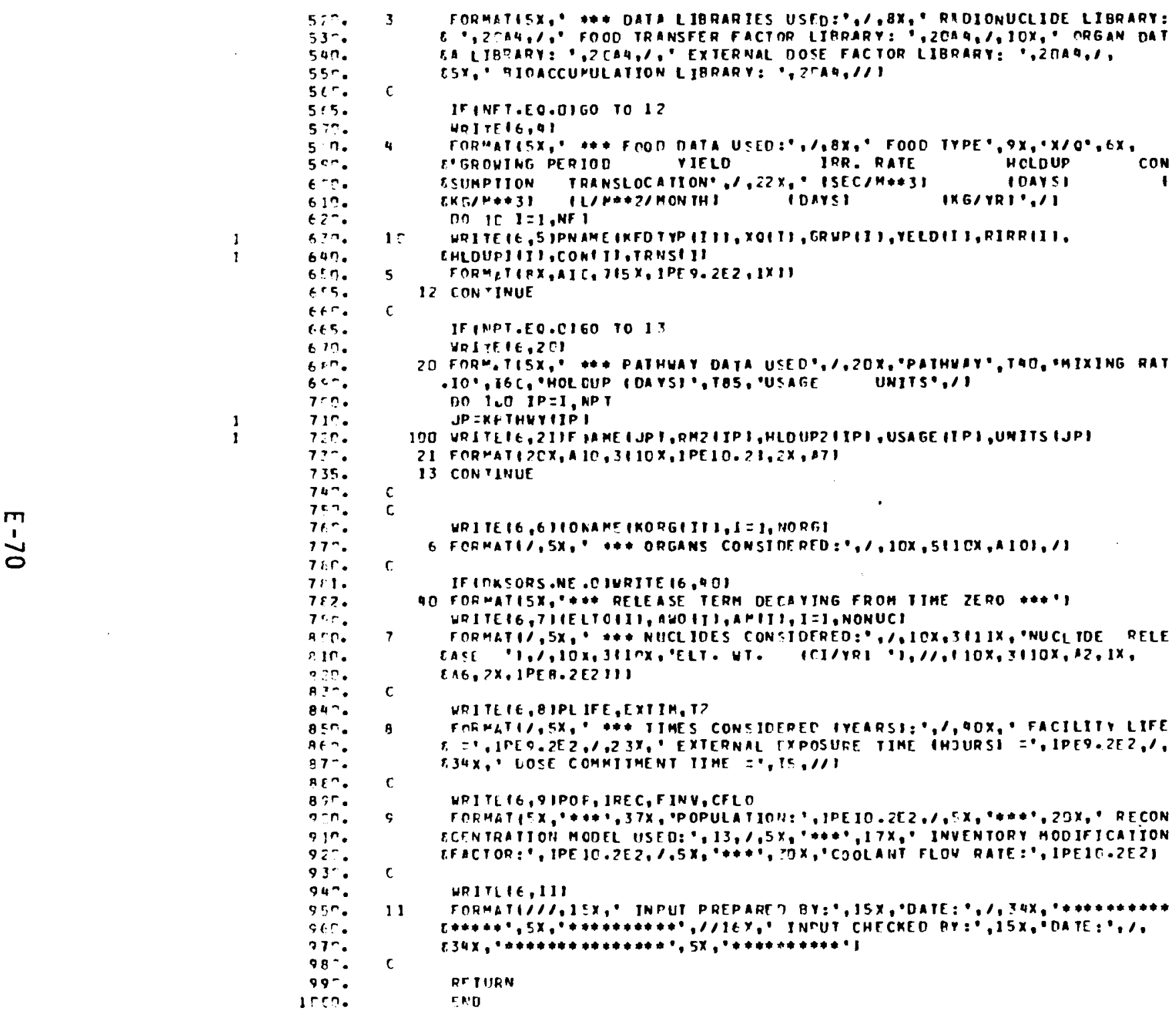

[NU FTN 24 E IRAMK 327 DRANK 


\section{PABLM}

AF IN,SO AA .DFCALC

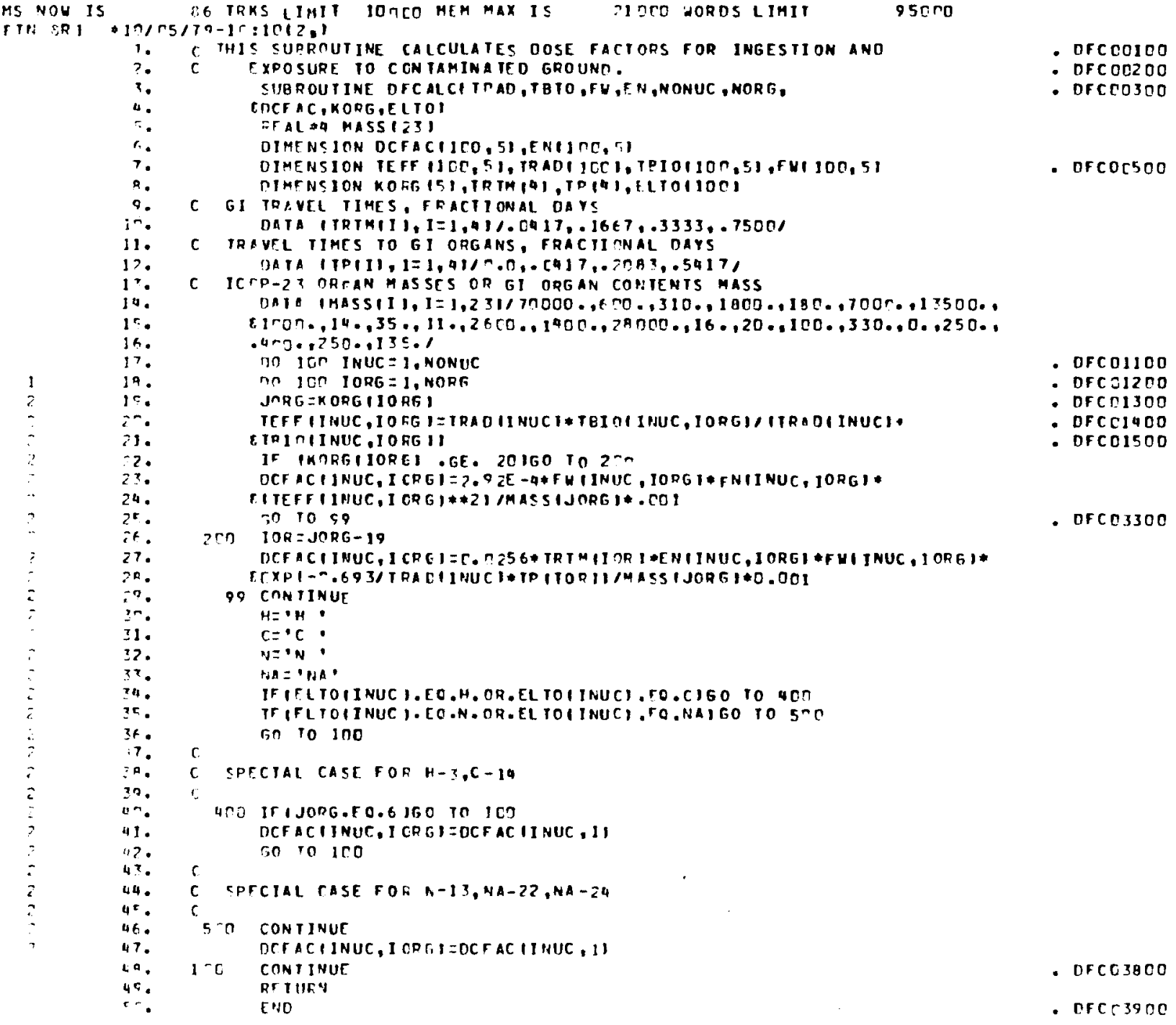




\section{PABLM}

if $\cup, S O A A$, NOSE

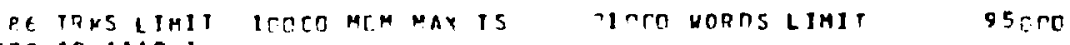

FI RI 12, $15,79-10: 111=3$

C ROUTINE FTE AIR ANE WBTER CONCENIOPIICN

SHEPOUTINE DCSEIIDE , NFT, NONUC, IFEC,CFL M,FLO, VOL, TOR, CIIM,

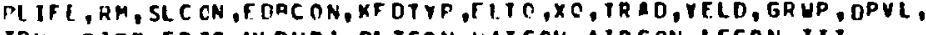

TND 1, KD THUY, F TC, HLDUP 1, PL TCON, KATCON, AIRCON, LFCON, IIT,

RRCCON, ICHN, I CF NIC, AL, DK, IFRH, OKSORS, IACI

INIF GF R OKSORS

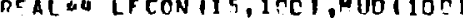

DIMEN

DTMFNCION AITCONIIS, ICOI, RE CON IICCI, WAT CONIIOO

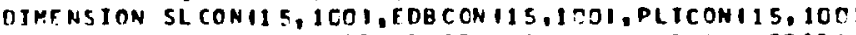

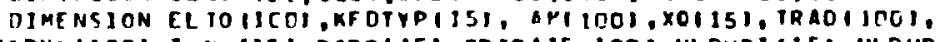

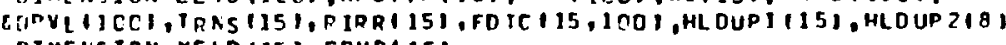

MTMENSTON VELTHET, GRWPIISI

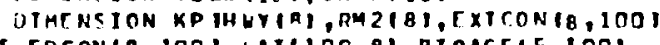

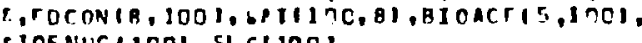

c

IOA IA ICRY, OEPE R, SLON $14,025,274,1$ CHKHGC, CHKNUCE 12,31

C DECAY OCLEASE TERP IAMI IF SOURCT IS DFCAYJNG

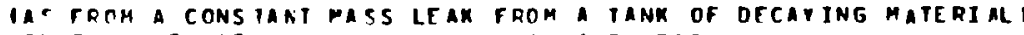

DON.T DO IT AFTER RELEASE FNDS, On IST VEAR

LITE = LLIF

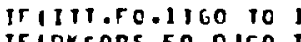

IF 1 IIt 0 Th

INUC $=m$

no 2 ?ñ I $1 \mathrm{C}=1, \mathrm{ICHN}$

Jis 1 OCNUCPIC

$1 \leq 1=1 \mathrm{NUC}+1$

$k=1 \leq T \cdot J-1$

Do $2 \cos 1=1 \mathrm{IST}, \mathrm{k}$

PCCI AMITI=AMIII/AL III

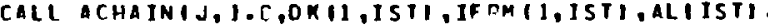
CAMTSTIBAMIISTI,CI

cos $>002 \quad I=151, k$

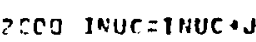

1 CONTINUT

a] IT=TII

DO $3: 1 \quad I=1, N C N L C$

HAICONIII $=0.6$

ir 1 UIRCONiJa 


\section{PABLM}

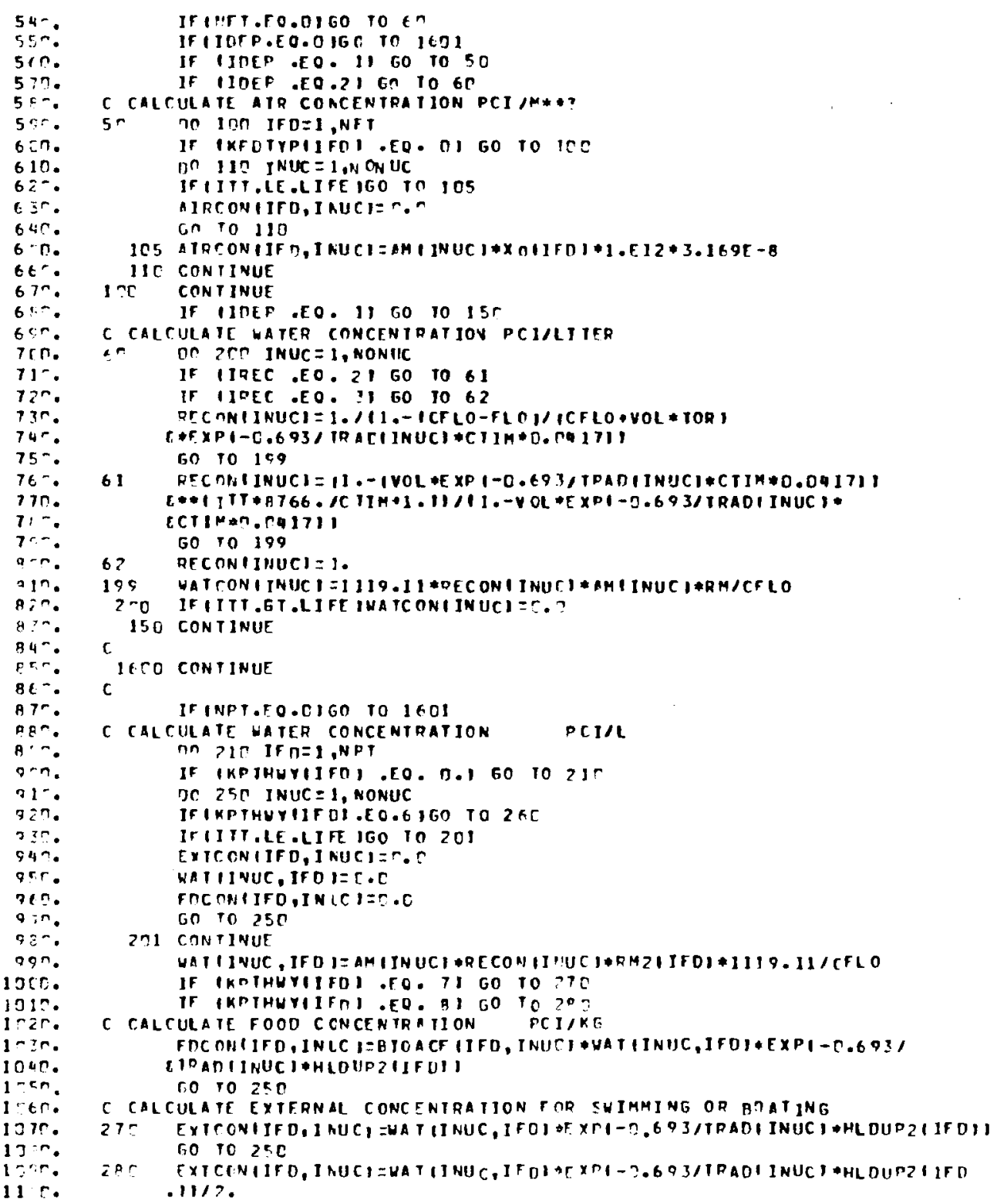




\section{PABLM}

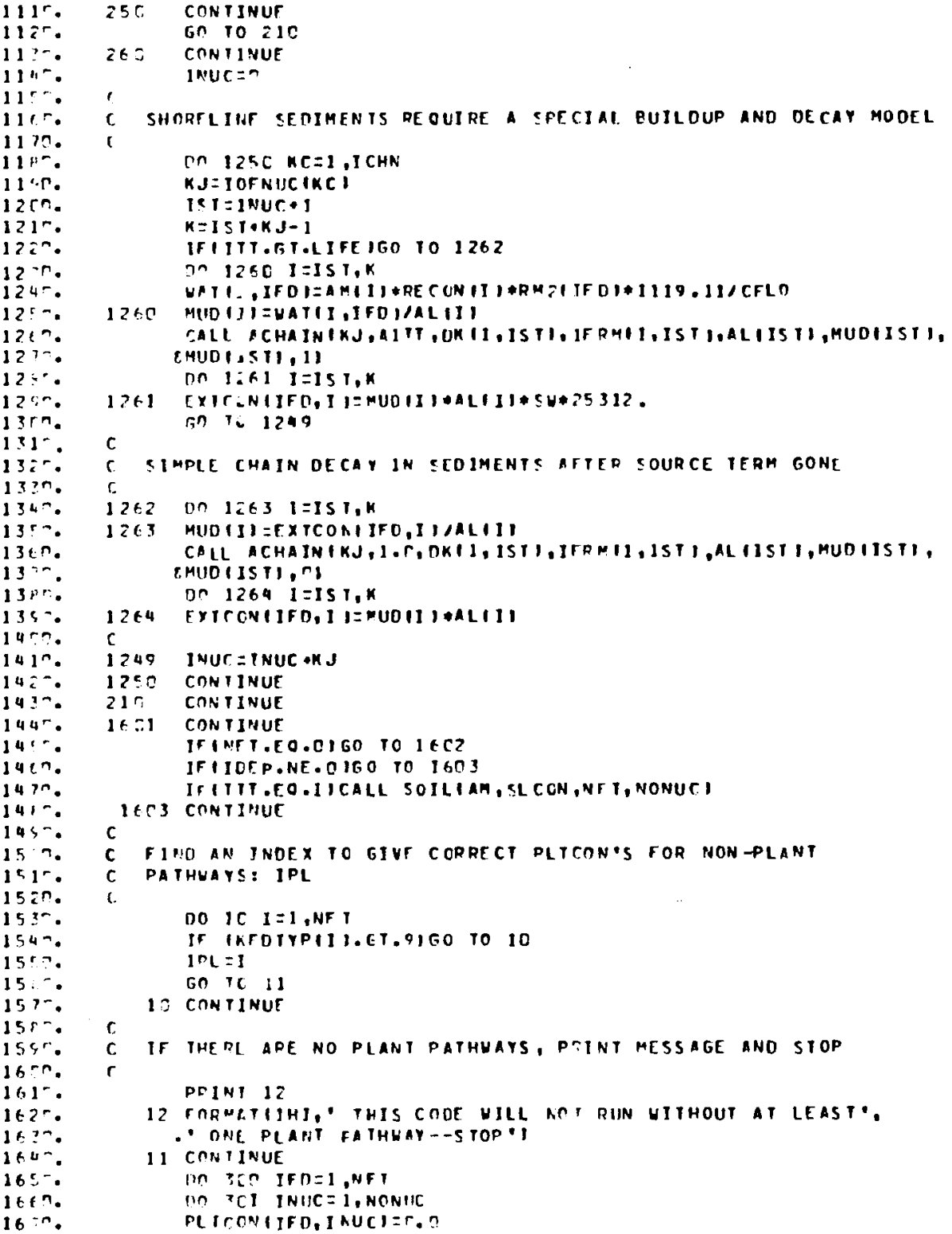




\section{PABLM}

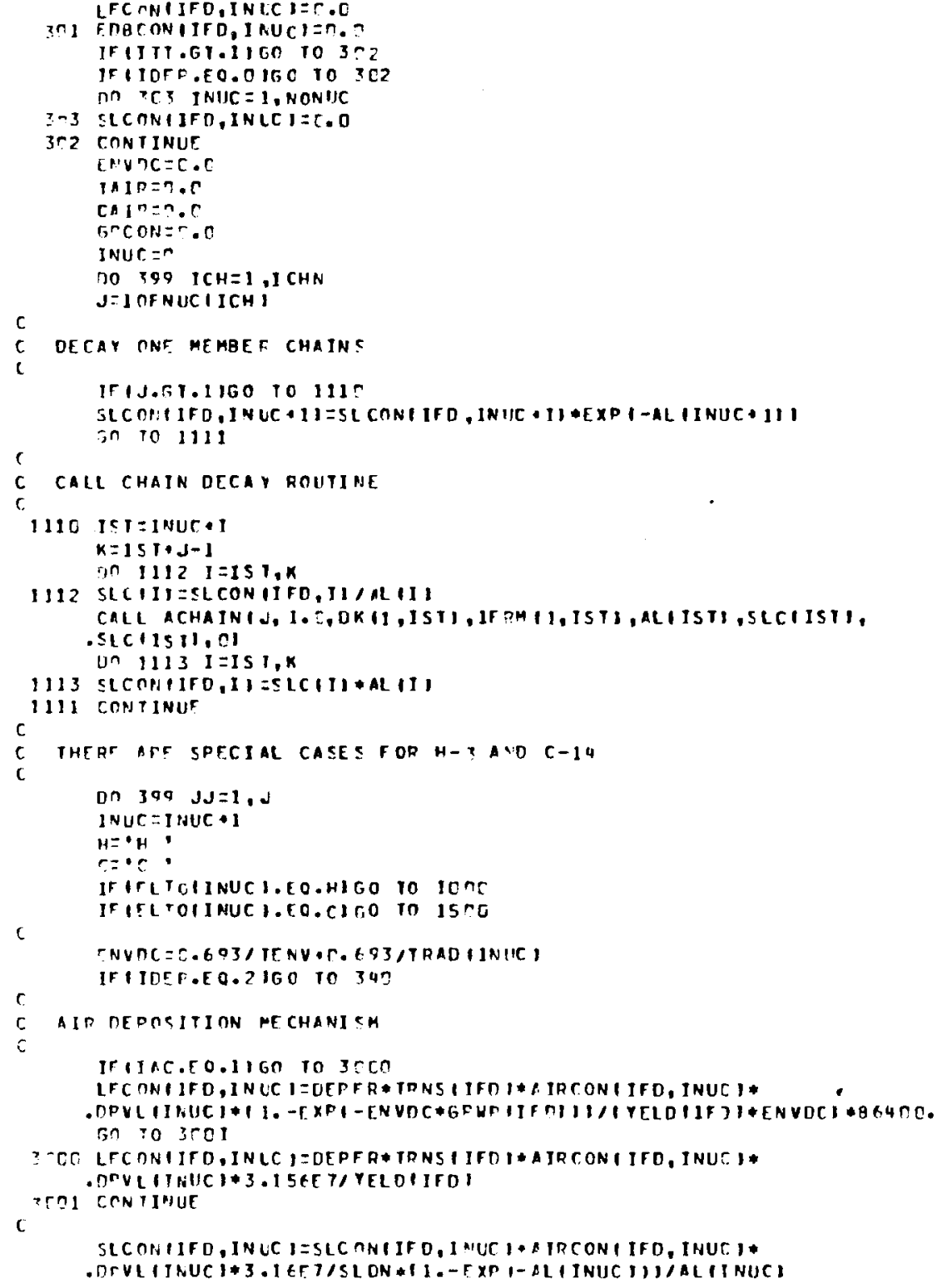




\section{PABLM}

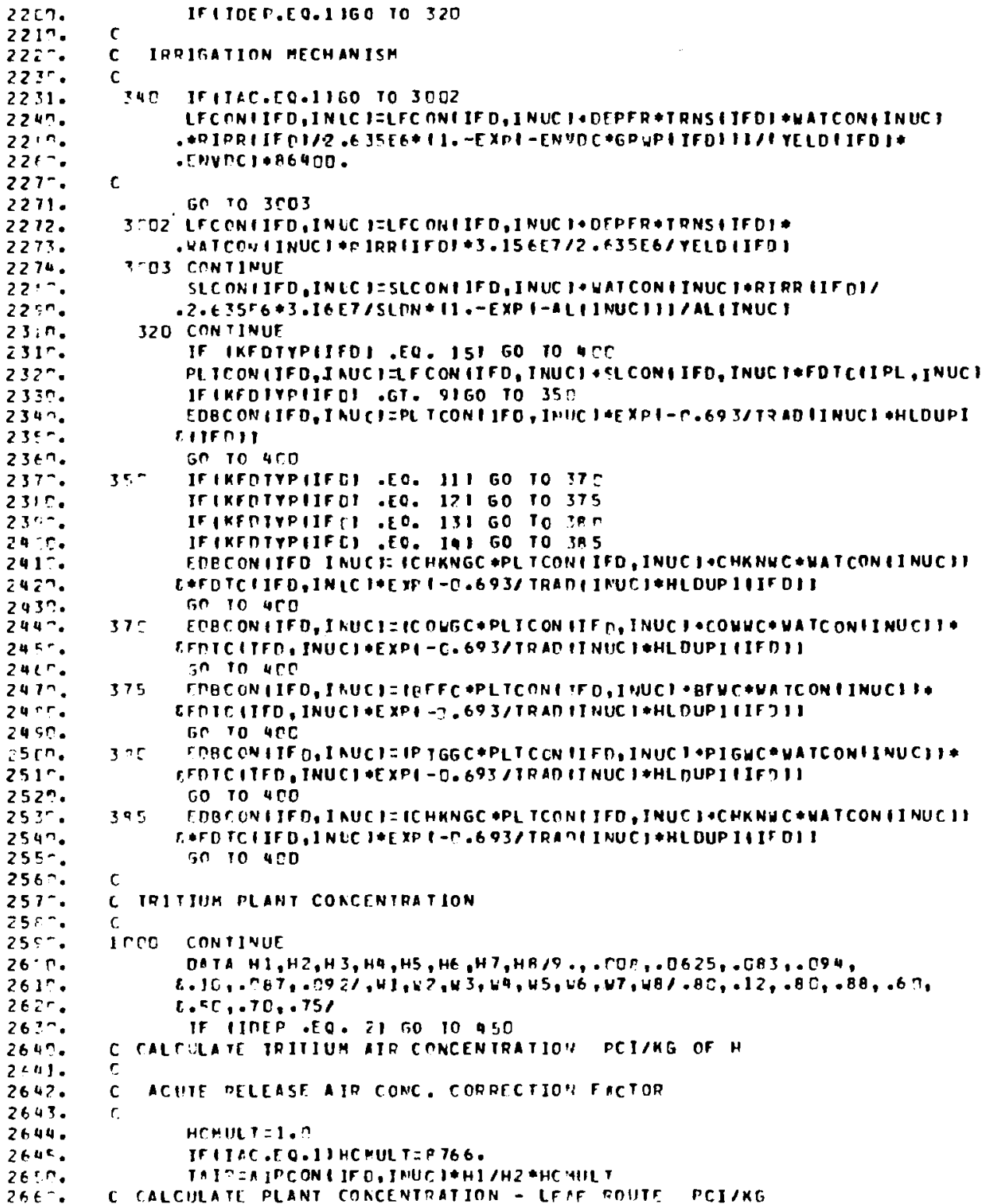




\section{PABLM}

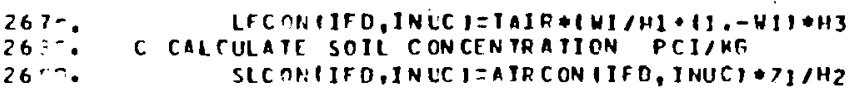

$27+3$.

2720

2735 .

$274 \pi$.

2759
274.

2765

27ir:

$27 c^{-}$

2850

$582=$

$583-$

$284 r$.

$28 \div 0$

$28,-$

$58 \div 5$

$28 \div$

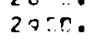

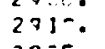

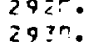

CI=PL TCONIIFD INIC I EEDI- C.EQT/TRADIINUCI. chothrilfol

\section{CALCULAJE ANIMAL PRODUCTS CONCIENTPATION}

C CALCILATE TRITIUR GDAIN CONCENTRATION PCIMKG

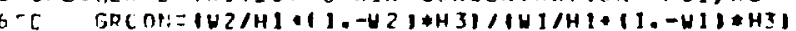
IFIKFOTYPIIFDI .EC. 11190 10 610

IF IKFDTYPIIFOI .FO. 12160 10 620

IF IKFOTYPIIFO . $00.131,60$ 10:35

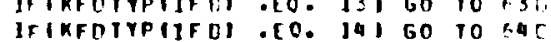

PLTCONIIFD, INUCIEPL TCONIITO, JNICIPGPCON

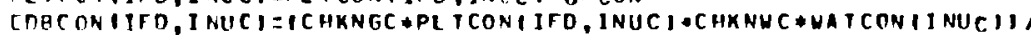

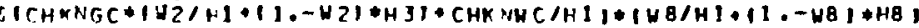

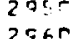

$237 \div$

$23 \div 0$

$235=$

$3 \sin$.

$3: 2 r$.

$3 r i n$.

$3=-5 r$.

$3 \sin 0$

30.90.

$30: \sin :$

31,90

3130 .

315

$316 \div$

$311 \div$

$31=\cdots$

$32: r$.

$3>10$ 5e $104 \mathrm{CO}$

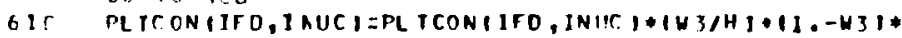

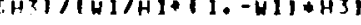

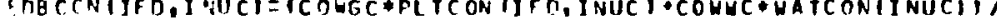

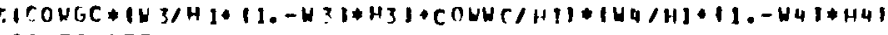

Go $10 \mathrm{C} C \mathrm{O}$

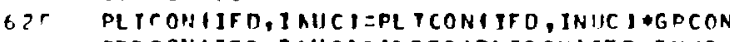

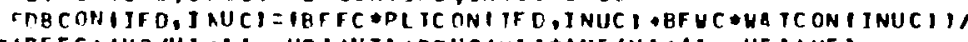

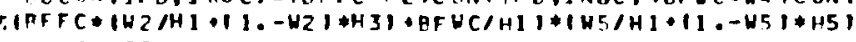

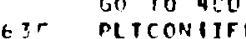

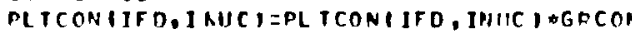

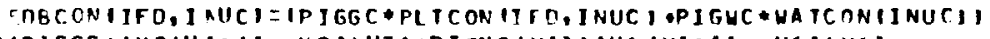

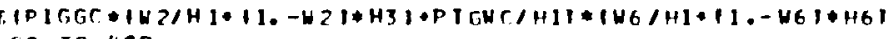

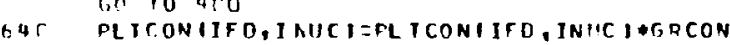

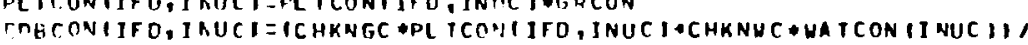

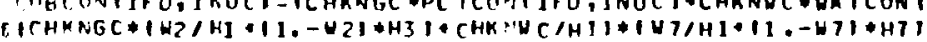
6010400

C CARDON-14 PLANT CONCENTOATION

15 CO CONTINUT

DATA C C, C $1, C 2, C 3, C 4, C 5, C 6, C 7, C F, C Q 17,1 E-5,1,6 E-4, .11$

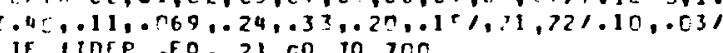

C CALCULATF C-1G AD CONCENTRATION - PCIAKG OF C 


\section{PABLM}

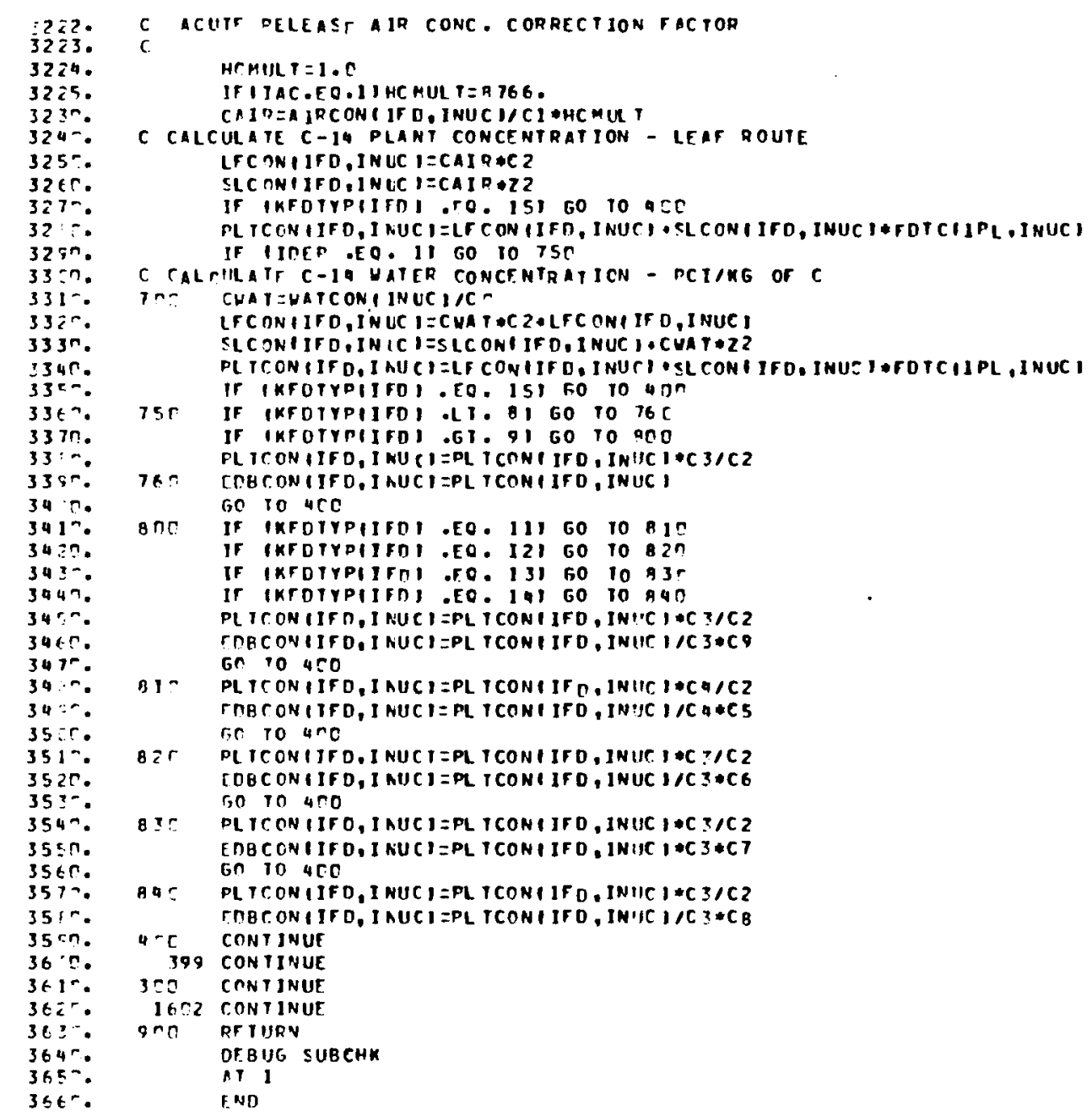

END FIN 4954 IRA:IK 511 RBAlK 


\section{PABLM}

OFIN,SO AA .ACHATN

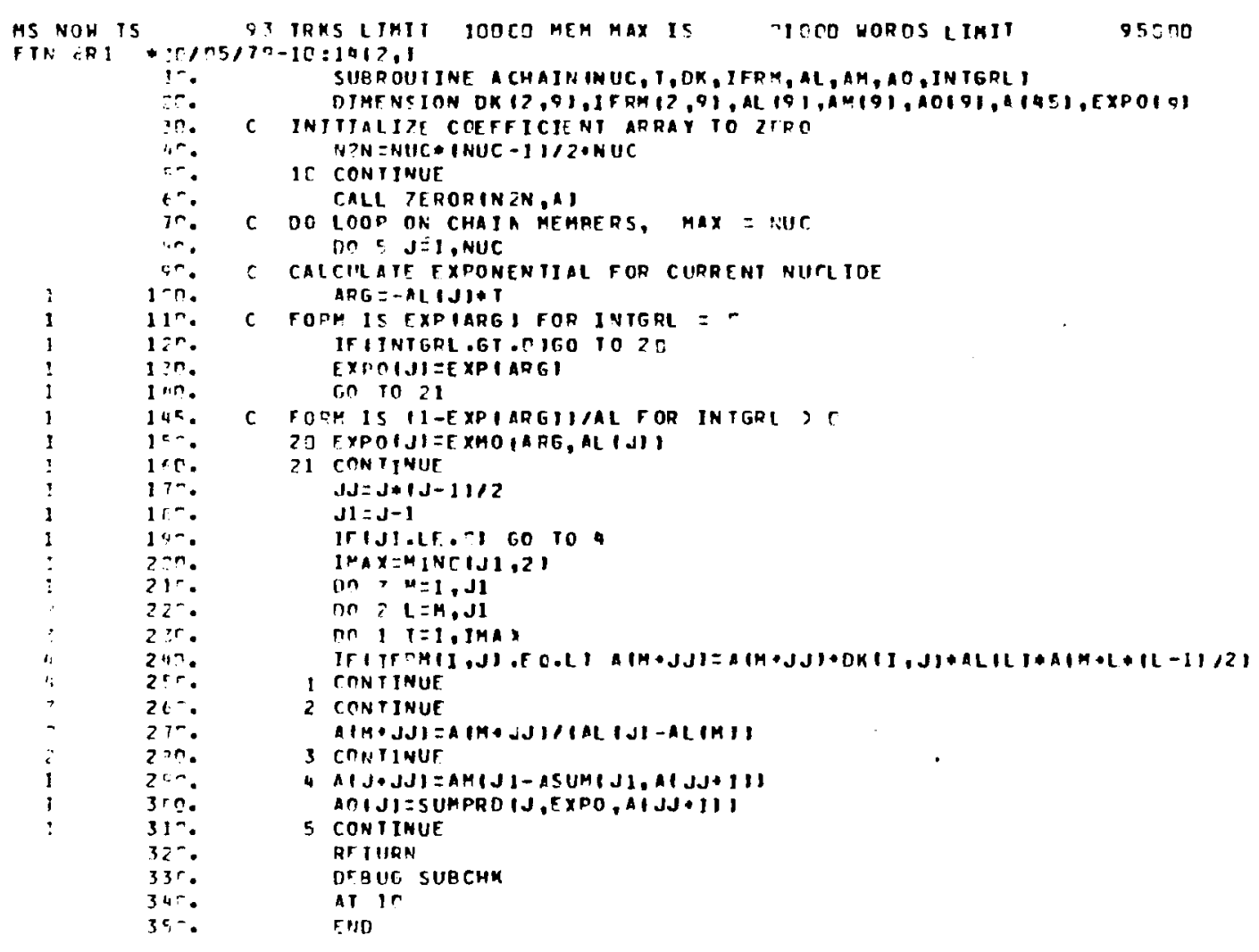

ENO FIN 4 G IPAIK 135 OPAYK 


\section{PABLM}

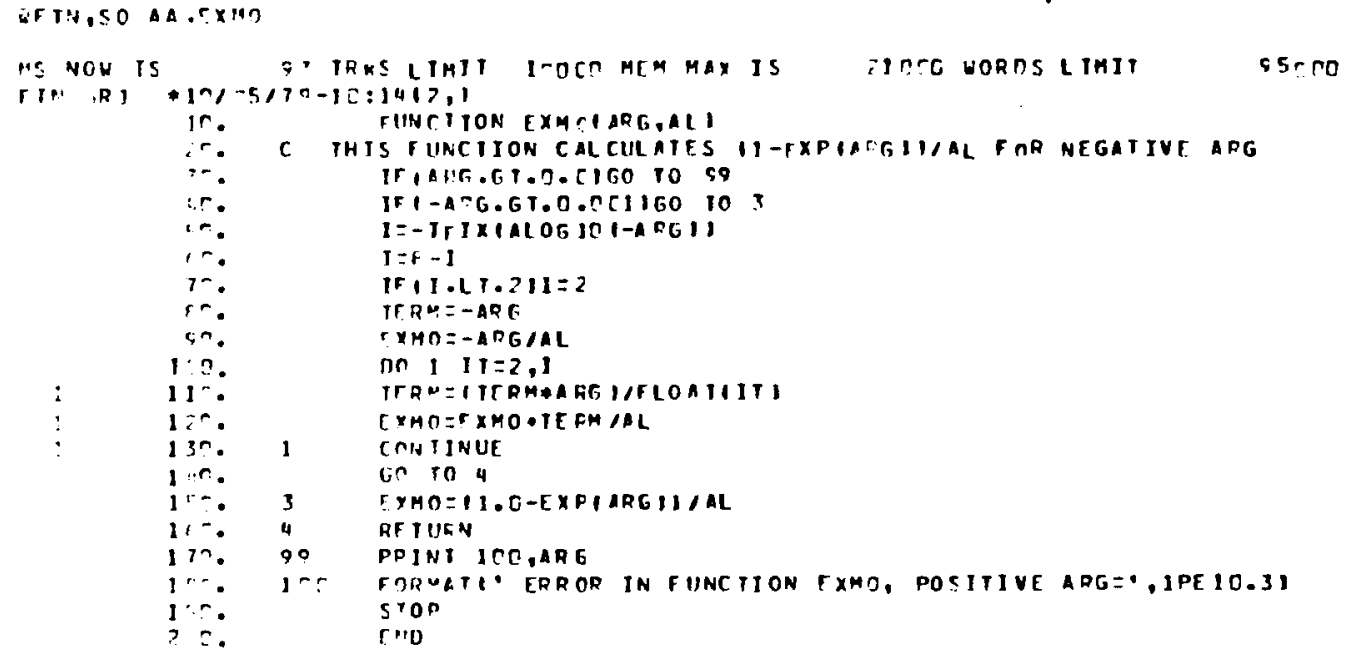

END FTN 1 J TFANK 40 DEANK 


\section{PABLM}

\section{ar IN,SO AA.ASUM}

MS NOH is Q TRKS LIMIT ICOCN HEM MAX IS

$$
\begin{aligned}
& \begin{array}{ll}
\because & \text { OIMENCION AIII } \\
\because & \text { ASUM=? }
\end{array} \\
& \text { co } i \mathrm{i}=1, \mathrm{~J} \\
& A \subseteq U M=A S U M \text { OAII }
\end{aligned}
$$

TICEC WOROS LIMIT

$950 \pi 0$

CNO FIN $4 Z$ TBANK IH DPANK 
6. PABLM

AF IV.SO AA SUMPRD

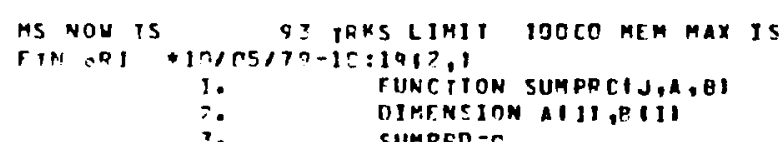

$m$ 


\section{PABLM}

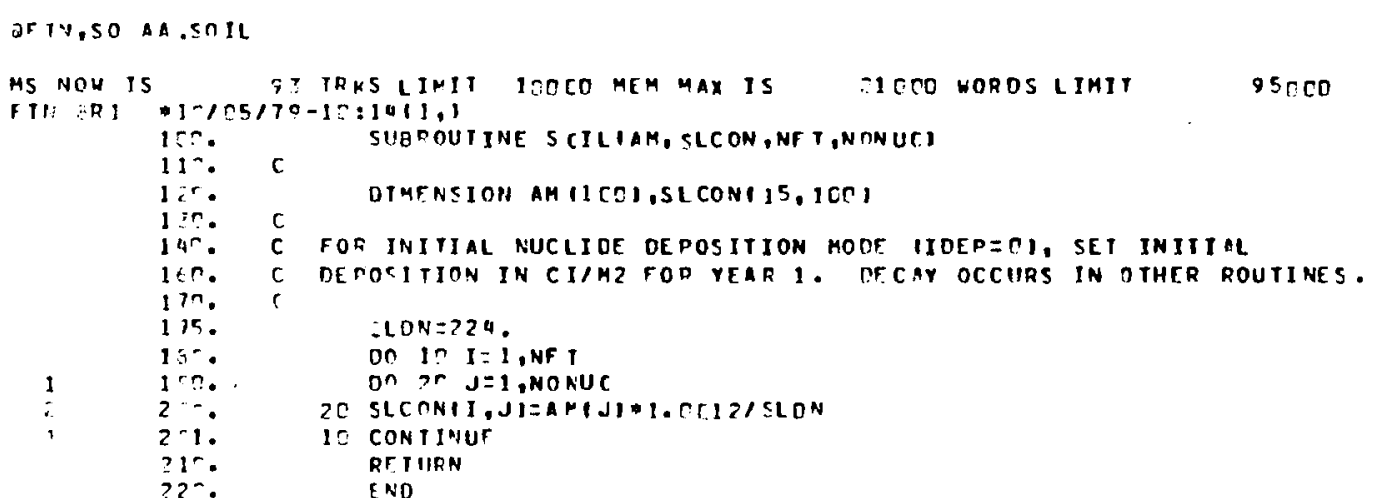

END FIN 67 IBANK 7 ORANK 


\section{PABLM}

aFTn, 50 aA. BOSCL

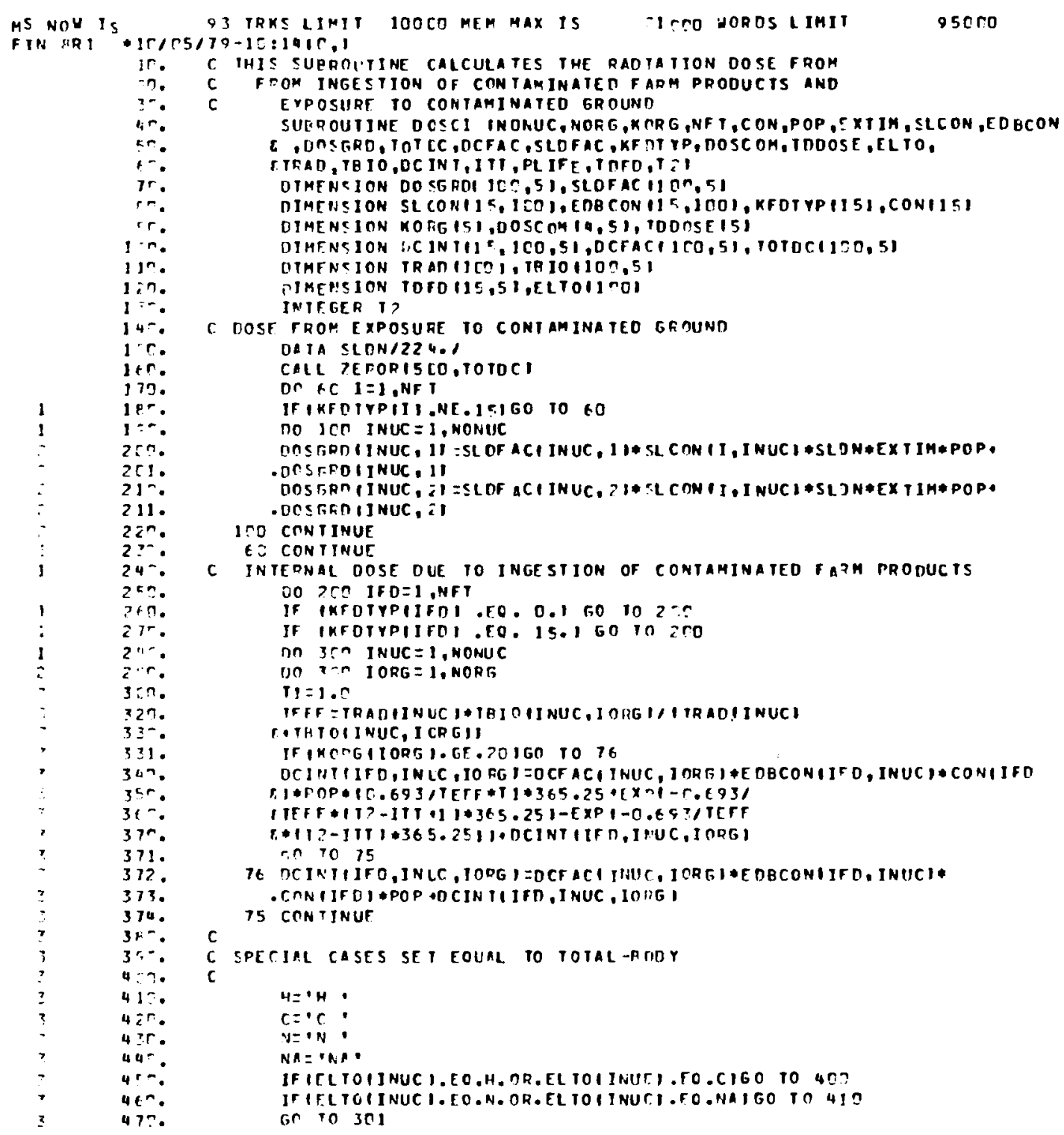




\section{PABLM}

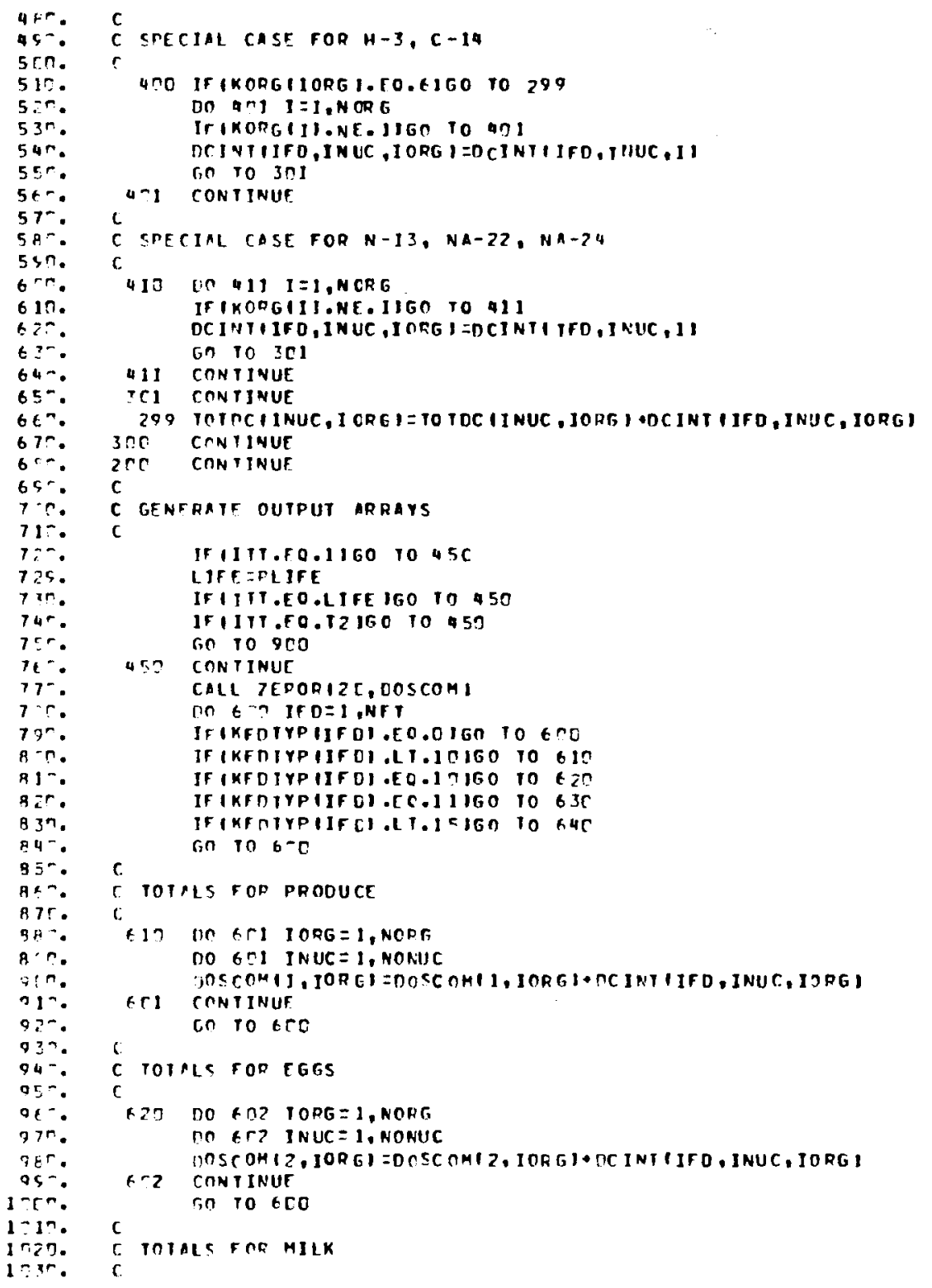




\section{PABLM}

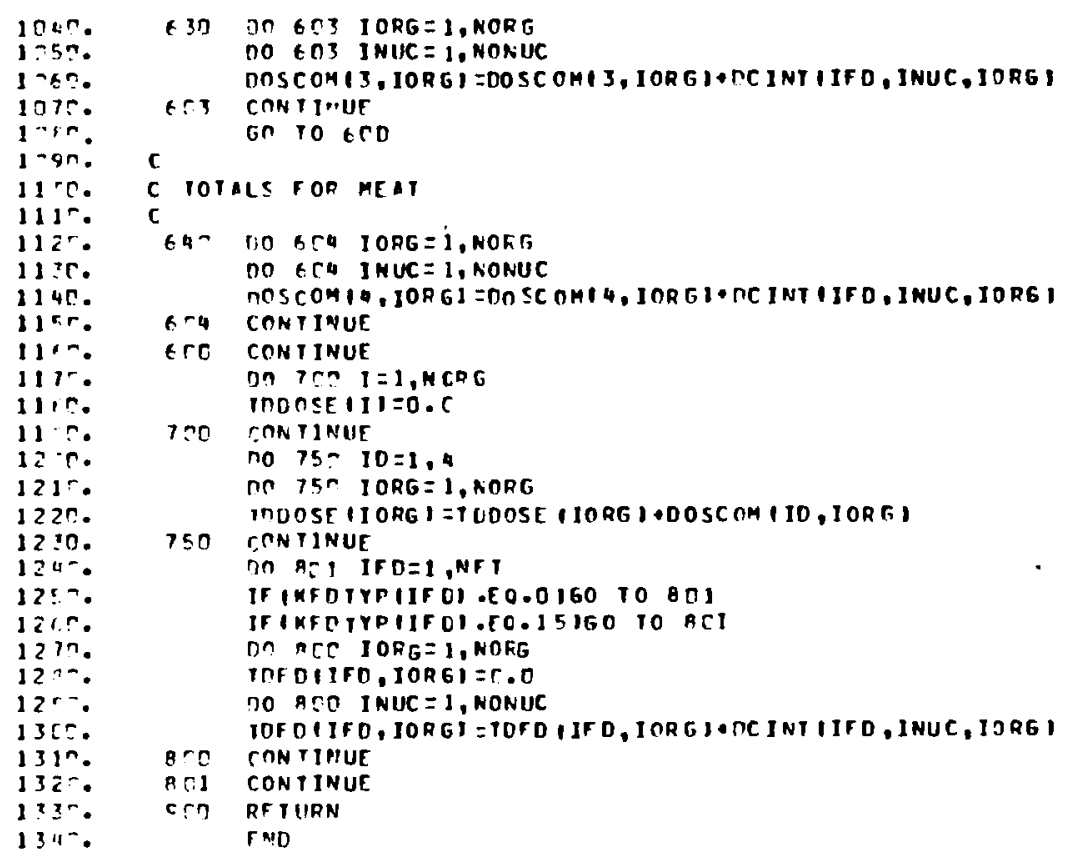

TND FIN 839 ITANK B? DPANK 


\section{PABLM}

AFIN,SO AA. חOCC2

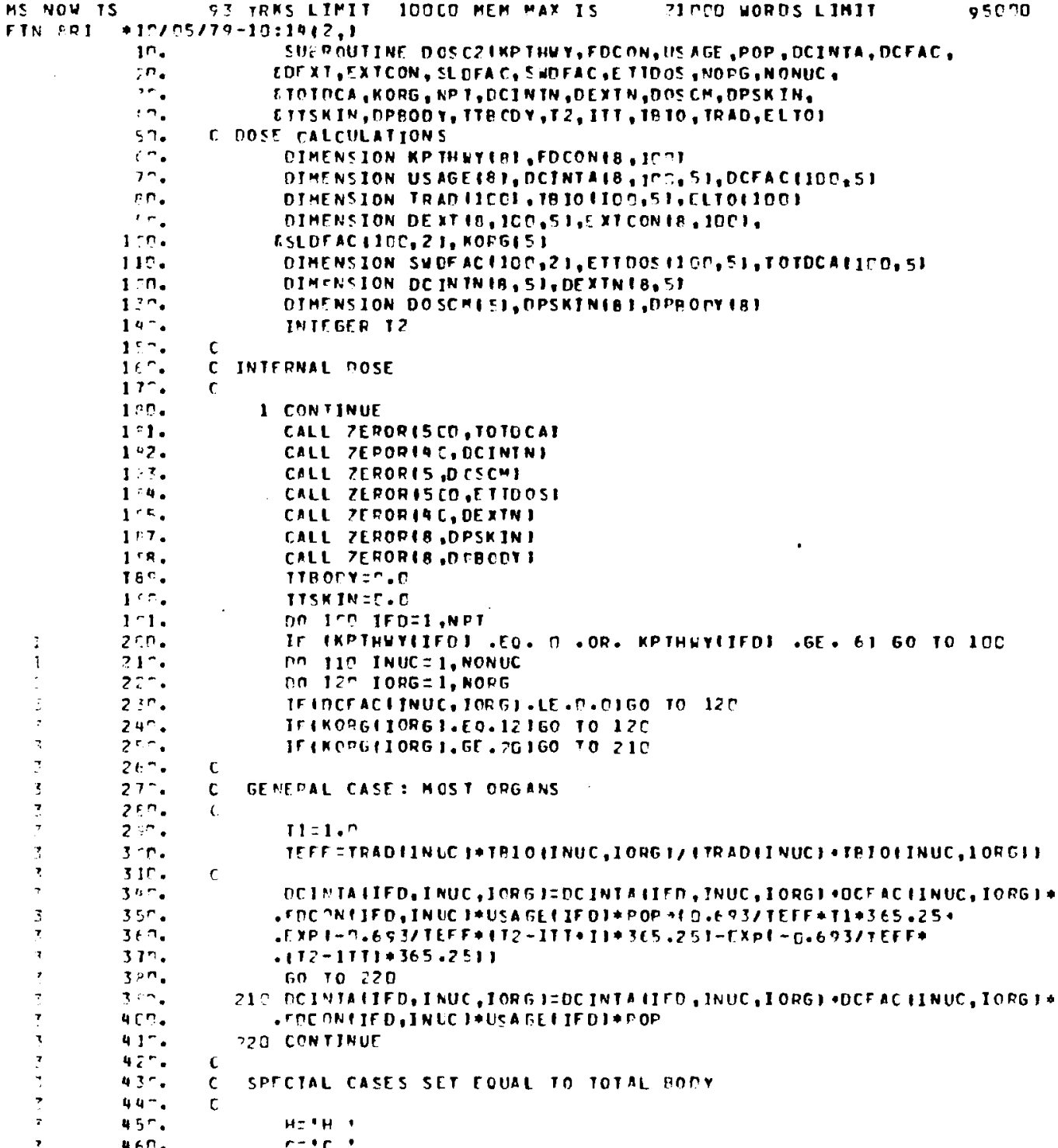




\section{PABLM}

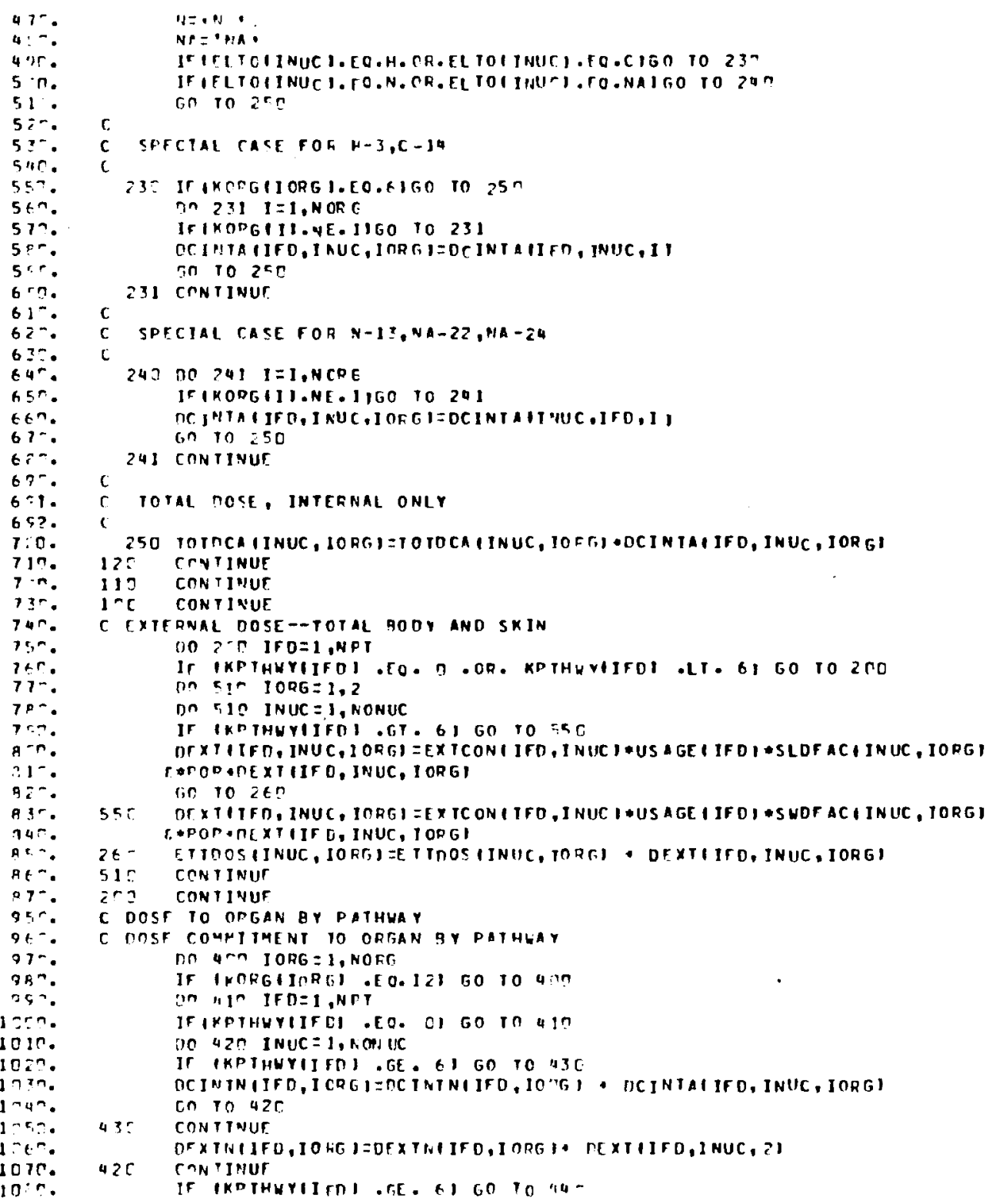


6. PABLM

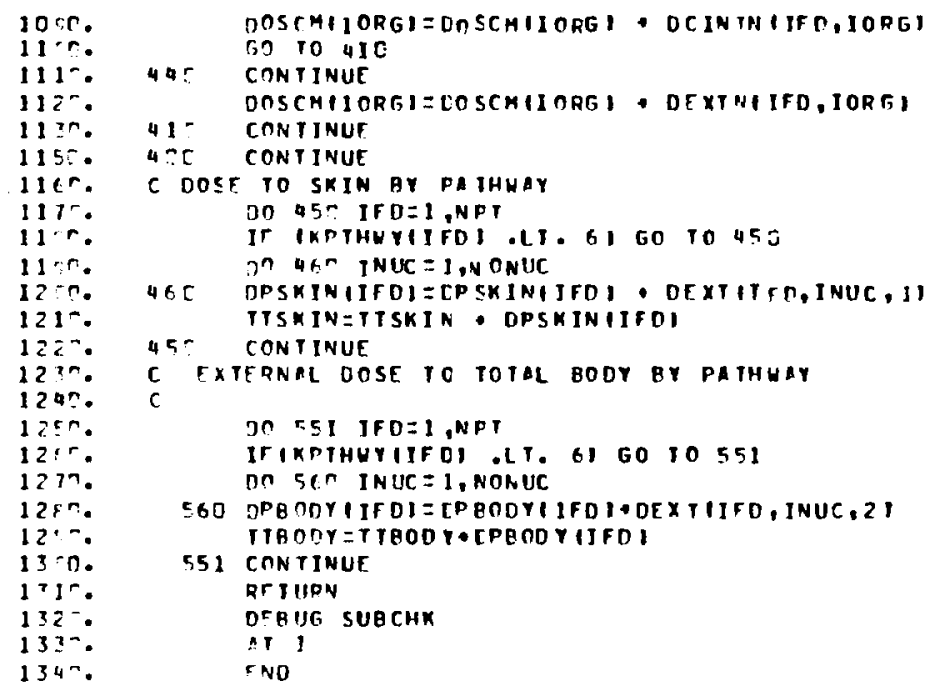

ENO FTN 14C5 IAANK DTE TEARK 


\section{PABLM}

$\because F: N, S O A R$, nOSOUT

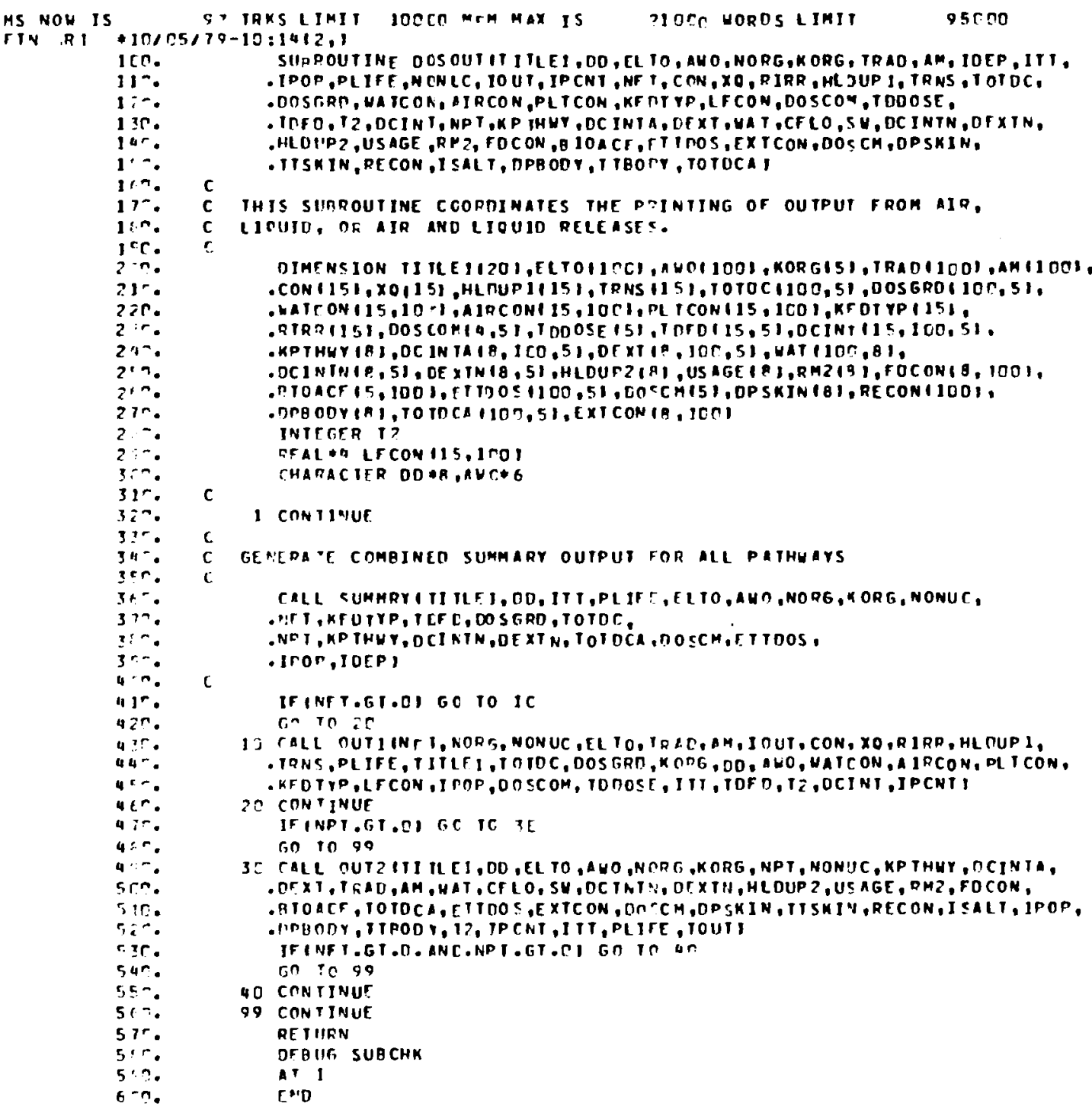

CRLL SUMHRYIIIILFI, DO,ITT,PLIFT, ELTO,AHO,NORG, KORG, NONUC, DIT T,KFUTYP, TEFE, DOSERD, TOTOC.

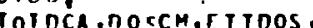
iror,idepi

IFINF T.ET.OOI GO 10 IC

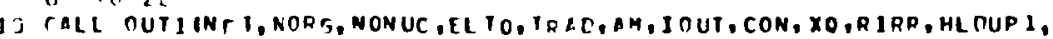

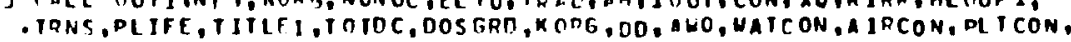

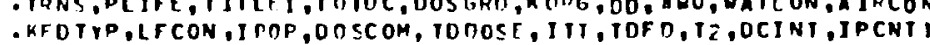

50 CONTINUE

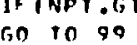

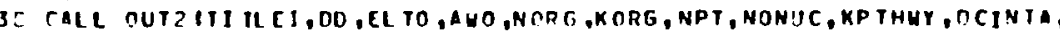
-OFXT, TKAD,AM, HAT, CFLO, SH,OCTMTN, OCXTH, HLDUP 2, USAGE, DHZ, FOCON,

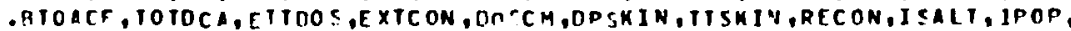
- POBODY, ITPOD I, 12, TPCNT, ITT, PLITE, TOUI JFINF T.GT.O. ANC.NPI.GT.CI GO IO Un$$
\text { on ic } 20
$$

90 CONTINUT

RE TIIRN

OFB IIG SUBCHK

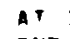

["D

CHE FIN 42 ? 19APM 210 IRANK 


\section{PABLM}

aFTN, SO MA SUMMRY

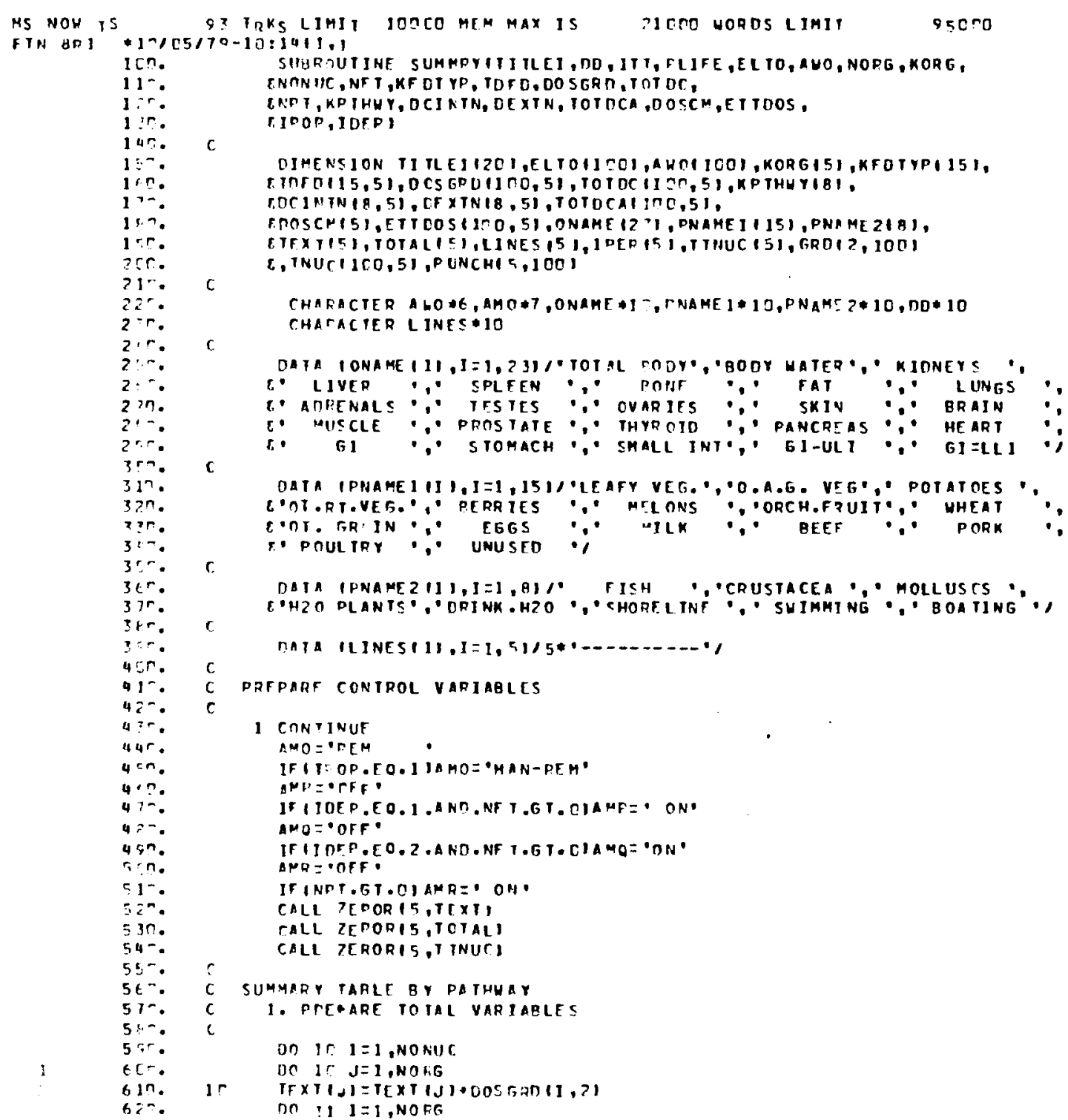




\section{PABLM}

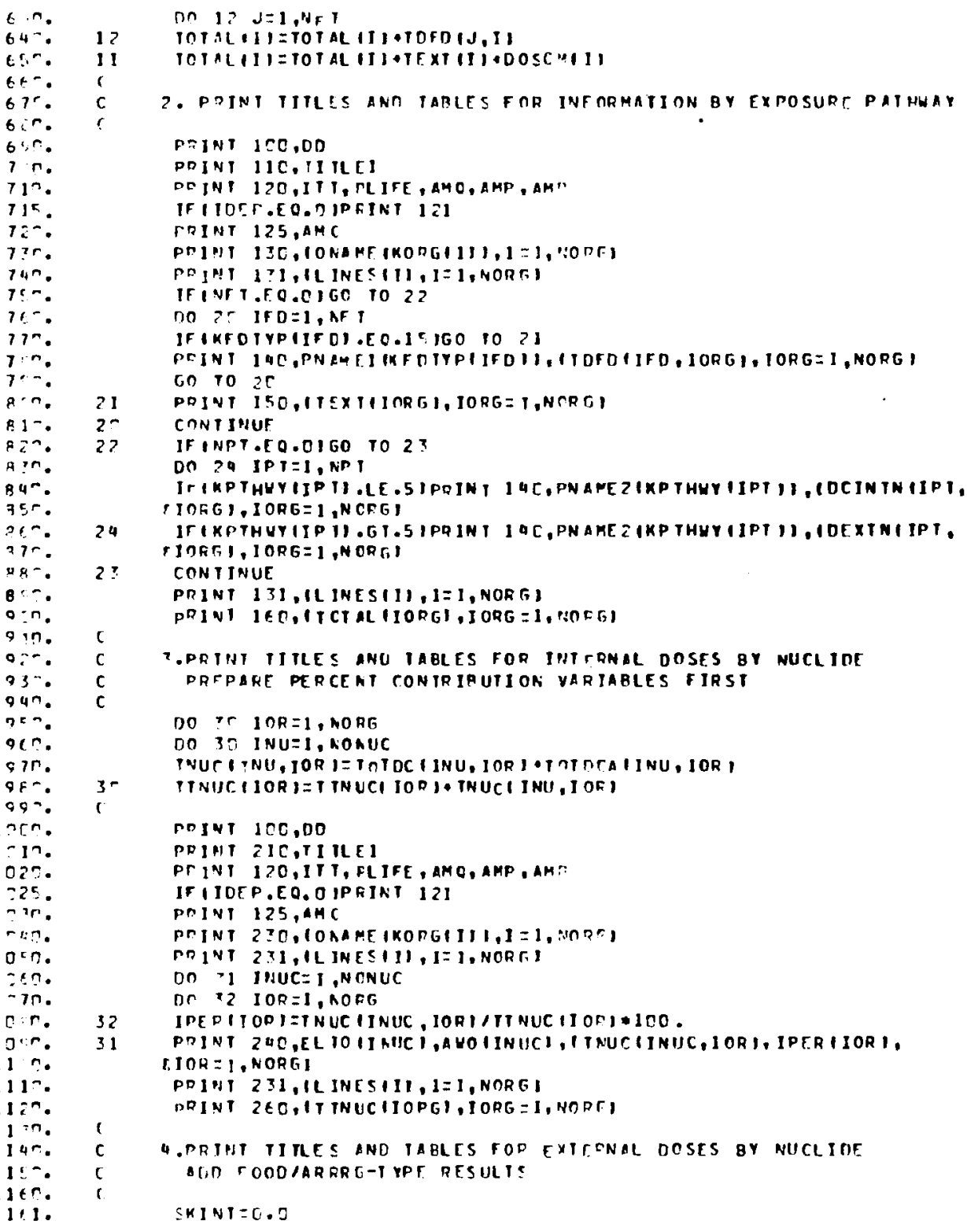




\section{PABLM}

41 PRINT 3AO,EL TOIINUCI, AHOIINIICI,GROL1, INUCI, TPER1, GROIZ, INUCI, T.IAERZ

POINT 331

PRINT $360,5 K I N T, B O D Y T$

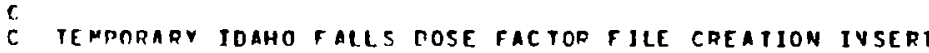

1. AUD TOIAL BODY EXTERNAL TO TOTAL BOOPY INTERALL

no 1 mo $7=1$, nONUC

on $999 \mathrm{~F} J=1, N C R E$

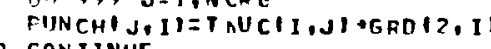

ICOC COn 1 INUE

c

WRI TE 19,1 CO2 II IT, AMO, AMP, TKORG II , I I 1, NORG

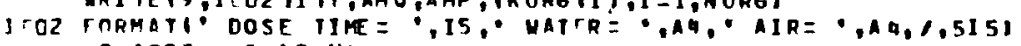

an 1 irn $3=1$, NOAUC

1

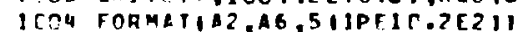

C ENT INSERT

C MERE IS WHERE ALL THE OAMN FORMATS TOO

ITE FORMATIIHI,T3E. 'COMBINED PATHM OY SUMMARY TOTALS PAELM VERSIONZO, $\sin , 1,1,1$

110 TORMATIT35. TOTALS BY PATHWAY TOP SPECIFIED ORGANS IINTEPNAL.

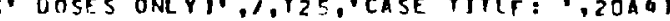

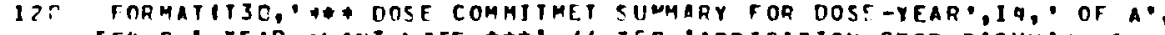

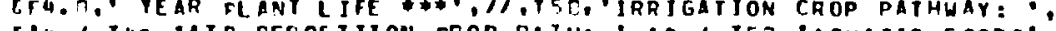
CA4, 1,T4O, TATR DEPOSITION CROP FATH: 'AO,1, T52, A QUATIC FOODC: T., rethuar: , a 4,11

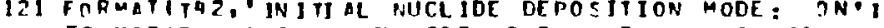

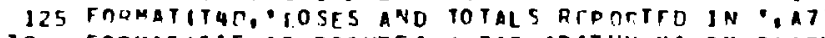

POSIIRE $, 1,1,15$, PSTHW YY $, 5 x, 5110 X, 41011$

$3 \geq 1$ Formetit15,

1710.014 


\section{PABLM}

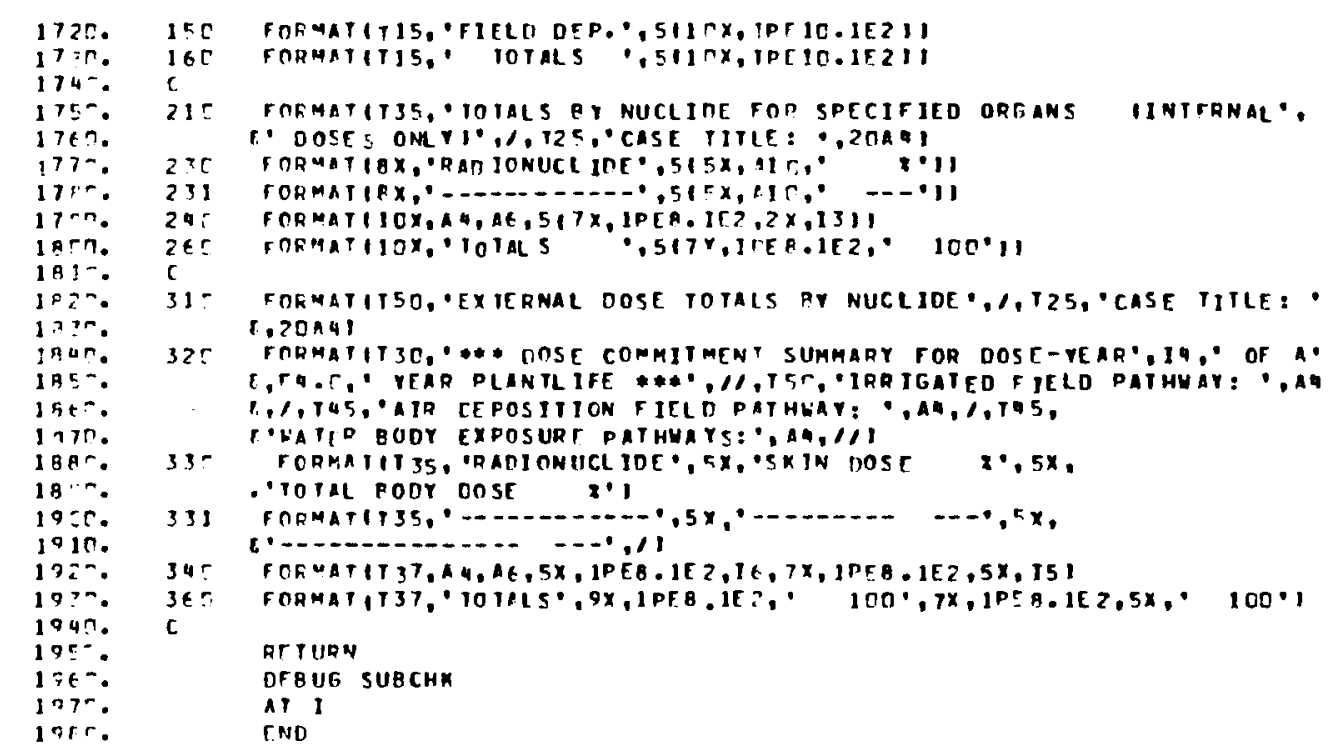

EHC FIN 87 I IAANK 276 T DEANK 


\section{PABLM}

aF IN,SO AA.OUT

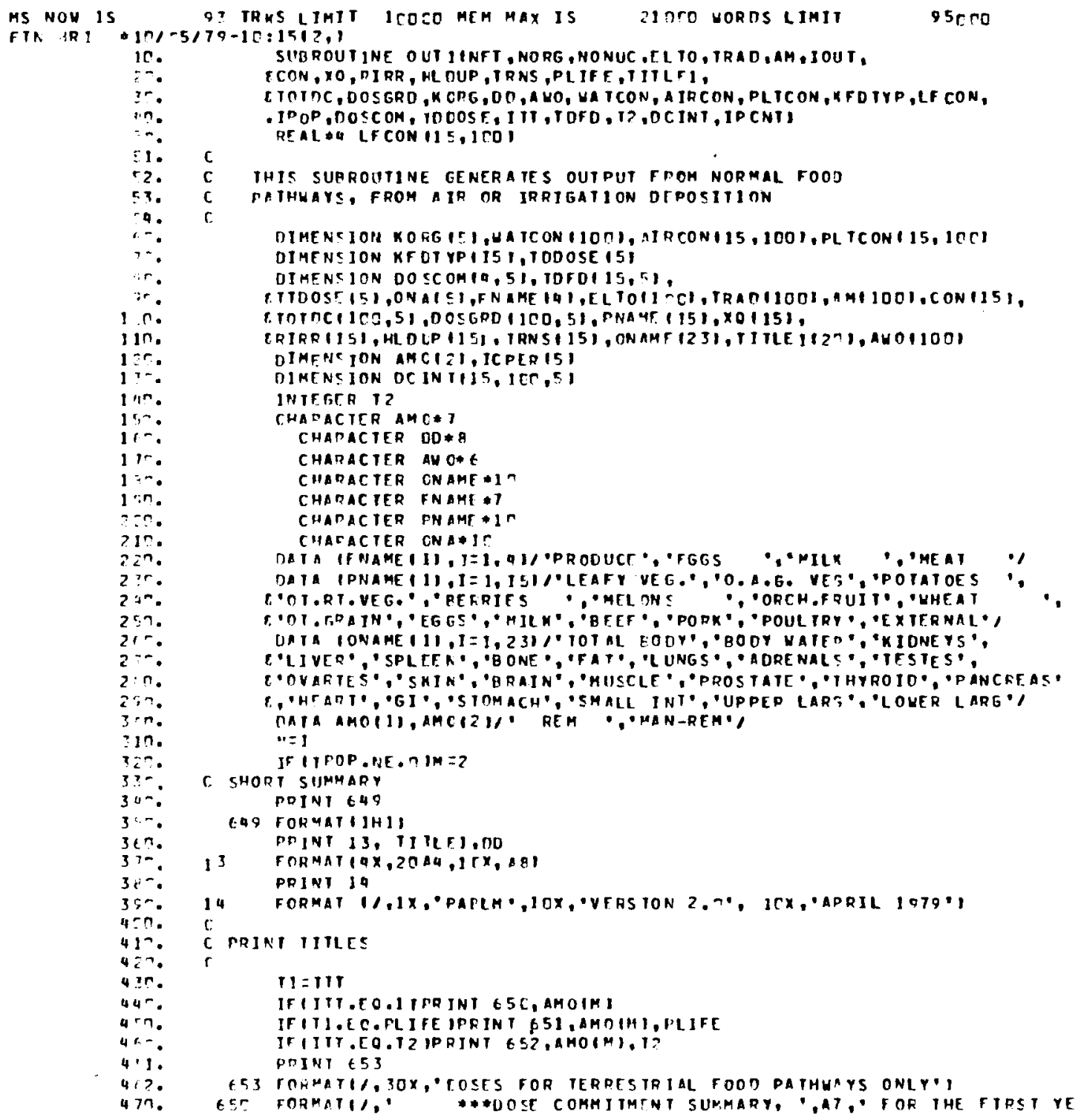




\section{PABLM}

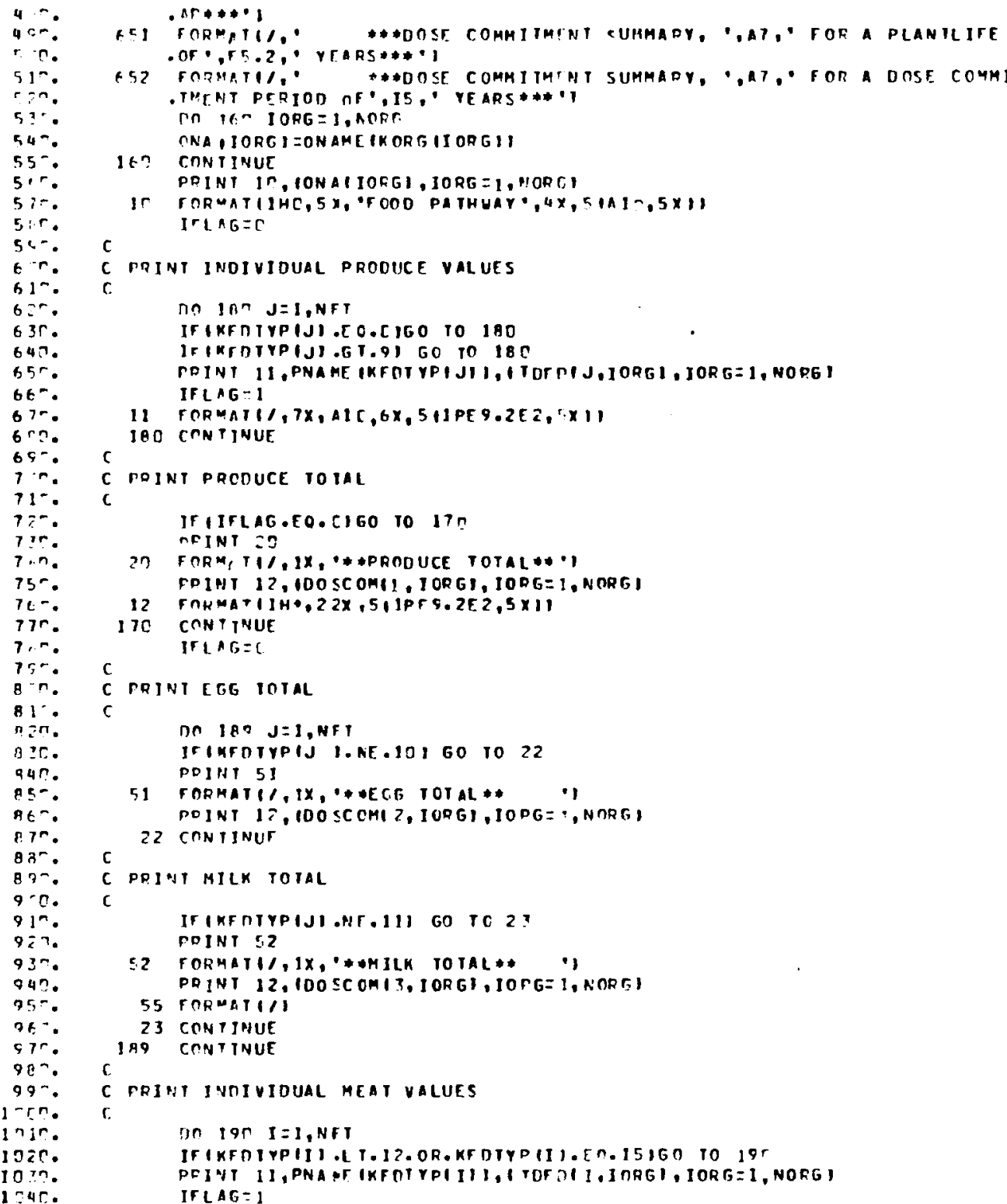

12 FOKMATIIHT, 22X,51PFS.2E $2,5 \times 11$

770 CONTINUE

C FRINTEGG TOTAL

DO 180 D $J=1, N F 1$

IFINEDTYPIJ I. NE. 10160 TO 22

PDINT 5 I

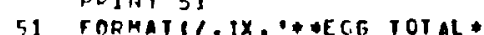

POINT 1\%, 10OSCOMI Z, IORGI, IOPG = , NORGI

2 CONTINUT

C PPINT MILK TOIAL

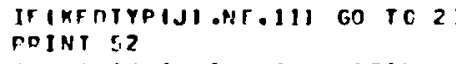

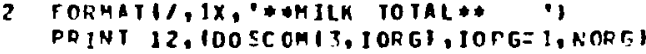

52 TORMATII

53 CONPJAUE

1 AQ CONTINUE

c FRINT IUTIVIDUAL MEAT Values

C. DO $19 T \quad I=1, N F T$

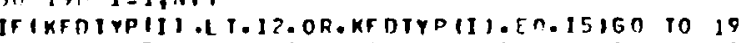

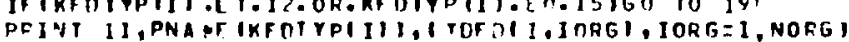
IF $A G=1$ 


\section{PABLM}

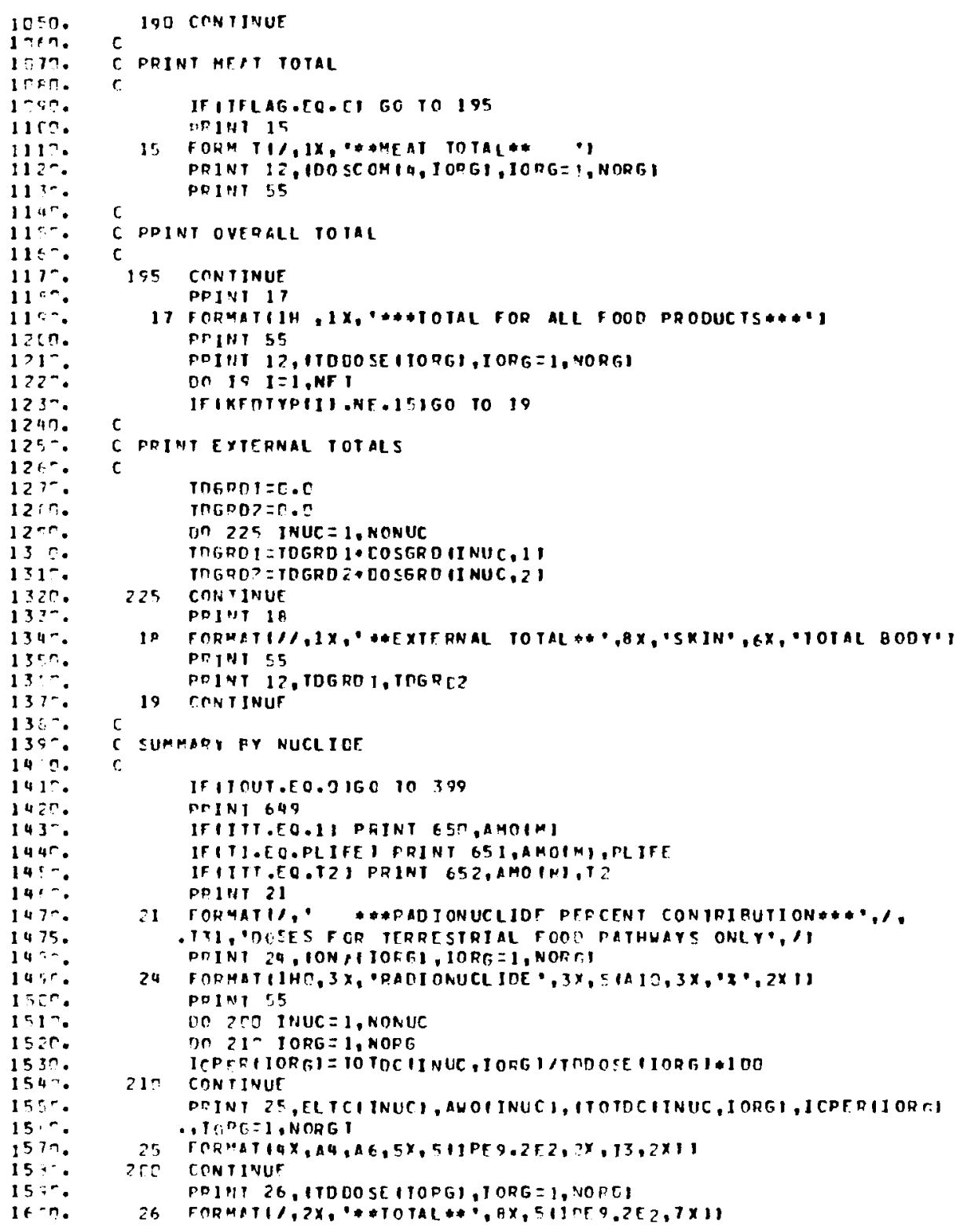

190 CONTINUE 


\section{PABLM}

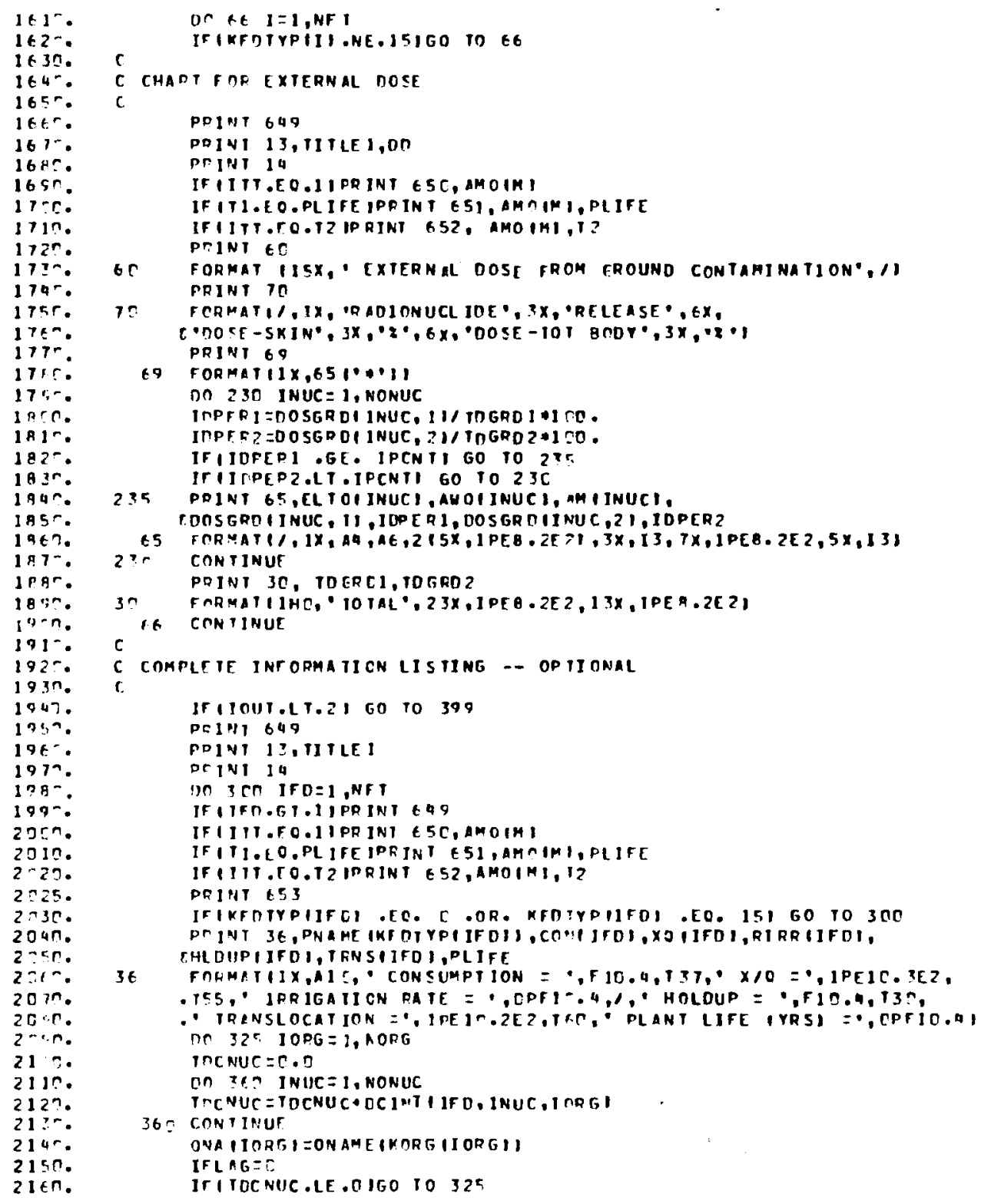




\section{PABLM}

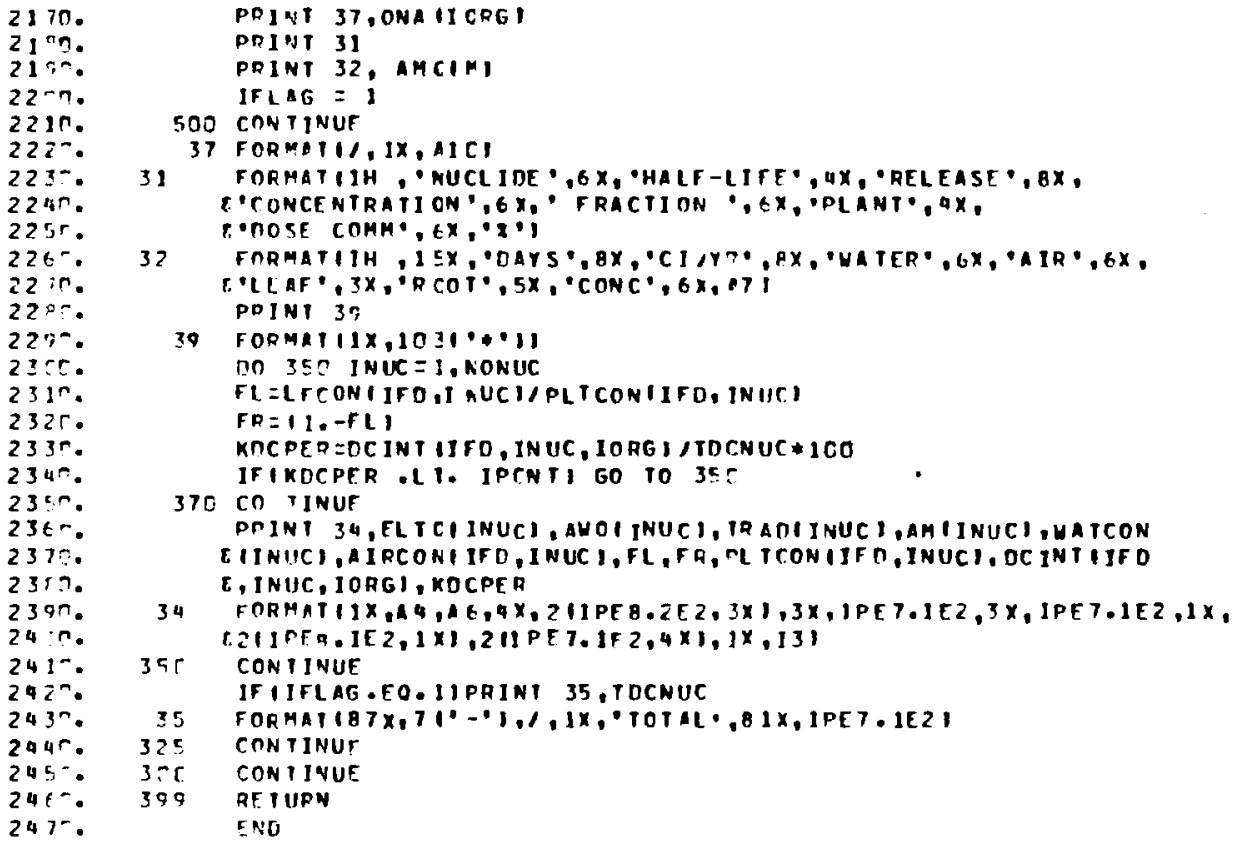

ENO TTN 767 I RANK 1503 DBA AK 


\section{PABLM}

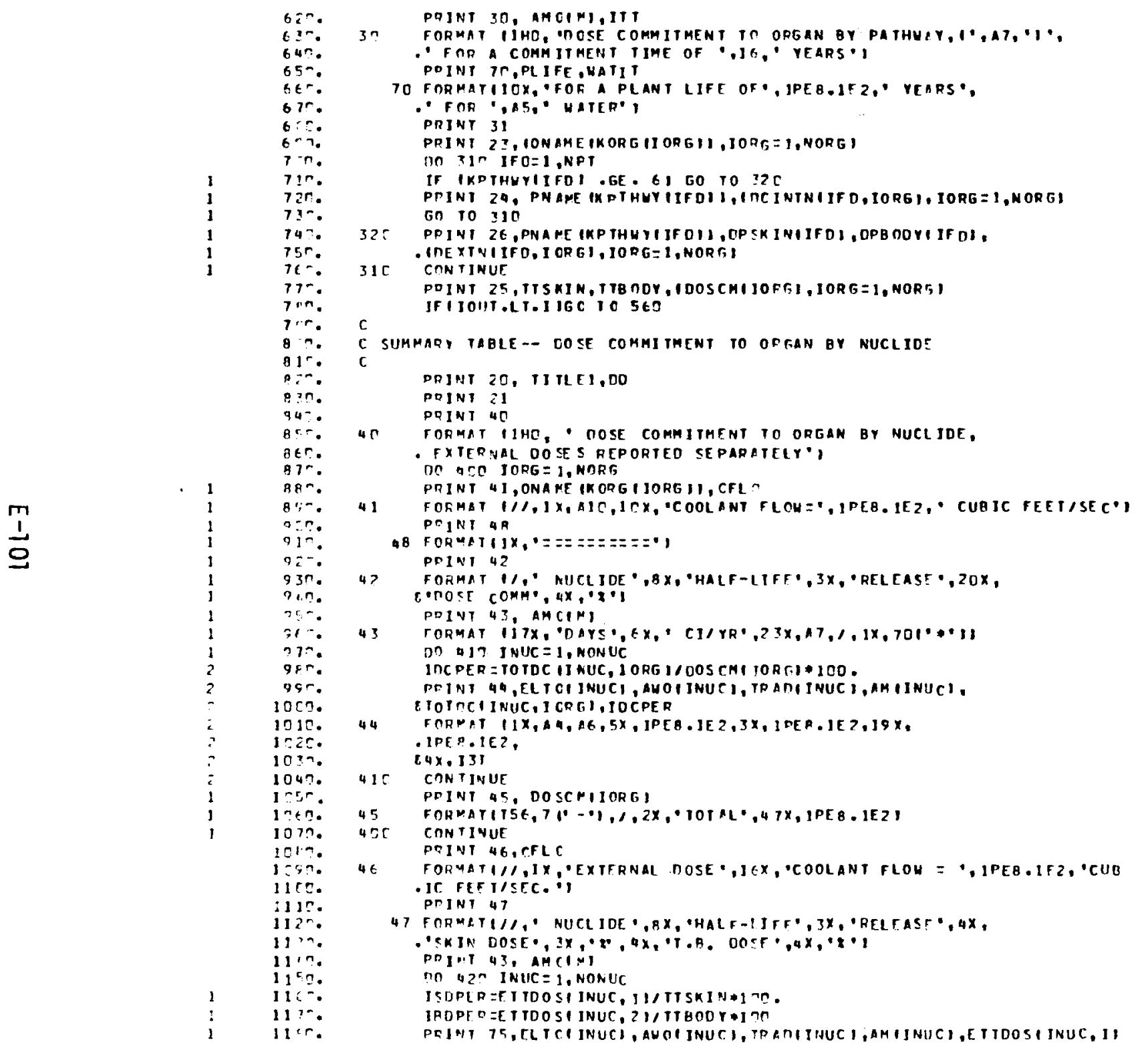




\section{PABLM}

arin,SO AA . OUTZ

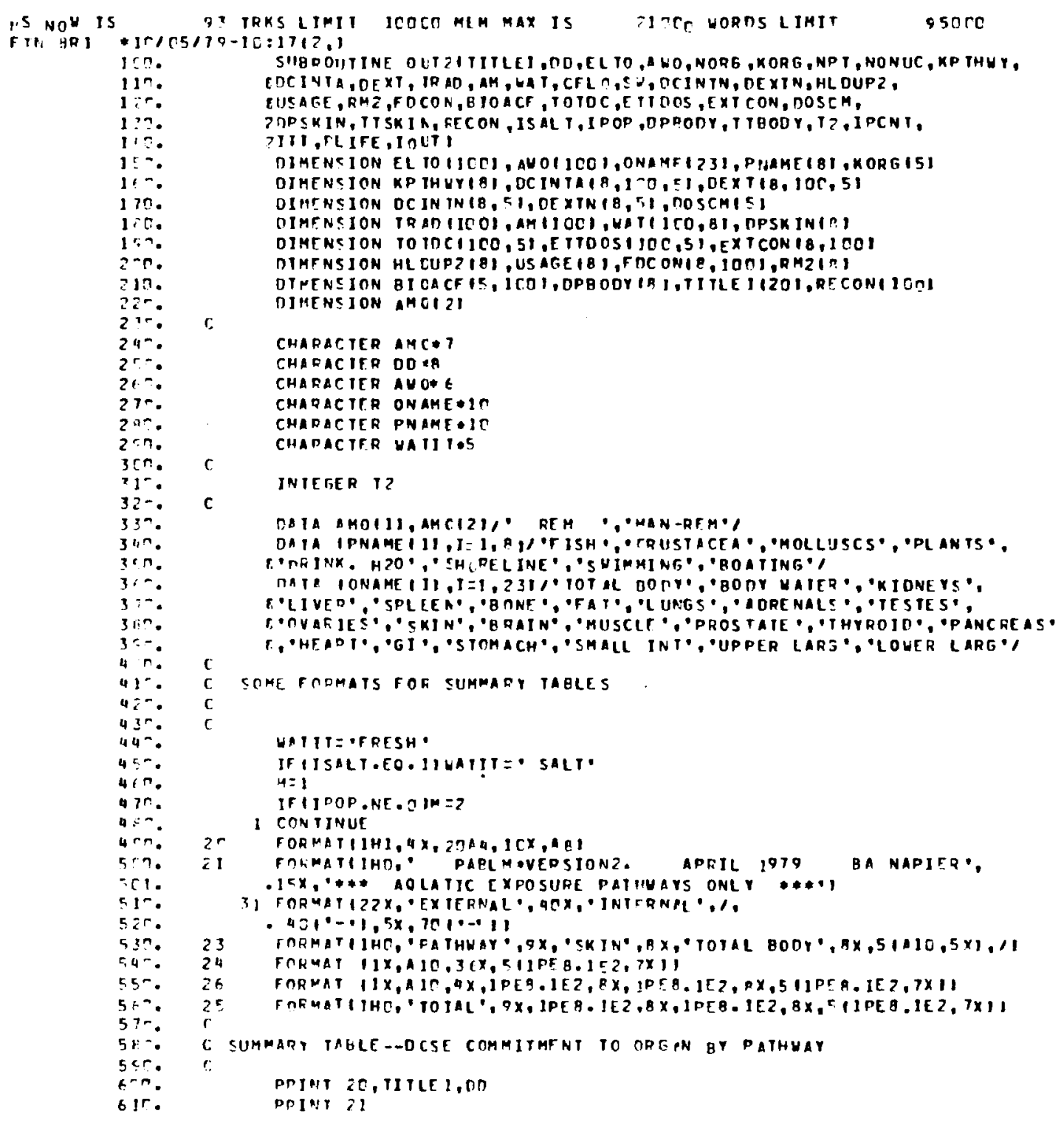




\section{PABLM}

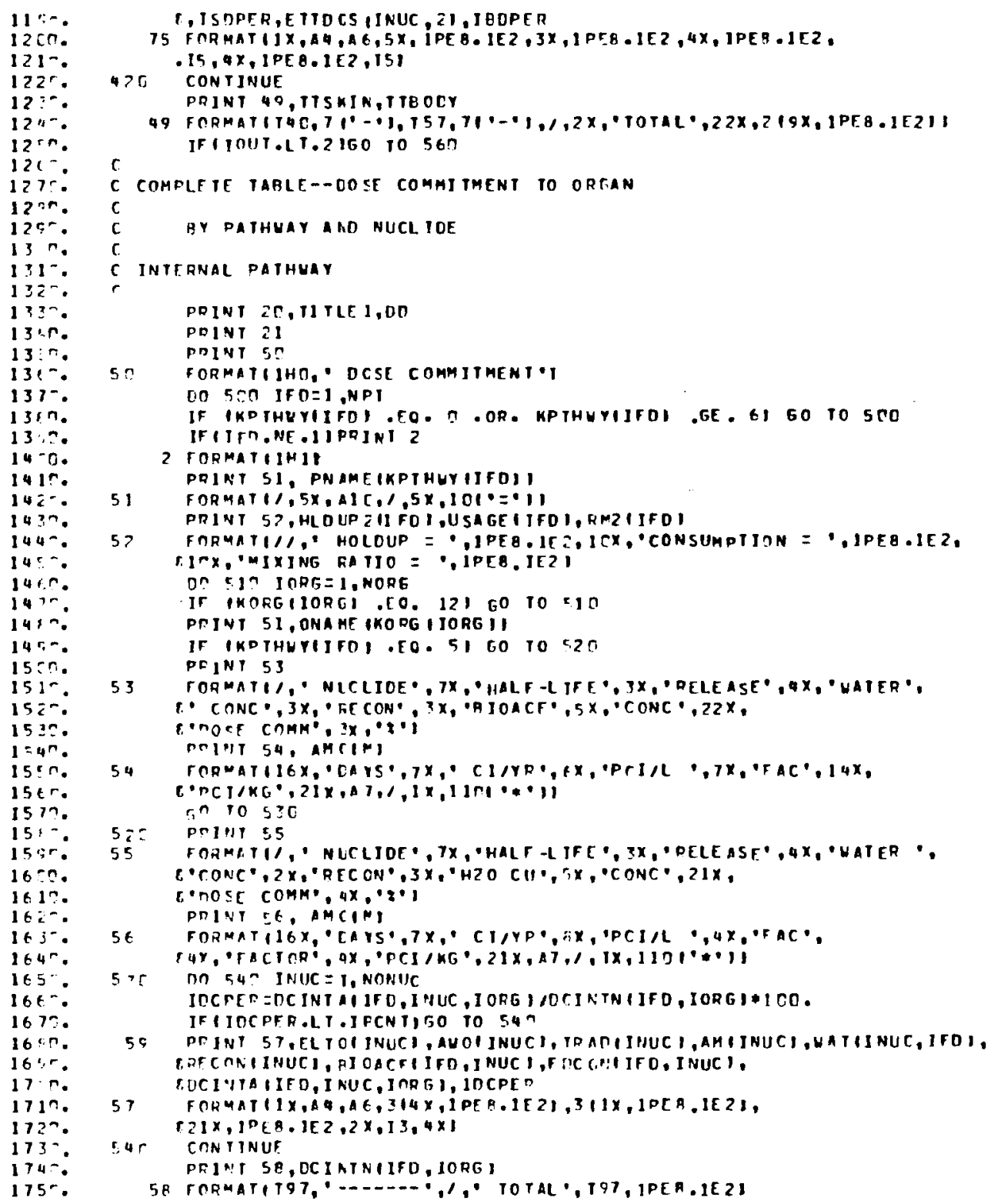

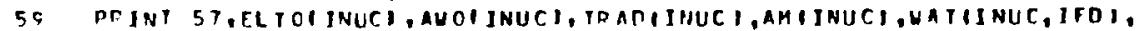

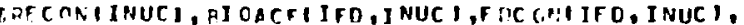

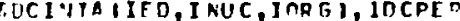

57 FOR AATI1X,A4,AE, 314X,1PEQ.1E2\},311X,1PEA,1E21,

sur CONTINUE

5B TORMATTOT, - 


\section{PABLM}

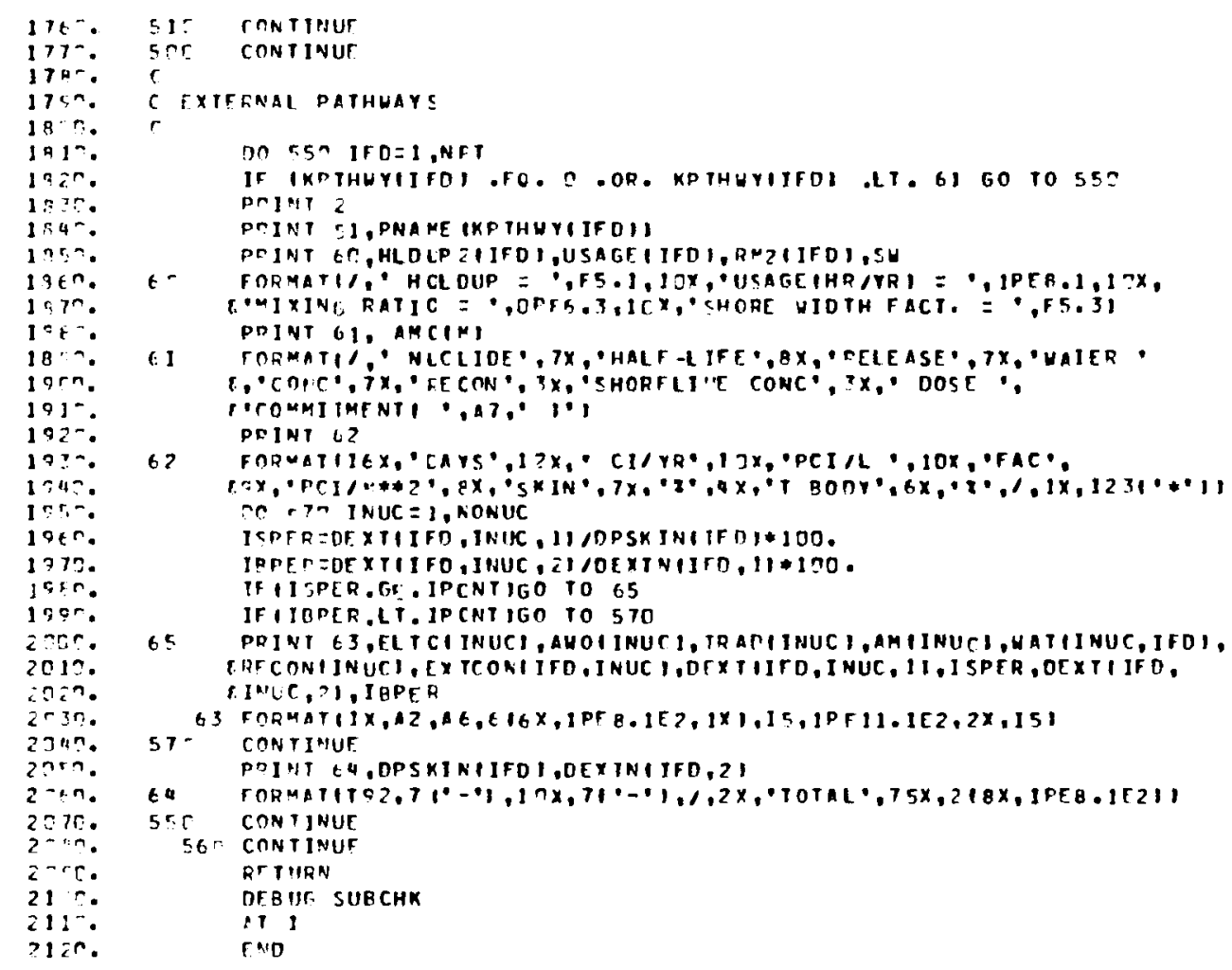

FND FTH 71A IPANK 2O4* OBAPK

ATACA AA.

ME NOH IS S? TRKS LIMIT 100 CO MEM MAX IS POC WOROS LIMIT PSCCO FIIRPUIR 27R? SL73R1 1ח/R5/70 1:::17:50

EPD PACK. ICXI=C1, IOC $=1.5 Y M=25, P C L=25, A P S=1$

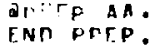

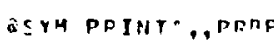

ir IV 

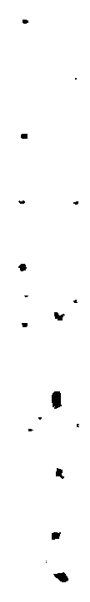

1

$i$

1

1 
APPENDIX $F$

INPUT PREPARATION AND DIAGNOSTICS 


\section{APPENDIX F}

\section{INPUT PREPARATION AND DIAGNOSTICS}

The input data required for the calculations falls into four catagories: general parameters, terrestrial parameters, aquatic parameters, and radionuclide release information. The preponderance of the data required by the code is contained in five data libraries that are accessed by the code (see Appendix E), thus eliminating much effort in preparing the input.

The general parameters include program control parameters, case-specific control parameters such as population and plant life, and reconcentration parameters. The terrestrial parameters characterize the type of farming done near the area of interest, and the aquatic parameters characterize the exposure pathways from liquid releases.

This appendix describes in detail the input variables, their use and the manner in which they are input to the program. The code has some selfgenerated diagnostics if an error is made on input. These are discussed after the input parameters. 


\section{DATA CARD DESCRIPTIONS}

\section{CARD 1--TITLE CARD}

An entire card in Format 20A4. Words entered here are reprinted as a title on the output pages. Each following case requires either a title or a blank card.

\section{CARDS 2 TO $\mathrm{N}$--NAMELIST DATA CARDS (ONE OR MORE NAMELIST CARDS)}

The minimum data for each case consists of one title card (Card 1), and one or more cards using the Namelist format (Cards 2 to $N$ ). The first Namelist card (Card 2) must be blank in Column 1, \$INPUT in columns 2-7, followed by at least one blank, followed by data items. The data items are separated by a comma, and the last data item must be followed by a \$END. The data items must have one of the three following forms:

1. Variable name = constant, where the variable name may be either subscripted or not.

2. Array name = set of constants (separated by commas). The number of constants must not exceed the number of elements in the array and they must be in the same order as the array is in storage, i.e., the first subscript changes most rapidly.

3. Subscripted variable = set of constants (separated by commas). This form results in the set of constants being placed in consecutive array elements, starting with the element designated by the subscripted variable. Again, the number of elements in the array between the given element in the array and the last element in the array.

The namelist variables retain their values throughout the excution of the program and need not be respecified unless a change is wished. The namelist input variables are shown in the following list: 


\section{TABLE OF NAMELIST VARIABLES}

\section{GENERAL PARAMETERS}

\section{A. Program control parameters}

1. NEXT: This variable is used to string together several calculations. It controls the reading of radionuclide release inventories. There are four options corresponding to NEXT $=1,2,3,4$.

NEXT $=1$. For doing one case. Read release data, do computations, and end.

NEXT $=2$. Read release data, do computations, and prepare to read another case.

NEXT $=3$. Use previously input release data, do computation, and prepare to do another case.

NEXT $=4$. Stop.

2. IDEP: Key for the type of radionuclide deposition mechanism on terrestrial plants.

IDEP $=0$. Initial deposition mechanism. Input is in $\mathrm{pCi} / \mathrm{m}^{2}$ on the soil at time zero.

IDEP $=1$. Atmospheric deposition mechanism. If IDEP $=1$, any aquatic pathways will have zero results.

IDEP $=2$. Water deposition (irrigation) mechanism. This also enables the aquatic exposure pathways. With this option, the IREC option (described below) and its supporting variables must be initialized.

3. IOUT: Key for completeness of output.

IOUT $=0 . \quad$ (default) Summary by exposure pathway only for input organs.

IOUT $=1$. Summaries by pathway and by nuclide for input organs.

IOUT $=2$. Complete output by pathway and nuclide for input organs. This option generates much paper.

4. IPCNT: The percent cut-off for reporting doses by nuclide for IOUT option 2. Default is zero. 
5. IAC: Key for type of radionuclide release, either continuous chronic or accidental acute. Default is zero, chronic. If IAC $=1$ for acute is used, PLIFE should be set equal to one.

6. DKSORS: Key for automatic decay of source term. Note that this is an integer value. Default is zero, no decay. This variable is useful to simulate a source such as a tank with a constant mass leak rate and decaying contents.

B. Case-specific general parameters

7. PLIFE: The time in years that the release of radionuclides continues, starting at the time the calculation begins. Zero for initial deposition mode, zero or one for acute releases.

8. T2: The time in years for which the accumulated dose is to be calculated. Note that this is an integer value.

9. IPOP: Key for population considered.

IPOP $=0 . \quad($ default $)$ Maximum individual $(P O P=1)$.

$I P O P=1$. Population. This requires that POP be specified.

10. POP: The population size for calculations other than maximum individual.

11. $\mathrm{KORG}(5)$ : Choice of organs by number:
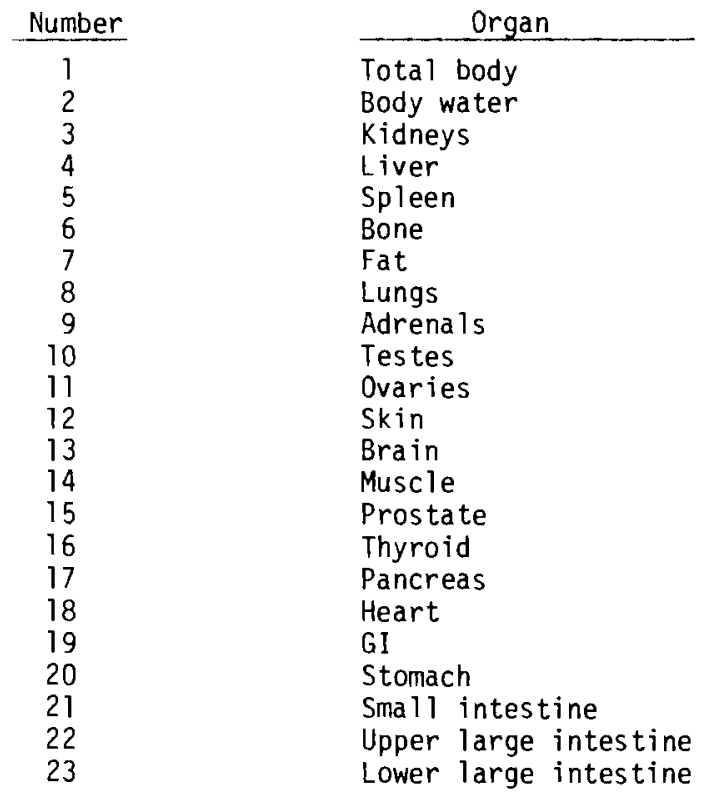


\section{Reconcentration parameters}

12. IREC: Reconcentration model used.

IREC $=1$. Cooling water is drawn from a cooling pond, small lake or reservoir which is connected to a larger body of water or is fed by a stream. Requires that namelist variables CFLO, FLO, CTIM, VOL, and TOR be included (described below).

IREC $=2$. The cooling water inlet is downriver from the outfall or on a lake or ocean site arranged such that recirculation occurs. Requires namelist variables CTIM and VOL be included.

$$
I R E C=3 \text {. No reconcentration, } \operatorname{RECON}=1 \text {. }
$$

13. CFLO: Coolant flow in $\mathrm{ft}^{3} / \mathrm{sec}$. This is the water by which the radionuclide release is diluted.

14. FLO: Makeup flow, $\mathrm{ft}^{3} / \mathrm{sec}$ (water drawn into the intake to replace losses).

15. CTIM: Cycle time in hours.

16. TOR: Pond turnover rate in inverse seconds.

17. VOL: For IREC $=1$, VOL is the pond volume in $\mathrm{ft}^{3}$

For IREC $=2$, VOL is the recycle fraction, (the [unitless] mixing ratio at the point of intake).

18. RM: The mixing ratio, used in calculating the water concentration of released nuclides.

D. Terrestrial exposure pathway parameters

19. KFDTYP(15): Numeric definition of the food types for which ingestion doses will be calculated.

Food Type

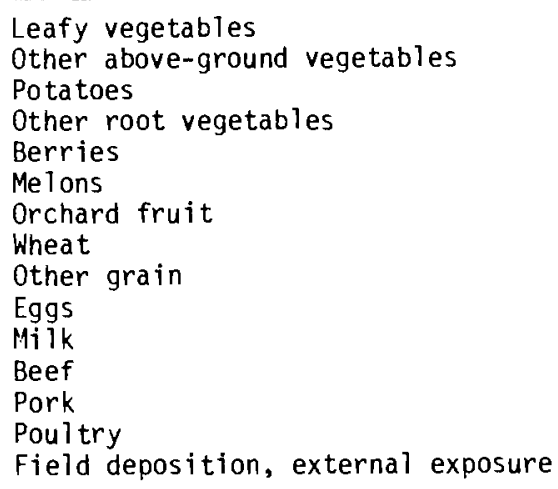


20. $X Q(15)$ : The air concentration per unit release $\left(\bar{x} / Q^{\prime}\right.$ in $\left.\mathrm{sec} / \mathrm{m}^{3}\right)$ of radionuclides at the growing site of the corresponding food type.

21. GRWP(15): The growing period in days of the corresponding food type.

22. YELD(15): The yield in $\mathrm{kg} / \mathrm{m}^{2}$ of the corresponding food type.

23. RIRR(15): The irrigation rate in $1 / \mathrm{m}^{2}$ month of the corresponding food type.

24. HLDUP1(15): The holdup period in days of the corresponding food type.

25. $\operatorname{CON}(15)$ : The consumption rate in $\mathrm{kg} / \mathrm{yr}$ of the corresponding food type.

26. TRNS(15): The translocation factor of the corresponding food type.

27. EXTIM: The time an individual spends being exposed to nuclides on contaminated farm ground, hours/year.

E. Aquatic exposure pathway parameters

28. KPTHWY(8): Key for definition of exposure pathways for which to do computation:

\begin{tabular}{c} 
Number \\
\hline 1 \\
2 \\
3 \\
4 \\
5 \\
6 \\
7 \\
8
\end{tabular}

Pathway

Fish
Crustacea
Molluscs
Water plants
Drinking water
Shoreline external exposure
Swimming external exposure
Boating external exposure

29. RM2(8): Mixing ratio at each of the corresponding dose pathways (dimensionless).

30. HLDUP2(8): Holdup time (days) for each of the corresponding pathways.

31. USAGE(8): Usage for each of the corresponding pathways; $\mathrm{kg} / \mathrm{yr}$ for edible foods, l/yr for drinking water, and $\mathrm{hr} / \mathrm{yr}$ for external exposure.

32. ISALT: Key for bioaccumulation factors.

ISALT $=0 . \quad$ (default) Fresh water factors.

ISALT $=1$. Salt water factors. Note that if ISALT $=1$, the drinking water pathway should logically not be used. 
33. SW: Shore width factor for use with shoreline exposure pathway. CARD $N+1--$ INVENTORY HEADER CARD

This card supplies NIN and FINV. NIN is the number of cards in the radionuclide source term. FINV is a multiplicative inventory modification factor which, if left blank, defaults to 1.0. The format is (I3, E10.2).

\section{CARDS $N+2$ TO M--RADIONUCLIDE SOURCE CARDS}

One card per input radionucuclide is required. The cards hold the atomic symbol and atomic weight with metastable and/or " $D$ " designation, and the source amount. The alphanumeric representation of the released nuclide must exactly match that in the radionuclide master data library; otherwise a match cannot be made. The source is in $\mathrm{Ci} / \mathrm{m}^{2}$ for $\mathrm{IDEP}=0, \mathrm{Ci} / \mathrm{yr}$ for chronic releases for IDEP $=1$ or 2 , and $\mathrm{Ci}$ for acute releases for IDEP $=1$ or 2 . The format is (A2, $A 6,4 X, E 8.2$ ). 


\section{SELF-GENERATED DIAGNOSTICS}

If an error or anomaly is detected, the program will write an informative message. These come from several places in the code. These are listed below with some hints as to what might be wrong. The list is ordered by originating routine.

MAIN

1. END OF INPUT FOR THIS RUN. Normal termination.

2. END OF FILE ON INPUT, STOP. The code was expecting another case, but ran out of data cards.

3. ERROR IN NUMBER OF NUCLIDES INPUT, NONUC $=X X X$, MAXIMUM ALLOWED IS XXX. There were either zero or too many inventory cards.

4. ERROR ON NAMELIST INPUT: Something is misspelled.

\section{RLIBIN}

5. DECAY CHAIN XXX HAS IMPROPER ORDER. CURRENT MEMBER INDEX IS XXX.

6. IMPROPER NUMBER. OF NUCLIDES IN MASTER LIBRARY, NUC $=X X X X$.

7. END OF FILE ON MASTER LIBRARY UNIT 10.

These three all indicate a problem with the radionuclide master data library.

$\underline{\text { FLIBIN }}$

8. END OF FILE AT TITLE CARD ON FOOD DATA LIBRARY. There is no data in the Food Transfer Coefficient File.

$\underline{\text { OLIBS }}$

9. ERROR IN ORGAN DATA LIBRARY INPUT, NC, NOLD = XXXX, NUCLIDE INPUT IS XXXXX, NUCLIDE NOLD IS $X X X$. There is an error in the order of the organ data library compared with the radionuclide master data library.

10. UNABLE TO IDENTIFY NUCLIDE $X X X X X$, NUCLIDES CHECKED $=x X X--$ STOP. There is a nuclide in the organ library that is not in the master library. 
11. END OF FILE ON ORGAN DATA LIBRARY.

NUCLIDES IN MASTER LIBRARY $=X X X$.

CURRENT NUCLIDE INDEX $=X X X$.

PREVIOUS NUCLIDE INDEX $=X X X$.

DATA ARRAY INDEX $=X X X$.

The organ data file ended before any data could be obtained.

SLIBIN

12. EXTERNAL DOSE FACTOR LIBRARY TITLE READ ERROR, STOP.

13. EXTERNAL DOSE FACTOR LIBRARY EMPTY, STOP.

14. PROBLEM IN EXTERNAL DF LIBRARY READ

NUCLIDES FOUND $=X X X$.

NUCLIDES CHECKED FROM MASTER LIBRARY $=X X X$, STOP.

These three messages indicate a problem with the external dose factor file.

BLIBIN

15. END OF FILE ON TITLE CARD READ, BIOACCUMULATION LIBRARY, STOP.

IDNUC

16. UNIDENTIFIED NUCLIDE XXXXX.

17. THERE WERE UNIDENTIFIED NUCLIDES, ISTOP $=X X X$. There is an error in the input source term.

OFPCHK

18. NO ORGANS SPECIFIED, NORG $=X X X$.

KORG was probably omitted from NAMELIST.

19. NO FOOD TYPES OR PATHWAYS SPECIFIED, NFT, NPT $=X X X, X X X$. The input data was lacking either KFDTYP, KPTHWY, or both. 


\section{SETDAT}

20. NO DATA IN ORGAN LIBRARY FOR NUCLIDE XXXX. THIS NUCLIDE DROPPED.

21. NO DATA FOR ELEMENT $X X$ IN FOOD DATA LIBRARY, THIS NUCLIDE DROPPED.

22. NO DATA FOR ELEMENT XXXXX IN BIOACCUMULATION FACTOR LIBRARY, THIS NUCLIDE DROPPED.

23. NONE OF THE INPUT NUCLIDES HAVE DATA IN LIBRARIES, NUC $=X X X$. Program terminated. 
APPENDIX G

SAMPLE PROBLEMS 
APPENDIX G

SAMPLE PROBLEMS

To illustrate the use of the PABLM computer code, two example problems are presented here. The problems illustrate chronic releases of radionuclides to the atmosphere and to a river.

The first sample problem includes doses to the population surrounding a nuclear facility. The facility is assumed to operate for 30 years before being shut down. The accumulated dose is calculated for the $30 \mathrm{yr}$ plant life plus another 40 years, for a total of 70 years.

The second sample illustrates the doses to a maximally-exposed individual living downstream from a waste tank leaking into a river. The source term is taken to be the same as that for the first example to illustrate the NEXT=3 option. The radioactive material in the tank is assumed to decay with time and to leak at a constant mass rate. The individual is assumed to irrigate from, fish in, and get drinking water from the river over a 70 year period.

Input for the first problem is:

\begin{tabular}{|c|c|c|}
\hline $\begin{array}{l}\text { Namel ist } \\
\text { Parameter }\end{array}$ & Value & Remarks \\
\hline NEXT & 2 & Program control variable \\
\hline IDEP & 1 & Atmospheric release \\
\hline IOUT & 0 & Summary output only \\
\hline IAC & 0 & Chronic release \\
\hline PLIFE & 30. & Thirty year release period \\
\hline $\mathrm{T} 2$ & 70 & Seventy year uptake time \\
\hline IPOP & 1 & Population case \\
\hline POP & $2.5 \times 10^{5}$ & Regional population \\
\hline \multirow[t]{4}{*}{ KORG } & & Organs of interest: \\
\hline & 1 & Total body \\
\hline & 6 & Bone \\
\hline & 8 & Lungs \\
\hline
\end{tabular}




\begin{tabular}{|c|c|c|}
\hline & 16 & Thyroid \\
\hline & 23 & GI-LLI \\
\hline \multirow[t]{10}{*}{ KFDTYP } & & Terrestrial exposure pathways: \\
\hline & 1 & Leafy vegetables \\
\hline & 2 & other above-ground vegetables \\
\hline & 4 & Root vegetables \\
\hline & 7 & Orchard fruit \\
\hline & 9 & Grain \\
\hline & 10 & Eggs \\
\hline & 11 & Milk \\
\hline & 12 & Beef \\
\hline & 15 & External exposure \\
\hline$X Q$ & $9 * 2.1 \times 10^{-8}$ & $\begin{array}{l}\text { Same air concentration per unit release } \\
\text { each food site, } \mathrm{sec} / \mathrm{m}^{3}\end{array}$ \\
\hline \multirow[t]{4}{*}{ GRWP } & 90. & Growing period at each food site, days \\
\hline & 60. & \\
\hline & $\begin{array}{c}4 * 90 . \\
30\end{array}$ & \\
\hline & 90. & \\
\hline \multirow[t]{8}{*}{ YELD } & 1.5 & Yield of each food, $\mathrm{kg} / \mathrm{m}^{2}$ \\
\hline & 0.7 & \\
\hline & 4.0 & \\
\hline & 2.0 & \\
\hline & 1.0 & \\
\hline & 0.84 & \\
\hline & 1.3 & \\
\hline & 0.84 & \\
\hline \multirow[t]{4}{*}{ HLDUP1 } & $5 * 14$ & Holdup period for each food type, days \\
\hline & 18. & \\
\hline & 4. & \\
\hline & 34. & \\
\hline \multirow[t]{4}{*}{ TRNS } & 1.0 & Translocation factors \\
\hline & $6 * 0.1$ & \\
\hline & 1.0 & \\
\hline & 0.1 & \\
\hline
\end{tabular}


CON

15.

Consumption rates of average individual in population.

15.

117.

64.

80.

20.

230.

40.

EXTIM 2920

External exposure time of average individual, $\mathrm{hr} / \mathrm{yr}$.

\begin{tabular}{c}
$\begin{array}{c}\text { Inventory } \\
\text { Data }\end{array}$ \\
\hline
\end{tabular}

NIN

ELTI, AWI, Q

$\frac{\text { Value }}{5}$

H 3

C 14

SR 90

CS 137

PU 239

\section{Remarks}

Input nuclides

50.0 Release, Ci/yr

5.0

0.5

1.0

0.1

For the second sample problem, it is assumed that the maximally-exposed individual is subjected to many of the same conditions as is the population in Example One. Thus, if the two problems are run concurrently, much of the data need not be re-entered. In addition to irrigated crops, the individual obtains food from the river.

Namelist

Parameter

NEXT

IDEP

DKSORS

PLIFE

IPOP

POP

IREC

RM

\begin{tabular}{c} 
Value \\
\hline 3 \\
2 \\
1 \\
70 \\
0 \\
1 \\
3
\end{tabular}

1.0
Remarks

Use previously input release

Liquid release

Source now decaying annually

70 year release

Maximum individual

For a leaking tank, no reconcentration. Complete mixing in river 


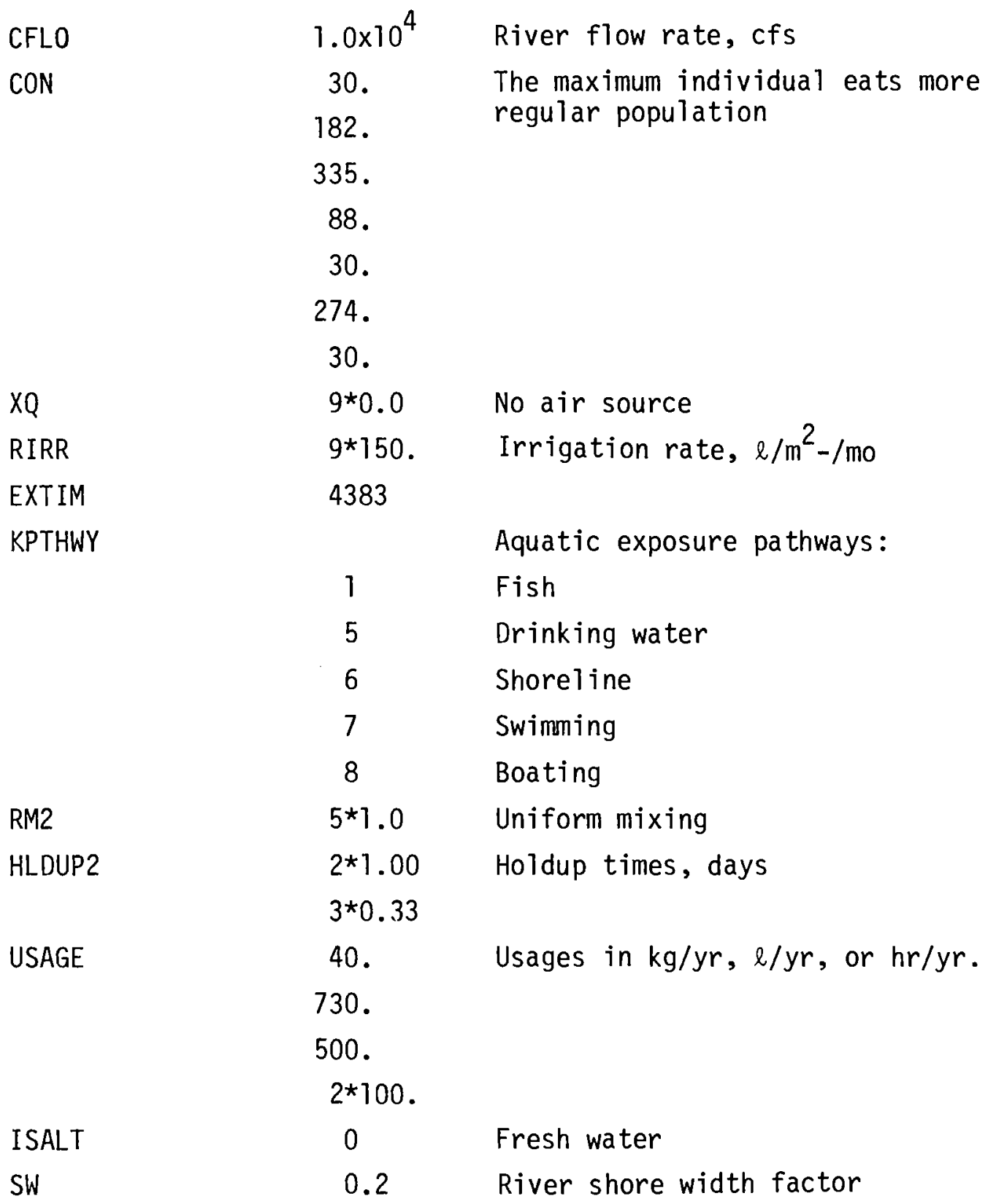

The input data card stream prepared from the preceding information is shown in Table G-1. Output reports generated by PABLM using the above information for the two sample problems are shown following the input listing.

Three sets of output tables are generated by PABLM for sample problem one. The first set represents the 70-year dose commitment from ingestion of farm products during the first year of the release from the nuclear facility. The second set contains the 70 year dose commitment from the accumulation of 
radionuclides during the 30 year life of the facility. The final set includes the total accumulated dose for the 30 year plant life and 40 years worth of continuing environmental contact. It can be seen that for radionuclides with a short biological half-life and little environmental accumulation the total dose is received during the release from the facility. However, nuclides which remain in the environment following the end of the release still contribute to dose during the rest of the dose period.

The second sample generates only two sets of tables, because the release is assumed to continue throughout the dose period. The first set again represents the 70-year dose commitment from the first year of ingestion. The second set is the 70-year accumulated dose from the 70 -year release. 
Sample Problems

W. D.4. DAGE ***

RUV JN 100979

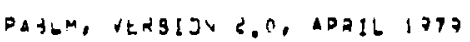

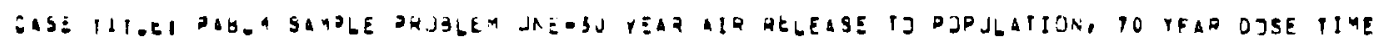

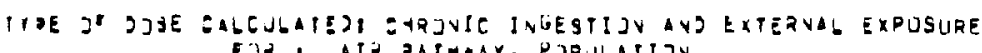

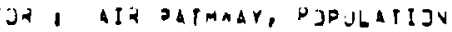

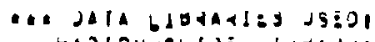

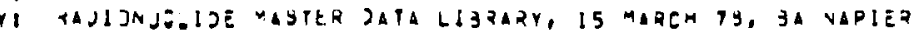

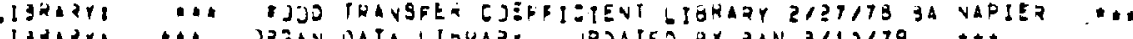

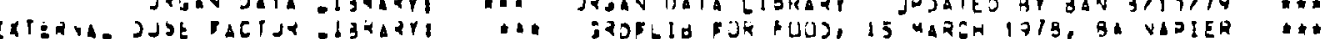

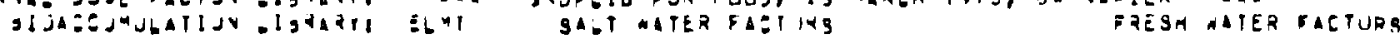

D.

\begin{tabular}{|c|c|}
\hline $1.50 E+U 1$ & $1.0 C E+O N$ \\
\hline $1,5 \cap E+01$ & $1.00 E=01$ \\
\hline $1,17 F+12$ & $1.005=01$ \\
\hline $4 \cap 5+01$ & $1.00 E-01$ \\
\hline$O O E+O 1$ & $1.00 E=n 1$ \\
\hline $2,005+01$ & $1,00 E=01$ \\
\hline $2,305+02$ & $1.00 E-01$ \\
\hline $4.0 O E .01$ & $1.0 \cap E+00$ \\
\hline $.0 n$ & $1.00 E=1$ \\
\hline
\end{tabular}

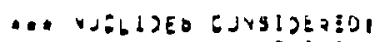

\begin{tabular}{|c|c|c|c|}
\hline 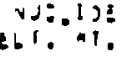 & $\begin{array}{r}\text { TEEEASE } \\
(Z 1 / 1 / 2)\end{array}$ & $\begin{array}{l}\text { YUCLISE } \\
\text { ELT. AT. }\end{array}$ & $\begin{array}{l}R \equiv(E A B E \\
(C[, T E)\end{array}$ \\
\hline s. & $\begin{array}{l}5.005+01 \\
.00\end{array}$ & $\begin{array}{ll}c & 1 \\
c y \\
c y & 137\end{array}$ & $\begin{array}{l}5.005+110 \\
1.005+00\end{array}$ \\
\hline
\end{tabular}

thragis

LOMEจ เA2G

Du 2st 1.0uteo

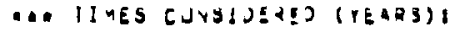

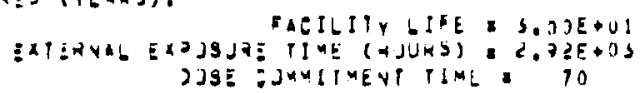

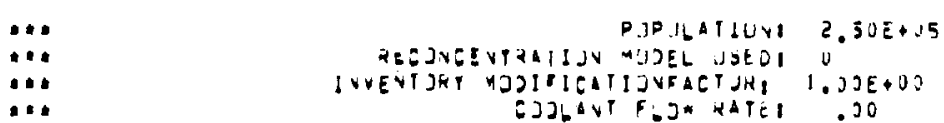




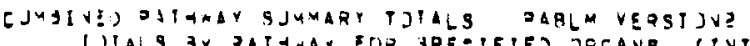

$\operatorname{lng} 070$

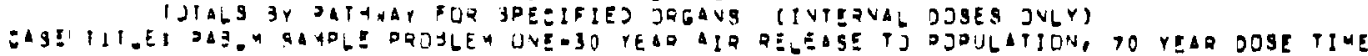

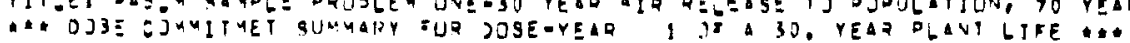

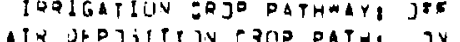

$$
\begin{aligned}
& \text { ávaric हjojs pathwariger }
\end{aligned}
$$

JJES AN TUTALS REOJRTED IV MANEREY

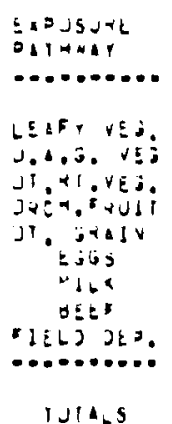

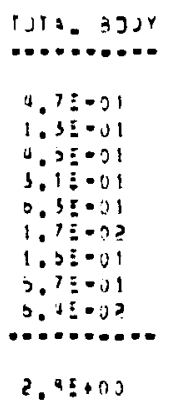

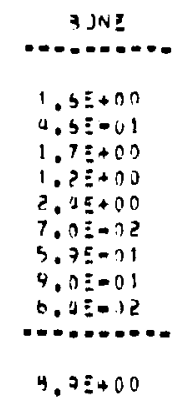

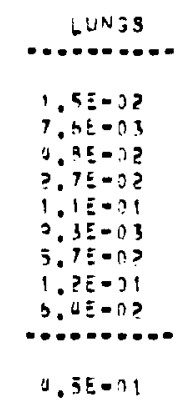

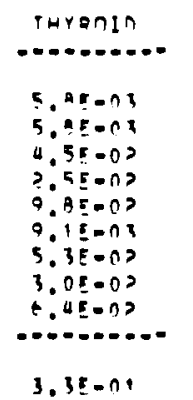

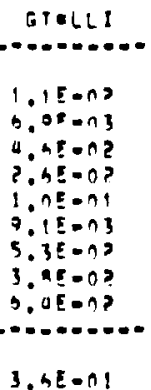

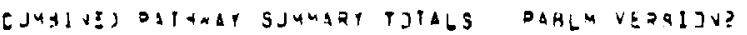

10079

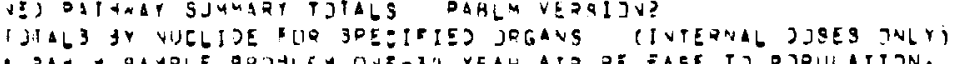

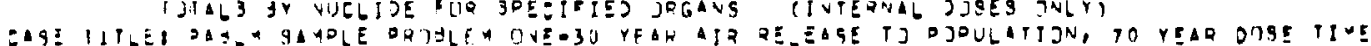

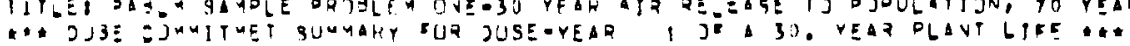

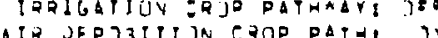

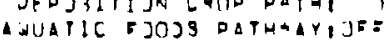

\begin{tabular}{|c|c|c|c|}
\hline יכנב & 2 JYES & $\begin{array}{c}\text { AVJ TIJTALS } \\
\text { BuVE }\end{array}$ & TEPכZTED \\
\hline - & $\cdots$ & - & \\
\hline$?, 5 E-0 ?$ & J & ." & , \\
\hline$?$ & ? & $1 . P E+O n$ & 13 \\
\hline $1,5 E+0.5$ & b; & b. TE+00 & 75 \\
\hline & $J$ & .0 & ? \\
\hline$S, j E=01$ & 23 & $7.3 E=1) 1$ & 3 \\
\hline & i & & $?$ \\
\hline$? \cdot+2=03$ & $\mathrm{~J}$ & $1.0 E=01$ & 1 \\
\hline$\therefore .1 E+00$ & (N) & R. $P E+010$ & 100 \\
\hline
\end{tabular}
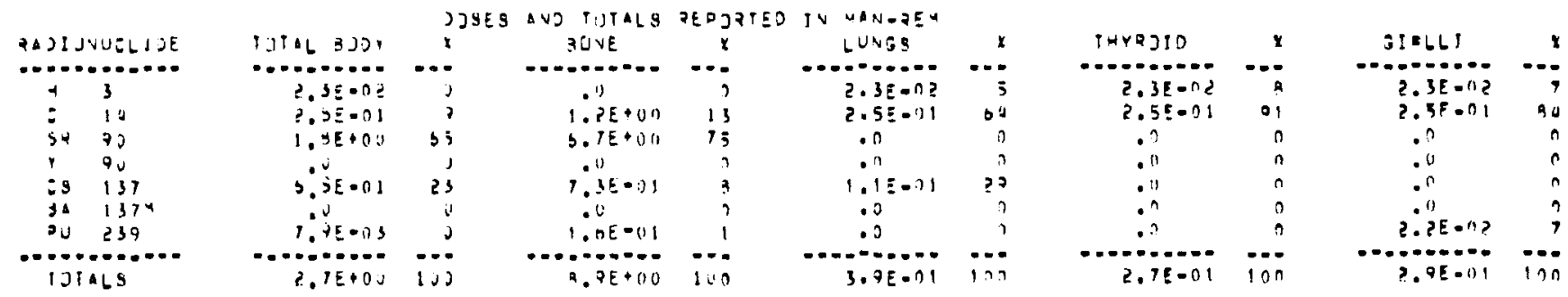


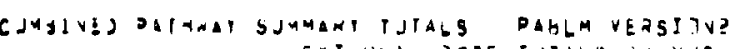

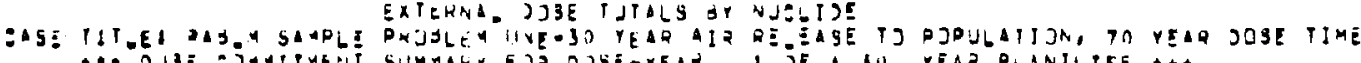

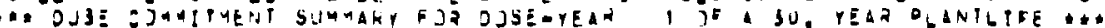

IMHIGATEO FIELO DITHAMYI J:E

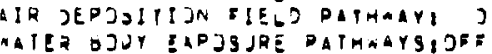

\begin{tabular}{|c|c|c|c|c|}
\hline 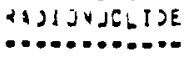 & 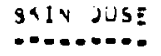 &... & שפתנס &. .8 \\
\hline$\vdots \quad 34$ & $: 0$ & v & $\because 3$ & \\
\hline 3 & :" & $\therefore$ & $\because$ & 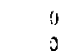 \\
\hline is? & 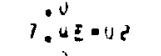 & $\frac{j}{3}$ & $\therefore 3 \leq-0 ?$ & 97 \\
\hline $\begin{array}{lll}314 & 1574 \\
30 & ? 39\end{array}$ & $\therefore 2 \vdots=05$ & " & $\therefore$ & 0 \\
\hline . & - A & $\cdots$ & . & $\cdots$ \\
\hline 1014.3 & $1,4 ! \cdot 02$ & 100 & $0.15-i j z$ & 100 \\
\hline
\end{tabular}



293.4

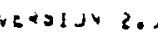
0301,170

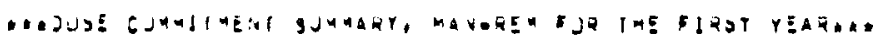

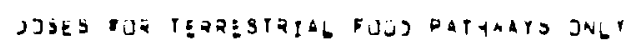

\begin{tabular}{|c|c|c|c|c|c|}
\hline 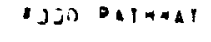 & צנבנפ וגם & ๑つ! & bun:s & $1 \times 12 J I J$ & $L J H E R \quad L A 2$ \\
\hline EAAT VEJ. & $\alpha, 2,50,1$ & $1.205+20$ & $1.43 \vdots-02$ & $5.70 E-.73$ & $1.11 E=0 ?$ \\
\hline J,A.D. VES & 1.275 .31 & $+.02 \leq-01$ & $1.025-03$ & $3.702-03$ & $0.45 \equiv .03$ \\
\hline JI.R.VES. & $+051 E-01$ & $1.375+30$ & $\cdot .7,5-112$ & $A .47 E-5 z$ & $4.055=02$ \\
\hline $3+64$, RUIT & $3.15 E \cdot J 1$ & $1.15 E+00$ & $c .75500 ?$ & $2.405-12$ & $2.03 E=0 ?$ \\
\hline $31.3+a 1 v$ & $3.315-41$ & $2.3+5+30$ & $1.0 j:=01$ & 9. RUE-?? & $1.025-.91$ \\
\hline jدJEE TJTAGKA & $1.8+\sum+40$ & $7.305+30$ & $c .035-41$ & $1.7+6-31$ & $1.73 E .01$ \\
\hline 01314.0 & $1.0,5=02$ & $2.77 E 032$ & $+.27 \leq-1,3$ & $\nabla .1 S E=13$ & $7.13 E-13$ \\
\hline$b a t u l a=A 4$ & $1.01 E-01$ & $5,50 E-11$ & $2.70 \equiv-.12$ & 5.3 JE.02 & $5.35 E \cdot 02$ \\
\hline $3 E^{2}$ & $5.075-01$ & 7.305 .31 & $1.175-111$ & $2,72 E-0 ?$ & $3.61 E=02$ \\
\hline A & $3.015-01$ & 7. JUE-OI & $1.115-01$ & $2.955-0 ?$ & $3.31 \equiv \cdot 02$ \\
\hline
\end{tabular}

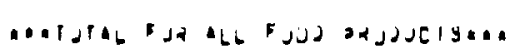
$3,1+\underline{E}+\underline{u}$
$3.32 E+i 311$
$9,855-11$
$2.11 E .01$
$2.745=01$

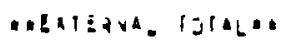

Sal 1312. ajor

1.,AE-3? $\quad 3.37 E \cdot 02$ 


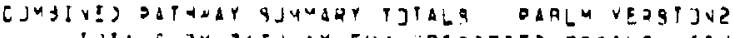

100290

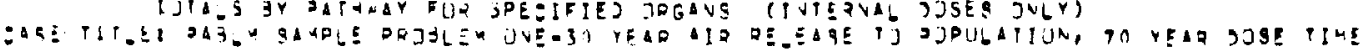

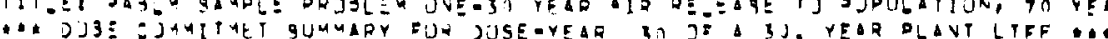

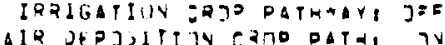

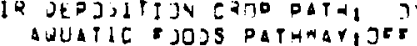

\section{EXPUYJRE \\ atimat}

LEAHY VES

jiation

jochomigio

it. 3 and

tista

SEe

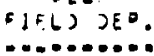

iviabs

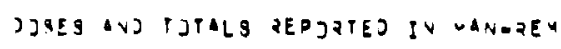

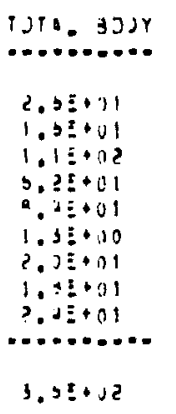

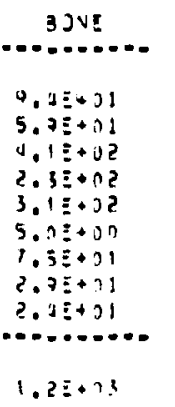

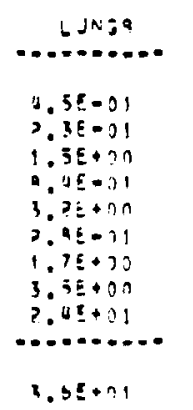

PHYan!s

GTMLLT

$1,7,0-01$

1.02
$1,72+00$

$1,3 E+00$
, $4 E-01$

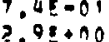

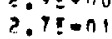

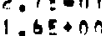

$2.9-9-01$
$2,4+01$

a..........

$3.2 \leq \cdot 1$

$3,7 E-n)$

$3,1 E-31$
$1,0 \pm+00$

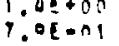

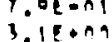

$3,7=01$

$1,45+n j$

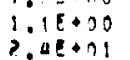

3.

$3,3+n 1$

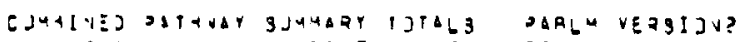

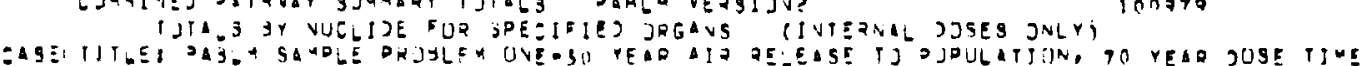

10090

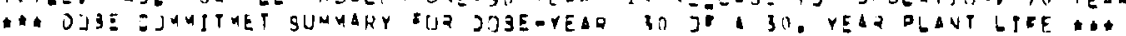

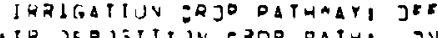

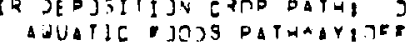
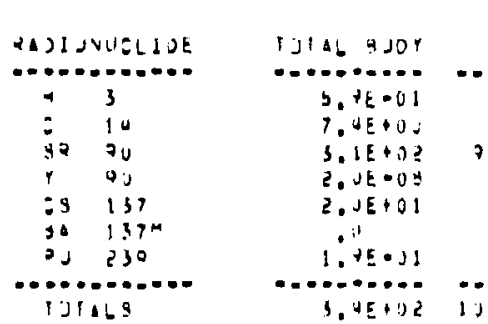

\begin{tabular}{|c|c|c|}
\hline 4 & $\begin{array}{c}\text { ANO TONELS } \\
\text { TON }\end{array}$ & \\
\hline & 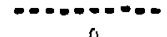 & \\
\hline & $3.7 E+111$ & 3 \\
\hline & $1.1 E+03$ & 73 \\
\hline & $7.4 E-0\rangle$ & \\
\hline & $2.2 E+01$ & 1 \\
\hline & .0 & \\
\hline & $1.1 E+00$ & .7 \\
\hline & $1.2 \varepsilon+03$ & 100 \\
\hline
\end{tabular}
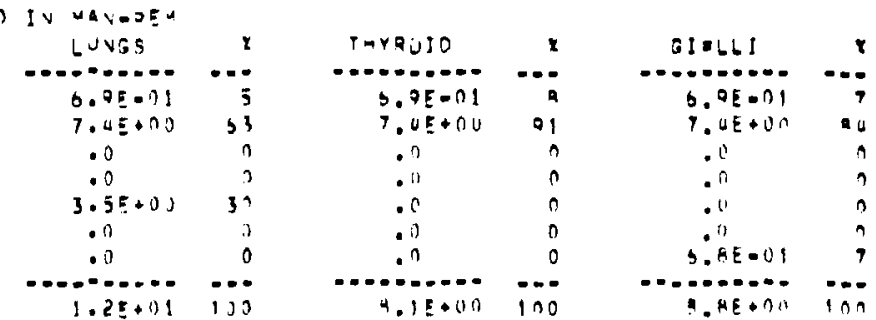


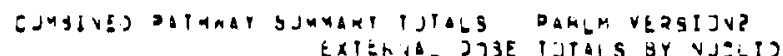

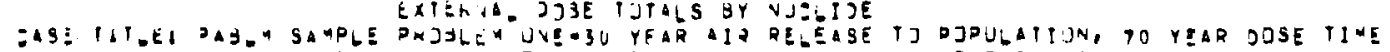

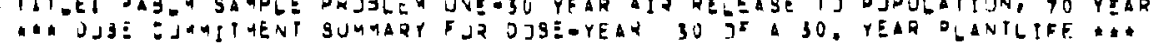

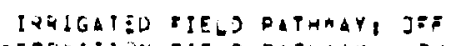

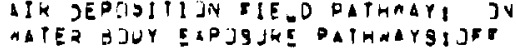

$\stackrel{P}{\perp}$

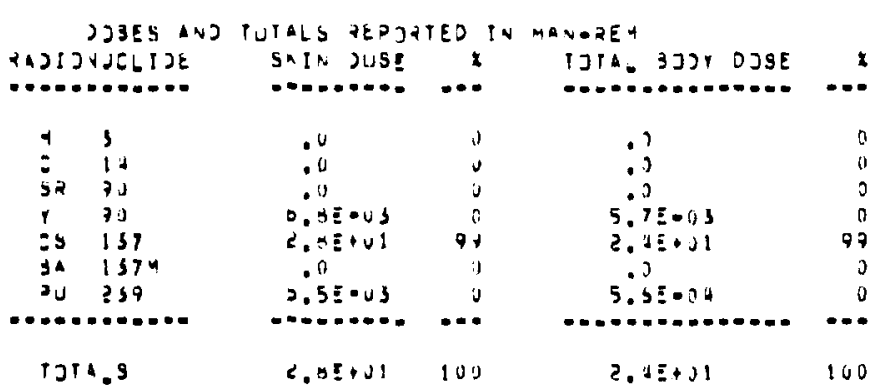




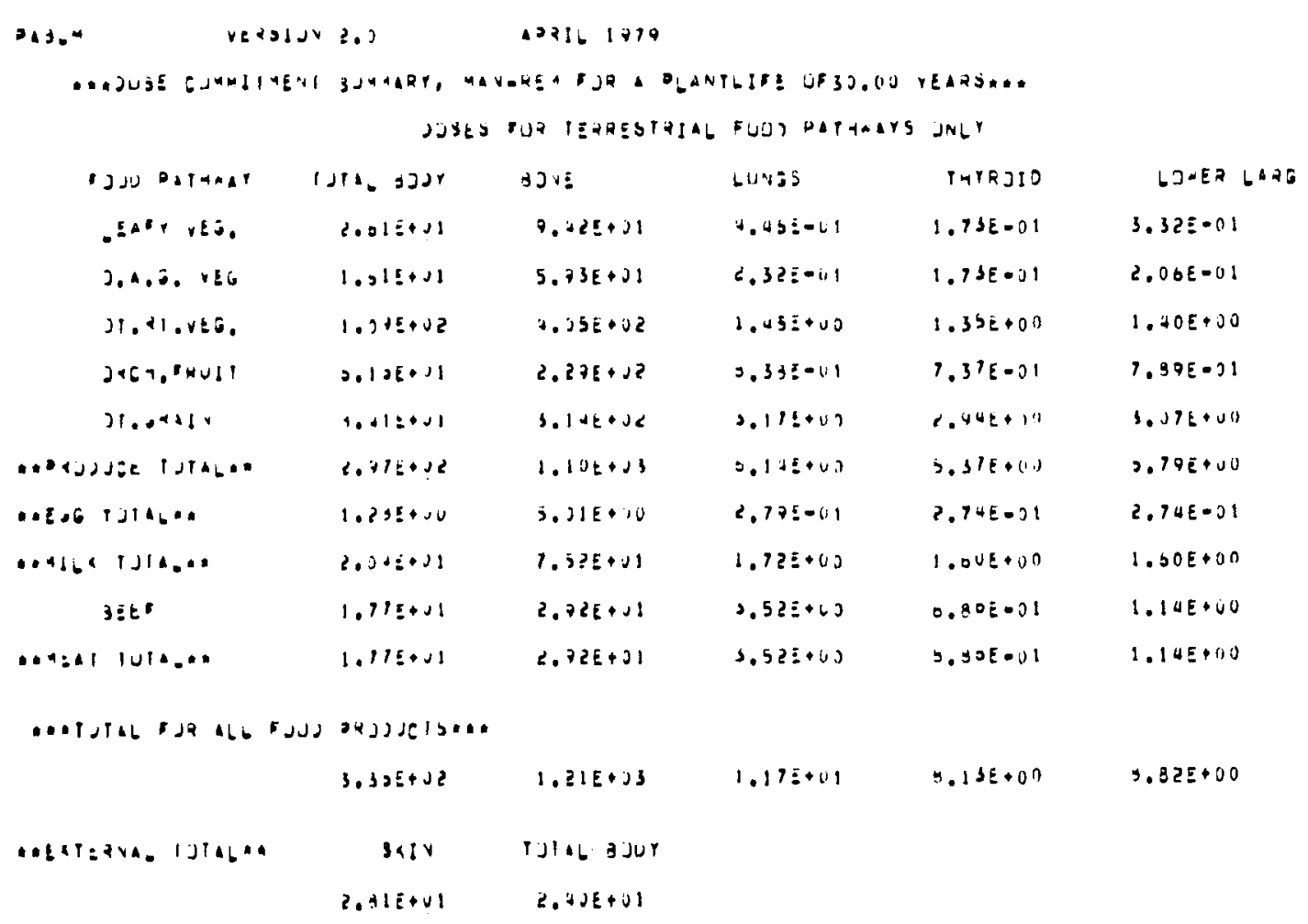




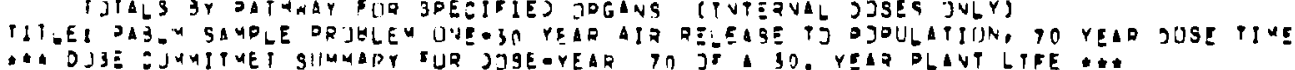

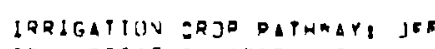

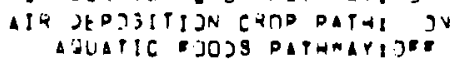

\begin{tabular}{|c|c|c|c|c|c|}
\hline 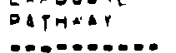 & זכבה - & 3JN5 & $\begin{array}{c}\text { GJVGa } \\
\end{array}$ & THYROID & GTELLI \\
\hline 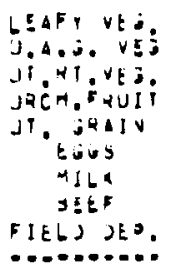 & 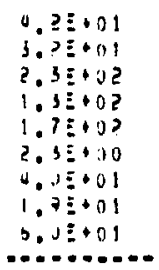 & 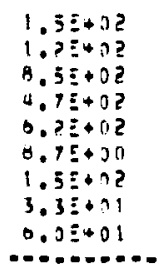 & 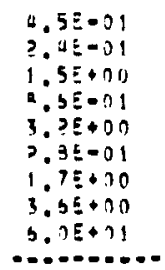 & 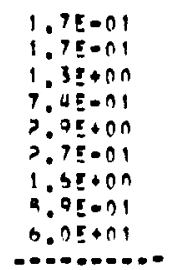 & 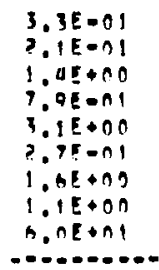 \\
\hline 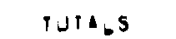 & $9,25+12$ & $2,5 \vdots+33$ & $7, P \equiv+31$ & 0.85001 & $B .0 E+01$ \\
\hline
\end{tabular}

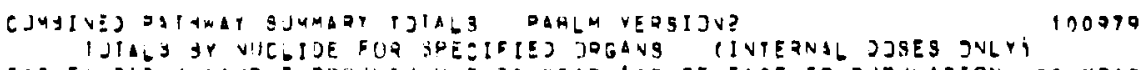

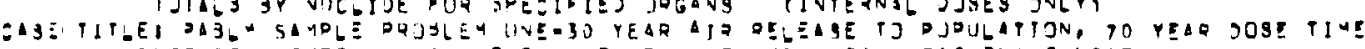

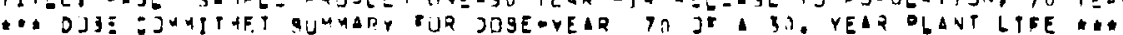

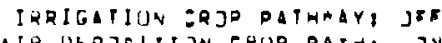

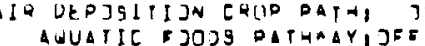

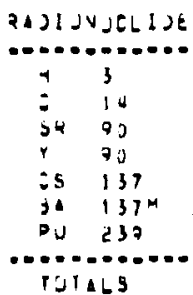

\begin{tabular}{|c|c|c|c|}
\hline & J JSES & AND TUIALS & TEDJATED \\
\hline IJIAL \&JDY & 4 & GONE & y \\
\hline 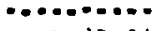 & $\cdots$ & & \\
\hline $3.7 E=01$ & $J$ & & 3 \\
\hline $1, d \varepsilon \cdot O J$ & 1 & $3.7 E+01$ & 1 \\
\hline S. SE+O? & 75 & $2.3 E+03$ & +1 \\
\hline $5.1 E \cdot 0$ & $J$ & 1.080 .00 & 0 \\
\hline $2.1 E \cdot 01$ & 3 & R.SE+U1 & ) \\
\hline.$j$ & ? & .3 & 3 \\
\hline $1 .+E=01$ & $a$ & $1.1 \varepsilon+n n$ & $?$ \\
\hline ; & $\ddot{i}$ & ; & \\
\hline$B .0 E+0 ?$ & 131 & $2.4 E+\cup 3$ & 1) 1 \\
\hline
\end{tabular}
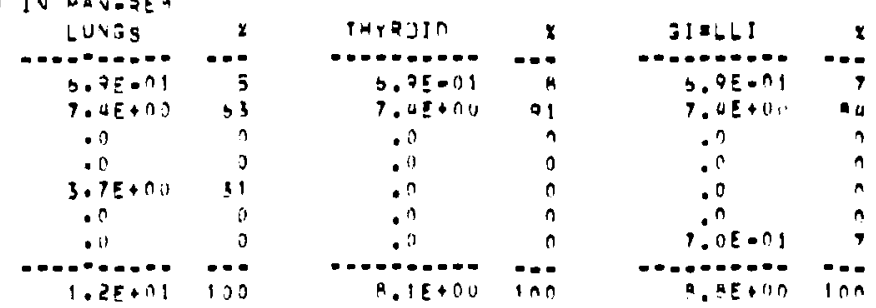


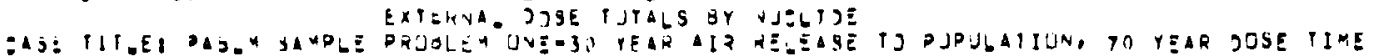

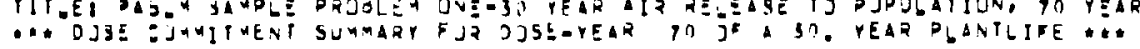

$$
\text { IKRIGATEU IELO DATHAMY JEF }
$$

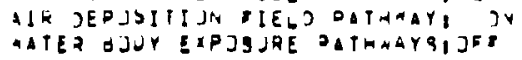

JJSES ANJ TJTALY ZEPJZTEO IQ MANOEET

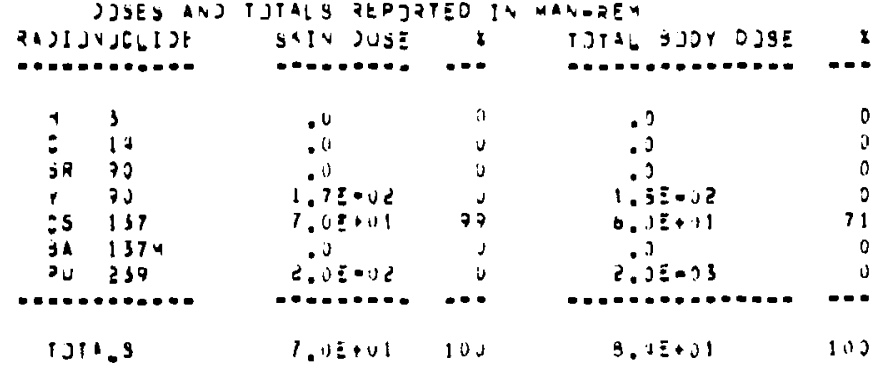




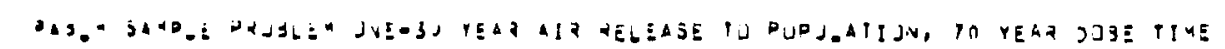

101979 04,4 veasisv 2.0

$\triangle 27161770$

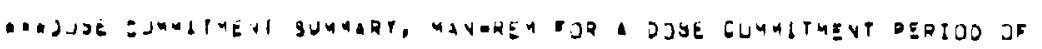

(i) reargan

JJSE

\begin{tabular}{|c|c|c|c|c|c|}
\hline 'Ju Dianal & צدכנד • & 3) Ј & LแVร" & 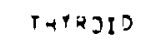 & LONER LA2G \\
\hline EAFY VES. & H. JE*JI & $1.52 E+J C$ & $4.515=01$ & $1.75 E-31$ & $3.335=01$ \\
\hline J.A.S. VES & $3.135+11$ & $1.17 E+J ?$ & $2.375-01$ & $1.75 E=01$ & $2.075=01$ \\
\hline & $2,315+12$ & $3.355+32$ & $1.475+00$ & $1.3>E+00$ & $1.205+00$ \\
\hline Jectornult & $1.25 E+J 2$ & $2.7+5+32$ & $0.57 \equiv-21$ & $7.37 E=01$ & $7.735-101$ \\
\hline $31.3401 \mathrm{~V}$ & $1.078+2 z$ & $2.57 E+25$ & $3.20 E+110$ & $2.74 E+10$ & $3.375+00$ \\
\hline 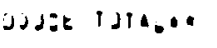 & $5.715+J 2$ & $2.22 E+03$ & $0.2+5+00$ & $5.375+100$ & $5 . J 1 E+00$ \\
\hline : & 3.275000 & y.S7E+iv & $2.735-31$ & $2.74 E \cdot n 1$ & $2.745-01$ \\
\hline "..." & $4007 \overline{t a n}$ & $1.73 E+J z$ & $1.7+2119$ & $1.005+10$ & $1.60 E+00$ \\
\hline $3 E E F$ & $1.375+v 1$ & $3 . ? 3 E+\sqrt{1}$ & $3,55 E+0.3$ & $9.005-01$ & $1.15 E+00$ \\
\hline \multirow[t]{3}{*}{ A IJia...A } & $1.318+01$ & $3.25 t+01$ & $5.555+103$ & $\because 40 E-31$ & $1.155+00$ \\
\hline & 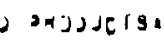 & & & & \\
\hline & $3,59 E+J 2$ & $2 .+15+31$ & $1.13 \pm+61$ & $9.13 E+31$ & $3.33 E+00$ \\
\hline \multirow[t]{2}{*}{ 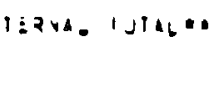 } & $3 \times 14$ & TJTAL $3 . J U$ r & & & \\
\hline & $7 . d ? 5+\nu !$ & $3.325+31$ & & & \\
\hline
\end{tabular}


PAHLM, VEHSIJV Z.U, ADPIL 17,7

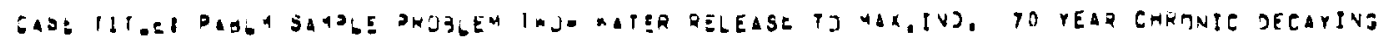

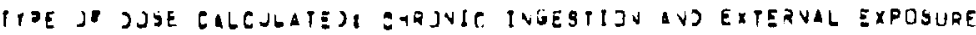

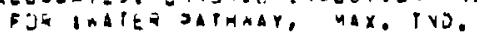

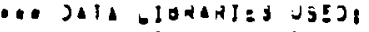

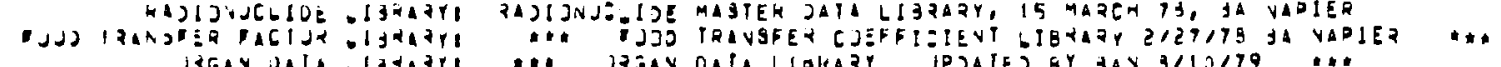

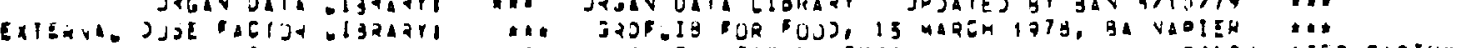

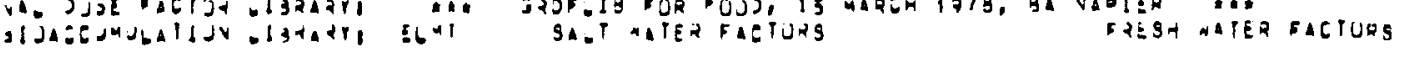

IIXIVORATL

t26Jue (Dars)

ofst

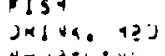

ondisidis

$1.00+0.00$
$1.00+090$

$1.00+0,000$

$1.00+300$

$$
\begin{aligned}
& 3.20+000 \\
& 1.30+000 \\
& 3.33=001 \\
& 3.33=012 \\
& 3.53=001
\end{aligned}
$$

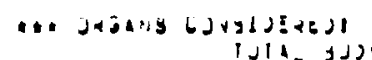

jJVE

.unas

$\begin{array}{lll}1.40 E+01 & 3.005001 & 1.00 E+00\end{array}$ $1.40 E+U 1$
$1.00+J 1$
$1.00 E+O 1$

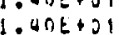

$1.40 E+01$

$1.305+11$

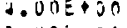

$3.40 \mathrm{E}+1$

.00

JSAGE

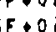

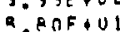

2.74502

3.00501

inconol

inn

$4.00+00 !$
$(K 6 / 18)$

$7.30+002$ (L/rR)

$1.00+100$ (nk, (nke)

1.0000U2 (HHORR)

\begin{tabular}{|c|c|c|c|c|c|}
\hline 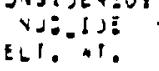 & 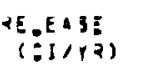 & $\begin{array}{l}\text { NUSLIIJE } \\
\text { ELT. NT. }\end{array}$ & $\begin{array}{l}7 E(E E S j k \\
(E I / Y H)\end{array}$ & $\begin{array}{l}\text { EJT. } \\
\text { YLTE }\end{array}$ & $\begin{array}{l}\text { ZEGEASE } \\
\text { (EI,YK) }\end{array}$ \\
\hline$? 3$ & 5.005001 & $\begin{array}{ll}\text { C } & 14 \\
\text { cs } & 131\end{array}$ & $\begin{array}{l}5.005+00 \\
1.005+110\end{array}$ & $\begin{array}{l}9293 \\
341374\end{array}$ & $\begin{array}{l}5.00 E=n 1 \\
.00\end{array}$ \\
\hline
\end{tabular}

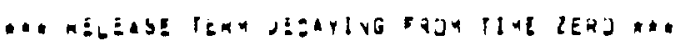

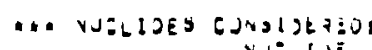

a. Ilages cuysiugtes (reatag), 


\begin{tabular}{|c|c|c|c|c|c|}
\hline$\{u-3)^{\circ} 2$ & $0-3 n^{\circ} c$ & $\{C-j \leq \cdot 2$ & $25=\sum \varepsilon^{*} 1$ & $50.7 \varepsilon^{\circ}$ & 89virit \\
\hline 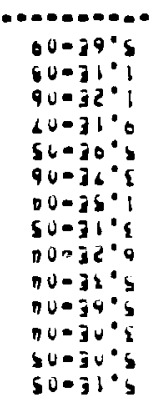 & 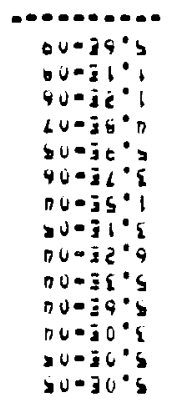 & 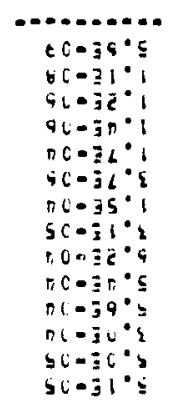 & 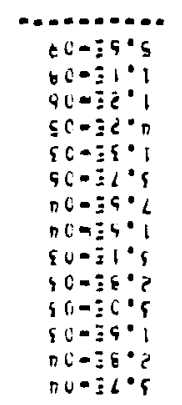 & 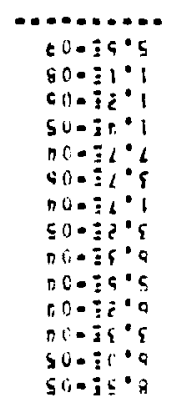 & 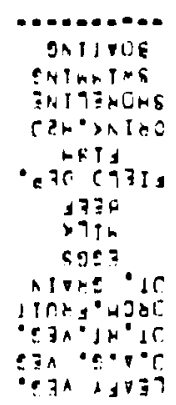 \\
\hline $197=19$ & OIGEAMT & isenta & 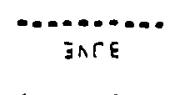 & ACE & 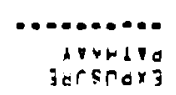 \\
\hline
\end{tabular}

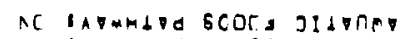

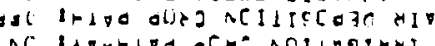

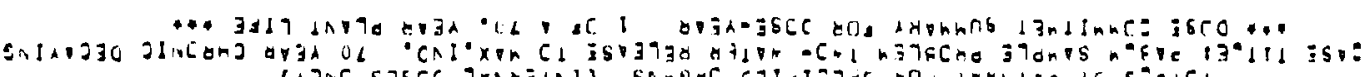




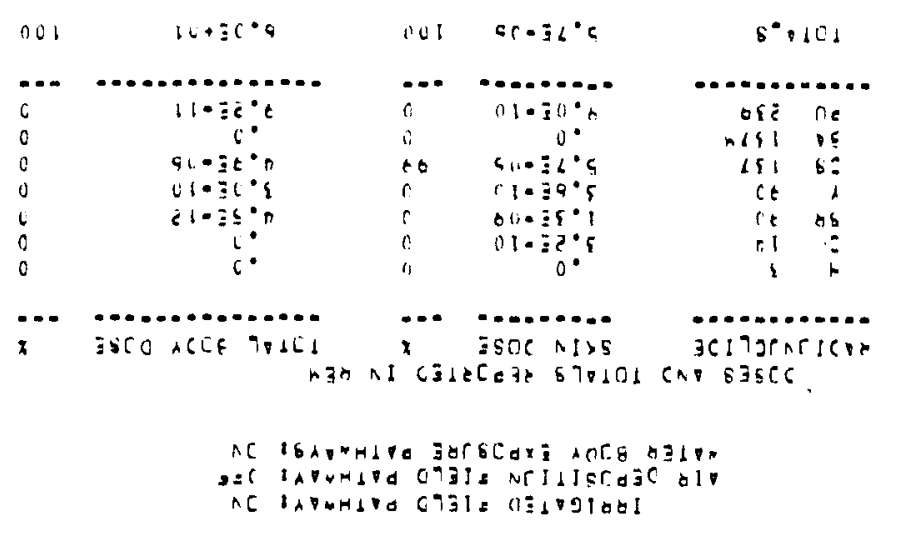

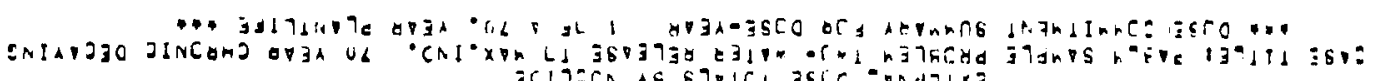
020001

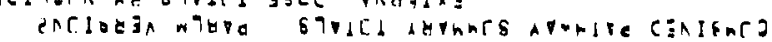
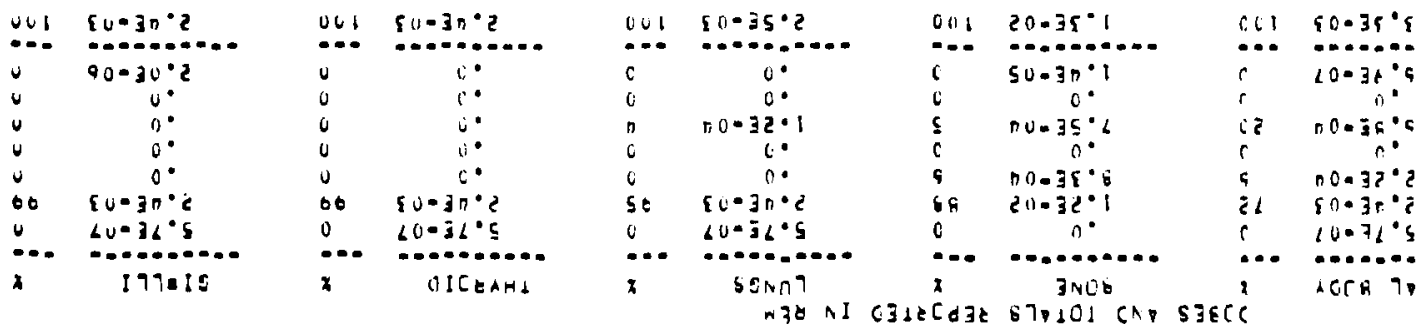

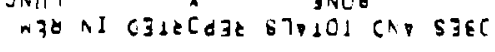

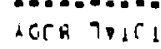

$$
\begin{aligned}
& \text { ac lapmetra secics jitpmep }
\end{aligned}
$$

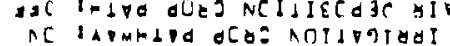

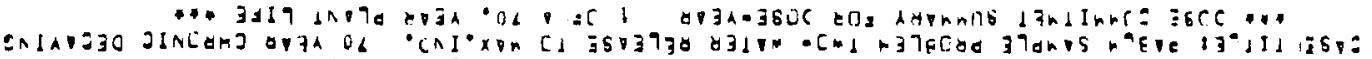

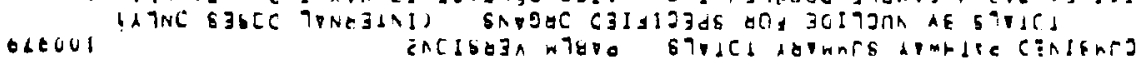




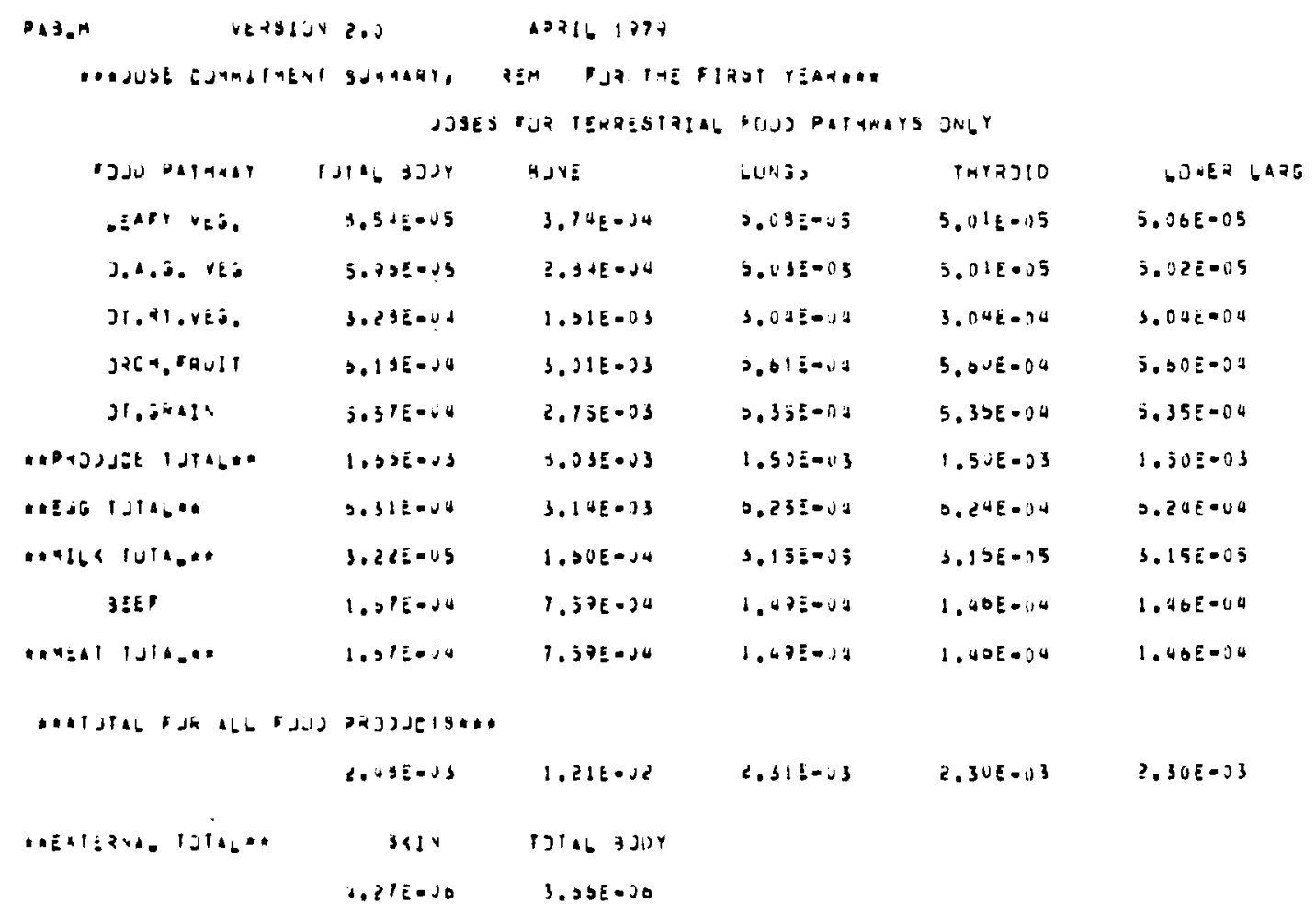




\begin{tabular}{|c|c|c|c|c|c|}
\hline $10=36 \cdot \mid$ & $10-\bar{x} 6^{\circ} 1$ & $10= \pm 2 \cdot 1$ & $00+36.1$ & 10.21 .2 & 59.10 .1 \\
\hline 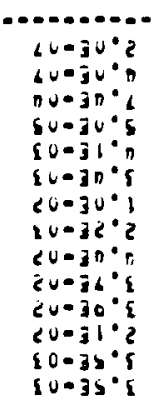 & 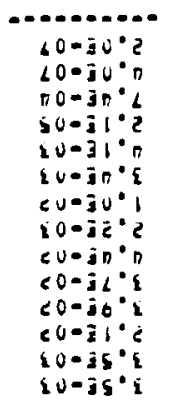 & 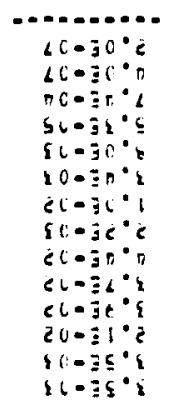 & 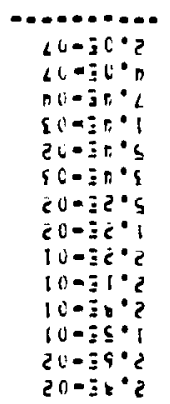 & 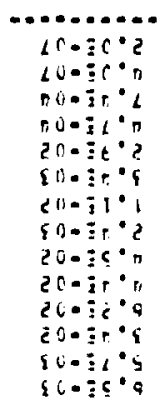 & 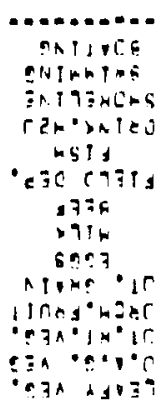 \\
\hline 17781 & olugamd & 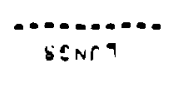 & כNCE & 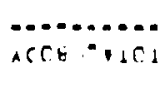 & $\begin{array}{r}\text { pondre } \\
\text { janstex }\end{array}$ \\
\hline
\end{tabular}

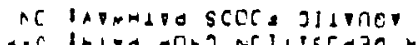

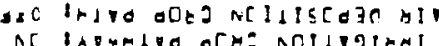

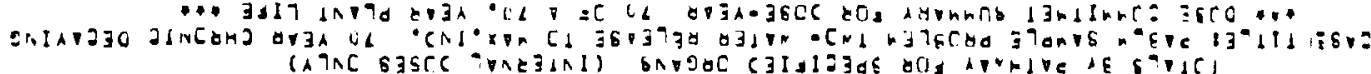

060001

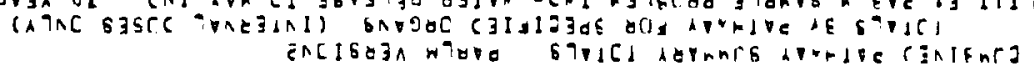

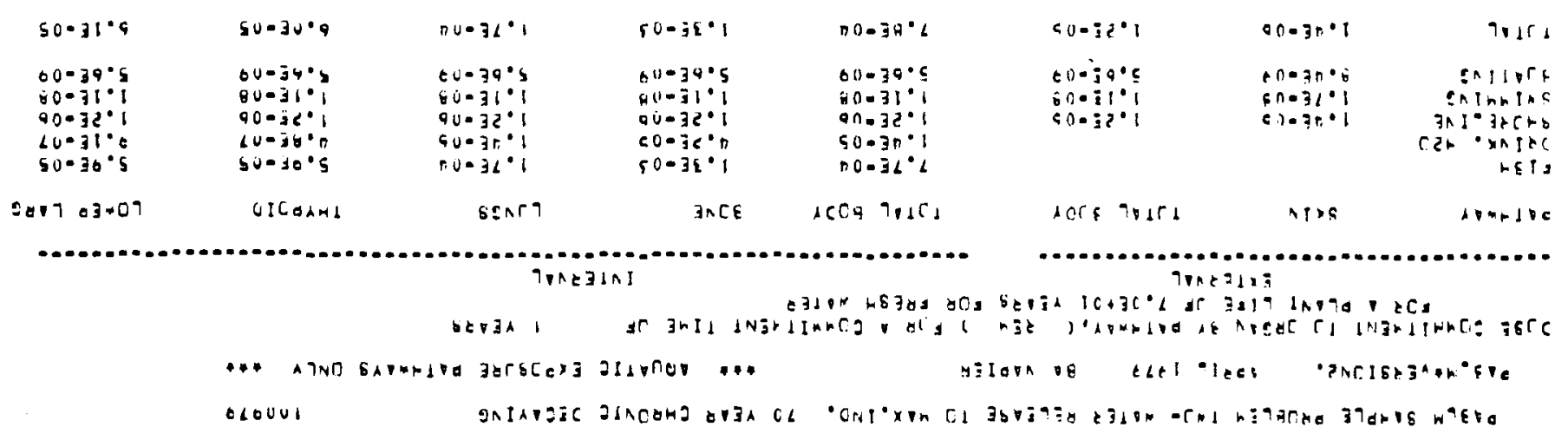




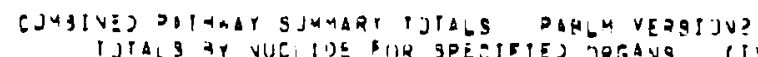

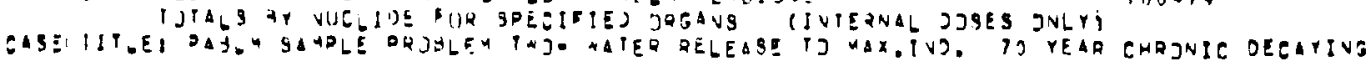

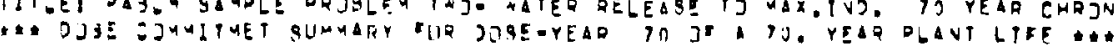

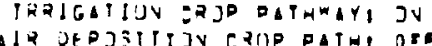

audatic jugs oathaty jv
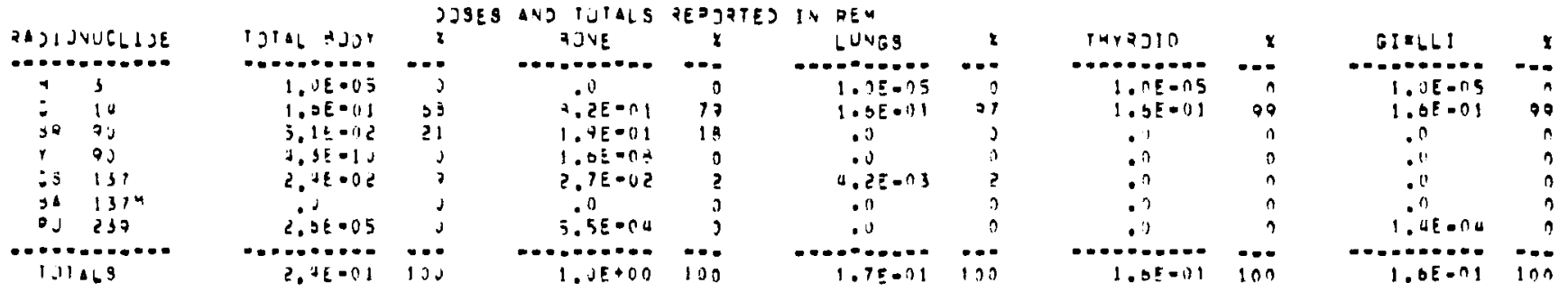

$\stackrel{i}{\stackrel{1}{\sim}}$

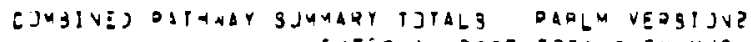

$\operatorname{lnn} 970$

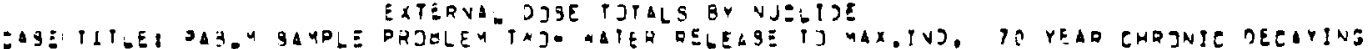

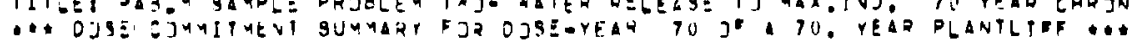

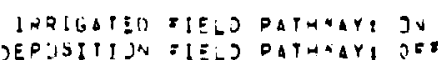

MIEZ BJUY ERDJ JRE DATAMAYSI JV

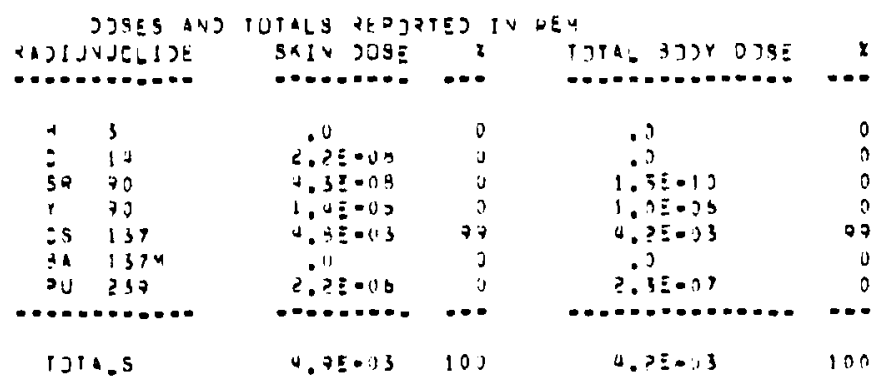




\begin{tabular}{|c|c|c|c|c|c|c|}
\hline$V E\{01 J$ & iv 2.3 & 02816170 & & & & \\
\hline AOJUJE CJMMLIHEN & I sunatant. & $2 E 4$ JJE $A P_{L} A V$ & TGIE! UFT).00 & VEAROE* & & \\
\hline 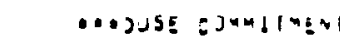 & $130 \times 442 y$ & $A E * \quad F J A J S E$ & EUHAITYEVT $P$ & jeflos je & 90 & TEARSEA \\
\hline & ول & S JIR IERRESTRIAL & hUJ Patrats & S JNLY & & \\
\hline 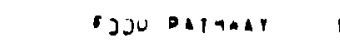 & 13r. & aวง! & (U) & כונדוTR & & b $752-\triangle A 2 G$ \\
\hline DEAFY VES. & $3.5+5=03$ & $2.355-32$ & $2.5 ?:-63$ & $3.4+E=13$ & & $3.52 E-33$ \\
\hline 3.4 .6 .056 & $3.725-23$ & $2.515-22$ & $3,53 \leq-03$ & $3.2 \times E=.33$ & & $3,50 E-33$ \\
\hline J.ग.VEG. & $3,33=-42$ & $1,525-21$ & $2,125-112$ & $2.12 E=32$ & & $2.125 \cdot 02$ \\
\hline$J A C A . R$ IRUI1 & $2.522-75$ & $3.915 \cdot 01$ & $5,79 !-02$ & $9.90 E-02$ & & 3.705002 \\
\hline 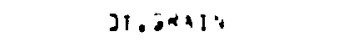 & $\{, 70 E=75$ & ?.1JE-J1 & $3.735=0 ?$ & $3.17 E=75$ & & $3.735-02$ \\
\hline 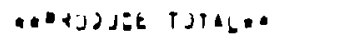 & $1,5 ? 5-11$ & $0.77 \varepsilon-01$ & $1.45 \equiv-111$ & $1.045 \cdot 01$ & & 1.055 .01 \\
\hline 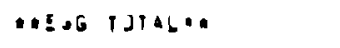 & $+.+5=-72$ & $2.219-31$ & $+.355=11 ?$ & 4.325 .32 & & $2,35 E \cdot 3 ?$ \\
\hline 0416 , IJla... & 2.15:=013 & $1.125 \cdot 02$ & $2.175=0.03$ & $3.1+E=3$ & & 2.175 .03 \\
\hline BLEC & $1,115 \cdot 02$ & $5.80 E-35$ & $1,035-3 ?$ & $1.02 E-02$ & & $1.025-02$ \\
\hline an=Al |Ula..." & 1,10002 & $5.235=02$ & $1 .(13 \vdots-1) ?$ & $1.02 E-3 ?$ & & $1.02 E \cdot .32$ \\
\hline 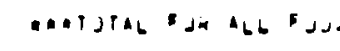 & 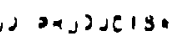 & & & & & \\
\hline & 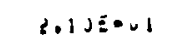 & $7.315=31$ & $1.015-01$ & $1.001 E=01$ & & $1,00 E-01$ \\
\hline 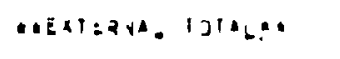 & Yर1 & 1214. S30\% & & & & \\
\hline & $3+115 \cdot+3$ & 3. $11 E-J 4$ & & & & \\
\hline
\end{tabular}




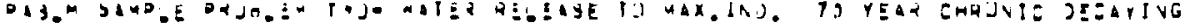

1011019

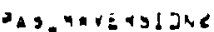
$12 \times 101+13$
3. VAPIEK

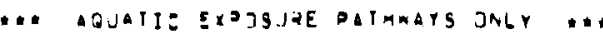

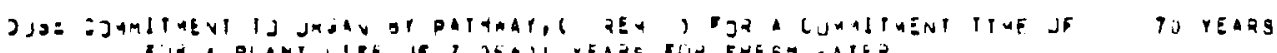

\begin{tabular}{|c|c|c|c|c|c|c|c|}
\hline Daltaner & 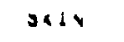 & IJIAL tנOYY & 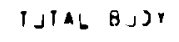 & SJVE & LJVOS & TMYROIO & LJAER GARO \\
\hline 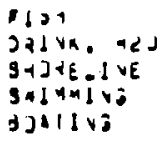 & $\begin{array}{l}\text { R.DE-ud } \\
7.0 E=07 \\
\text { S.SE-Ul }\end{array}$ & 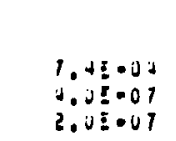 & $\begin{array}{l}2.9 E-02 \\
4.7 E-04 \\
1.4 E-04 \\
4.0 E-01 \\
? .0 E-1) 7\end{array}$ & $\begin{array}{l}3.4 E-1.2 \\
1.4 E-0, \\
7.2 E=04 \\
\square .0 E=07 \\
2.0 E-07\end{array}$ & $\begin{array}{l}3.0 E-03 \\
5.3 E=05 \\
3.2 E-01 \\
3 . J E-O) \\
3 . J E-O 7\end{array}$ & $\begin{array}{l}4.1 E=03 \\
2.1 E=05 \\
7 . \Delta E=04 \\
30 E=07 \\
2.0 E=07\end{array}$ & $\begin{array}{l}4.1 E=03 \\
5.0 E=05 \\
7.0 E=04 \\
4.0 E=07 \\
2.0 E=07\end{array}$ \\
\hline 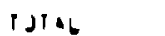 & b. 1E-ut & $1,+5=04$ & 3. UE $=02$ & $5.0 E-U E$ & $3 ., y E=0\}$ & $4.0 F=03$ & $4.9 E=03$ \\
\hline
\end{tabular}




+
+
+
-1
1
+
-1




\section{DISTRIBUTION}

No. of

Copies

OFFSITE

UNITED STATES

A. A. Churm

DOE Chicago Patent Group

9800 South Cass Avenue

Argonne, IL 60439

27 DOE Technical Information Center

2 Argonne National Laboratory Reference Library 9800 South Cass Avenue Argonne, IL 60439

Battelle Memorial Institute Office of Nuclear Waste Isolation

Attn: Beverly Rawles

505 King Avenue

Columbus, $\mathrm{OH} 43201$

John Bredehoeft

U.S. Geological Survey

Reston, VA 22092

John Bird

Geology Department

Corne11 University

Itahca, NY 14853

2 Brookhaven National Laboratory Reference Section Information Division Upton, Long Island, NY 11973

20 Wayne $A$. Carbiener

Office of Nuclear Waste Isolation

Battelle Memorial Institute 505 King Avenue

Columbus, $\mathrm{OH} 43201$
No. of

Copies

Neville G. W. Cook

Department of Materials Science and Mineral Engineering

Hearst Mlining Building

University of California

Berkeley, CA 94720

Carl R. Cooley

DOE Office of Nuclear Waste Management

Washington, DC 20545

Environmental Protection Agency

Office of Radiation Programs

Technology Assessment Division

M/S AW559

Washington, DC 20460

Robert M. Garrel1s

Dept of Geologic Sciences

Northwestern University

Evanston, IL 60201

Col in A. Heath

DOE Division of Nuclear Waste Management

Washinton, DC 20545

William M. Hewitt

Office of Nuclear Waste

Isolation

Battelle Memorial Institute

505 King Avenue

Columbus, $\mathrm{OH} 43201$

Peter L. Hofmann

Office of Nuclear Waste Isolation

Battelle Memorial Institute

505 King Avenue

Columbus, $\mathrm{OH} 43201$ 
No. of

Copies

Muzaffer Kehnemuyi

Office of Nuclear Waste Isolation

Battelle Memorial Institute

505 King Avenue

Columbus, $\mathrm{OH} 43201$

John F. Kircher

Office of Nuclear Waste Isolation

Battelle Memorial Institute

505 King Avenue

Columbus, $\mathrm{OH} 43201$

2 Lawrence Berkeley Laboratory

Reference Library

University of California

Berkeley, CA 94720

2 Lawrence Livermore Laboratory

Reference Library

P.0. Box 808

Livermore. CA 94550

2 Los Alamos Scientific Laboratory

Reference Library

P.0. Box 1663

Los Alamos, NM 87544

J. B. Martin

Asst. Director for Radioactive Waste Management Branch

NRC Division of Materials and

Fuel Cycle Facility Licensing

Washington, DC 20555

John T. McGinnis

Office of Nuclear Waste Isolation

Battelle Memorial Institute

505 King Avenue

Columbus, $\mathrm{OH} 43201$

2 Barry N. Naft

NUS Corporation

4 Research Place

Rockville, MD 20805
No. of

Copies

2 J. 0. Neff

Department of Energy

Columbus Program Office

505 King Avenue

Columbus, $\mathrm{OH} 43201$

2 Neil A. Norman

Environmental Sciences

Department

Bechtel National Inc.

P.0. Box 3965

San Francisco, CA 94105

2 Oak Ridge National Laboratory

Central Research Library

Document Reference Section

Oak Ridge, TN 37830

Frank L. Parker

Dept. of Environmental Eng.

Vanderbilt University

Nashville, TN 37235

George F. Pinder

Dept. of Civil Engineering

Princeton University

Princeton, $\mathrm{NJ} 08540$

2 Savannah River Laboratory

Reference Library

Aiken, SC 29801

Howard P. Stephens

Sandia Laboratories

P.0. Box 5800

Albuquerque, NM 87115

David B. Stewart

U.S. Geological Survey

National Center 959

Reston, VA 22092

Robert Williams

Electric Power Research Inst.

$3412 \mathrm{Hillview} \mathrm{Avenue}$

P.0. Box 10412

Palo Alto, CA 94304 
No. of

Copies

Blake Robertson

Ford, Bacon, and Davis, Utah, Co. P.0. Box 8009

Salt Lake City, Utah 84108

Roberta Roswel1

Ford, Bacon, and Davis, Utah, Co. P.0. Box 8009

Salt Lake City, Utah 84108

FORE IGN

D'Al les sandro Avogadro

Commission of European Communities

Joint Research Centre

I-21020 Ispra (Varese)

ITALY

K. H. Hubenthal

Bundesministerium fur Forschung und Technology

Stressemannstrasse 2

Postfach 200706

D-5300 Bonn

F.R. Of GERMANY

Center for Atomic Energy

Documentation (ZAED)

ATTN: Dr. Bell

Postfach 3640

D-7500 Karlsruhe

F.R. of GERMANY

Ferruccio Gera

Radiation Protection and Waste Management Division

Nuclear Energy Agency/OECD

38 Boulevard Suchet

F-75016 Paris

FRANCE

V. K. Barwe11

Environmenta1 Research Branch Atomic Energy of Canada Limited Chalk River, Onterio KOJIJO CANADA
No. of

Copies

2 INIS Clearinghouse

International Atomic Energy Agency

Karntner Ring II

P.0. Box 590

A-1011 Vienna

AUSTRIA

Klaus Kuhn

Institut fur Tiefagerung

Wissenschaftliche Abteilung

Berliner Strasse 2

D-3392 Claustha1-Zellerfeld

F.R. of GERMANY

Hans W. Levi

Hahn-Meitner-Institute fur Kernforschung

Glienicker Strasse 100

D-1000 Berl in 39

F.R. of GERMANY

Library

Studsvik Energiteknik $A B$

S-611 01 Nykoping

SWEDEN

Franz Peter 0esterle

Physikalisch-Chemische Bundesanstalt

Bundesallee 100

D-3300 Braunschweig

F.R. of GERMANY

Tjalle Vandergraff

Atomic Energy of Canada Limited

Whiteshel1 Nuclear Research

Establishment

Tinawa, Manitoba ROE ILQ

CANADA

Glenn Merrett

Storage and Disposal Branch

Whiteshe11 Nuclear Research Establishment

Tinawa, Manitoba ROE ILQ

CANADA 
No. of

Copies

Egbert Schapermeier

Battelle-Institute e.V.

Am Romerhof 35

D-6000 Frankfurt am Main 90

F.R. of GERMANY

ONSITE

4 DOE Richland Operations Office

0. J. Elgert

H. E. Ransom

J. J. Schreiber

F. R. Standerfer

3 Rockwe11 Hanford Operations

R. A. Deju

B. Hanson

Rockwel1 Document Control

69 Pacific Northwest Laboratory

W. J. Bair

A. Brandstetter (10)

M. 0. Cloninger (2)

F. H. Dove

K. E. Harding (4)

G. R. Hoenes

W. E. Kennedy

K. Landstrom

W. D. McCormack

B. A. Napier (20)

D. E. Olesen

A. M. Platt

R. G. Schreckhise

N. M. Sherer

D. Silviera

J. K. Soldat

D. L. Strenge (2)

B. E. Vaughan

E. C. Watson

Technical Information Library (5)

Publishing Coordination (2)

Water and Land Resources Dept.

Library (10) 
RECIPIENTS OF PNL-3209

If you wish to be on the distribution list for future model computer code and report revisions, please fill out the form below and return it to Dr. Albin Brandstetter.

\section{REQUEST FOR MODEL REPORT REVISION}

Name

Title and Affiliation

Address

Date Signature

Please fill out this form and mail to:

Dr. Albin Brandstetter

Project Manager, AEGIS

Battelle, Pac if ic Northwest Laboratory

P.0. Box 999

Richland, WA 99352

U.S.A. 
$r$

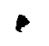

$\bullet$

$-5$

1

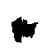

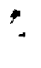

-

? 